\title{
animals
}

Quantification and

Mitigation Strategies to

Reduce Greenhouse

Gas Emissions

from Livestock

Production Systems

Edited by

Mizeck Chagunda and Peter Løvendahl Printed Edition of the Special Issue Published in Animals 
Quantification and Mitigation Strategies to Reduce Greenhouse Gas Emissions from Livestock Production Systems 



\section{Quantification and Mitigation Strategies to Reduce Greenhouse Gas Emissions from Livestock Production Systems}

Special Issue Editors

Mizeck Chagunda

Peter Lovendahl 
This is a reprint of articles from the Special Issue published online in the open access journal Animals (ISSN 2076-2615) from 2018 to 2019 (available at: https://www.mdpi.com/journal/animals/ special_issues/Quantification_and_Mitigation_Strategies_to_Reduce_Greenhouse_Gas_Emissions_ from_Livestock_Production_Systems).

For citation purposes, cite each article independently as indicated on the article page online and as indicated below:

LastName, A.A.; LastName, B.B.; LastName, C.C. Article Title. Journal Name Year, Article Number, Page Range.

\section{ISBN 978-3-03928-530-3 (Pbk) \\ ISBN 978-3-03928-531-0 (PDF)}

(C) 2020 by the authors. Articles in this book are Open Access and distributed under the Creative Commons Attribution (CC BY) license, which allows users to download, copy and build upon published articles, as long as the author and publisher are properly credited, which ensures maximum dissemination and a wider impact of our publications.

The book as a whole is distributed by MDPI under the terms and conditions of the Creative Commons license CC BY-NC-ND. 


\section{Contents}

About the Special Issue Editors $\ldots \ldots \ldots \ldots \ldots \ldots \ldots$ vii

Preface to "Quantification and Mitigation Strategies to Reduce Greenhouse Gas Emissions

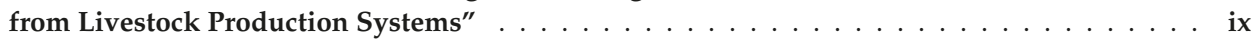

Jagoba Rey, Raquel Atxaerandio, Roberto Ruiz, Eva Ugarte, Oscar González-Recio,

Aser Garcia-Rodriguez and Idoia Goiri

Comparison Between Non-Invasive Methane Measurement Techniques in Cattle

Reprinted from: Animals 2019, 9, 563, doi:10.3390/ani9080563 . . . . . . . . . . . . . . . .

Philip C. Garnsworthy, Gareth F. Difford, Matthew J. Bell, Ali R. Bayat, Pekka Huhtanen, Björn Kuhla, Jan Lassen, Nico Peiren, Marcin Pszczola, Diana. Sorg, Marleen H.P.W. Visker and Tianhai Yan

Comparison of Methods to Measure Methane for Use in Genetic Evaluation of Dairy Cattle Reprinted from: Animals 2019, 9, 837, doi:10.3390/ani9100837 . . . . . . . . . . . . . . 10

Pratap Pragna, Surinder S. Chauhan, Veerasamy Sejian, Brian J. Leury and Frank R. Dunshea Climate Change and Goat Production: Enteric Methane Emission and Its Mitigation

Reprinted from: Animals 2018, 8, 235, doi:10.3390/ani8120235 . . . . . . . . . . . . . . . .

Lifeng Dong, Tingting Zhang and Qiyu Diao

Effect of Dietary Supplementation of Moringa Oleifera on the Production Performance and Fecal Methanogenic Community of Lactating Dairy Cows

Reprinted from: Animals 2019, 9, 262, doi:10.3390/ani9050262 . . . . . . . . . . . . .

Yunlong Liu, Tao Ma, Dandan Chen, Naifeng Zhang, Bingwen Si, Kaidong Deng, Yan Tu and Qiyu Diao

Effects of Tea Saponin Supplementation on Nutrient Digestibility, Methanogenesis, and Ruminal Microbial Flora in Dorper Crossbred Ewe

Reprinted from: Animals 2019, 9, 29, doi:10.3390/ani9010029 _ . . . . . . . . . . . . . .

Bénédicte Suybeng, Edward Charmley, Christopher P. Gardiner, Bunmi S. Malau-Aduli and Aduli E. O. Malau-Aduli

Methane Emissions and the Use of Desmanthus in Beef Cattle Production in Northern Australia Reprinted from: Animals 2019, 9, 542, doi:10.3390/ani9080542 . . . . . . . . . . . . . . .

Aklilu W. Alemu, Atmir Romero-Pérez, Rafael C. Araujo and Karen A. Beauchemin Effect of Encapsulated Nitrate and Microencapsulated Blend of Essential Oils on Growth Performance and Methane Emissions from Beef Steers Fed Backgrounding Diets Reprinted from: Animals 2019, 9, 21, doi:10.3390/ani9010021 . . . . . . . . . . . . . . . . .

Lifeng Dong, Binchang Li and Qiyu Diao

Effects of Dietary Forage Proportion on Feed Intake, Growth Performance, Nutrient Digestibility, and Enteric Methane Emissions of Holstein Heifers at Various Growth Stages Reprinted from: Animals 2019, 9, 725, doi:10.3390/ani9100725 . . . . . . . . . . . . . .

Tony van der Weerden, Pierre Beukes, Cecile de Klein, Kathryn Hutchinson, Lydia Farrell, Tinke Stormink, Alvaro Romera, Dawn Dalley, Ross Monaghan, David Chapman, Kevin Macdonald and Robyn Dynes

The Effects of System Changes in Grazed Dairy Farmlet Trials on Greenhouse Gas Emissions Reprinted from: Animals 2018, 8, 234, doi:10.3390/ani8120234 . . . . . . . . . . . . . . 113 
Alexandra Sintori, Irene Tzouramani and Angelos Liontakis

Greenhouse Gas Emissions in Dairy Goat Farming Systems: Abatement Potential and Cost

Reprinted from: Animals 2019, 9, 945, doi:10.3390/ani9110945 


\section{About the Special Issue Editors}

Mizeck Chagunda is a Professor and Chair of Animal Breeding and Husbandry in the Tropics and Subtropics at the University of Hohenheim, Germany. Mizeck earned his doctorate degree in Animal Breeding and Genetics from the University of Göttingen, Germany, after obtaining his MSc and BSc from the University of Malawi. He has previously worked at the University of Malawi, Aarhus University in Denmark, and SRUC (Scotland's Rural College) in Scotland. Mizeck's research interests are in improving biological and economic efficiency in livestock production systems. He achieves this through investigating novel phenotypes and difficult-to-measure traits, the environmental impact of livestock, and the use of technologies and data-driven decision-support systems, optimising animal breeding strategies and breeding goals. This includes methods for quantifying greenhouse gases (GHGs), applying life cycle analysis (LCA) and techniques for measuring methane from breath in ruminants. As an example of direct industry-relevant research, Mizeck was part of the BIOSENS team (Aarhus University) that developed and tested models that ended up as embedded software for HerdNavigator ${ }^{\circledR}$.

Peter Lovendahl is a Senior Scientist working at Aarhus University (AU-Foulum, Denmark), Center for Quantitative Genetics and Genomics. Peter earned his MSc and later PhD at the Royal Veterinary and Agricultural University in Copenhagen, now a part of Copenhagen University. Peter has studied phenotypic and genetic variation in a wide range of traits in dairy cattle and pigs. The range of traits has included milk production, endocrine regulation, behaviour, milking behaviour, maternal behaviour and aggression in sows, fertility traits in dairy cows, feed efficiency, methane emission in cows, and metagenomic aspects of ruminant digestion. Peter has focused on improved phenotyping as a means of improving genetic progress in dairy cattle and pig production, especially focusing on methods for automated recording of new traits of possible use in genetic selection. Peter has been involved in numerous collaborative projects with industry partners, including the development of new management tools for dairy farming. 



\title{
Preface to "Quantification and Mitigation Strategies to Reduce Greenhouse Gas Emissions from Livestock Production Systems"
}

\author{
Mizeck Chagunda ${ }^{1}$ and Peter Lovendahl ${ }^{2}$ \\ 1 Animal Breeding and Husbandry in the Tropics and Subtropics, University of Hohenheim, \\ 70599 Stuttgart, Germany \\ 2 Department of Molecular Biology and Genetics, Faculty of Science and Technology, \\ Aarhus University, PO Box 50, DK-8830 Tjele, Denmark
}

In recent years, the evidence of change in the global climate system has been unequivocal, and climate change has become a growing international concern. Further, it is well-established that the release of greenhouse gases (GHGs) predominantly derived from human activities is a major contributing factor to most of the observed climate change.

As the largest land-use system on earth, the livestock sector occupies $30 \%$ of the world's ice-free surface (Herrero et al., 2013). On the one hand, livestock supply chains are estimated to account for $14.5 \%$ of total human-induced GHG emissions (Gerber et al., 2013). In livestock value chains, GHG emissions arise from processes both on and off the farm, and these emissions include methane $\left(\mathrm{CH}_{4}\right)$, nitrous oxide $\left(\mathrm{N}_{2} \mathrm{O}\right)$ and carbon dioxide $\left(\mathrm{CO}_{2}\right)$. On the other hand, livestock supply chains contribute to $40 \%$ of global agricultural gross domestic product, providing income for more than 1.3 billion people and nourishment for at least 800 million food-insecure people, all the while using vast areas of rangelands, one-third of the freshwater, and one-third of global cropland as feed. Different initiatives are being taken to reduce GHG emissions. For example, the European Union has committed itself to reducing its GHG emissions by $20 \%$ by the year 2020, relative to 1990 levels. Different countries and groups of countries have different targets. However, it is important to undertake initiatives that can reduce GHG emissions without compromising livestock productivity. Finding a balance between improving productivity and reducing GHG emissions in livestock systems is crucial for maintaining sustainability in the future. Although primarily focused on ruminant production (Henderson et al., 2017) reported that promising practices for reducing enteric $\mathrm{CH}_{4}$ emissions and for sequestering soil $\mathrm{C}$ in grazing lands could abate up to $379 \mathrm{MtCO}_{2}$-eq $\mathrm{yr}^{-1}$ of emissions. This is equivalent to $11 \%$ of annual global ruminant GHG emissions. (Henderson et al., 2017). Efficient agricultural practices are key to reducing greenhouse gas emissions. These practices can be achieved through several aspects of livestock production. For example, livestock genetic improvement, changes in feeding strategies, nutritional improvement, disease control and animal health improvement, and improvement in animal welfare and general husbandry. However, care ought to be taken as a focus on reducing emissions in one particular part of a system may result in an inherent increase elsewhere in the system.

Technical solutions to reduce GHG emissions have been and continue to be extensively researched. Globally, different research groups are investigating different components in this regard on an ongoing basis. Although some of this information has been previously reported elsewhere, new knowledge is being generated and more effective strategies are being developed. Accompanying these efforts to reduce GHG emissions should be efforts to develop methods and procedures for quantifying GHG emissions in different livestock systems. Although metabolic calorimetric chambers 
have been considered the gold standard for quantifying GHG in ruminants for some time, they are expensive, require highly skilled technicians, and are not normally compatible for use in practical animal production environments where the majority of animals are found. This Special Issue aimed to put together contributions in these two broad but related areas: 1) measurement techniques and protocols, use of proxies, and methodological opportunities and challenges including uncertainty in quantification of GHG emissions from livestock systems; and 2) methods, techniques, and strategies for reducing GHG emissions from livestock production systems. These contributions were sought as both reviews and original research. After manuscripts went through the normal peer review process, where some were accepted and others rejected, a total of 10 papers ended up in the Special Issue. Two papers were on quantification while eight were on mitigation strategies for GHGs. In terms of species (and subspecies), papers covered dairy cattle and dairy goats, beef cattle, goats, and sheep.

Papers on the quantification of GHG focused on novel high-throughput non-invasive methods that have the potential for not only generating the much-needed data upon which evidence-based interventions can be developed, but also methods that can be deployed in more extensive production systems. By comparing these novel techniques to traditional techniques, both papers argue that there is sufficient correlation in the data from the different methods tested. These include methods such as the portable and innovative Laser Methane DetectorTM (Chagunda et al., 2009), and the automatic breath sampler (Lassen et al., 2010). Data from these different measuring methods can be combined for either international genetic improvement studies or for providing the much-needed framework for combining data that would inform some mitigation strategies (Garnsworthy et al., 2019 and Jagoba et al., 2019). However, they warn that the joint use of different GHG measuring methods should be considered only if sources of disagreement-which result from different between-subject and within-subject variabilities—are identified and corrected for (Jagoba et al., 2019).

The first paper, on methane emissions mitigation, lays the foundation by initially considering the effect of and environmental stresses that are common factors which negatively influence rumen function and enteric methane $\left(\mathrm{CH}_{4}\right)$ emission (Pragna et al., 2018). This is demonstrated using the goat. Further, Pragna et al. (2018) highlight the three mechanisms by which enteric $\mathrm{CH}_{4}$ can be reduced: targeting the endproduct of digestion to propionate, providing an alternate hydrogen sink, and selectively inactivating rumen methanogens. The strategies that can be implemented to mitigate enteric $\mathrm{CH}_{4}$ include nutritional interventions, management strategies, and application of advanced biotechnological tools (Pragna et al., 2018). The next four papers on mitigation strategies demonstrate some results from experiments on how some specific nutritional interventions may reduce methane emissions from ruminates. First, is the use of dietary supplements of Moringa oleifera in lactating dairy cows. The second paper investigates the effects of tea saponin in crossbred dorper ewes while the third is on the use of desmanthus in beef cattle (Dong et al., 2019; Liu et al., 2019; Suybeng et al., 2019). The fourth discusses the effect of encapsulated nitrate and microencapsulated blend of essential oils in beef steers (Alemu et al., 2019).

The next group of two papers deals with GHG emissions reduction through management interventions. The first paper in this group deals with the effect of dietary forage proportion in Holstein heifers at various growth stages (Dong et al., 2019) while the other deals with the effect of changes in grazed farmlets for dairy cattle (Van der Weerden et al., 2018). These two papers highlight the fact that improved livestock management systems are a key driver not only to reducing methane emissions but also reducing nitrogen leaching which in itself also contributes to GHG emissions. The data generated from these management systems can be used to develop regional and national emission inventories and mitigation approaches (Dong et al., 2019; Van der Weerden et al., 2018). 
Last, but by far not the least, this Special Issue closes with a paper discussing the abatement potential and cost of different GHG mitigation strategies in dairy goat farming systems (Sintori et al., 2019).

\section{References}

1. Alemu, A.W.; Romero-Pérez, A.; Araujo, R.C.; Beauchemin, K.A. Effect of Encapsulated Nitrate and Microencapsulated Blend of Essential Oils on Growth Performance and Methane Emissions from Beef Steers Fed Backgrounding Diets. Animals 2019, 9, 21.

2. Chagunda, M.G.G.; Ross, D.; Roberts, D.J. On the Use of a Laser Methane Detector in Dairy Cows. Comput. Electron. Agric. 2009, 68, 157-160.

3. Dong, L.; Li, B.; Diao, Q. Effects of Dietary Forage Proportion on Feed Intake, Growth Performance, Nutrient Digestibility, and Enteric Methane Emissions of Holstein Heifers at Various Growth Stages. Animals 2019, 9, 725.

4. Dong, L.; Zhang, T.; Diao, Q. Effect of Dietary Supplementation of Moringa oleifera on the Production Performance and Fecal Methanogenic Community of Lactating Dairy Cows. Animals 2019, 9, 262.

5. Garnsworthy, P.C.; Difford, G.F.; Bell, M.J.; Bayat, A.R.; Huhtanen, P.; Kuhla, B.; Lassen, J.; Peiren, N.; Pszczola, M.; Sorg, D.; Visker, M.H.; Yan, T. Comparison of Methods to Measure Methane for Use in Genetic Evaluation of Dairy Cattle. Animals 2019, 9, 837.

6. Gerber, P.J., Steinfeld, H., Henderson, B., Mottet, A., Opio, C., Dijkman, J., Falcucci, A. and Tempio, G., 2013. Tackling Climate Change through Livestock: A Global Assessment of Emissions and Mitigation Opportunities. Food and Agriculture Organization of the United Nations (FAO).

7. Henderson, B., Falcucci, A., Mottet, A., Early, L., Werner, B., Steinfeld, H. and Gerber, P., Marginal Costs of Abating Greenhouse Gases in the Global Ruminant Livestock Sector. Mitig. Adapt. Strateg. Glob. Chang. 2017, 22, 199-224.

8. Herrero, M., Havlík, P., Valin, H., Notenbaert, A., Rufino, M.C., Thornton, P.K., Blümmel, M., Weiss, F., Grace, D. and Obersteiner, M. Biomass Use, Production, Feed Efficiencies, and Greenhouse Gas Emissions from Global Livestock Systems. Proc. Natl. Acad. Sci. USA 2013, 110, 20888-20893.

9. Lassen, J.; Løvendahl, P.; Madsen, J. Accuracy of Noninvasive Breath Methane Measurements using Fourier Transform Infrared Methods on Individual Cows. J. Dairy Sci. 2012, 95, 890-898.

10. Liu, Y.; Ma, T.; Chen, D.; Zhang, N.; Si, B.; Deng, K.; Tu, Y.; Diao, Q. Effects of Tea Saponin Supplementation on Nutrient Digestibility, Methanogenesis, and Ruminal Microbial Flora in Dorper Crossbred Ewe. Animals 2019, 9, 29.

11. Pragna, P.; Chauhan, S.S.; Sejian, V.; Leury, B.J.; Dunshea, F.R. Climate Change and Goat Production: Enteric Methane Emission and Its Mitigation. Animals 2018, 8, 235.

12. Rey, J.; Atxaerandio, R.; Ruiz, R.; Ugarte, E.; González-Recio, O.; Garcia-Rodriguez, A.; Goiri, I. Comparison between Non-Invasive Methane Measurement Techniques in Cattle. Animals 2019, 9, 563.

13. Sintori, A.; Tzouramani, I.; Liontakis, A. Greenhouse Gas Emissions in Dairy Goat Farming Systems: Abatement Potential and Cost. Animals 2019, 9, 945.

14. Suybeng, B.; Charmley, E.; Gardiner, C.P.; Malau-Aduli, B.S.; Malau-Aduli, A.E.O. Methane Emissions and the Use of Desmanthus in Beef Cattle Production in Northern Australia. Animals 2019, 9, 542.

15. Van der Weerden, T.; Beukes, P.; De Klein, C.; Hutchinson, K.; Farrell, L.; Stormink, T.; Romera, A.; Dalley, D.; Monaghan, R.; Chapman, D.; Macdonald, K.; Dynes, R. The Effects of System Changes in Grazed Dairy Farmlet Trials on Greenhouse Gas Emissions. Animals 2018, 8, 234.

Mizeck Chagunda, Peter Løvendahl

Special Issue Editors 


\title{
Comparison Between Non-Invasive Methane Measurement Techniques in Cattle
}

\author{
Jagoba Rey ${ }^{1, *}$, Raquel Atxaerandio ${ }^{1}$, Roberto Ruiz ${ }^{1}$, Eva Ugarte ${ }^{1}$, Oscar González-Recio ${ }^{2,3}$, \\ Aser Garcia-Rodriguez ${ }^{1}$ and Idoia Goiri ${ }^{1, *}$ \\ 1 Department of Animal Production, NEIKER-Tecnalia, Granja Modelo de Arkaute, Apdo. 46, \\ 01080 Vitoria-Gasteiz, Spain \\ 2 Departamento de Producción Agraria, Escuela Técnica Superior de Ingeniería Agronómica, Alimentaria y de \\ Biosistemas, Universidad Politécnica de Madrid, Ciudad Universitaria s/n, 28040 Madrid, Spain \\ 3 Departamento de Mejora Genética Animal, Instituto Nacional de Investigación y Tecnología Agraria y \\ Alimentaria, 28040 Madrid, Spain \\ * Correspondence: jrey@neiker.eus (J.R.); igoiri@neiker.eus (G.I.); Tel.: +34-945-121-313 (J.R.)
}

Received: 28 June 2019; Accepted: 8 August 2019; Published: 15 August 2019

Simple Summary: Enteric methane emissions pose a serious issue to ruminant production and environmental sustainability. To mitigate methane emissions, combined research efforts have been put into animal handling, feeding and genetic improvement strategies. For all research efforts, it is necessary to record methane emissions from individual cows on a large scale under farming conditions. The objective of this trial was to compare two large-scale, non-invasive methods of measuring methane (non-dispersive infrared methane analyzer (NDIR) and laser), in order to see if they can be used interchangeably. For this, paired measurements were taken with both devices on a herd of dairy cows and compared. Significant sources of disagreement were identified between the methods, such that it would not be possible to use both methods interchangeably without first correcting the sources of disagreement.

\begin{abstract}
The aim of this trial was to study the agreement between the non-dispersive infrared methane analyzer (NDIR) method and the hand held laser methane detector (LMD). Methane $\left(\mathrm{CH}_{4}\right)$ was measured simultaneously with the two devices totaling 164 paired measurements. The repeatability of the $\mathrm{CH}_{4}$ concentration was greater with the NDIR (0.42) than for the LMD (0.23). However, for the number of peaks, repeatability of the LMD was greater ( 0.20 vs. 0.14 , respectively). Correlation was moderately high and positive for $\mathrm{CH}_{4}$ concentration (0.73 and 0.74 , respectively) and number of peaks ( 0.72 and 0.72 , respectively), and the repeated measures correlation and the individual-level correlation were high (0.98 and 0.94 , respectively). A moderate concordance correlation coefficient was observed for the $\mathrm{CH}_{4}$ concentration (0.62) and for the number of peaks (0.66). A moderate-high coefficient of individual agreement for the $\mathrm{CH}_{4}$ concentration (0.83) and the number of peaks (0.77) were observed. However, $\mathrm{CH}_{4}$ concentrations population means and all variance components differed between instruments. In conclusion, methane concentration measurements obtained by means of NDIR and LMD cannot be used interchangeably. The joint use of both methods could be considered for genetic selection purposes or for mitigation strategies only if sources of disagreement, which result in different between-subject and within-subject variabilities, are identified and corrected for.
\end{abstract}

Keywords: NDIR; laser; agreement; enteric emissions; interchangeability

\section{Introduction}

The livestock sector plays an important role in climate change, representing $14.5 \%$ of all anthropogenic emissions. Within livestock, one of the most relevant sources of greenhouse gases 
is enteric methane $\left(\mathrm{CH}_{4}\right)$ representing $39 \%$ of sector emissions [1]. Methane is a potent greenhouse gas with a high global warming potential, calculated as 25 times greater than that of carbon dioxide $\left(\mathrm{CO}_{2}\right)$ [2]. For these reasons, enteric $\mathrm{CH}_{4}$ has become a great concern worldwide. In fact, agreements like "The Paris Agreement" in 2015 have pointed out the importance of the reduction of $\mathrm{CH}_{4}$ emission by cattle.

Moreover, enteric $\mathrm{CH}_{4}$ production is associated with considerable dietary energy losses for ruminants, ranging from $1.7 \%$ to $14.9 \%$ of gross energy intake for lactating cows [3] that could lead to decreased energy gain and productivity. Feed is typically the main production cost item in mixed and intensive systems. Wasting part of the feed energy in the form of $\mathrm{CH}_{4}$ is not only a climate change issue but also a production problem. In this context, the reduction of livestock greenhouse gases emissions, and in particular enteric $\mathrm{CH}_{4}$, is posed as a top issue in the agribusiness sector.

The reduction of these emissions can be addressed from the combination of handling, feeding and genetic improvement strategies. However, in order to implement any of these strategies and especially to breed animals with lower $\mathrm{CH}_{4}$ production, it is necessary to have individual $\mathrm{CH}_{4}$ data on a large number of animals in commercial conditions.

Methane concentration is heritable [4], and accurate and reliable individual measurements are necessary to include this trait in the breeding programs. These measurements must be made on a large number of animals under commercial conditions [5]. Several methods to record $\mathrm{CH}_{4}$ emissions from individual animals have been proposed, each with specific advantages, scope of application and also flaws [6-8]. Rapid and non-labor-extensive methods of measuring $\mathrm{CH}_{4}$ are required in order to implement national genetic evaluations. The non-dispersive infrared analyzer $\mathrm{CH}_{4}$ analyzer (NDIR) and the hand-held laser $\mathrm{CH}_{4}$ detector (LMD) are two alternative methodologies that measure $\mathrm{CH}_{4}$ concentrations in the breath of dairy cattle. Both technologies are non-invasive and allow high throughput in commercial conditions. Both methods have been proved to reliably quantify individually $\mathrm{CH}_{4}$ concentrations in exhaled air at farm conditions [9-12].

Garnsworthy et al. [13] used for the first time a NDIR $\mathrm{CH}_{4}$ detector to quantify $\mathrm{CH}_{4}$ emissions from individual cows on a farm, by sampling air released by eructation during milking. With this technique, a sampling point was installed inside the feed bin of automated milking systems (AMS) and $\mathrm{CH}_{4}$ concentration on exhaled air was continuously measured in each cow's visits to the AMS. The LMD is a hand-held gas detector for remote measurements of column density for $\mathrm{CH}_{4}$ containing gases that was originally developed for the detection of gas leaks. However, Chagunda, et al. [14] demonstrated its ability to quantify $\mathrm{CH}_{4}$ concentration in exhaled air and estimate enteric $\mathrm{CH}_{4}$ output in dairy cows. Their conclusions were later corroborated by other authors $[15,16]$.

Generating large databases of $\mathrm{CH}_{4}$ emissions that help addressing reduction strategies has been lately proposed. Exchanging data from different measurements devices in different countries for more accurate studies or genetic evaluations would be an advantage. Thus, harmonizing measurement methodologies is a main concern in recent years, and assessing the equivalence or the statistical agreement between measuring methods is crucial to propose strategies to combine data from different devices. It is important to establish the agreement prior to measuring large numbers of individuals. One approach to analyze this agreement, usually used in medical field, is to record simultaneous repeated records on different subjects using the two methods [17] in order to analyze different sources of disagreement like differences on population means, on between-subject or on within-subject variabilities, as well as the calculation of agreement indices, such as concordance correlation coefficient (CCC) and the coefficient of individual agreement (CIA).

Up to date, few comparative studies have been conducted on these two instruments to determine their equivalence or lack thereof [18], but no study has compared their agreement on paired measurements on the same breath air samples, up to the best of our knowledge. Therefore, the aim of this study was to analyze the agreement and concordance of $\mathrm{CH}_{4}$ emissions through LMD and the NDIR on paired measurements under field conditions. 


\section{Materials and Methods}

\subsection{Experimental Setup and $\mathrm{CH}_{4}$ Concentration Determination}

The LMD is a hand held open path laser measuring device. The model used in this study was LaserMethaneMini (Tokyo Gas Engineering Co., Ltd. Anritsu Devices Co., Ltd., Tokyo, Japan). The principle of the LMD measuring technology was described previously by Chagunda et al. [12-14]. Briefly, this device is based on infrared absorption spectroscopy using a semiconductor laser for $\mathrm{CH}_{4}$ detection. The device must be pointed towards the nostrils of the cow from a fixed distance. Then, the LMD measures the density of the air column between the device and the animal's nostrils. The reflected laser beam is detected by the device, and its signal is processed and converted to the cumulative $\mathrm{CH}_{4}$ concentration along the laser path in ppm-m. The LMD was connected to a tablet (Samsung Galaxy Tab A6, New Jersey, USA) running GasViewer app (Tokyo Gas Engineering Solutions, Tokyo, Japan) via Bluetooth connection for exporting and storing the data in real time at $0.5 \mathrm{~s}$ intervals. The effect of atmospheric ambient $\mathrm{CH}_{4}$ concentration from the measurements was discounted using the offset function of the LMD.

The NDIR (Guardian NG Edinburg Instruments Ltd., Livinstong, UK) is one of the so-called sniffer methods that measure $\mathrm{CH}_{4}$ concentration (ppm) in breath or exhaled air. These methods have been previously used by Garnsworthy et al. [10] to assess the $\mathrm{CH}_{4}$ production of dairy cows at commercial farms. Briefly, a gas sampling tube from the front of a cow's head to a gas analyzer to continuously measure $\mathrm{CH}_{4}$ concentration in the cow's breath is used. Then, air is drawn through the instrument by an integral pump between the gas inlet port and analyzer. The device used in this study had a range of 0 to $10,000 \mathrm{ppm}$. For this study, air was sampled continuously at a rate of $1 \mathrm{~L} / \mathrm{min}$ through an $8 \mathrm{~mm}$ polyamide tube, using approximately $2 \mathrm{~m}$ of tube from the analyzer to cow's nostrils. Methane concentration was recorded at $1 \mathrm{~s}$ intervals and stored in a datalogger (Data Recorder SRD-99; Simex Sp. z o.o, Gdańsk, Poland). Baseline or ambient $\mathrm{CH}_{4}$ concentration was calculated as mean $\mathrm{CH}_{4}$ concentration before starting the measurements and subtracted from the measured data. Each day before starting measurements, the NDIR analyzer was verified using standard mixtures of $\mathrm{CH}_{4}$ in nitrogen $(0.0 \%, 0.25 \%, 0.50 \%, 0.75 \%$ and $1.0 \%$; MESA International Technologies INC, Santa Ana, CA, USA).

For this trial, records were measured in 29 Holstein (11) and Brown Swiss (18) dairy cows in the Fraisoro Agricultural School (Zizurkil, Spain). All animal experiments were carried out in accordance with EU Directive 2010/63/EU for animal experiments and approved by the ethics committee (NEIKER-OEBA-2017-004). Cows were $18.5 \%$ of the 1 st parity, $52 \%$ of the 2 nd parity, $18.5 \%$ of the 3rd parity and $11 \%$ of the 4 th parity. Average days in milk at the beginning of the experiment was $102 \pm 88 \mathrm{~d}$. Cows were offered a partial mixed ration consisting of corn silage, grass silage and straw ad libitum, and a mean of $5 \mathrm{~kg}$ of concentrate supplied in the AMS.

Breath $\mathrm{CH}_{4}$ concentration was measured on six different days during four months, except for two cows that died during the experimental period. Measurements were performed after morning unifeed distribution between 10:00 and 14:00. Animals were restrained and $\mathrm{CH}_{4}$ was measured simultaneously with the two devices during a 5 min sampling period, obtaining a total of 164 paired measurements. An operator pointed the LMD at a cow's nostril at a fixed distance of $1 \mathrm{~m}$ and trying to maintain the angle from which the LMD was pointed to the cow. Data was recorded every $0.5 \mathrm{~s}$ in a tablet. Another operator simultaneously placed NDIR sampling tube on the cow's nostrils in order to measure $\mathrm{CH}_{4}$ concentration in exhaled air with the NDIR and data was recorded every $1 \mathrm{~s}$ in a datalogger.

\subsection{Calculations and Statistical Analysis}

The average $\mathrm{CH}_{4}$ concentration from LMD and NDIR was calculated as the arithmetic mean of all concentration values within each 5 min profile measured with the LMD and the NDIR analyzer respectively. The number of eructation events or peaks in each $5 \mathrm{~min}$ profile was also calculated for both devices as described in [18]. 
In order to perform a concordance analysis, phenotypes with the same units are required. Some assumptions must be taken into account in order to convert mean LMD values in ppm-m into ppm. Data obtained with LMD at a distance of one meter (D) was transformed considering an exhaled air bubble of $10 \mathrm{~cm}(\mathrm{X})$ from the cow's nostrils, and $2 \mathrm{ppm} \mathrm{CH}_{4}$ concentration in the environment air (A). The resulting phenotype was calculated as:

$$
\mathrm{CH}_{4}(\mathrm{ppm}-\mathrm{m})=\mathrm{X}(\mathrm{m}) \times \mathrm{CH}_{4}(\mathrm{ppm})+\mathrm{D}(\mathrm{m}) \times \mathrm{A}(\mathrm{ppm})
$$

Data was analyzed using a linear mixed effects model with Kronecker product covariance structure in a doubly multivariate set-up [19] using the MIXED procedure of SAS with longitudinal repeated measures (SAS ${ }^{\circledR}$ Institute INC, Cary, NC, EEUU, Version 7.15, 2017). A Kenward-Roger correction was used to compute the correct denominator degrees of freedom of fixed effects in the presence of repeated measures [20]. The linear mixed effects model for the ith records can be written as:

$$
\mathrm{y}_{\mathrm{i}}=\mu+\mathrm{b}_{1}\left(\mathrm{~S}_{\mathrm{i} 1}\right)+\mathrm{b}_{2}\left(\mathrm{~S}_{\mathrm{i} 2}\right)+\mathrm{b}_{3} \mathrm{D}+\mathrm{b}_{4} B+\mathrm{b}_{\mathrm{i} 1}\left(\mathrm{Z}_{\mathrm{i} 1}\right)+\mathrm{b}_{\mathrm{i} 2}\left(\mathrm{Z}_{\mathrm{i} 2}\right)+\mathrm{e}_{\mathrm{i}}
$$

where every method replication response is denoted by superscript $i$ and $y_{i}$ is the method replication response $\left(\mathrm{CH}_{4}\right.$ concentration, $\left.\mathrm{ppm}\right)$. Terms $\mathrm{S}_{\mathrm{i} 1}$ and $\mathrm{S}_{\mathrm{i} 2}$ indicate the instrument each response belongs to (LMD and NDIR) and will take a value of either zero or one to link $y_{i}$ to the corresponding instrument. The regression coefficients $b_{1}$ and $b_{2}$ are the respective fixed effects of instruments, $b_{3}$ denotes the fixed effect of day of measurement and $b_{5}$ is the fixed effect of the breed. Terms $b_{i 1}$ and $b_{i 2}$ are random effect parameters for each cow with each of the two devices, with bi $\sim N D(0, G)$, and $Z_{i 1}$ and $Z_{i 2}$ relate responses $\mathrm{y}_{\mathrm{i}}$ to the respective methods. Term $\mathrm{e}_{\mathrm{i}}$ is the random residuals from each instrument response with $\mathrm{e}_{\mathrm{i}} \sim \mathrm{ND}\left(0, \mathrm{R}_{\mathrm{i}}\right)$.

The method described in detail by Roy [19] was employed to formally test the significance of differences for the between-subject and within-subject variances of the two instruments by means of a log likelihood ratio test between models differing for various combinations of structured and unstructured variance-covariance matrices $G$ and $R_{\mathrm{i}}$. Using the variance components of the previous model, CIA and CCC were calculated.

Repeatability for each method was calculated as the between-cow $\left(\sigma_{\mathrm{B}}^{2}\right)$ variance divided by the between-cow and within-cow $\left(\sigma_{\mathrm{W}}^{2}\right)$ variance.

$$
\mathrm{REP}=\frac{\sigma_{\mathrm{B}}^{2}}{\sigma_{\mathrm{B}}^{2}+\sigma_{\mathrm{W}}^{2}}
$$

Additionally, the repeated measures correlation $\left(\mathrm{r}_{\mathrm{p}}\right)$ was calculated as:

$$
r_{p}=\frac{\sigma_{\mathrm{B} 1 \mathrm{~B} 2}^{2}}{\sqrt{\sigma_{\mathrm{B} 1}^{2} \times \sigma_{\mathrm{B} 2}^{2}}}
$$

with $\sigma_{\mathrm{B} 1 \mathrm{~B} 2}{ }^{2}$ being the covariance between cows for the LMD and NDIR, and $\sigma_{\mathrm{B} 1}{ }^{2}$ and $\sigma_{\mathrm{B} 2}{ }^{2}$ being the between-subject variance for method 1 and 2 , respectively.

Individual level of correlation was calculated using variance components applying the statistical model described previously but including the stage of lactation and lactation number as fixed effects [21].

A Pearson correlation coefficient and Spearman's rank correlation test were used to assess the association between the overall mean $\mathrm{CH}_{4}$ concentrations across all paired individual cow records [22].

\section{Results and Discussion}

Strategies to address $\mathrm{CH}_{4}$ abatement strategies need large amounts of $\mathrm{CH}_{4}$ measurements. Combining measurements from different countries has been proposed as a possible strategy and is being studied elsewhere. However, different research groups often utilize different types of device to 
record $\mathrm{CH}_{4}$. In this context, a common goal is to decide if the measurement systems agree suitably to each other, and thus can be used interchangeably. The current study is the first directly comparing spot-sampling methods based on breath analysis called the NDIR and LMD simultaneously in the same breath air samples.

An example of $\mathrm{CH}_{4}$ profile of a cow as measured with the NDIR sensor and the LMD can be seen in Figure 1. Five different eructation events or $\mathrm{CH}_{4}$ peaks can be seen with both devices. Mean number of peaks differed between instruments (Table 1), being the LMD capable of detecting higher number of peaks ( 4.69 vs. $4.24, p<0.001$ ), this could be related with the higher sensitivity of the LMD to detect small variations on $\mathrm{CH}_{4}$ concentration, even away from the animal [11] and with the time of recording (every $0.5 \mathrm{~s}$ vs. $1 \mathrm{~s}$ with LMD and NDIR, respectively). However, these differences on the mean number of peaks are of small biological relevance. Moreover, the between subjects variance for the number of peaks did not differ between instruments and a large and positive repeated measures correlation and individual-level correlation were observed (Table 1). Thus, it can be said that both methods are capable to detect the eructation events or peaks in a similar way.
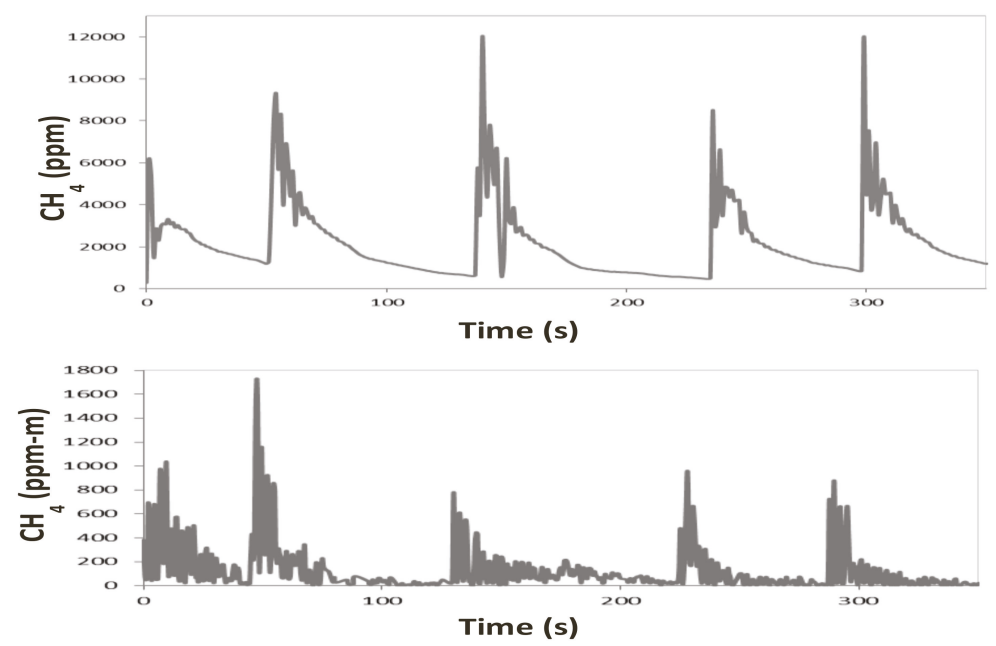

Figure 1. Representation of $\mathrm{CH}_{4}$ concentration for a cow measured with a non-dispersive infrared (NDIR) sensor (above), and laser methane detector (LMD; below) with different belching events.

In our study, a mean $\mathrm{CH}_{4}$ concentration of 97 ppm-m with a minimum of 21 ppm-m and a maximum of 303 ppm-m were recorded with the LMD. With the NDIR sensor a mean $\mathrm{CH}_{4}$ concentration of $1268 \mathrm{ppm}$ with a minimum of $58 \mathrm{ppm}$ and a maximum of $3575 \mathrm{ppm}$ was recorded. The values observed with the LMD agree with those observed in other studies; for instance, Chagunda et al. [12-14] found average $\mathrm{CH}_{4}$ concentrations between 107-369 ppm-m, depending on the animal activity. The values observed with the NDIR sensor are in line with those observed in other studies [23].

Before considering any method for comparison one needs to ensure that its replication error is acceptable. Repeatability is relevant to the study of method comparison because the repeatabilities of the two methods limit the amount of agreement, which is possible. If one method has poor repeatability the agreement between the two methods is likely to be poor too. As shown in Table 1, the repeatability for the concentration of $\mathrm{CH}_{4}$ was greater with the NDIR sensor (0.42) than with the LMD (0.23). However, for the number of peaks, the repeatability with the LMD (0.20) was greater than with the NDIR sensor (0.14). The repeatability values obtained in the current trial with the NDIR sensor agree with those reported by Lassen et al. [24] made in the AMS, and with Negussie et al. [25] who reported a repeatability value of 0.36 , measuring $\mathrm{CH}_{4}$ based on $\mathrm{CH}_{4} / \mathrm{CO}_{2}$ ratio, but were lower than those 
reported by Sorg et al. [18] who obtained a repeatability of $0.77(0.13)$. However, the latter authors processed the NDIR data using head lifting algorithms and modeled it in a Fourier series approach on the time of day of measurement to account for diurnal patterns of $\mathrm{CH}_{4}$ emission as described by Difford et al. [26]. Repeatability from measurements obtained with LMD was lower than that obtained with the NDIR but similar to those found by other authors [18,27]. The LMD measures were less repeatable than those of NDIR probably because the LMD measurement took place in the open space of the barn, while the NDIR sampled air in the nostrils where environmental influences are likely less variable, e.g., air movement due to ventilation and wind speed.

Though discouraged in comparison studies with repeated measures per subject, we provide the Pearson's and Spearman's correlation coefficients, which were moderately high and positive between instruments for $\mathrm{CH}_{4}$ concentration ( 0.73 and 0.74 , respectively) and the number of peaks ( 0.72 and 0.72 , respectively). These correlation coefficients could be shrunk because repeated measurements per subject inflate the residual error variance. In these cases, the repeated measures correlation is more appropriate because the effect of repeated measurements per subject are accounted for and prevents a downward bias of correlations due to imprecise measurements. In this sense, repeated measures correlation and individual-level correlation between methods were high ( 0.98 and 0.94 , respectively) for $\mathrm{CH}_{4}$ concentration (Table 1), which was higher than that observed by Sorg et al. [18]. Individual-level correlations have been used as proxies for genetic correlations in difficult or expensive to measure traits, being the genetic correlation the most informative correlation metric for assessing how to incorporate a method in a selection index [21].

We did not observe a significant breed effect. The $\mathrm{CH}_{4}$ concentrations population means and all variance components (between-subject and within-subject) differed $(p<0.05)$ between instruments (Table 1). It must be pointed out that this study aimed to assess the agreement or lack thereof between LMD and NDIR. Neither methods are considered as the gold standard, but they allow high throughput recording in a whole cattle population, which is of main interest for the dairy industry. This method comparison study aimed to evaluate whether these methods can be used interchangeably in commercial farms. Traditionally, if there is no reference method, assessing agreement has been based on the intraclass correlation coefficient and CCC. In this study a moderate CCC was observed between instruments for both $\mathrm{CH}_{4}$ concentration (0.62) and for the number of peaks (0.66; Table 1). This CCC value was higher than that observed by Sorg et al. [18] probably due to the high variance estimates in the present study. This coefficient with fixed within-subject variability increase as between-subject variability increases and some authors question whether this coefficient is adequate in assessing agreement at the individual level, being necessary to evaluate agreement using both CCC and CIA in order to overcome the inherent shortcomings of both metrics $[28,29]$. The CIA evaluates agreement relative to imprecision in such a way that a good individual agreement means that the individual difference between readings from different methods is close to the difference between replicated readings within a method, and could therefore be inflated by low repeatability values. We observed higher values of CIA between instruments for both $\mathrm{CH}_{4}$ concentration (0.83) and number of peaks (0.77) than CCC values, which can be explained by the observed moderate repeatability values (Table 1 ). However, CIA values were moderately high and based on the threshold of "good" interchangeability (0.455) defined by Barnhart et al. [17], $\mathrm{CH}_{4}$ concentration measurements of both instruments might be used interchangeably.

Nevertheless, based on the criteria for the statistical agreement of the equivalence of means and total variability suggested by Roy [19], the observed differences in the mean populations, between-subject variabilities and within-subject variabilities (Table 1), $\mathrm{CH}_{4}$ concentration obtained by means of NDIR and LMD could not be considered interchangeable. When two methods are compared without a gold standard, neither provides an unequivocally correct measurement, but $\mathrm{CH}_{4}$ measures obtained with both devices can be used interchangeably provided that the sources of disagreement are identified and corrected. In this sense, Difford et al. [26] in a study comparing two sniffer methods with simultaneous 
repeated measurements proposed a process of calibration and standardization to overcome these sources of disagreement with positive results.

Table 1. Sources of (dis)agreement for the $\mathrm{CH}_{4}$ concentration and number of peaks.

\begin{tabular}{|c|c|c|c|c|}
\hline \multirow{2}{*}{ Item } & \multicolumn{2}{|c|}{$\mathrm{CH}_{4}$ Concentration in (ppm) } & \multicolumn{2}{|c|}{ Number of Peaks } \\
\hline & NDIR & LMD_cal & NDIR & LMD_cal \\
\hline LSMean (SE) & $1280(88.3)^{a}$ & $991(57.3)^{b}$ & $4.24(0.1)^{\mathrm{a}}$ & $4.69(0.1)^{b}$ \\
\hline Between-cow variation & $149081^{\text {a }}$ & $54556^{\mathrm{b}}$ & 0.18 & 0.19 \\
\hline Within-cow variation & $352398^{a}$ & $187742^{b}$ & $1.16^{\mathrm{a}}$ & $0.76^{\mathrm{b}}$ \\
\hline Repeatability & 0.42 & 0.23 & 0.14 & 0.20 \\
\hline Repeat measures correlation & \multicolumn{2}{|c|}{0.98} & \multicolumn{2}{|c|}{1.00} \\
\hline Individual level correlation & \multicolumn{2}{|c|}{0.94} & \multicolumn{2}{|c|}{1.00} \\
\hline Pearson correlation & \multicolumn{2}{|c|}{0.73} & \multicolumn{2}{|c|}{0.72} \\
\hline Spearman correlation & \multicolumn{2}{|c|}{0.74} & \multicolumn{2}{|c|}{0.72} \\
\hline Concordance correlation coefficient & \multicolumn{2}{|c|}{0.62} & \multicolumn{2}{|c|}{0.66} \\
\hline Coefficient of individual agreement & \multicolumn{2}{|c|}{0.83} & \multicolumn{2}{|c|}{0.77} \\
\hline
\end{tabular}

NDIR: Non-dispersive infrared $\mathrm{CH}_{4}$ sensor; LMD_cal: Laser $\mathrm{CH}_{4}$ detector transformed to ppm; SE: Standard error; estimates with subscripts differ $(p<0.05)$.

\section{Conclusions}

Methane concentration measurements obtained by means of NDIR and LMD instruments cannot be directly used interchangeably under commercial conditions. The joint use of both methods could be considered to establish classifications of individuals, in relation to their $\mathrm{CH}_{4}$ emissions, in studies for genetic selection purposes or to evaluate $\mathrm{CH}_{4}$ emissions reduction strategies only if sources of disagreement, which result in different between-subject and within-subject variabilities, are identified and corrected for.

Author Contributions: J.R., R.A., I.G. and A.G.-R. designed the study and methodology. J.R., I.G., R.A. and A.G.-R. have done the field work. J.R., I.G. and A.G.-R., have done the statistical analysis of the data and writing the original manuscript, subsequently supervised by O.G.-R., E.U., R.R. and R.A. Funding acquisition, A.G.-R., R.R., E.U. and O.G.-R.

Funding: This research was financed by RTA2015-00022-C03-02 (METALGEN) project from the national plan of research, development and innovation 2013-2020 and the Department of Economic Development and Competitiveness (Basque Government, Vitoria-Gasteiz, Spain). The first author of this paper was granted a scholarship from the Department of Agriculture of the Basque Country.

Acknowledgments: The authors wish to thank the staff from Escuela Agraria de Fraisoro (Basque Department of Environment, Rural Development, Agriculture and Fishery) for assistance during sampling.

Conflicts of Interest: The authors declare no conflict of interest.

\section{References}

1. Gerber, P.J.; Steinfeld, H.; Henderson, B.; Mottet, A.; Opio, C.; Dijkman, J.; Falcucci, A.; Tempio, G. Tackling Climate Change Through Livestock-A Global Assessment of Emissions and Mitigation Opportunities; Food and Agriculture Organization of the United Nations (FAO): Rome, Italy, 2013.

2. IPCC (International Panel on Climate Change). Synthesis Report: Contribution of Working Groups I, II, and III to the Fifth Assessment Report of the Intergovernmental Panel on Climate Change; Core Writing Team, Pachauri, R.K., Meyer, L.A., Eds.; IPCC: Geneva, Swictzerland, 2014; p. 155.

3. Holter, J.B.; Young, A.J. Methane Prediction in Dry and Lactating Holstein Cows. J. Dairy Sci. 1992, 75, 2165-2175. [CrossRef]

4. Van Engelen, S.; Bovenhuis, H.; van der Tol, P.P.J.; Visker, M.H.P.W. Genetic background of methane emission by Dutch Holstein Friesian cows measured with infrared sensors in automatic milking systems. J. Dairy Sci. 2018, 101, 2226-2234. [CrossRef] [PubMed] 
5. Negussie, E.; de Haas, Y.; Dehareng, F.; Dewhurst, R.J.; Dijkstra, J.; Gengler, N.; Morgavi, D.P.; Soyeurt, H.; van Gastelen, S.; Yan, T.; et al. Large-scale indirect measurements for enteric methane emissions in dairy cattle: A review of proxies and their potential for use in management and breeding decisions. J.Dairy. Sci. 2016, 100, 2433-2453. [CrossRef] [PubMed]

6. Storm, I.M.L.D.; Hellwing, A.L.F.; Nielsen, N.I.; Madsen, J. Methods for measuring and estimating methane emission from ruminants. Animals 2012, 2, 160-183. [CrossRef] [PubMed]

7. Hill, J.; McSweeney, C.; Wright, A.-D.G.; Bishop-Hurley, G.; Kalantar-Zadeh, K. Measuring methane production from ruminants. Trends Biotechnol. 2016, 34, 26-35. [CrossRef] [PubMed]

8. Patra, A.K. Recent advances in measurements and dietary mitigation of enteric methane emission in ruminants. Front. Vet. Sci. 2016, 3, 1-17. [CrossRef] [PubMed]

9. Bell, M.J.; Potterton, S.L.; Craigon, J.; Saunders, N.; Wilcox, R.H.; Hunter, M.; Goodman, J.R.; Garnsworthy, P.C. Variation in enteric methane emissions among cows on commercial dairy farms. Animal. 2014, 9, 1540-1646. [CrossRef]

10. Garnsworthy, P.C.; Craigon, J.; Hernandez-Medrano, J.H.; Saunders, N. Variation among individual dairy cows in methane measurements made on farm during milking. J.Dairy Sci. 2012, 95, 3181-3189. [CrossRef]

11. Ricci, P.; Chagunda, M.G.G.; Rooke, J.; Houdijk, J.G.M.; Duthie, C.A.; Hyslop, J.; Roeche, R.; Waterhouse, A. Evaluation of the laser methane detector to estimate methane emissions from ewes and steers. J. Anim. Sci. 2014, 92, 5239-5250. [CrossRef]

12. Chagunda, M.G.G. Opportunities and challenges in the use of the Laser Methane Detector to monitor enteric methane emissions from ruminants. Animal 2013, 7, 394-400. [CrossRef]

13. Garnsworthy, P.C.; Craigon, J.; Hernandez-Medrano, J.H.; Saunders, N. On-farm methane measurements during milking correlate with total methane production by individual dairy cows. J. Dairy Sci. 2012, 95, 3166-3180. [CrossRef] [PubMed]

14. Chagunda, M.G.G.; Ross, D.; Roberts, D.J. On the use of a laser methane detector in dairy cows. Comput. Electron. Agric. 2009, 68, 157-160. [CrossRef]

15. Chagunda, M.G.G.; Yan, T. Do methane measurements from a laser detector and an indirect open-circuit respiation calorimetric chamber agree sufficiently closely? Anim. Feed Sci. Tecnol. 2011, 165, 8-14. [CrossRef]

16. Sorg, D.; Mühlbach, S.; Rosner, F.; Kuhla, B.; Dermo, M.; Meese, S.; Schwarm, A.; Kreuzer, M.; Swalve, H. The agreement between two next-generation laser methane detectors and respiration chamber facilities in recording methane concentrations in the spent air produced by dairy cows. Comput. Electron. Agric. 2017, 143, 262-272. [CrossRef]

17. Barnhart, H.X.; Haber, M.; Kosinski, A.S. Assessing individual agreement. J. Biopharm. Stat. 2017, 17, 697-719. [CrossRef] [PubMed]

18. Sorg, D.; Difford, G.F.; Mühlbach, S.; Kuhla, B.; Swalve, H.; Lassen, J.; Strabel, T.; Pszczola, M. Comparison of a laser methane detector with the GreenFeed and two breath analysers for on-farm measurements of methane emissions from dairy cows. Comput. Electron. Agric. 2018, 153, 285-294. [CrossRef]

19. Roy, A. An application of linear mixed effects model to assess the agreement between two methods with replicated observations. J. Biopharm. Stat. 2009, 19, 150-173. [CrossRef]

20. Kenward, M.G.; Roger, J.H. Small sample inference for fixed effects from restricted maximum likelihood. Biometrics. 1997, 53, 982-997. [CrossRef]

21. Difford, G.F.; Olijhoek, D.W.; Hellwing, A.L.F.; Lund, P.; Bjerring, M.A.; de Haas, Y.; Lassen, J.; Løvendahl, P. Ranking cow's methane emissions under commercial conditions with sniffers versus respiration chambers. Acta Agric. Scand. A Anim. Sci. 2019, 68, 25-32.

22. SAS. The little SAS Enterprise Guide Book; SAS: Cary, NC, USA, 2017.

23. Huhtanen, P.; Cabezas-Garcia, E.H.; Utsumi, S.; Zimmerman, S. Comparison of methods to determine methane emissions from dairy cows in farm conditions. J. Dairy Sci. 2015, 98, 2294-3409. [CrossRef]

24. Lassen, J.; Lovendahl, P. Heritability estimates for enteric methane emissions from Holstein cattle measured using noninvasive methods. J. Dairy Sci. 2015, 99, 1959-1967. [CrossRef] [PubMed]

25. Negussie, E.; Liinamo, A.-E.; Mäntysaari, P.; Mäntysaari, E.; Lidauer, M. Between and within-individual variation in methane output measurements in dairy cows. In Book of Abstracts of the 63rd Annual Meeting of the European Association of Animal Science: Bratislava, Slovakia, 27-31 August 2012; Wageningen Academic Publishers: Wageningen, The Netherlands, 2012; p. 170. 
26. Difford, G.F.; Lassen, J.; Lovendahl, P. Interchangeability between methane measurements in dairy cows assessed by comparing precision and agreement of two non-invasive infrared methods. Comput. Electron. Agric. 2016, 124, 220-226. [CrossRef]

27. Lassen, J.; Lovendahl, P.; Madsen, J. Accuracy of noninvasive breath methane measurements using Fourier transform infrared methods on individual cows. J. Dairy Sci. 2012, 95, 890-898. [CrossRef] [PubMed]

28. Barnhart, H.X.; Haber, M.; Lokhnygina, Y.; Kosinski, A.S. Comparison of concordance correlation coefficient and coefficient of individual agreement in assesing agreement. J. Biopharm. Stat. 2017, 17, 721-738. [CrossRef] [PubMed]

29. Atkinson, G.; Nevill, A. Comment on the use of concordance correlation to assess the agreement between two variables. Int. Biometr. Soc. 2016, 53, 775-777.

(C) 2019 by the authors. Licensee MDPI, Basel, Switzerland. This article is an open access article distributed under the terms and conditions of the Creative Commons Attribution (CC BY) license (http://creativecommons.org/licenses/by/4.0/). 


\title{
Comparison of Methods to Measure Methane for Use in Genetic Evaluation of Dairy Cattle
}

\author{
Philip C. Garnsworthy ${ }^{1, *}$, Gareth F. Difford ${ }^{2,3}$, Matthew J. Bell ${ }^{1}$, Ali R. Bayat ${ }^{4}$,
} Pekka Huhtanen ${ }^{5}$, Björn Kuhla ${ }^{6}$, Jan Lassen ${ }^{2}$, Nico Peiren ${ }^{7}$, Marcin Pszczola ${ }^{8}$, Diana. Sorg ${ }^{9,10}$, Marleen H.P.W. Visker ${ }^{3}$ and Tianhai Yan ${ }^{11}$

1 School of Biosciences, University of Nottingham, Sutton Bonington Campus, Loughborough LE12 5RD, UK; Matthew.Bell@nottingham.ac.uk

2 Department of Molecular Biology and Genetics-Center for Quantitative Genetics and Genomics, Aarhus University, Blichers Allé 20, 8830 Tjele, Denmark; garethdifford@gmail.com (G.F.D.);

jan.lassen@mbg.au.dk (J.L.)

3 Animal Breeding and Genomics, Wageningen University \& Research, P.O. Box 338, 6700 AH Wageningen, The Netherlands; marleen.visker@frieslandcampina.com

4 Milk Production, Production Systems, Natural Resources Institute Finland (Luke), FI 31600 Jokioinen, Finland; alireza.bayat@luke.fi

5 Department of Agricultural Research for Northern Sweden, Swedish University of Agricultural Sciences, SE-901 83 Umeå, Sweden; Pekka.Huhtanen@slu.se

6 Institute of Nutritional Physiology "Oskar Kellner", Leibniz Institute for Farm Animal Biology (FBN), Wilhelm-Stahl-Allee 2, 18196 Dummerstorf, Germany; b.kuhla@fbn-dummerstorf.de

7 Flanders Research Institute for Agriculture, Fisheries and Food, Animal Sciences Unit, Scheldeweg 68, 9090 Melle, Belgium; Nico.Peiren@ilvo.vlaanderen.be

8 Department of Genetics and Animal Breeding, Poznan University of Life Sciences, Wolynska 33, 60-637 Poznan, Poland; mbee@up.poznan.pl

9 Institute of Agricultural and Nutritional Sciences, Martin Luther University Halle-Wittenberg, Animal Breeding, Theodor-Lieser-Str. 11, 06120 Halle, Germany; dianasorg@yahoo.de

10 German Environment Agency (Umweltbundesamt), Wörlitzer Platz 1, 06844 Dessau-Roßlau, Germany

11 Agri-Food and Biosciences Institute, Hillsborough, Co. Down BT26 6DR, UK; Tianhai.Yan@afbini.gov.uk

* Correspondence: phil.garnsworthy@nottingham.ac.uk; Tel.: +44-115-951-6100

Received: 30 August 2019; Accepted: 15 October 2019; Published: 21 October 2019

Simple Summary: Methane is a greenhouse gas with a global warming potential 28 times that of $\mathrm{CO}_{2}$. Enteric methane accounts for $17 \%$ of global methane emissions and $3.3 \%$ of total global greenhouse gas emissions from human activities. There is, therefore, significant research interest in finding ways to reduce enteric methane emissions by ruminants. Partners in Expert Working Group 2 (WG2) of the European Cooperation in Science and Technology (COST) Action METHAGENE have used several methods for measuring methane output by individual dairy cattle under various environmental conditions. Methods included respiration chambers, the sulphur hexafluoride $\left(\mathrm{SF}_{6}\right)$ tracer technique, breath sampling during milking or feeding, the GreenFeed system, and the laser methane detector. Respiration chambers are considered the 'gold standard', but are unsuitable for large-scale measurements of methane emissions, which are needed for genetic evaluations. In this study, the suitability of methods for large-scale studies was reviewed and compared. All methods showed high correlations with respiration chambers, but comparisons among alternative methods generally had lower correlations. Results confirm, however, that there is sufficient correlation between methods for measurements from all methods to be combined, with appropriate weightings, for use in international genetic studies. This will pave the way for breeding cattle with lower methane emissions.

\footnotetext{
Abstract: Partners in Expert Working Group WG2 of the COST Action METHAGENE have used several methods for measuring methane output by individual dairy cattle under various environmental conditions. Methods included respiration chambers, the sulphur hexafluoride $\left(\mathrm{SF}_{6}\right)$ tracer technique, breath sampling during milking or feeding, the GreenFeed system, and the laser methane detector.
} 
The aim of the current study was to review and compare the suitability of methods for large-scale measurements of methane output by individual animals, which may be combined with other databases for genetic evaluations. Accuracy, precision and correlation between methods were assessed. Accuracy and precision are important, but data from different sources can be weighted or adjusted when combined if they are suitably correlated with the 'true' value. All methods showed high correlations with respiration chambers. Comparisons among alternative methods generally had lower correlations than comparisons with respiration chambers, despite higher numbers of animals and in most cases simultaneous repeated measures per cow per method. Lower correlations could be due to increased variability and imprecision of alternative methods, or maybe different aspects of methane emission are captured using different methods. Results confirm that there is sufficient correlation between methods for measurements from all methods to be combined for international genetic studies and provide a much-needed framework for comparing genetic correlations between methods should these become available.

Keywords: methane; dairy cows; genetic evaluation; greenhouse gases; environment

\section{Introduction}

Methane is a greenhouse gas with a global warming potential 28 times that of $\mathrm{CO}_{2}$ [1]. Methane from ruminant livestock is generated during microbial fermentation in the rumen and hindgut (enteric methane), and from decomposition of manure. Enteric methane contributes $80 \%$ of methane emissions by ruminants, and manure decomposition contributes $20 \%$. Enteric methane accounts for $17 \%$ of global methane emissions and 3.3\% of total global greenhouse gas emissions from human activities [2]. There is, therefore, a significant research interest in finding ways to reduce enteric methane emissions by ruminants.

Ruminant animals have evolved with a digestive system to digest plant materials efficiently. Like most mammals, ruminants lack the cellulase enzyme required to break the beta-glucose linkages in cellulose, but they play host to diverse populations of rumen microbes that can digest cellulose and other plant constituents. When rumen bacteria, protozoa and fungi ferment carbohydrates and proteins in plant materials, they produce volatile fatty acids, principally acetate, propionate and butyrate. High-fibre diets favour acetate synthesis. Synthesis of acetate and butyrate are accompanied by release of metabolic hydrogen, which, if allowed to accumulate in rumen fluid, has negative effects on microbial growth, and feed digestibility [3]. Rumen Archaea are microorganisms that combine metabolic hydrogen with $\mathrm{CO}_{2}$ to produce methane and water. Archaea play a vital role, therefore, in protecting the rumen from excess metabolic hydrogen, and the methane they produce is an inevitable product of rumen fermentation.

The amount of methane produced by a ruminant animal is related to the amount of organic matter digested in the rumen, particularly the fibre fraction, and hence the amount of acetate and metabolic hydrogen produced. The main determinants of daily methane production, therefore, are dry matter intake and diet composition: the more feed consumed, and/or the greater the fibre content of the diet, the more methane is produced per day. Nutritional approaches for methane mitigation include reducing the forage to concentrate ratio of diets, increasing dietary oil content, and dietary inclusion of rumen modifiers and methane inhibitors $[2,4,5]$. Some of these mitigation strategies act through reductions in forage digestibility or feed intake, which can have negative consequences for feed efficiency and methane output per kg of product. Methane output per $\mathrm{kg}$ of product is affected mainly by milk yield or growth rate per animal, and by herd-level factors, such as fertility, disease incidence and replacement rate, which affect not only the milk yield of the herd, but also methane produced by replacement animals [6]. Even when all these influences have been taken into account, methane output varies considerably between individual animals. During development of the Metabolisable Energy 
system, thousands of determinations of methane production by sheep and cattle were performed at the Rowett Research Institute, Aberdeen, UK, using animals fed a restricted amount of feed in closed-circuit respiration chambers. Under these carefully controlled conditions, for animals fed on the same feed, the between-animals coefficient of variation (CV) in methane was 8.1\% [7]. Analysis of 1335 records of methane production by cattle fed on a variety of diets in respiration chambers showed a strong relationship $\left(\mathrm{r}^{2}=0.91\right)$ between methane production and dry matter intake [8]. At the average dry matter intake, however, there was a twofold difference in methane production between the lowest and highest emitters, and at the average methane production rate there was a twofold difference in dry mater intake. These two studies illustrate the range in variation among individual animals that may be encountered under research conditions.

Researchers view individual variation in different ways, according to the aims of their research. When comparing treatments, or evaluating the nutritional value of diets, investigators want to minimise between-animal variation so as to maximise the power of their study, minimise the number of animals required, and increase the chance of detecting a significant difference between treatments. When evaluating populations for genetic studies, on the other hand, variation between animals is of interest, so the aim is to quantify variation, which can then be partitioned into genetic and environmental components. These components are used to determine the amount of variation that is heritable, and genetic correlations between traits currently used in breeding and a possible new trait like methane production. This enables the breeder to decide if there is any merit to adding the new trait to the breeding goal. In terms of methane mitigation, nutritional and management approaches provide greater short-term reductions, but genetic approaches provide greater long-term reductions because genetic improvements are cumulative and permanent. All disciplines require a measurement to be suitably accurate and precise to conduct hypothesis testing and draw reasonable inferences with a given level of certainty. However, several factors influence the choice of the most suitable measurement method such as cost, level of accuracy, precision, scope of application, and scale, which vary across disciplines [9]. For instance, genetic selection programs require methane measurements on thousands of related individuals under the environmental conditions in which the animals are expected to perform [10]. This can be challenging because dairy cattle perform in a wide range of conditions (e.g., grazing vs indoor housing).

Respiration chambers are calibrated to be accurate and precise, and are the gold standard for benchmarking new methods. Where an alternative method may be cheaper, less invasive, easier to implement, or have a wider scope of applications, it is of value to assess the relative accuracy, precision and correlation with the gold standard to assess the relative worth of the alternative method [11]. All methods measure methane with some level of error, so the 'true value' of an individual is not known. However, when the level of measurement error increases, so too does the imprecision. When comparing two methods where one or both methods has high imprecision a phenomenon known as 'attenuation of errors' occurs [12]. The increased measurement error biases the correlation between the two methods downwards and reduces the efficacy of detecting significant differences in accuracy [13]. Or in terms of linear regression terms, when the observed CV of an alternative method is higher than that of the gold standard method, the slope of regression between the methods is decreased and the intercept is biased upwards [14,15].

A variety of technologies are being developed and employed to measure methane emissions by individual dairy cattle under various environmental conditions, as is evidenced by frequent reviews (e.g., $[9,16,17])$. The aim of the current study was to review and compare the suitability of methods for large-scale measurements of methane output by individual animals, which may be combined with other databases for genetic evaluations. Comparisons included assessing the accuracy, precision and correlation between methods. Combining datasets from different countries and research centres could be a successful strategy for making genetic progress in a trait that is difficult to measure, such as methane emissions if the methods are correlated [17]. Potential for combining large-scale data is of particular interest because data sharing could lead to powerful international collaborations and 
efficient sharing of resources. Accuracy and precision of methods are important, but data from different sources can be appropriately weighted or adjusted when combined, so any methods can be combined if they are suitably correlated with the 'true' value. The objective of the current study, therefore, was to examine correlations among results obtained by different methods, ultimately leading to an estimate of confidence limits for selecting individual animals that are high or low emitters.

\section{Methods for Measuring Methane}

Partners in Expert Working Group 2 (WG2) of the European Cooperation in Science and Technology (COST) Action METHAGENE (www.methagene.eu) have used a variety of methods for measuring methane output by individual animals. Methods include respiration chambers, the sulphur hexafluoride $\left(\mathrm{SF}_{6}\right)$ tracer technique, breath sampling during milking or feeding, the GreenFeed system, and the laser methane detector. Each method measures different components of methane output. Only respiration chambers measure total emissions from the animal via the oral, nasal and anal routes; all other methods ignore emissions via the anus and only measure methane emitted in breath. Breath measurements are justified because $99 \%$ of methane is emitted from the mouth and nostrils, and only $1 \%$ via the anus [18]. The $\mathrm{SF}_{6}$ technique samples breath over $24 \mathrm{~h}$, whereas other techniques use spot samples of breath over periods of minutes throughout the day, so diurnal variation has to be considered. The majority of methane $(87 \%)$ is released by eructation $[18,19]$, which provides a clear signal for sample processing.

The main features of methods for measuring methane output by individual animals are summarised in Table 1. Values for each feature are based on the experience of experts in METHAGENE WG2 who have used the methods. All values are relative, and somewhat subjective, because absolute values will depend on installation and implementation of each method at different research centres. Each method is described and discussed in more detail in the next five sub-sections.

Table 1. Summary of the main features of methods for measuring methane output by individual animals ${ }^{1}$.

\begin{tabular}{|c|c|c|c|c|c|c|}
\hline Method & $\begin{array}{l}\text { Purchase } \\
\text { Cost }^{2}\end{array}$ & $\begin{array}{c}\text { Running } \\
\text { Costs }\end{array}$ & Labour $^{2}$ & Repeatability & $\begin{array}{c}\text { Behaviour } \\
\text { Alteration }^{3}\end{array}$ & Throughput \\
\hline Respiration chamber & High & High & High & High & High & Low \\
\hline $\mathrm{SF}_{6}$ technique & Medium & High & High & Medium & Medium & Medium \\
\hline $\begin{array}{l}\text { Breath sampling during } \\
\text { milking and feeding }\end{array}$ & Low $^{4}$ & Low & Low & Medium & None & High \\
\hline GreenFeed & Medium & Medium & Low & Medium & Low & Medium \\
\hline Laser methane detector & Low & Low & High & Low & Low-Medium & Medium \\
\hline
\end{tabular}

\subsection{Respiration Chamber}

Respiration chambers for open- or closed-circuit indirect calorimetry are considered the 'Gold Standard', and were used extensively in nutrition studies when establishing the Metabolisable Energy system [7]. A single animal (or occasionally more) is confined in a chamber for between 2 and 7 days. Concentration of methane (and other gases if required) is measured at the air inlet and outlet vents of the chamber. The difference between outlet and inlet concentrations is multiplied by airflow to indicate methane emissions rate. In most installations, a single gas analyser is used to measure both inlet and outlet concentrations, often for two or more chambers. This involves switching the analyser between sampling points at set intervals, so concentrations are actually measured for only a fraction of the day.

Respiration chambers vary in construction materials, size of chamber, gas analysis equipment and airflow rate, all of which can influence results. Validation of 22 chambers at six UK research sites revealed an uncertainty of $25.7 \%$ between facilities, which was reduced to $2.1 \%$ when correction factors 
were applied to trace each facility to the international standard for methane [20]. The main sources of uncertainty were stability and measurement of airflow, which are crucial for measuring methane emission rate. The authors concluded, however, that chambers were accurate for comparing animals measured at the same site. It is an added challenge, when benchmarking alternative methods against respiration chambers, that the respiration chambers themselves have not been benchmarked against respiration chambers at other facilities.

For large-scale evaluation of methane emissions by individual animals, respiration chambers are challenging, with only a single study in growing Angus steers and heifers exceeding 1000 animals, which found methane production to be moderately heritable $\mathrm{h}^{2}=0.27 \pm 0.07$ [21]. Installation costs and running costs are high, and only one animal can be measured at a time. If the monitoring time is three days per animal, and chambers are run continuously, then maximum throughput would be approximately 100 animals per chamber per year. In practice, throughput is likely to be 30 to 50 animals per year. Cows are social animals, and confinement in a chamber may ultimately influence their feeding behaviour, resulting in less feed being consumed and in a different meal pattern compared with farm conditions. Altered feeding patterns or levels is not a problem for metabolic studies evaluating feeds, but can be a problem when evaluating individual animals. Furthermore, the representativeness of respiration chambers to grazing systems has been called into question [22]. However, promising developments have led to more animal friendly respiration chambers constructed from cheaper, transparent materials. These lower the cost and reduce the stress of confinement with minimal disruptions to accuracy, precision and no drop in feed intake of the cows [23].

\subsection{The $S F_{6}$ Technique}

The $\mathrm{SF}_{6}$ tracer gas technique was developed in an attempt to measure methane emissions by animals without confinement in respiration chambers [24]. Air is sampled near the animal's nostrils through a tube attached to a halter and connected to an evacuated canister worn around the animal's neck or on its back. A capillary tube or orifice plate is used to restrict airflow through the tube so that the canister is between 50 and $70 \%$ full after approximately $24 \mathrm{~h}$. A permeation tube containing $\mathrm{SF}_{6}$ is placed into the rumen of each animal. The pre-determined release rate of $\mathrm{SF}_{6}$ is multiplied by the ratio of methane to $\mathrm{SF}_{6}$ concentrations in the canister to calculate methane emission rate.

Many research centres have used the $\mathrm{SF}_{6}$ technique with variations in design of sampling and collection equipment, permeation tubes, and gas analysis [25]. Reliable results depend on following standard protocols, with greatest variation coming from accuracy of determining $\mathrm{SF}_{6}$ release rate from permeation tubes and control of sampling rate. With capillary tubes, sampling rate decreases as pressure in the canister increases, whereas an orifice plate gives a steadier sampling rate over $24 \mathrm{~h} \mathrm{[26].} \mathrm{A} \mathrm{source} \mathrm{of} \mathrm{error} \mathrm{that} \mathrm{has} \mathrm{not} \mathrm{been} \mathrm{evaluated} \mathrm{is} \mathrm{that} \mathrm{animals} \mathrm{might} \mathrm{interact} \mathrm{and} \mathrm{share}$ methane emissions when the sampling tube of one animal is near the head of another animal. There is good agreement between methane emissions measured by the $\mathrm{SF}_{6}$ technique and respiration chambers, although results from the $\mathrm{SF}_{6}$ technique are more variable $[27,28]$.

For large-scale evaluation of methane emissions by individual animals, the $\mathrm{SF}_{6}$ technique is more useful than respiration chambers. Animal behaviour and intake might be affected by wearing the apparatus, and by daily handling to exchange canisters, but the technique is considerably less intrusive than respiration chambers, because cows remain in the herd. Labour and monetary costs for changing canisters each day and for lab analysis are high. Throughput is limited by the number of sets of apparatus available, handling facilities, labour, and the capacity of the lab for gas analysis. Animals need to be measured for 5 to 7 days, and it is recommended that group size should be less than 15 animals [25], so maximum throughput would be about 750 animals per year. Heritability has been estimated for methane production in grazing Holstein cows at $h^{2}=0.33 \pm 0.15$ [29]. 


\subsection{Breath Sampling during Milking and Feeding}

Several research groups have developed methods to measure methane concentration in breath of cows during milking and/or feeding. These are often referred to as 'sniffer methods' because they use devices originally designed to detect dangerous gas leaks. Air is sampled near the animal's nostrils through a tube fixed in a feed bin and connected directly to a gas analyser. The feed bin might be in an automatic milking station [14,30-33] or in a concentrate feeding station [34]. Different research centres use different gas analysers (Nondispersive Infrared (NDIR), Fourier-transform infrared (FTIR) or photoacoustic infrared (PAIR)) and different sampling intervals (1, 5, 20 or 90-120 s). Methane concentration during a sampling visit of typically between 3 and $10 \mathrm{~min}$ may be specified as the overall mean, or the mean of eructation peaks. Some centres use $\mathrm{CO}_{2}$ as a tracer gas and calculate daily methane output according to ratio of methane to $\mathrm{CO}_{2}$ and daily $\mathrm{CO}_{2}$ output predicted from performance of the cow [35]. Repeatability and rank correlations were higher for eructation peaks than for mean concentrations, and were higher for eructation peaks than for methane to $\mathrm{CO}_{2}$ ratio [36]. However, all methods show good repeatability.

For large-scale evaluation of methane emissions by individual animals, breath-sampling methods have significant advantages compared with other methods. Breath-sampling methods are non-invasive because, once installed, animals are unaware of the equipment and are in their normal environment. Animals follow their normal routine, which includes milking and feeding, so no training of animals, handling, or change of diet is required. Equipment is relatively cheap, although more expensive gas analysers are available, and running costs are negligible.

The compromise for non-invasiveness of breath-sampling is that concentrations of gasses in the sampled air are influenced by cow head position relative to the sampling tube [15]. The use of head position sensors and data filtering algorithms can remove the effects when the cow's head is completely out of the feed bin [37], but not within the feed bin. Consequently, sniffer measurements are more variable than flux methods, with factors like variable air flow in the barn increasing measurement error (imprecision), and head position, a highly repeatable characteristic, inflating between-cow variability.

Using $\mathrm{CO}_{2}$ as a tracer gas partly addresses the issue but, because $\mathrm{CO}_{2}$ arises from metabolism as well as rumen fermentation, variability of $\mathrm{CO}_{2}$ emissions has to be considered. A further consideration is diurnal variation in breath concentrations of methane and $\mathrm{CO}_{2}$ because animals are spot-sampled at different times of day and night. Diurnal variation can be accounted for either by fitting a model derived from the whole group of animals, or by including time of measurement in the statistical model [30].

The number of observations per analyser is limited only by number of cows assigned to one automatic milking station or concentrate feeding station and length of time equipment is installed. Typically, each analyser will record 40 to 70 animals 2 to 7 times per day for 7 to 10 days, although the number of sampling stations per analyser can be increased by using an automatic switching system [32]. Throughput per analyser is likely to be 2000 to 3000 animals per year. Estimates of heritability for methane production measured using this method range from $\mathrm{h}^{2}=0.12$ to 0.45 over multiple studies [38,39].

\subsection{GreenFeed}

GreenFeed (C-Lock Inc., Rapid City, SD, USA) is a sophisticated sniffer system where breath samples are provided when animals visit a bait station [15]. As with other sniffer systems, GreenFeed samples breath from individual animals several times per day for short periods (3 to $7 \mathrm{~min}$ ). GreenFeed is a portable standalone system used in barn and pasture applications, and incorporates an extractor fan to ensure active airflow and head position sensing for representative breath sampling [9]. Measurements are pre-processed by the manufacturer, and data are available in real time through a web-based data management system [40]. As GreenFeed captures a high proportion of emitted air and measures airflow, which can be calibrated using a tracer gas, methane emission is estimated as a flux at each visit. Providing visits occur throughout the $24 \mathrm{~h}$, methane emission can be estimated directly as g/day $[15,40])$. 
A limitation of the GreenFeed system is that animals require training to use the system, although animals which have been trained to use the system will readily use it again [41]. However, some animals will not use the system or will use it infrequently, and frequency of visits is affected by diet [42]. This can be a challenge when screening commercial herds for methane emission under genetic evaluation.

The manufacturer recommends 15 to 25 animals per GreenFeed unit, and recordings are made typically for 7 days. If all animals visit the unit adequately, throughput per unit is likely to be 750 to 1250 animals per year.

\subsection{Laser Methane Detector}

The laser methane detector (LMD) is a highly responsive, hand-held device that is pointed at an animal's nostrils and measures methane column density along the length of the laser beam (ppm.m). In the first implementation of LMD on a farm, measurements for each cow were taken over periods of 15 to $25 \mathrm{~s}$ between eructation events, and could detect methane emitted each time the animal breathed out [43]. In a later study with sheep and beef cattle, monitoring periods of 2 to 4 min allowed authors to separate breathing cycles from eructation events [44]. Typically, animals are restrained either manually or in head yokes at a feed fence for the required length of time. The operator has to stand at the same distance ( 1 to $3 \mathrm{~m}$ ) from each animal every time and must be careful to keep the laser pointed at the animal's nostrils throughout the measurement period.

The LMD can be used in the animal's normal environment, although for consistency restraint is required during measurement. Because the LMD measures methane in the plume originating from the animal's nostrils, results can be affected by factors such as: distance from the animal; pointing angle; animal's head orientation and head movement; air movement and temperature in the barn; adjacent animals; and operator variation [45]. Operator variation is likely to be one of the biggest factors, because the operator controls distance and pointing angle, and is responsible for ensuring that the laser remains on target. The structure of the barn and the resulting ventilation conditions and wind speed at the location of the measurement are also considerable sources of variation in recorded methane.

Assuming operator fatigue does not limit measurements, each LMD could record up to 10 animals per hour. If each animal is recorded 3 times (on 3 consecutive days, for example, as in [46]), throughput is likely to be up to 1000 animals per year.

\section{Agreement between Methods}

In method comparison studies, simultaneous repeated measures per cow with two or more methods are required in order to assess systematic differences between methods (means) and random differences (precision) and correlation between methods free of residual error. Furthermore, short time differences between repeated measures per subject are needed to ensure that the underlying biology of the cow has not changed. Not all methods can be recorded simultaneously, and the methane emission of cows changes both throughout the day and over the lactation period. In such instances, either cross-over designs are needed, or else matched-pair repeated measures designs. Members of METHAGENE WG2 provided data from studies in which two or more methods had been used to measure methane output ( $\mathrm{g} /$ day) by individual dairy cows. Methods had been applied to each cow either concurrently or consecutively within a short timeframe.

Seven main methods were represented: respiration chambers; $\mathrm{SF}_{6}$; GreenFeed; $\mathrm{LMD}$; and three breath-sampling systems based on different gas analysers. Gas analysers incorporated different technologies to measure methane: NDIR (e.g., Guardian Plus, Edinburgh Instruments, Edinburgh, UK), FTIR (e.g., Gasmet 4030, Gasmet Technologies Oy, Helsinki, Finland), and PAIR (e.g., F10, Gasera Ltd., Turku, Finland). In the contributing studies, NDIR and FTIR were used in automatic milking stations, and PAIR was used in concentrate feeding stations. One NDIR study and all FTIR and PAIR studies used $\mathrm{CO}_{2}$ as a tracer gas, with daily $\mathrm{CO}_{2}$ output calculated either from milk yield, live weight and days pregnant (t1) or from metabolisable energy intake (t2). Two NDIR studies were based on 
methane concentration in eructation peaks rather than mean methane concentration, so were treated as separate methods. By separating NDIR studies, a total of 8 distinct methods were available, giving a matrix of 28 potential combinations for comparisons. Data were available for 13 method combinations.

Method comparisons were conducted using bivariate models (repeatability animal models) to obtain correlations between 'true values', also known as repeated measures correlations or individual level correlations $[33,47]$. Variance components, including between-cow variation and within-cow variation (precision) and means (accuracy), were used in the calculation of between-cow coefficient of variation $(\mathrm{CV}, \%)$ and total $\mathrm{CV}$ and repeatability (Table 2$)$. Where single measurements were available for each method Pearson's correlation was reported and where repeated measures per subject were available repeated measures correlation was reported. Lin's concordance correlation coefficient [48] was calculated for each method comparison.

Table 2. Comparisons of methods for recording methane emission in dairy cattle.

\begin{tabular}{|c|c|c|c|c|c|c|c|c|}
\hline \multicolumn{9}{|c|}{ Alternate Methods ${ }^{1}$ Versus Respiration Chambers } \\
\hline Method & N Cows & N Obs & Mean S.E. & Rep S.E. & $\begin{array}{c}\text { Between-Cow } \\
\mathrm{CV}^{2}\end{array}$ & Total CV & $\begin{array}{l}\text { Correlation }{ }^{3} \\
\text { (S.E.) }\end{array}$ & $\mathrm{CCC}^{4}$ (S.E.) \\
\hline $\mathrm{SF}_{6}$ & 33 & 97 & $471(14.3)$ & $0.44(0.13)$ & 11.6 & 17.4 & \multirow{2}{*}{$0.87(0.08)$} & \multirow[t]{2}{*}{$0.30(0.17)$} \\
\hline Respiration Chambers & 33 & 97 & $437(10.7)$ & $0.36(0.08)$ & 8.4 & 14.0 & & \\
\hline GreenFeed & 27 & 63 & $433(8.7)$ & $0.64(0.08)$ & 12.8 & 15.9 & \multirow{2}{*}{$0.81(0.10)$} & \multirow[t]{2}{*}{$0.41(0.12)$} \\
\hline Respiration Chambers & 27 & 63 & $459(6.5)$ & $0.51(0.09)$ & 8.1 & 11.3 & & \\
\hline NDIR Peaks & 12 & 12 & $376(12.1)$ & N/A & N/A & 11.1 & \multirow{2}{*}{$0.89(0.07)$} & \multirow[t]{2}{*}{$0.88(0.10)$} \\
\hline Respiration Chambers & 12 & 12 & $377(10.7)$ & N/A & N/A & 9.4 & & \\
\hline NDIR $\mathrm{CO}_{2} \mathrm{t} 1$ & 20 & 60 & $573(16.8)$ & $0.58(0.11)$ & 10.1 & 13.1 & \multirow{2}{*}{$0.72(0.11)$} & \multirow[t]{2}{*}{$0.38(0.21)$} \\
\hline Respiration Chambers & 20 & 60 & $521(13.7)$ & $0.61(0.12)$ & 9.1 & 11.7 & & \\
\hline PAIR $\mathrm{CO}_{2} \mathrm{t} 2$ & 21 & 21 & $555(21.3)$ & N/A & N/A & 11.3 & \multirow{2}{*}{$0.80(0.08)$} & \multirow[t]{2}{*}{$0.70(\mathrm{~N} / \mathrm{A})$} \\
\hline Respiration Chambers & 21 & 21 & $585(14.1)$ & N/A & N/A & 17.1 & & \\
\hline \multicolumn{9}{|c|}{ Alternate methods ${ }^{1}$ versus Alternate methods } \\
\hline $\mathrm{SF}_{6}$ & 48 & 144 & 405 (22.5) & N/A & N/A & 38.5 & \multirow{2}{*}{$0.40(0.18)$} & \multirow[t]{2}{*}{0.34 (N/A) } \\
\hline GreenFeed & 48 & 144 & $373(13.9)$ & N/A & N/A & 25.8 & & \\
\hline LMD & 11 & 88 & $432(24.8)$ & $0.21(0.11)$ & 19.4 & 42.7 & \multirow{2}{*}{$0.77(0.23)$} & \multirow[t]{2}{*}{$0.18(0.23)$} \\
\hline GreenFeed & 11 & 88 & $423(18.5)$ & $0.49(0.12)$ & 11.4 & 16.8 & & \\
\hline $\mathrm{NDIR} \mathrm{CO}_{2} \mathrm{t} 1$ & 27 & 63 & $586(19.4)$ & $0.59(0.13)$ & 13.2 & 17.2 & \multirow{2}{*}{$0.64(0.18)$} & \multirow[t]{2}{*}{$0.14(0.19)$} \\
\hline GreenFeed & 27 & 63 & $453(9.8)$ & $0.75(0.08)$ & 9.7 & 11.2 & & \\
\hline NDIR $\mathrm{CO}_{2} \mathrm{t} 1$ & 39 & 118 & $365(8.3)$ & $0.66(0.11)$ & 13.9 & 17.1 & \multirow{2}{*}{$0.60(0.11)$} & \multirow[t]{2}{*}{$0.18(0.19)$} \\
\hline LMD & 39 & 118 & $363(10.3)$ & $0.14(0.09)$ & 7.5 & 19.6 & & \\
\hline FTIR $\mathrm{CO}_{2}$ t2 & 34 & 68 & 315 (12.3) & $0.77(0.13)$ & 21.3 & 24.3 & \multirow{2}{*}{$0.57(0.25)$} & \multirow[t]{2}{*}{$0.20(0.22)$} \\
\hline LMD & 34 & 68 & $299(6.1)$ & $0.27(0.15)$ & 7.5 & 14.5 & & \\
\hline NDIR $\mathrm{CO}_{2} \mathrm{t} 1$ & 45 & 90 & $383(8.7)$ & $0.85(0.04)$ & 14.0 & 15.2 & \multirow{2}{*}{$0.58(0.15)$} & \multirow[t]{2}{*}{$0.14(0.19)$} \\
\hline NDIR Peaks & 45 & 90 & $393(8.1)$ & $0.59(0.09)$ & 10.7 & 13.9 & & \\
\hline FTIR $\mathrm{CO}_{2} \mathrm{t} 1$ & 43 & 103 & $392(8.1)$ & $0.81(0.05)$ & 14.1 & 15.3 & \multirow{2}{*}{$0.97(0.02)$} & \multirow[t]{2}{*}{$0.79(0.12)$} \\
\hline NDIR $\mathrm{CO}_{2} \mathrm{t} 1$ & 43 & 103 & $382(8.9)$ & $0.86(0.04)$ & 12.2 & 13.6 & & \\
\hline FTIR $\mathrm{CO}_{2} \mathrm{t} 1$ & 45 & 90 & 392 (7.9) & $0.81(0.05)$ & 12.2 & 13.6 & \multirow{2}{*}{$0.53(0.17)$} & \multirow[t]{2}{*}{$0.15(0.19)$} \\
\hline NDIR Peaks & 45 & 90 & $382(8.2)$ & $0.60(0.09)$ & 10.8 & 14.0 & & \\
\hline
\end{tabular}

${ }^{1} \mathrm{SF}_{6}=$ Sulphur hexafluoride tracer gas technique, LMD = Laser methane detector; NDIR = Nondispersive Infrared; FTIR $=$ Fourier Transform Infrared; PAIR = Photoacoustic Infrared. $\mathrm{CO}_{2} \mathrm{t} 1$ method uses $\mathrm{CO}_{2}$ predicted from milk yield, live weight and days pregnant; $\mathrm{CO}_{2} \mathrm{t} 2$ method uses $\mathrm{CO}_{2}$ predicted from metabolisable energy intake. ${ }^{2}$ Coefficient of variation (\%). ${ }^{3}$ When repeated measures per cow were made the repeated measures correlation was reported, when single measures per cow were made Pearson's correlation was reported, N/A not available, due to single measurements. ${ }^{4}$ Lin's concordance correlation coefficient [48].

Respiration chambers were the most precise method, as can be seen by the smaller between-cow $\mathrm{CV} \%$ and total $\mathrm{CV}$ compared to alternative methods, and respiration chambers are by definition the most accurate (Table 2). All methods tested showed high correlations with respiration chambers but none of the correlations exceeded 0.90. This is in part due to the increased imprecision of alternative methods, as even the most accurate and precise method will compare poorly to a less precise method. These correlations are also likely to be underestimated because none of the methods could be recorded simultaneously with respiration chambers and had to be recorded in cross-over designs. Consequently, 
the true value for each cow may have changed due to changes in the underlying biology of the cow over time between measurements.

For the methods with repeated measures per cow, the two mass flux methods, $\mathrm{SF}_{6}$ and GreenFeed, had the highest repeated measures correlations $(0.87 \pm 0.08$ and $0.81 \pm 0.10)$, which outperformed the concentration-based NDIR method using $\mathrm{CO}_{2}$ tracer gas method t1. Of the two concentration methods evaluated against respiration chambers using single measurements, NDIR Peaks had a higher correlation $(0.89 \pm 0.07)$ than the PAIR $\mathrm{CO}_{2}$ tracer gas method t2 $(0.80 \pm 0.10)$.

Comparisons among alternative methods generally had lower correlations than comparisons with respiration chambers, despite having relatively higher numbers of animals, and in most cases simultaneous or near simultaneous repeated measures per cow per method. This could be due to the increased variability and imprecision of alternative methods, as seen by the increased CVs or due to the possibility that different aspects of methane emission are captured using different methods. The study of [49] comparing $\mathrm{SF}_{6}$ and GreenFeed reported a low Pearson correlation of 0.40 , despite having a large number of animals with repeated measures per method, the authors appear not to have estimated a repeated measures correlation, which could be larger. Estimating a repeated measures correlation between these two mass flux methods is a priority as it would clarify the inexplicable disagreement between two methods which both correlate highly with the gold standard method. With the exception of the aforementioned study, the imprecision was low in the mass flux measure comparisons as compared to the concentration-based methods [50]. Two of the sniffer methods evaluated, FTIR $\mathrm{CO}_{2} \mathrm{t} 1$ and NDIR $\mathrm{CO}_{2} \mathrm{t} 1$, correlated close to unity (0.97), most likely due to the shared prediction equation for $\mathrm{CO}_{2}$ tracer gas. Nevertheless, all correlations derived from actual data were positive. This suggests that combination of datasets obtained with different methods is a realistic proposition for genetic studies. Calculation of adjustment or weighting factors for bias, accuracy and precision is beyond the scope of the current study, but would improve the value of combined datasets.

\section{Conclusions}

Measuring methane on large numbers of cows is a challenge. The high costs and low throughput of respiration chambers restrict their use to research studies measuring methane emissions on small numbers of individual animals. Respiration chambers remain the gold standard method, but benchmarking alternative methods against respiration chambers is challenging, because simultaneous replicate measures per cow are not feasible. Methods like $\mathrm{SF}_{6}$ and GreenFeed require lower capital investment and running costs than Respiration Chambers, and have higher throughput and potential for use in extensive and grazing situations, but costs are still prohibitive for recording large numbers of animals. Methods based on concentration are less precise and accurate than flux methods, but they are viable for large-scale measurement, which is a prerequisite of genetic evaluations. Further development is needed to increase the accuracy and precision of concentration methods. Several reviews of methods for measuring methane have made qualitative judgments based on individual comparison studies without expanding scope to genetic evaluations and considering repeated measure correlations between methods as proxies for genetic correlations. Results confirm that there is sufficient correlation between methods for measurements from all methods to be combined for international genetic studies and provide a much-needed framework for comparing genetic correlations between methods should these be made available. 
Author Contributions: Conceptualization, P.C.G., G.F.D., M.J.B., A.R.B., N.P., D.S. and M.H.P.W.V.; methodology, G.F.D.; software, G.F.D.; validation, G.F.D., M.J.B. and P.C.G.; formal analysis, G.F.D.; investigation, P.C.G., G.F.D., M.J.B., A.R.B., P.H., B.K., J.L., N.P., M.P., D.S., M.H.P.W.V. and T.Y.; resources, P.C.G., G.F.D., M.J.B., A.R.B., P.H., B.K., J.L., N.P., M.P., D.S., M.H.P.W.V. and T.Y.; data curation, G.F.D. and M.J.B.; writing—original draft preparation, P.C.G., G.F.D. and M.J.B.; writing—review and editing, P.C.G., G.F.D., M.J.B., A.R.B., P.H., B.K., J.L., N.P., M.P., D.S., M.H.P.W.V. and T.Y.; visualization, G.F.D. and P.C.G.; supervision, P.C.G.; project administration, P.C.G. and M.J.B.; funding acquisition, J.L. and P.C.G.

Funding: This research was funded by European Cooperation in Science and Technology (COST), grant number FA1302.

Conflicts of Interest: The authors declare no conflict of interest. The funders had no role in the design of the study; in the collection, analyses, or interpretation of data; in the writing of the manuscript, or in the decision to publish the results.

\section{References}

1. Myhre, G.; Shindell, D.; Bréon, F.; Collins, W.; Fuglestvedt, J.; Huang, J.; Koch, D.; Lamarque, J.; Lee, D.; Mendoza, B.; et al. Anthropogenic and Natural Radiative Forcing; Stocker, T.F., Qin, D., Plattner, G.-K., Tignor, M., Allen, S.K., Boschung, J., Nauels, A., Xia, Y., Bex, V., Midgley, P.M., Eds.; Cambridge University Press: Cambridge, UK; New York, NY, USA, 2013.

2. Knapp, J.R.; Laur, G.L.; Vadas, P.A.; Weiss, W.P.; Tricarico, J.M. Invited review: Enteric methane in dairy cattle production: Quantifying the opportunities and impact of reducing emissions. J. Dairy Sci. 2014, 97, 3231-3261. [CrossRef] [PubMed]

3. Janssen, P.H. Influence of hydrogen on rumen methane formation and fermentation balances through microbial growth kinetics and fermentation thermodynamics. Anim. Feed Sci. Technol. 2010, 160, 1-22. [CrossRef]

4. Beauchemin, K.A.; Kreuzer, M.; O'Mara, F.; McAllister, T.A. Nutritional management for enteric methane abatement: A review. Aust. J. Exp. Agric. 2008, 48, 21-27. [CrossRef]

5. Cottle, D.J.; Nolan, J.V.; Wiedemann, S.G. Ruminant enteric methane mitigation: A review. Anim. Prod. Sci. 2011, 51, 491-514. [CrossRef]

6. Garnsworthy, P.C. The environmental impact of fertility in dairy cows: A modelling approach to predict methane and ammonia emissions. Anim. Feed Sci. Technol. 2004, 112, 211-223. [CrossRef]

7. Blaxter, K.L.; Clapperton, J.L. Prediction of the amount of methane produced by ruminants. Br. J. Nutr. 1965, 19, 511-522. [CrossRef]

8. Mills, J.A.N.; Crompton, L.A.; Reynolds, C.K. Ruminant Nutrition Regimes to Reduce Methane and Nitrogen Emissions-A Meta-Analysis of Current Databases. Final Project Report MDC 07/04/A. 2008. Available online: https://dairy.ahdb.org.uk/non_umbraco/download.aspx?media=5903 (accessed on 18 October 2019).

9. Hammond, K.J.; Crompton, L.A.; Bannink, A.; Dijkstra, J.; Yáñez-Ruiz, D.R.; O’Kiely, P.; Kebreab, E.; Eugenè, M.A.; Yu, Z.; Shingfield, K.J.; et al. Review of current in vivo measurement techniques for quantifying enteric methane emission from ruminants. Anim. Feed Sci. Technol. 2016, 219, 13-30. [CrossRef]

10. Falconer, D.; Mackay, T. Introduction to Quantitative Genetics, 4th ed.; Longman: Harlow, UK, 1996; p. 480.

11. Barnhart, H.X.; Kosinski, A.S.; Haber, M.J. Assessing Individual Agreement. J. Biopharm. Stat. 2007, 17, 697-719. [CrossRef]

12. Spearman, C. The Proof and Measurement of Association between Two Things. Am. J. Psychol. 1904, 15, 72-101. [CrossRef]

13. Adolph, S.C.; Hardin, J.S. Estimating phenotypic correlations: Correcting for bias due to intraindividual variability. Funct. Ecol. 2007, 21, 178-184. [CrossRef]

14. Garnsworthy, P.C.; Craigon, J.; Hernandez-Medrano, J.H.; Saunders, N. On-farm methane measurements during milking correlate with total methane production by individual dairy cows. J. Dairy Sci. 2012, 95, 3166-3180. [CrossRef] [PubMed]

15. Huhtanen, P.; Cabezas-Garcia, E.H.; Utsumi, S.; Zimmerman, S. Comparison of methods to determine methane emissions from dairy cows in farm conditions. J. Dairy Sci. 2015, 98, 3394-3409. [CrossRef] [PubMed]

16. Storm, I.M.L.D.; Hellwing, A.L.F.; Nielson, N.I.; Madsen, J. Methods for Measuring and Estimating Methane Emission from ruminants. Animals 2012, 2, 160-183. [CrossRef] [PubMed] 
17. de Haas, Y.; Pszczola, M.; Soyeurt, H.; Wall, E.; Lassen, J. Phenotypes to genetically reduce greenhouse gas emissions in dairying. J. Dairy Sci. 2017, 100, 855-870. [CrossRef] [PubMed]

18. Murray, R.M.; Bryant, A.M.; Leng, R.A. Rates of production of methane in the rumen and large intestine of sheep. Br. J. Nutr. 1976, 36, 1-14. [CrossRef]

19. Blaxter, K.L.; Joyce, J.P. The accuracy and ease with which measurements of respiratory metabolism can be made with tracheostomized sheep. Br. J. Nutr. 1963, 17, 523-537. [CrossRef]

20. Gardiner, T.D.; Coleman, M.D.; Innocenti, F.; Tompkins, J.; Connor, A.; Garnsworthy, P.C.; Moorby, J.M.; Reynolds, C.K.; Waterhouse, A.; Wills, D. Determination of the absolute accuracy of UK chamber facilities used in measuring methane emissions from livestock. Measurement 2015, 66, 272-279. [CrossRef]

21. Donoghue, K.A.; Bird-Gardiner, T.; Arthur, P.F.; Herd, R.M.; Hegarty, R.F. Genetic and phenotypic variance and covariance components for methane emission and postweaning traits in Angus cattle. J. Anim. Sci. 2016, 94, 1438-1445. [CrossRef]

22. Pinares-Patiño, C.S.; Hickey, S.M.; Young, E.A.; Dodds, K.G.; MacLean, S.; Molano, G.; Sandoval, E.; Kjestrup, H.; Harland, R.; Hunt, C.; et al. Heritability estimates of methane emissions from sheep. Animal 2013, 7 (Suppl. 2), 316-321. [CrossRef]

23. Hellwing, A.L.F.; Lund, P.; Weisbjerg, M.R.; Brask, M.; Hvelplund, T. Technical note: Test of a low-cost and animal-friendly system for measuring methane emissions from dairy cows. J. Dairy Sci. 2012, 95, 6077-6085. [CrossRef]

24. Johnson, K.A.; Huyler, M.; Westberg, H.H.; Lamb, B.; Zimmerman, P.R. Measurement of methane emissions from ruminant livestock using a sulfur hexafluoride tracer technique. Environ. Sci. Technol. 1994, 28, 359-362. [CrossRef] [PubMed]

25. Berndt, A.; Boland, T.M.; Deighton, M.H.; Gere, J.I.; Grainger, C.; Hegarty, R.S.; Iwaasa, A.D.; Koolaard, J.P.; Lassey, K.R.; Luo, D.; et al. Guidelines for Use of Sulphur Hexafluoride (SF 6 ) Tracer Technique to Measure Enteric Methane Emissions from Ruminants; Lambert, M.G., Ed.; New Zealand Agricultural Greenhouse Gas Research Centre: Palmerston North, New Zealand, 2014; p. 166.

26. Deighton, M.H.; Williams, S.R.O.; Hannah, M.C.; Eckard, R.J.; Boland, T.M.; Wales, W.J.; Moat, P.J. A modified sulphur hexafluoride tracer technique enables accurate determination of enteric methane emissions from ruminants. Anim. Feed Sci. Technol. 2014, 197, 47-63. [CrossRef]

27. Grainger, C.; Clarke, T.; McGinn, S.M.; Auldist, M.J.; Beauchemin, K.A.; Hannah, M.C.; Waghorn, G.C.; Clark, H.; Eckard, R.J. Methane emissions from dairy cows measured using the sulfur hexafluoride (SF6) tracer and chamber techniques. J. Dairy Sci. 2007, 90, 2755-2766. [CrossRef] [PubMed]

28. Muñoz, C.; Yan, T.; Wills, D.A.; Murray, S.; Gordon, A.W. Comparison of the sulfur hexafluoride tracer and respiration chamber techniques for estimating methane emissions and correction for rectum methane output from dairy cows. J. Dairy Sci. 2012, 95, 3139-3148. [CrossRef] [PubMed]

29. Breider, I.S.; Wall, E.; Garnsworthy, P.C.; Pryce, J.E. Genetic relationships between methane emission and milk yield, live weight and dry matter intake. In Proceedings of the World Congress on Genetics Applied to Livestock Production, Abstract No. 134, Auckland, New Zealand, 11-16 February 2018.

30. Lassen, J.; Løvendahl, P.; Madsen, J. Accuracy of noninvasive breath methane measurements using Fourier transform infrared methods on individual cows. J. Dairy Sci. 2012, 95, 890-898. [CrossRef]

31. Bell, M.J.; Potterton, S.L.; Craigon, J.; Saunders, N.; Wilcox, R.H.; Hunter, M.; Goodman, J.R.; Garnsworthy, P.C. Variation in enteric methane emissions among cows on commercial dairy farms. Animal 2014, 8, 1540-1546. [CrossRef]

32. Pszczola, M.; Rzewuska, K.; Mucha, S.T. Heritability of methane emissions from dairy cows over a lactation measured on commercial farms. J. Anim. Sci. 2017, 95, 4813-4819. [CrossRef]

33. Difford, G.F.; Olijhoek, D.W.; Hellwing, A.L.F.; Lund, P.; Bjerring, M.A.; de Haas, Y.; Lassen, J.; Løvendahl, P. Ranking cows' methane emissions under commercial conditions with sniffers versus respiration chambers. Acta. Agric. Scand. A Anim. Sci. 2018, 68, 25-32. [CrossRef]

34. Negussie, E.; Lehtinen, J.; Mäntysaari, P.; Bayat, A.R.; Liinamo, A.-E.; Mäntysaari, E.A.; Lidauer, M.H. Non-invasive individual methane measurement in dairy cows. Animal 2017, 11, 890-899. [CrossRef]

35. Madsen, J.; Bjerg, B.S.; Hvelplund, T.; Weisbjerg, M.R.; Lund, P. Methane and carbon dioxide ratio in excreted air for quantification of methane production in ruminants. Livest. Sci. 2010, 129, 223-227. [CrossRef] 
36. Bell, M.J.; Saunders, N.; Wilcox, R.H.; Homer, E.M.; Goodman, J.R.; Craigon, J.; Garnsworthy, P.C. Methane emissions among individual dairy cows during milking quantified by eructation peaks or ratio with carbon dioxide. J. Dairy Sci. 2014, 97, 6536-6546. [CrossRef] [PubMed]

37. Difford, G.F.; Lassen, J.; Løvendahl, P. Interchangeability between methane measurements in dairy cows assessed by comparing precision and agreement of two non-invasive infrared methods. Comput. Electron. Agric. 2016, 124, 220-226. [CrossRef]

38. Lassen, J.; Løvendahl, P. Heritability estimates for enteric methane emissions from Holstein cattle measured using noninvasive methods. J. Dairy Sci. 2016, 99, 1959-1967. [CrossRef] [PubMed]

39. Breider, I.S.; Wall, E.; Garnsworthy, P.C. Heritability of methane production and genetic correlations with milk yield and body weight in Holstein-Friesian dairy cows. J. Dairy Sci. 2019, 102, 7277-7281. [CrossRef]

40. Hammond, J.K.; Humphries, D.J.; Crompton, L.A.; Green, C.; Reynolds, C.K. Methane emissions from cattle: Estimates from short-term measurements using a GreenFeed system compared with measurements obtained using respiration chambers or sulphur hexafluoride tracer. Anim. Feed Sci. Technol. 2015, 203, 41-52. [CrossRef]

41. Velazco, J.I.; Cottle, D.J.; Hegarty, R.S. Methane emissions and feeding behaviour of feedlot cattle supplemented with nitrate or urea. Anim. Prod. Sci. 2014, 54, 1737-1740. [CrossRef]

42. Hammond, K.J.; Jones, A.K.; Humphries, D.J.; Crompton, L.A.; Reynolds, C.K. Effects of diet forage source and neutral detergent fiber content on milk production of dairy cattle and methane emissions determined using GreenFeed and respiration chamber techniques. J. Dairy Sci. 2016, 99, 7904-7917. [CrossRef]

43. Chagunda, M.G.G.; Ross, D.; Roberts, D.J. On the use of a laser methane detector in dairy cows. Comput. Electron. Agric. 2009, 68, 157-160. [CrossRef]

44. Ricci, P.; Chagunda, M.G.G.; Rooke, J.; Houdijk, J.G.M.; Duthie, C.-A.; Hyslop, J.; Roehe, R.; Waterhouse, A. Evaluation of the laser methane detector to estimate methane emissions from ewes and steers. J. Anim. Sci. 2014, 92, 5239-5250. [CrossRef]

45. Sorg, D.; Mühlbach, S.; Rosner, F.; Kuhla, B.; Derno, M.; Meese, S.; Schwarm, A.; Kreuzerc, M.; Swalve, H. The agreement between two next-generation laser methane detectors and respiration chamber facilities in recording methane concentrations in the spent air produced by dairy cows. Comput. Electron. Agric. 2017, 143, 262-272. [CrossRef]

46. Mühlbach, S.; Sorg, D.; Rosner, F.; Kecman, J.; Swalve, H.H. Genetic analyses for $\mathrm{CH}_{4}$ concentrations in the breath of dairy cows measured on-farm with the Laser Methane Detector. In Proceedings of the World Congress on Genetics Applied to Livestock Production, Abstract No. 186, Auckland, New Zealand, 11-16 February 2018.

47. Bakdash, J.Z.; Marusich, L.R. Repeated measures correlation. Front. Psychol. 2017, 8, 456. [CrossRef] [PubMed]

48. Lin, L.; Torbeck, L.D. Coefficient of accuracy and concordance correlation coefficient: New statistics for methods comparison. J. Pharm. Sci. Technol. 1998, 52, 55-59.

49. Hristov, A.N.; Oh, J.; Giallongo, F.; Frederick, T.; Harper, M.T.; Weeks, H.; Branco, A.F.; Price, W.J.; Moate, P.J.; Deighton, M.H.; et al. Short communication: Comparison of the GreenFeed system with the sulfur hexafluoride tracer technique for measuring enteric methane emissions from dairy cows. J. Dairy Sci. 2016, 5461-5465. [CrossRef] [PubMed]

50. Sorg, D.; Difford, G.F.; Mühlbach, S.; Kuhla, B.; Swalve, H.H.; Lassen, J.; Strabel, T.; Pszczola, M. Comparison of a laser methane detector with the GreenFeed and two breath analysers for on-farm measurements of methane emissions from dairy cows. Comput. Electron. Agric. 2018, 153, 285-294. [CrossRef] 


\title{
Climate Change and Goat Production: Enteric Methane Emission and Its Mitigation
}

\author{
Pratap Pragna ${ }^{1,2}$, Surinder S. Chauhan ${ }^{3}$, Veerasamy Sejian ${ }^{1, *}$, Brian J. Leury ${ }^{3}$ and \\ Frank R. Dunshea ${ }^{3}$ \\ 1 ICAR - National Institute of Animal Nutrition and Physiology, Adugodi, Bangalore 560030, India; \\ pragnaprathap@gmail.com \\ 2 Academy of Climate Change Education and Research, Kerala Agricultural University, \\ Vellanikkara 680656, India \\ 3 Faculty of Veterinary and Agricultural Sciences, The University of Melbourne, Parkville, VIC 3010, Australia; \\ ss.chauhan@unimelb.edu.au (S.S.C.); brianjl@unimelb.edu.au (B.J.L.); fdunshea@unimelb.edu.au (F.R.D.) \\ * Correspondence: drsejian@gmail.com
}

Received: 7 November 2018; Accepted: 5 December 2018; Published: 7 December 2018

Simple Summary: Given that goats are considered more climate resilient than other ruminant species, research efforts are therefore needed to understand goat productivity during exposure to high ambient temperatures. Heat stress can affect the digestion and rumen fermentation pattern of goats, which contributes to the reduction in production performance in goats. Diet composition, breed and environmental stresses are common factors which negatively influence rumen function and enteric methane $\left(\mathrm{CH}_{4}\right)$ emission. There are three mechanisms by which enteric $\mathrm{CH}_{4}$ can be reduced: targeting end product of digestion to propionate, providing alternate hydrogen sink and selectively inactivating rumen methanogens. The various strategies that can be implemented to mitigate enteric $\mathrm{CH}_{4}$ include nutritional interventions, management strategies and application of advanced biotechnological tools.

\begin{abstract}
The ability of an animal to cope and adapt itself to the changing climate virtually depends on the function of rumen and rumen inhabitants such as bacteria, protozoa, fungi, virus and archaea. Elevated ambient temperature during the summer months can have a significant influence on the basic physiology of the rumen, thereby affecting the nutritional status of the animals. Rumen volatile fatty acid (VFA) production decreases under conditions of extreme heat. Growing recent evidence suggests there are genetic variations among breeds of goats in the impact of heat stress on rumen fermentation pattern and VFA production. Most of the effects of heat stress on rumen fermentation and enteric methane $\left(\mathrm{CH}_{4}\right)$ emission are attributed to differences in the rumen microbial population. Heat stress-induced rumen function impairment is mainly associated with an increase in Streptococcus genus bacteria and with a decrease in the bacteria of Fibrobactor genus. Apart from its major role in global warming and greenhouse effect, enteric $\mathrm{CH}_{4}$ is also considered as a dietary energy loss in goats. These effects warrant mitigating against $\mathrm{CH}_{4}$ production to ensure optimum economic return from goat farming as well as to reduce the impact on global warming as $\mathrm{CH}_{4}$ is one of the more potent greenhouse gases (GHG). The various strategies that can be implemented to mitigate enteric $\mathrm{CH}_{4}$ emission include nutritional interventions, different management strategies and applying advanced biotechnological tools to find solution to reduce $\mathrm{CH}_{4}$ production. Through these advanced technologies, it is possible to identify genetically superior animals with less $\mathrm{CH}_{4}$ production per unit feed intake. These efforts can help the farming community to sustain goat production in the changing climate scenario.
\end{abstract}

Keywords: climate change; heat stress; goat; immunization; methane; volatile fatty acids 


\section{Introduction}

Morphologically versatile goat species with unique browsing potential adapt to a changing climate more readily than other ruminant species and consequently they continue to be an important source of income and nutrition to many poor and marginal farmers around the world [1]. Goats are also the major means of employment and income for women, children and aged people in tropical and subtropical regions [2]. The important sources of income from the sector include milk, meat, manure, wool and skin [3]. Small ruminant, and in particular goat, farming is very important because of the relatively low input requirements and the corresponding high expected output [4]. Furthermore, goats emit less enteric methane $\left(\mathrm{CH}_{4}\right)$ than all other domestic ruminant animals per unit body weight [5].

A changing climate scenario for extensive grazing systems exposes the animals to various types of stressors that may affect their production, health and survival [6]. Among these, heat stress seems to be the major stressor which negatively influences the animal performance [7]. Furthermore, heat stress can also affect the digestion and rumen fermentation pattern of goats which contributes to the reduction in production performance [8]. The ability of an animal to cope and adapt itself to a changing climate depends on maintaining appropriate functioning of the rumen and ruminal microbes [9]. Elevated ambient temperature may prove detrimental to these processes and may ultimately result in influencing the level of $\mathrm{CH}_{4}$ production particularly with respect to the intensity of its production in goat and this will require appropriate mitigation strategies to curtail such emissions to sustain goat production in the changing climate scenario [8]. Given that goats are considered more climate resilient than other ruminant species, research efforts are therefore needed to understand goat productivity during exposure to high ambient temperatures. This review is therefore an attempt to collate and synthesize existing knowledge and recent research pertaining to the effects of heat stress on rumen fermentation, enteric $\mathrm{CH}_{4}$ emissions, and the various mechanisms associated with $\mathrm{CH}_{4}$ production and its mitigation in goats.

\section{Goat as Ideal Climate Model Animal}

Small ruminants, in particular goats, are considered an important source of income and nutrition for poor and marginal farmers around the world [5]. Low initial investment and high turnover rate for goat production are the primary reasons behind the promotion of the goat industry in developing countries [10]. Goats are often referred to as village banks in some rural areas where the villagers invest their money on purchasing and feeding goats and consider it as an appropriate way to save money for the future [11]. Globally, there are estimated to be over 860 million goats [12] and recent trends show an increased demand for dairy products from goats, particularly in developing countries where they act as a substitute for dairy products from large ruminants for human dietary needs [13].

Goats are versatile animals that adapt to a changing climate more readily than the other ruminant species and are well suited to small farming systems [1]. Much of the global goat population is concentrated in the arid and semi-arid agro-ecological zones that have frequent droughts and famines [14]. However, these species are reported to be less affected by the harsh climate compared with other ruminants that are highly sensitive to subtle changes in the surrounding environmental fluctuations [15]. Hence, goat rearing is a major source of human nutrition and also the means of economic stability for many small and marginal farmers, providing meat and manure as two major sources of income [14].

Because of their browsing habit and the anatomical advantage of the upper lips, goats can thrive well with limited feedstuffs, especially in arid and semi-arid regions [16]. In addition, goats also have a physiological advantage because they efficiently utilize poor quality feedstuffs and produce appreciably good output in terms of milk, meat and manure [17]. During feed scarcity, goats can reduce their metabolic processes to conserve energy resources [8]. Table 1 describes the advantageous characteristics in goats over other livestock species to survive harsh climatic conditions. 
Table 1. Advantageous characteristics associated with goats over other livestock species to survive in harsh climatic conditions.

\begin{tabular}{|c|c|c|}
\hline Criteria & Special Characteristics of Goats & References \\
\hline Adaptability & $\begin{array}{l}\text { Goats are better adapted to broad environmental conditions ranging } \\
\text { from arid dry to cold arid to hot humid. Goats in the tropical warm } \\
\text { climate are more or less dwarf and have less body weight, while goats } \\
\text { in colder climates have bigger size and more fur growth. Due to their } \\
\text { lesser body size, their metabolic requirements are considerably low, } \\
\text { they have the ability to reduce their metabolism and their loose skin } \\
\text { aids in easy dissipation of body heat. }\end{array}$ & [18] \\
\hline Thermo-tolerance & $\begin{array}{l}\text { Goats are more thermo-tolerant than all other ruminant species. } \\
\text { They possess the ability to survive in different agro-ecological zones. }\end{array}$ & [19] \\
\hline Drought tolerance & $\begin{array}{l}\text { Goats possess the ability to thrive well in drought prone areas } \\
\text { because of reduced water requirement in comparison to sheep and } \\
\text { other domestic ruminants. Goats have better water conservation } \\
\text { ability than other ruminant animals because of their browse diet. } \\
\text { Further, the gut, especially the rumen, acts as a water reservoir during } \\
\text { the periods of dehydration. }\end{array}$ & [19] \\
\hline $\begin{array}{l}\text { Ability to thrive well } \\
\text { on low pasture }\end{array}$ & $\begin{array}{l}\text { Efficient utilizers of poor quality and a wide range of pastures. } \\
\text { Goats have improved digestibility compared to all other rumen and } \\
\text { animals and, moreover, because the small-sized feed consumption is } \\
\text { also low, these factors together favour less } \mathrm{CH}_{4} \text { production. }\end{array}$ & [19] \\
\hline $\begin{array}{l}\text { Low enteric methane } \\
\text { emission }\end{array}$ & $\begin{array}{l}\text { Goats produce less enteric methane compared to sheep and other } \\
\text { ruminants. }\end{array}$ & [20] \\
\hline $\begin{array}{l}\text { More demand for } \\
\text { goat meat }\end{array}$ & $\begin{array}{l}\text { Goat meat possesses less fat content and has no religious taboo; hence, } \\
\text { it is relished by all. The lower saturated fat content in the goat meat } \\
\text { improves the blood cholesterol level and stabilizes the heart rhythm } \\
\text { of consumer. Goat meat contains vitamin B, B12 and omega- } 3 \text { fatty } \\
\text { acids. Further goat meat is lower in calories and cholesterol than the } \\
\text { meat from other animals. }\end{array}$ & {$[21]$} \\
\hline $\begin{array}{l}\text { Milk with more } \\
\text { nutrition }\end{array}$ & $\begin{array}{l}\text { Goat milk is more nutritious than the milk from other species of } \\
\text { livestock, easily digestible due to the presence of some beneficial fatty } \\
\text { acids and contains fats and proteins in a finer state. Goat milk } \\
\text { contains vitamin A, niacin, thiamin, ribofavin and pantotheanate. }\end{array}$ & {$[22]$} \\
\hline $\begin{array}{l}\text { Digestibility and feed } \\
\text { conversion efficiency }\end{array}$ & $\begin{array}{l}\text { Increased efficiency to convert feed into milk and meat than all other } \\
\text { domestic ruminants, they can even digest poor quality feed. } \\
\text { Goats have less proportion of gut in relation their total body weight, } \\
\text { which enables the rapid movement of digesta from the rumen and the } \\
\text { entire gastrointestinal tract. }\end{array}$ & [19] \\
\hline $\begin{array}{l}\text { Less initial } \\
\text { investment }\end{array}$ & $\begin{array}{l}\text { Minimum investment compared to large ruminants due to lower } \\
\text { price. It is possible to get more animals at the cost of one cow. } \\
\text { Less quantity of feed is required for goats compared to other } \\
\text { domesticated livestock species. }\end{array}$ & [1] \\
\hline $\begin{array}{l}\text { Women } \\
\text { entrepreneurship }\end{array}$ & $\begin{array}{l}\text { Because of their small size, goats are easy to herd by women. } \\
\text { They can let the animals graze on common property resources and } \\
\text { private fallow lands. As they move as a herd, it is easy to track them. }\end{array}$ & [19] \\
\hline $\begin{array}{l}\text { Suitable for landless } \\
\text { farmers }\end{array}$ & $\begin{array}{l}\text { Small area is required to rear goats because of their small size, } \\
\text { they require less feed and they can be easily integrated into other } \\
\text { farming systems. }\end{array}$ & [14] \\
\hline
\end{tabular}

\section{Impact of Heat Stress on Rumen Function}

Elevated ambient temperature during the summer months can have a significant influence on the basic physiology of rumen function, thereby affecting the nutritional status of the animals [23]. Rumen volatile fatty acid (VFA) production is altered during the conditions of extreme temperature, 
while feed digestibility is increased with increasing ambient temperature because of a reduction in feed intake and passage rate, which allows more time for the microbes and enzymes to digest feed [24]. Table 2 describes the various impacts of heat stress on rumen function.

Table 2. Different impacts of heat stress on the rumen function in goats.

\begin{tabular}{|c|c|c|}
\hline Type of Heat Stress & Effect on Rumen Fermentation Pattern & Reference \\
\hline Summer heat stress & Altered basic physiology of rumen function & {$[23]$} \\
\hline Extreme temperature stress & Reduced VFA production & [24] \\
\hline Summer heat stress & Decreased rumen $\mathrm{pH}$ and acidosis & [25] \\
\hline Heat stress & Reduction in ruminal $\mathrm{pH}$; reduced rumen fermentation & [26] \\
\hline Heat stress & Decreased rumen $\mathrm{pH}$ & {$[27]$} \\
\hline Summer heat stress & Decreased VFA production; Reduced production of acetate & {$[28,29]$} \\
\hline Heat stress & $\begin{array}{l}\text { Decrease in acetate and acetate to propionate ratio and an } \\
\text { increase in butyrate }\end{array}$ & {$[30]$} \\
\hline Heat stress & $\begin{array}{l}\text { Increase of Streptococcus genus bacteria and a decrease in } \\
\text { the bacteria of Fibrobactor genus }\end{array}$ & [31] \\
\hline Heat stress & $\begin{array}{l}\text { Decrease in the Streptococcus genus and increase in } \\
\text { Clostridium coccoides-Eubacterium genus }\end{array}$ & [32] \\
\hline Increased temperature and $\mathrm{RH}$ & $\begin{array}{l}\text { Decline in the concentrations of amylolytic and cellulolytic } \\
\text { bacteria; decreased diet digestibility }\end{array}$ & [9] \\
\hline Late summer & Increase in enteric $\mathrm{CH}_{4}$ emissions & [33] \\
\hline Late summer season & Increase in enteric $\mathrm{CH}_{4}$ emissions & [34] \\
\hline Summer heat stress & increase in $\mathrm{CH}_{4}$ emission & [35] \\
\hline
\end{tabular}

Note: $\mathrm{RH}$ : Relative humidity; VFA: Volatile fatty acid; $\mathrm{CH}_{4}$ : Methane.

\subsection{Rumen Fermentation Pattern}

Environmental factors such as temperature and relative humidity (RH) can have significant role in the feed consumption of animals. An increase in temperature and RH decreases the dry matter intake of the animals and rumination as a result of increased amount of buffering agents entering the rumen and this could be attributed to the reduced chewing activity [7]. Additionally, blood flow is redirected from the gastrointestinal tract to the periphery for heat dissipation, which further decreases the digestibility [8]. Furthermore, an increased respiration rate during summer season increases expired $\mathrm{CO}_{2}$ output leading to decreased blood and rumen $\mathrm{pH}$ and acidosis [25]. Likewise, Castro-Costa et al. [26] reported a reduction in ruminal $\mathrm{pH}$ in heat exposed Murciano-Granadina dairy goats and attributed this to the reduced rumen fermentation during heat stress. Similarly, Yan-fen et al. [27] also reported a decreased rumen $\mathrm{pH}$ and $\mathrm{NH}_{3}-\mathrm{N}$ concentration in dairy goats exposed to heat stress.

\subsection{Volatile Fatty Acid Production}

There are reports showing a decrease in VFA production during the periods of heat stress $[28,29]$. Similarly, Tajima et al. [30] reported a decrease in acetate and acetate to propionate ratio and an increase in butyrate level in heat stressed animals, which they attributed to alterations in the number of rumen microbiota during the periods of heat stress. Likewise, Hirayama et al. [24] reported a reduction in plasma acetate and VFA concentrations in heat exposed $\left(35^{\circ} \mathrm{C}\right)$ Saanen goats compared to Saanen goats kept under thermoneutral conditions $\left(20^{\circ} \mathrm{C}\right)$. They attributed these changes to reduced feed intake and rumen microbial diversity. Further, in a study conducted in indigenous goat breeds, we [28] reported a reduced production of acetate concentrations in heat exposed Osmanabadi and Malabari goats, whereas the Salem goats did not exhibit any change. In the same experiment, we also observed an increase in propionate concentration in the Salem black goats and a decline in the propionate production in Malabari goats. These variations in the heat stress response could be explained by the differences in the adaptive capability among the breeds, suggesting Salem black as the superior adaptive breed in the climate change scenario. Further, Chaidanya et al. [29] reported a reduction in VFA concentrations in rumen of goats exposed to high ambient temperature coupled with high 
relative humidity. The reduction in the VFA concentration could be attributed to the increased rumen temperature during the heat stress periods.

\subsection{Rumen Microbial Population}

Heat stress induced rumen function impairment is mainly associated with an increase of Streptococcus genus bacteria and a decrease in the bacteria of Fibrobactor genus [31]. Further, Tajima et al. [30] also reported these changes along with altered rumen bacterial diversity with a decrease in uncultivated Cluster E group sequences during heat stress. Similarly, Uyeno et al. [32] observed a decrease in the Streptococcus genus and an increase in both Streptococcus spp. and Clostridium coccoides-Eubacterium genus in the rumen. Changes in the rumen microbial ecosystem due to heat exposure can influence feed digestibility and composition of the end products by altering the rumen fermentation pattern [32]. Further, Bernabucci et al. [9] observed a decline in the concentrations of amylolytic and cellulolytic bacteria in animals exposed to ambient conditions having a temperature humidity index (THI) 85. The decreased dry matter intake and passage rate in heat stressed animals could reduce the bacterial diversity ultimately culminating in decreased diet digestibility [9]. There are few research reports available on how high ambient temperature selectively affects microbial population. However, this impact could be attributed to the sensitivity of certain rumen microbes to increased temperature exposure.

\subsection{Enteric Methane Emission}

Environmental temperature is a key factor that determines $\mathrm{CH}_{4}$ production, since feed intake and digestibility differ with ambient temperature. Mbanzamihigo et al. [33] reported an increase in enteric $\mathrm{CH}_{4}$ emissions during late summer (August-September) compared to early summer (June-July) in the Northern Hemisphere. Similarly, in another experiment conducted in young wethers grazing a moist hilly island pasture, a perennial rye grass/white clover dominant pasture and a late summer season pasture showed $\mathrm{CH}_{4}$ yields of $4.1 \%, 3.9 \%$ and $5.3 \%$, respectively. Increased $\mathrm{CH}_{4}$ yield in wethers grazing late summer season pastures is attributed to the quality deterioration (poor dry matter digestibility, lower protein and soluble carbohydrate content and increased cell wall content) of the pastures during the summer season [34]. This study revealed the indirect effect of elevated ambient temperature on the $\mathrm{CH}_{4}$ production through altered pasture characteristics. Further, Ulyatt et al. [35] reported an increase in $\mathrm{CH}_{4}$ emission during grazing of summer grassland compared to Kikuyu grassland. Figure 1 shows the impact of heat stress on various rumen functions in goat.

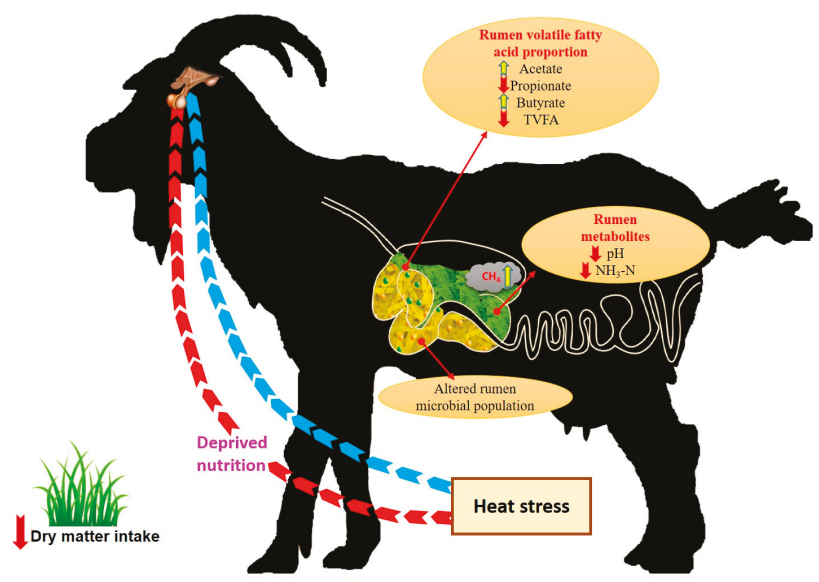

Figure 1. Impact of heat stress on various rumen functions in goat (these concepts were adopted from References [28,29]). TVFA: Total Volatile Fatty Acid. 


\subsection{Factors Influencing Enteric Methane Emission in Goats}

Various factors affect the enteric methane production in goats and these are broadly classified as weather associated factors such season and increased ambient temperature; feed associated factors such as diet composition, time after feeding, and feed additives; and animal associated factors that include inflow of saliva, types of microbial population, and breed [36].

Composition of feed is the primary factor that determines the rumen fermentation pattern and enteric methane emissions [37]. Further, the propionate to acetate ratio also influences the rumen fermentation pattern and is determined by the concentrate to forage content of the diets [38]. In comparison with roughage feed, concentrates contain less structural carbohydrates, so the intake of concentrates may increase the production of propionate and decrease the production of acetate, ultimately resulting in reduced $\mathrm{CH}_{4}$ production. An increase in concentrate intake is associated with increased propionate production and this may reduce the number of $\mathrm{H}_{2}$ atoms available to the methanogenic bacteria, again resulting in reduced methane production. However, the higher level of concentrate feeding can cause sub-acute acidosis, both sub-clinical and clinical, which may adversely impact normal ruminal fermentation processes through both alteration of the functions of essential rumen microbes and impaired VFA absorption due to low ruminal $\mathrm{pH}$ [39].

In recent years, the usage of microbial feed additives has increased to improve growth performance of meat animals. In addition, some microbial feed additives have been used to reduce $\mathrm{CH}_{4}$ production in ruminant animals. Malik et al. [40] used acetogens as a feed additive to replace prominent $\mathrm{CH}_{4}$-producing methanogenic bacteria to reduce enteric methane production by acting as alternate hydrogen. The prominent $\mathrm{CH}_{4}$-producing methanogenic bacteria have a low $\mathrm{H}_{2}$ threshold level, thus do not allow the naturally resident acetogens to utilize hydrogen. Other feed additives such as fat and oil supplements have also been reported to have an effect on the rumen fermentation profile, thereby reducing rumen protozoan population and $\mathrm{CH}_{4}$ reduction [41]. However, high fat diets can alter the rumen microbial population and ultimately it can hamper the fibre digestibility by specifically inactivating the rumen microbes that are associated with fibre digestion [41]. Plant bioactives, including saponins and tannins, can reduce $\mathrm{CH}_{4}$ production in ruminants [42].

Breed is another important factor that determines enteric $\mathrm{CH}_{4}$ production [43]. These breed-to-breed differences in enteric $\mathrm{CH}_{4}$ production could be attributed to their variation in body size, adaptation, rumen volume and the variation in the feed intake [43]. Rumen associated factors such as rumen $\mathrm{pH}$, type of volatile fatty acids fermented, type of substrates fermented, rate of fermentation, absorption capacity of rumen wall, and rumen protozoa concentration determine the level of $\mathrm{CH}_{4}$ production [44]. Rumen methanogens remove $\mathrm{H}_{2}$ molecules that are synthesized during the organic matter fermentation produced during fermentation of organic matter in the hind gut and rumen and produce $\mathrm{CH}_{4}$ [45]. Further, the increased production of propionate decreases the $\mathrm{CH}_{4}$ production by consuming $\mathrm{H}_{2}$ molecules [46].

Geographic location and climate are known to be the most crucial factors significantly affecting $\mathrm{CH}_{4}$ production and this could be due to ambient temperature differences as well as difference in feed resources available [44]. Animals reared in arid and semi-arid regions have been reported to produce less $\mathrm{CH}_{4}$ production compared with animals in temperate regions, and this could be due to the differences in the type or amount of feed consumed in different locations [44]. Among the climate variables temperature, humidity, solar radiation and wind velocity are the important variables that influences $\mathrm{CH}_{4}$ production. Increased ambient temperature coupled with high relative humidity $(\mathrm{RH})$ directly affects $\mathrm{CH}_{4}$ production by altering the rumen fermentation profile and indirectly by altering the quality of pasture or forage [46]. Although heat stress may reduce the feed intake, the increased methane emission could still be attributed to the heat stress associated negative impact on feed digestibility by inhibiting the rumen microbial populations that are essential for the normal digestion process. The various factors influencing enteric methane production from goats are summarized in Figure 2. 


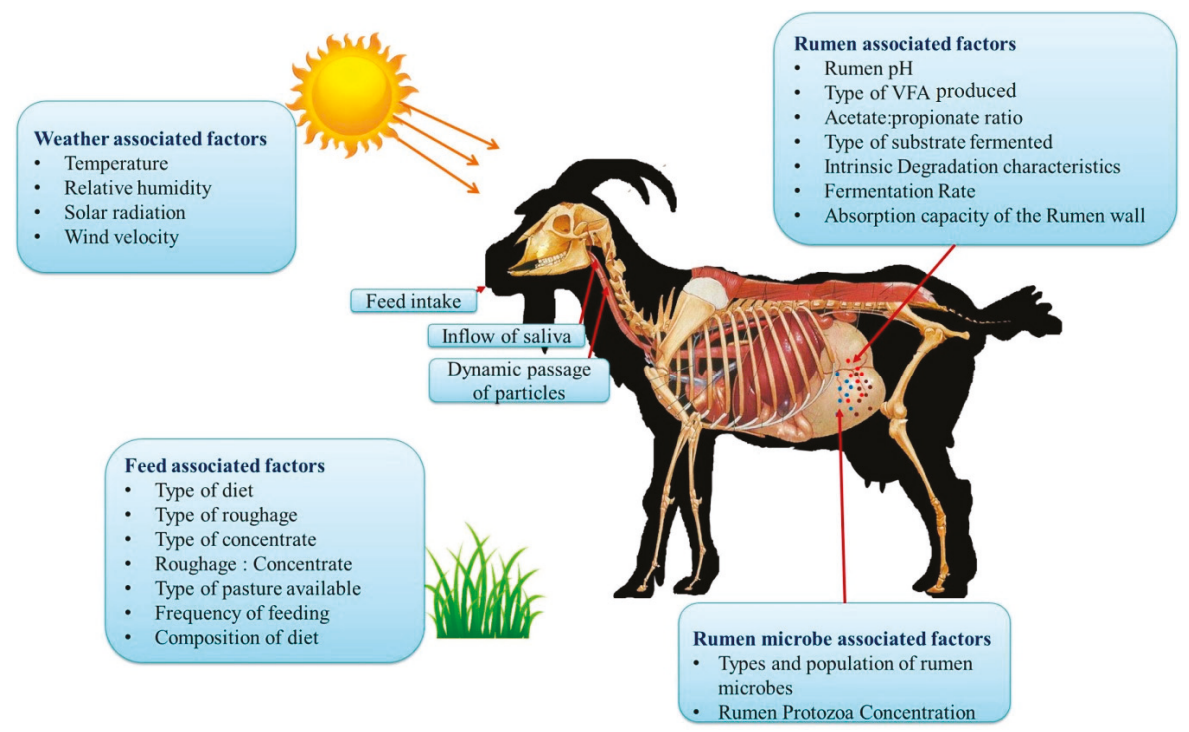

Figure 2. Various factors influencing enteric methane emission in goats (these concepts were adopted from References $[8,28,29])$.

\subsection{Enteric Methane Mitigation Strategies in Goats}

Apart from its major role in global warming and the greenhouse effect, enteric $\mathrm{CH}_{4}$ is also considered as a dietary energy loss of around $2-12 \%$ in ruminants. Consequently, the global scientific community is targeting the development of suitable $\mathrm{CH}_{4}$ mitigation strategies to reduce both global warming and dietary energy loss. The various strategies that can be implemented to mitigate enteric $\mathrm{CH}_{4}$ include feeding feed sources containing plant secondary metabolites, ration manipulation, fat and oil supplementation, bacteriocin supplementation, rumen modification, etc. [29,45-47]. Various mechanisms to reduce enteric methane production in goats are summarised in Figure 3.

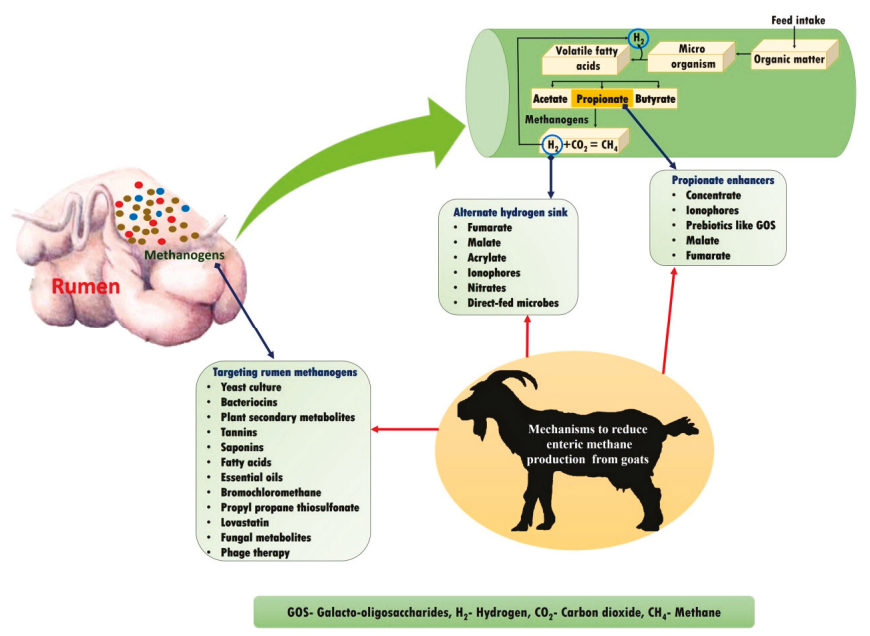

Figure 3. Various mechanisms to reduce enteric methane emission in goats. 


\subsubsection{Nutritional Intervention to Reduce Enteric Methane Production in Goats}

Among the various $\mathrm{CH}_{4}$ mitigation strategies, nutritional intervention or dietary manipulation is the most effective and commonly used strategy to mitigate enteric $\mathrm{CH}_{4}$ emission in ruminant livestock $[48,49]$. It is well known that increasing the ratio of concentrate to forage in the diet can reduce the amount of energy loss as enteric $\mathrm{CH}_{4}$ and this is mainly due to change of fermented substrate from fibre to starch [48]. In an experiment conducted on Murciano-Granadina goats in late lactation, Ibáñez et al. [50] observed a lower $\mathrm{CH}_{4}$ production in goats fed with concentrate (ground corn) diet than beet pulp fed goats. However, concentrate feeding beyond a certain limit is not appreciable as it can cause severe damage to the animal itself and to its production performance. In addition, grains that may be used for concentrates are more valuable for human feeds in arid and semi-arid regions where much of the global goat production is located.

Supplementing the feed with more lipids and fatty acids was reported to reduce the dietary energy loss in goats [51]. However, the effectiveness of lipid supplementation relies on the source, inclusion rate, fatty acid profile and the composition of the rest of the diet $[48,52]$. Reduction in enteric $\mathrm{CH}_{4}$ emission to the tune of around $40 \%$ is possible using high quality lipid feed supplements [46]. By differing the mode of action, lipid feed additives may reduce the methanogen and ciliated protozoan population in the rumen. Further, lipid supplementation reduces fibre and organic matter degradability and decreases the fermentable substrate availability and thereby minimising $\mathrm{CH}_{4}$ production [53]. Abubakr et al. [54] conducted an experiment in Boer X Catcang crossbred goats where they found that adding decanter cake and palm kernel cake at up to $80 \%$ inclusion decreases methanogenesis by reducing rumen protozoa in goats. Further, Zhou et al. [55] reported the ability of lauric acid to reduce $\mathrm{CH}_{4}$ production by reducing the viability of Methanobrevibacter ruminantium. Likewise, Kong et al. [56] reported a significant reduction in the methanogenesis without affecting the quantity of rumen methanogenic archaea after flaxseed supplementation.

Ionophore supplementation is another extensively researched $\mathrm{CH}_{4}$ abatement strategy. Ionophores cause a shift in the rumen fermentation pattern from acetate and butyrate production to propionate by increasing the gram-positive bacteria population, resulting in decreasing the production of $\mathrm{CH}_{4}$ [57]. Monensin is the most studied ionophore and routinely used as an animal nutrition supplement [58]. Saanen goats supplemented with oils with sodium bicarbonate and monensin showed a shift in the production of molar concentrations of acetate to propionate, thereby reducing the production of $\mathrm{CH}_{4}$ [59]. Furthermore, up to a $75 \%$ reduction in $\mathrm{CH}_{4}$ production was observed on addition of $10 \%$ encapsulated fumarate to the diet without any negative effect on animal growth [58].

Although several anti-methonogenic compounds are well proved in terms of their $\mathrm{CH}_{4}$ reduction potential, certain individual components have antinutritional properties that inhibit their commercial usage. However, data obtained from anti-methonogenic supplementation studies are good models and they can pave a way towards effective $\mathrm{CH}_{4}$ mitigation strategies [60,61]. Abecia et al. [45] conducted an experiment in Murciano-Granadina lactating goats to evaluate the potential of bromochloromethane (BCM) complex to reduce enteric $\mathrm{CH}_{4}$ production and they observed $32 \%$ reduction in $\mathrm{BCM}$ fed goats as compared to the control group. In another experiment conducted in Murciano-Granadina goats, Martínez-Fernández et al. [62] observed 33\% and 64\% methane reduction per kg of dry matter intake with propyl propane thiosulfinate (PTS) and BCM supplementation, respectively. Further, Murciano-Granadina goats supplemented with PTS and BCM decreased $\mathrm{CH}_{4}$ production by $48 \%$ and $98 \%$, respectively, which was attributed to the redirection of $\mathrm{H}_{2}$ from $\mathrm{CH}_{4}$ production to propionate metabolic pathways [63]. Similarly, Mitsumori et al. [64] also reported 71\% and 91\% reductions in $\mathrm{CH}_{4}$ production in Shiba Japanese goats supplemented with $2 \mathrm{~g} / 100 \mathrm{~kg}$ Live Weight and $5 \mathrm{~g} / 100 \mathrm{~kg} \mathrm{LW}$ of BCM, respectively. Candyrine et al. [65] conducted a study on Saanen goats with three levels of lovastatin (naturally produced from fermentation of palm kernel with Aspergillus terreus) supplementation and the authors observed $7.8 \%, 20 \%$ and $21 \% \mathrm{CH}_{4}$ reduction for low (2 mg lovastatin/ kg BW/day), medium (4 mg lovastatin $/ \mathrm{kg} \mathrm{BW/day)} \mathrm{and} \mathrm{high} \mathrm{(6} \mathrm{mg} \mathrm{lovastatin} / \mathrm{kg}$ BW/day) treatment groups, respectively. Further, Azlan et al. [66] reported 32\% reduction in enteric 
$\mathrm{CH}_{4}$ production when supplementing Boer crossbred goats with $14 \mathrm{mg} / \mathrm{kg}$ BW of lovastatin produced from rice straw treated with Aspergillus terreus.

Microbial feed additives are another important nutritional intervention in the $\mathrm{CH}_{4}$ mitigation studies. Apart from the effects on $\mathrm{CH}_{4}$ mitigation, probiotic feeding can improve the growth performance of meat animals and it can also reduce the incidence of diarrhoea [67]. However, studies proving the efficiency of direct fed probiotics to reduce the production of enteric $\mathrm{CH}_{4}$ are few [68]. The same authors also reported that nitrate as feed additive can reduce rumen methanogenesis in different ruminant species and production conditions [68]. Chaucheyras-Durand et al. [69] showed that yeast cells can reduce the production of enteric $\mathrm{CH}_{4}$ by deviating hydrogen atoms from methanogens to acetogenic strains of ruminal bacteria to enhance the production of acetate. Yeasts such as S. cerevisiae and the lactic acid utilizing bacteria Propionibacterium spp. and Megasphaera elsdenii can decrease rumen methanogenesis when included in the diet as supplements [60]. Wang et al. [61] found that replacing ordinary rice feed with red yeast rice, which is a traditional Chinese culinary and medicinal product, resulted in a $13 \%$ reduction in $\mathrm{CH}_{4} / \mathrm{DM}$ intake in Boer crossbred goats.

Organic acids such as malic acid and fumerate have the potential to reduce $\mathrm{CH}_{4}$ production in the ruminant by serving as an alternative hydrogen sink. Organic acid administration has been proven to reduce methane production in a dose-dependent manner in several in vitro studies [70]. In an experiment conducted in Xinong Saanen dairy goats, Li et al. [71] reported a significant reduction in $\mathrm{CH}_{4}$ production in goats supplemented with fumaric acid. Further, in the same study, along with fumeric acid supplementation, the authors also altered the particle size of concentrate and forage feed and observed $32 \%$ and $18 \% \mathrm{CH}_{4}$ reduction in low forage and concentrate particle size diet and high forage and concentrate particle size diet, respectively [71].

Phenolic monomers, condensed tannins and other plant secondary metabolites in dose-dependent manner can reduce enteric $\mathrm{CH}_{4}$ emission from the ruminants because of their ability to reduce methanogenesis. Puchala et al. [72] reported 57\% reduction in $\mathrm{CH}_{4}$ in terms of g/kg DMI in condensed tannin containing Lespedeza cuneata fed Angora goats compared to Angora goats fed a combination of Festucaarundinacea and Digitariaischaemum. Dietary tannins can directly hinder $\mathrm{CH}_{4}$ production as well as indirectly limit methanogenesis through reducing the availability of hydrogen atoms. In a meta-analysis using 30 experiments comprising 171 treatments to evaluate the extent of dietary tannins to reduce the $\mathrm{CH}_{4}$ emission, Jayanegara et al. [73] found a negative correlation between enteric $\mathrm{CH}_{4}$ production and tannin supplementation. Furthermore, Wina et al. [74] reported a reduction in methanogens in methanol extract saponin containing Sapindus rarak fed animals. Similarly, Mao et al. [75] reported a $27 \%$ reduction in enteric $\mathrm{CH}_{4}$ production with tea saponin supplementation. Further, in an experiment conducted in goats fed with natural tannin containing Mimosa spp., Bhatta et al. [46] reported a $\mathrm{CH}_{4}$ reduction after Mimosa spp. supplementation even at low concentrations (2-8 g/ kg DM of the diet). In a study conducted in Nanjiang Yellow goats, Dong et al. [76] reported a reduction in enteric methane production on Artemisiae annuae extract and herbal medicines mixture supplementation to different diets. Further, under in vitro condition, Denman et al. [77] reported $91 \%$ reduction in methane production using bromochloromethane at $5 \mathrm{~g} / 100 \mathrm{~kg}$ LW in Japanese native goats.

\subsubsection{Management Strategies to Reduce $\mathrm{CH}_{4}$ Production from Goats}

Improving management strategies not only reduces enteric methane emission but also helps to improve animal productivity [78]. Reduction or culling of unproductive animals from the herd has the potential to simultaneously improve the productivity and to reduce $\mathrm{CH}_{4}$ emission $[79,80]$. In subsistence production systems, reduction in the herd size allows distribution of adequate amount of feed and proper veterinary care to all animals. Additionally, selective culling can reduce $\mathrm{CH}_{4}$ production both per unit of animal product and for the total herd [81]. However, in some subsistence farming systems, there may be insufficient high breeding value animals to allow selective culling. Slaughter weight of goats can be advanced at a young age through early finishing approaches. This can 
potentially reduce the lifetime net $\mathrm{CH}_{4}$ emissions, thus making available proportionally few $\mathrm{CH}_{4}$ producing animals [79].

Reductions in enteric $\mathrm{CH}_{4}$ production can be achieved through efficient pasture management practices in goats. Feeding animals high quality fodder can reduce the wastage of dietary energy. Improving quality of the forage also increases feed intake and reduces the retention time of digesta in the rumen, thereby stimulating energetically more efficient post-ruminal digestion and decreases the percentage of energy transformed to $\mathrm{CH}_{4}$ [79]. Sejian et al. [82] reported a reduced $\mathrm{CH}_{4}$ emission in animals fed with high quality fodder as compared to animals consuming low quality fodder. Reductions in enteric $\mathrm{CH}_{4}$ production can also be achieved through feeding high quality fodder with higher soluble carbohydrates and lower fibre or through grazing on less-matured pastures [48,79]. Harvesting or grazing of forage at early stages of maturity also reduces the plant cell wall lignification, thereby increasing digestibility and reducing the $\mathrm{CH}_{4}$ emission per unit of digestible dry matter [83] Similarly, Pinares-Patiño et al. [84] conducted a grazing experiment in timothy pasture at four different vegetative phases, namely, early vegetative stage, heading, flowering and senescence, and they observed lower $\mathrm{CH}_{4}$ production only at heading stage, which confirms the significance of growth stages of forage in $\mathrm{CH}_{4}$ production. Waghorn and Hegarty [85] calculated that animals grazing on high quality pasture ( $20 \%$ higher ME value) may show a reduction in enteric $\mathrm{CH}_{4}$ production of approximately $50 \%$. Likewise, animals consuming certain high quality tropical and temperate legumes show reduced enteric $\mathrm{CH}_{4}$ production, as the legumes contain condensed tannins that are toxic to methanogenic archaea, ciliate protozoa, and fibre degrading bacteria [86]. Further, the grasses with high concentrations of water-soluble carbohydrates have been investigated as suitable tool to reduce enteric $\mathrm{CH}_{4}$ emission from the ruminant livestock [87]. De Ramus et al. [88] reported 22\% reduction in enteric $\mathrm{CH}_{4}$ production annually through the efficient use of grazed forage crops through management-intensive grazing. Furthermore, around 5\% reduction in enteric $\mathrm{CH}_{4}$ production is possible through improving total tract NDF digestibility [53]. Archimede et al. [89] reported $17 \%$ more $\mathrm{CH}_{4}$ production from animals fed with $\mathrm{C} 4$ grasses than the animals fed with $\mathrm{C} 3$ grasses.

In the majority of regions around the globe, goats are raised under continuous grazing systems, where animals have ad libitum access to pasture. However, unrestricted access to the pasture can result in the elimination of edible pasture and the domination of less edible pasture due to the uncontrolled selective grazing [31]. Hence, adoption of controlled grazing is a reliable strategy to reduce enteric $\mathrm{CH}_{4}$ and to improve productivity. In these systems, grazing land is divided into different paddocks that are alternatively grazed and rested until the pasture restores its quality. A continuous supply of uniform quality feed throughout the year enables animals to increase their production and to decrease $\mathrm{CH}_{4}$ production per kilogram of weight gain [20].

Size of the forage has profound effect on the $\mathrm{CH}_{4}$ emissions. Animals deviate considerable amount of their energy to the chewing process [90]. Particle size reduction of fodder by mechanical means helps to enhance digestibility through bringing more microbial access to the substrate, decreasing energy expenses, $\mathrm{CH}_{4}$ production and increasing the passage rate of digesta and animal productivity [91].

Selection of genetically superior animals with less $\mathrm{CH}_{4}$ production per unit feed intake is another management strategy that can be employed to reduce $\mathrm{CH}_{4}$ production from the ruminants [92]. The direct selection of low $\mathrm{CH}_{4}$ producing animals is practically impossible because of high cost for measuring $\mathrm{CH}_{4}$. However, selection is possible through the indirect means such as rumen digesta retention time and feed intake [80]. Genetic selection of goats with higher feed conversion efficiency generates a reduced amount of $\mathrm{CH}_{4}$. Further, genetic selection for the less $\mathrm{CH}_{4}$ production indirectly helps the farmer to increase their profits without any extra carbon credits by increasing the feed conversion efficiency and growth rate per animal [92]. A 3-10\% reduction in $\mathrm{CH}_{4}$ production can be achieved through improving the feed use efficiency by $10 \%$ [93]. 


\subsubsection{Advanced Biotechnological Tools for Methane Mitigation}

The inhibition of enteric $\mathrm{CH}_{4}$ emission in ruminant animals is possible though biotechnological interventions. One of the possible future strategies to reduce enteric $\mathrm{CH}_{4}$ production is to immunize the animals against their own methanogens. In an experiment conducted in Australia using vaccines against three selected methanogens, Wright et al. [94] reported $8 \%$ reduction in $\mathrm{CH}_{4}$ production. However, another experiment conducted in different geographical zone with vaccines prepared using different set of bacteria could not elicit any positive response [94]. The reasons for the immunization failures could be due to the variation in rumen methanogenic diversity present in the animals raised in different conditions and the replacement of the biological niche left by the targeted species by another methanogen [95]. $\mathrm{CH}_{4}$ inhibition was also attempted through oral supplementation IgY as a feed additive [96]. Zhang et al. [97] conducted an experiment in Boer goats to evaluate the efficiency of a candidate vaccine protein (EhaF) on the rumen methanogens and microbes but did not find any changes in $\mathrm{CH}_{4}$ production among control and vaccinated goats. However, vaccination influenced the composition of rumen bacteria.

Use of bacteriocins offers another possible strategy to reduce $\mathrm{CH}_{4}$ emission from ruminant animals. Bacteriocins are the proteins produced by bacteria that can obstruct certain microbial species in the rumen [98]. An in vitro study conducted by Lee et al. [99] using bovicin HC5 (a bacteriocin produced by Streptococcus spp.) showed 50\% reduction in $\mathrm{CH}_{4}$ production without inducing methanogen adaptation. Likewise, Santoso et al. [100] reported a $10 \%$ reduction in $\mathrm{CH}_{4}$ emission in an in vivo study that used nisin, a bacteriocin produced by Lactobacillus lactis subsp.

The lytic potential and genes of the bacteriophages makes them potential tools to mitigate enteric $\mathrm{CH}_{4}$ emission [101]. Certain bacteriophages may inhabit the rumen wall to maintain the homeostasis of the rumen micro fauna. Due to their host specific nature, they lyse certain microbes such as methanogens and Streptococcus bovis or pathogens such as salmonella and E. coli O157:H7 [47]. McAllister and Newbold [70] reported that siphophages (Siphoviridae phage) can infect methanogens such as Methano brevibacter, Methanobacterium and Methanococcus spp.; however, siphophages have yet to be isolated from the rumen. However, there are few available data relating to the genetic functionality and blueprint of the archaeal methanogenic phages and, to date, no bacteriophages from rumen have been isolated [47].

Another plausible method of biological control of methanogens is the use of $\mathrm{CH}_{4}$ oxidizers. The $\mathrm{CH}_{4}$ oxidizing bacteria have already been isolated from the rumen [102]. However, in vitro studies conducted using carbon isotopes reveal that only $0.3-8 \%$ of $\mathrm{CH}_{4}$ oxidation to $\mathrm{CO}_{2}$ happens in the rumen [103]. Valdez et al. [104] reported a reduction in $\mathrm{CH}_{4}$ production by adding $\mathrm{CH}_{4}$ oxidizing bacterium isolated from the gut of young pigs. However, detailed in vivo studies are needed to establish the level of $\mathrm{CH}_{4}$ reduction. Another novel approach for enteric $\mathrm{CH}_{4}$ reduction is through the genetic modification of fermentation characteristics of rumen bacteria. However, research is still in the preliminary stages and very little progress has been made pertaining to applying the molecular techniques to characterize and quantify the microbial populations [86].

\section{Conclusions and Future Perspectives}

Goats undoubtedly need to be the priority focus for livestock industries due to their advantages over other ruminant animals from a climate resilience point of view. Elevated ambient temperature during the summer months can have a significant influence on the basic physiology of rumen, thereby affecting the rumen fermentation pattern, VFA and other rumen metabolites production. Furthermore, growing evidence suggests that heat stress influences the rumen microbial population, resulting in alterations in ruminal digestion process in goats. In addition, heat stress has also been shown to increase the production of enteric $\mathrm{CH}_{4}$ emission resulting in dietary energy loss. Thus, the productive performances of the animals are compromised. Nutritional interventions and other management strategies are traditional ways by which enteric $\mathrm{CH}_{4}$ emission is reduced in goats. More recently, several researchers have targeted reducing enteric $\mathrm{CH}_{4}$ through advanced 
biotechnological tools such immunization therapy, using bacteriocins, etc. but without much success. Further refinements in these technologies are essential before these technologies are implemented at field level. In the near future, these technologies offer scope for identifying genetically superior animals with less $\mathrm{CH}_{4}$ production per unit feed intake. However, further research efforts are needed to elucidate the mechanisms associated with enteric $\mathrm{CH}_{4}$ emission during heat stress exposure by establishing the relationships among the rumen microbes through metagenomics approaches in goats in the changing climate scenario. Such efforts may help to develop more focussed mitigation strategies for reducing enteric $\mathrm{CH}_{4}$ emission in goats. This may help to sustain goat production in the changing climate scenario by preventing the dietary energy loss incurred during the process of enteric $\mathrm{CH}_{4}$ emission.

Author Contributions: Conceptualization, P.P. and V.S.; Preparation of Manuscript, P.P., V.S., S.S.C., B.J.L. and F.R.D.; Figure Preparation, P.P., V.S. and S.S.C.; Table Preparation, P.P., S.S.C. and V.S.; and Scientific Editing, F.R.D., B.J.L. and S.S.C.

Funding: This research received no external funding.

Acknowledgments: The authors profusely thank Frank R. Dunshea for supporting this manuscript by bearing the publication charge.

Conflicts of Interest: The authors declare no conflict of interest.

\section{References}

1. Feleke, F.B.; Berhe, M.; Gebru, G.; Hoag, D. Determinants of adaptation choices to climate change by sheep and goat farmers in Northern Ethiopia: The case of Southern and Central Tigray, Ethiopia. SpringerPlus 2016, 5, 1692. [CrossRef] [PubMed]

2. Bezabih, M.Y.; Berhane, G. Livestock Production Systems Analysis. Am. Int. J. Contemp. Sci. Res. 2014, 1, $16-51$.

3. Thornton, P.K. Livestock production: Recent trends, future prospects. Philos. Trans. R. Soc. Lond. B Biol. Sci. 2010, 365, 2853-2867. [CrossRef] [PubMed]

4. Brahmi, A.; Khaldi, R.; Jaouad, M.; Hicheri, A.; Touati, I.; Rkhissi, A.; Ifaoui, H.; Khaldi, G. Impacts of climate change on the small ruminants farming systems in north western Tunisia and adaptation tools. In New Approaches for Grassland Research in a Context of Climate and Socio-Economic Changes; Acar, Z., López-Francos, A., Porqueddu, C., Eds.; Options Méditerranéennessérie; CIHEAM: Zaragoza, Spain, 2012; pp. 427-431.

5. Koluman, N.; Silanikove, N.; Koluman, A. Climate Change and Goat Agriculture Interactions in the Mediterranean Region. In Sustainable Goat Production in Adverse Environments; Simões, J., Gutiérrez, C., Eds.; Springer: Cham, Switzerland, 2017; pp. 393-405.

6. Sejian, V.; Bhatta, R.; Gaughan, J.B.; Dunshea, F.R.; Lacetera, N. Review: Adaptation of animals to heat stress. Animal 2018. [CrossRef] [PubMed]

7. Bernabucci, U.; Lacetera, N.; Baumgard, L.H.; Rhoads, R.P.; Ronchi, B.; Nardone, A. Metabolic and hormonal acclimation to heat stress in domesticated ruminants. Animal 2010, 4, 1167-1183. [CrossRef] [PubMed]

8. Yadav, B.; Gynendra, S.; Verma, A.K.; Dutta, N.; Sejian, V. Impact of heat stress on rumen functions. Vet. World 2013, 6, 992-996. [CrossRef]

9. Bernabucci, U.; Lacetera, N.; Danieli, P.P.; Bani, P.; Nardone, A.; Ronchi, B. Influence of different periods of exposure to hot environment on rumen function and diet digestibility in sheep. Int. J. Biometeorol. 2009, 53, 387-395. [CrossRef]

10. Pollott, G.; Wilson, R.T. Sheep and Goats for Diverse Products and Profits; FAO Diversification Booklet No. 9; FAO Library: Rome, Italy, 2009; 42p.

11. Oluwatayo, I.B.; Oluwatayo, T.B. Small Ruminants as a Source of Financial Security, a Case Study of Women in Rural Southwest Nigeria; Working Paper 1; Institute for Money, Technology and Financial Inclusion (IMTFI): Irvine, CA, USA, 2012; 21p.

12. Aziz, M.A. Present status of the world goat populations and their productivity. World 2010, 861, 1 .

13. Lérias, J.R.; Hernández-Castellano, L.E.; Suárez-Trujillo, A.; Castro, N.; Pourlis, A.; Almeida, A.M. The mammary gland in small ruminants: Major morphological and functional events underlying milk production-A review. J. Dairy Res. 2014, 81, 304-318. [CrossRef] 
14. Kumar, S.; Roy, M.M. Small Ruminant's Role in Sustaining Rural Livelihoods in Arid and Semiarid Regions and their Potential for Commercialization. In New Paradigms in Livestock Production from Traditional to Commercial Farming and Beyond; Agrotech Publishing Academy: Udaipur, India, 2013; pp. 57-80.

15. Agossou, D.J.; Dougba, T.D.; Koluman, N. Recent Developments in Goat Farming and Perspectives for a Sustainable Production in Western Africa. Int. J. Environ. Agric. Biotechnol. 2017, 2, 2047-2051. [CrossRef]

16. Yami, A.; Merkel, R.C. Sheep and Goat Production Handbook for Ethiopia. Ethiopia Sheep and Goat Productivity Improvement Program. 2008. Available online: https://archive.org/details/ SheepGoatHandbook (accessed on 15 October 2018).

17. Kosgey, I.S.; Rowlands, G.J.; Van Arendonk, J.A.; Baker, R.L. Small ruminant production in smallholder and pastoral/extensive farming systems in Kenya. Small Rumin. Res. 2008, 77, 11-24. [CrossRef]

18. Amankwah, K.; Klerkx, L.; Oosting, S.J.; Sakyi-Dawson, O.; Van der Zijpp, A.J.; Millar, D. Diagnosing constraints to market participation of small ruminant producers in northern Ghana: An innovation systems analysis. NJAS-Wageningen J. Life Sci. 2012, 60, 37-47. [CrossRef]

19. Silanikove, N. The physiological basis of adaptation in goats to harsh environments. Small Rumin. Res. 2000, 35, 181-193. [CrossRef]

20. Soren, N.M.; Sejian, V.; Terhuja, M.; Dominic, G. Enteric methane emission in sheep: Process description and factors influencing production. In Sheep Production Adapting to Climate Change; Sejian, V., Bhatta, R., Gaughan, J., Malik, P.K., Naqvi, S.M.K., Lal, R., Eds.; Springer: Singapore, 2017; pp. 209-233.

21. Archana, P.R.; Sejian, V.; Ruban, W.; Bagath, M.; Krishnan, G.; Aleena, J.; Manjunathareddy, G.B.; Beena, V.; Bhatta, R. Comparative assessment of heat stress induced changes in carcass traits, plasma leptin profile and skeletal muscle myostatin and HSP70 gene expression patterns between indigenous Osmanabadi and Salem Black goat breeds. Meat Sci. 2018, 141, 66-80. [CrossRef] [PubMed]

22. Getaneh, G.; Mebrat, A.; Wubie, A.; Kendie, H. Review on Goat Milk Composition and its Nutritive Value. J. Nutr. Health Sci. 2016, 3, 1-10.

23. Baumgard, L.H.; Rhoads, R.P. Ruminant Nutrition Symposium: Ruminant production and metabolic responses to heat stress. J. Anim. Sci. 2012, 90, 1855-1865. [CrossRef] [PubMed]

24. Hirayama, T.; Katoh, K.; Obara, Y. Effects of heat exposure on nutrient digestibility, rumen contraction and hormone secretion in goats. Anim. Sci. J. 2004, 75, 237-243. [CrossRef]

25. Choubey, M.; Kumar, A. Nutritional interventions to combat heat stress in dairy animals. Vetscan 2012, 7, 19-27.

26. Castro-Costa, A.; Salama, A.A.; Moll, X.; Aguiló, J.; Caja, G. Using wireless rumen sensors for evaluating the effects of diet and ambient temperature in non-lactating dairy goats. J. Dairy Sci. 2015, 98, 4646-4658. [CrossRef]

27. Ma, Y.-F.; Du, R.-P.; Gao, M. Effect of Heat Stress on Dairy Goat Performance and Rumen Epithelial Cell Morphology. Sci. Agric. Sin. 2013, 46, 4486-4495.

28. Pragna, P.; Sejian, V.; Soren, N.M.; Bagath, M.; Krishnan, G.; Beena, V.; Devi, P.I.; Bhatta, R. Summer season induced rhythmic alterations in metabolic activities to adapt to heat stress in three indigenous (Osmanabadi, Malabari and Salem Black) goat breeds. Biol. Rhythm Res. 2018, 49, 551-565. [CrossRef]

29. Chaidanya, K.; Soren, N.M.; Sejian, V.; Bagath, M.; Manjunathareddy, G.B.; Kurien, K.E.; Varma, G.; Bhatta, R. Impact of heat stress, nutritional stress and combined (heat and nutritional) stresses on rumen associated fermentation characteristics, histopathology and HSP70 gene expression in goats. J. Anim. Behav. Biometeorol. 2017, 5, 36-48. [CrossRef]

30. Tajima, K.; Nonaka, I.; Higuchi, K.; Takusari, N.; Kurihara, M.; Takenaka, A.; Mitsumori, M.; Kajikawa, H.; Aminov, R.I. Influence of high temperature and humidity on rumen bacterial diversity in Holstein heifers. Anaerobe 2007, 13, 57-64. [CrossRef] [PubMed]

31. Freestone, P.; Lyte, M. Stress and microbial endocrinology: Prospects for ruminant nutrition. Animal 2010, 4, 1248-1257. [CrossRef] [PubMed]

32. Uyeno, Y.; Sekiguchi, Y.; Tajima, K.; Takenaka, A.; Kurihara, M.; Kamagata, Y. An rRNA-based analysis for evaluating the effect of heat stress on the rumen microbial composition of Holstein heifers. Anaerobe 2010, 16, 27-33. [CrossRef] [PubMed]

33. Mbanzamihigo, L.; Fievez, V.; da Costa Gomez, C.; Piattoni, F.; Carlier, L.; Demeyer, D. Methane emissions from the rumen of sheep fed a mixed grass-clover pasture at two fertilisation rates in early and late season. Can. J. Anim. Sci. 2002, 82, 69-77. [CrossRef] 
34. Ulyatt, M.J.; Lassey, K.R.; Shelton, I.D.; Walker, C.F. Methane emission from sheep grazing four pastures in late summer in New Zealand. N. Z. J. Agric. Res. 2005, 48, 385-390. [CrossRef]

35. Ulyatt, M.J.; Lassey, K.R.; Shelton, I.D.; Walker, C.F. Methane emission from dairy cows and wether sheep fed subtropical grass-dominant pastures in midsummer in New Zealand. N. Z. J. Agric. Res. 2002, 45, 227-234. [CrossRef]

36. Aluwong, T.; Wuyep, P.A.; Allam, L. Livestock-environment interactions: Methane emissions from ruminants. Afr. J. Biotechnol. 2011, 10, 1265-1269.

37. Brouček, J. Methane yield from cattle, sheep, and goats housing with emphasis on emission factors: A review. Slovak J. Anim. Sci. 2015, 48, 122-139.

38. Bhatta, R.; Malik, P.K.; Sejian, V. Enteric methane emission and reduction strategies in sheep. In Sheep Production Adapting to Climate Change; Sejian, V., Bhatta, R., Gaughan, J., Malik, P.K., Naqvi, S.M.K., Lal, R., Eds.; Springer: Singapore, 2017; pp. 291-305.

39. Castillo-González, A.R.; Burrola-Barraza, M.E.; Domínguez-Viveros, J.; Chávez-Martínez, A. Rumen microorganisms and fermentation. Arch. Med. Vet. 2014, 46, 349-361. [CrossRef]

40. Malik, P.K.; Thulasi, A.; Soren, N.M.; Jose, L.; Prasad, K.S.; Prasad, C.S. Phylogenic diversity analysis of rumen acetogens in adult sheep fed on conventional roughage diet. Indian J. Anim. Sci. 2015, 85, 1104-1107.

41. Patra, A.K. A meta-analysis of the effect of dietary fat on enteric methane production, digestibility and rumen fermentation in sheep, and a comparison of these responses between cattle and sheep. Livest. Sci. 2014, 162, 97-103. [CrossRef]

42. Rochfort, S.; Parker, A.; Dunshea, F.R. Plant bioactives for ruminant health and productivity-A review. Phytochemistry 2008, 69, 299-322. [CrossRef] [PubMed]

43. Fraser, M.D.; Fleming, H.R.; Moorby, J.M. Traditional vs Modern: Role of Breed Type in Determining Enteric Methane Emissions from Cattle Grazing as Part of Contrasting Grassland-Based Systems. PLoS ONE 2014, 9, e107861. [CrossRef] [PubMed]

44. Cottle, D.J.; Nolan, J.V.; Wiedemann, S.G. Ruminant enteric methane mitigation: A review. Anim. Prod. Sci. 2011, 51, 491-514. [CrossRef]

45. Pragna, P.; Sejian, V.; Bagath, M.; Krishnan, G.; Devaraj, C.; Afsal, A.; Aleena, J.; Archana, P.R.; Bhatta, R. Metabolic adaptation of livestock in heat stress challenges. In National Initiative on Climate Resilient Agriculture Workshop Compendium on "Livestock and Climate Change"; Hemanth, G.K., Sejian, V., Giridhar, K., Naveen, K.G.S., Eds.; Veterinary College, Karnataka Veterinary Animal and Fishery Sciences University: Hassan, Karnataka, India; National Initiatives on Climate Resilient Agriculture, Indian Council of Agriculture Research and Hyderabad: India, 2018; pp. 33-36.

46. Chaidanya, K.; Soren, N.M.; Sejian, V.; Bagath, M.; Kurien, E.K.; Varma, G.; Bhatta, R. Impact of heat stress, nutritional stress and combined (heat and Nutritional) stresses on rumen enzymes and fermentation metabolites in Osmanabadi bucks. In Proceedings of the Interenational Conference Compendium on Climate Change Adaptation and Biodiversity: Ecological Sustainability and Resource Management for Livelihood Security, Portblair, Andaman and Nicobar Island, 8-10 December 2016; Andaman Science Association at ICAR-Central Island Agricultural Research Institute: Portblair, Andaman and Nicobar Island.

47. Baumgard, L.H.; Rhoads, R.P.; Rhoads, M.L.; Gabler, N.K.; Ross, J.W.; Keating, A.F.; Boddicker, R.L.; Lenka, S.; Sejian, V. Impact of climate change on livestock production. In Environmental Stress and Amelioration in Livestock Production; Sejian, V., Naqvi, S.M.K., Ezeji, T., Lakritz, J., Lal, R., Eds.; Springer-Verlag GMbH Publisher: Germany, 2012; pp. 413-468.

48. Beauchemin, K.A.; Kreuzer, M.; O'mara, F.; McAllister, T.A. Nutritional management for enteric methane abatement: A review. Aust. J. Exp. Agric. 2008, 48, 21-27. [CrossRef]

49. Sejian, V.; Lal, R.; Lakritz, J.; Ezeji, T. Measurement and prediction of enteric methane emission. Int. J. Biometeorol. 2011, 55, 1-6. [CrossRef]

50. Ibáñez, C.; López, M.C.; Criscioni, P.; Fernández, C. Effect of replacing dietary corn with beet pulp on energy partitioning, substrate oxidation and methane production in lactating dairy goats. Anim. Prod. Sci. 2015, 55, 56-63. [CrossRef]

51. Lascano, C.E.; Carulla, J.E.; Vargas, J.J. Strategies for reducing methane emissions from ruminants. Rev. Bras. Geogr. Fís. 2011, 6, 1315-1335. 
52. Knapp, J.R.; Laur, G.L.; Vadas, P.A.; Weiss, W.P.; Tricarico, J.M. Invited review: Enteric methane in dairy cattle production: Quantifying the opportunities and impact of reducing emissions. J. Dairy Sci. 2014, 97, 3231-3261. [CrossRef] [PubMed]

53. McGinn, S.M.; Beauchemin, K.A.; Coates, T.; Colombatto, D. Methane emissions from beef cattle: Effects of monensin, sunflower oil, enzymes, yeast, and fumaric acid. J. Anim. Sci. 2004, 82, 3346-3356. [CrossRef] [PubMed]

54. Abubakr, A.R.; Alimon, A.R.; Yaakub, H.; Abdullah, N.; Ivan, M. Digestibility, rumen protozoa, and ruminal fermentation in goats receiving dietary palm oil by-products. J. Saudi Soc. Agric. Sci. 2013, 12, 147-154. [CrossRef]

55. Zhou, X.; Meile, L.; Kreuzer, M.; Zeitz, J.O. The effect of saturated fatty acids on methanogenesis and cell viability of Methanobrevibacter ruminantium. Archaea 2013, 2013, 106916. [CrossRef] [PubMed]

56. Kong, Y.; He, M.; McAlister, T.; Seviour, R.; Forster, R. Quantitative fluorescence in situ hybridization of microbial communities in the rumens of cattle fed different diets. Appl. Environ. Microbiol. 2010, 76, 6933-6938. [CrossRef] [PubMed]

57. Kataria, R.P. Use of feed additives for reducing greenhouse gas emissions from dairy farms. Microbiol. Res. 2016, 6, 19-25. [CrossRef]

58. Wallace, R.J.; Wood, T.A.; Rowe, A.; Price, J.; Yanez, D.R.; Williams, S.P.; Newbold, C.J. Encapsulated fumaric acid as a means of decreasing ruminal methane emissions. Int. Congr. Ser. 2006, 1293, 148-151. [CrossRef]

59. Li, X.Z.; Yan, C.G.; Long, R.J.; Jin, G.L.; Khuu, J.S.; Ji, B.J.; Choi, S.H.; Lee, H.G.; Song, M.K. Conjugated linoleic acid in rumen fluid and milk fat, and methane emission of lactating goats fed a soybean oil-based diet supplemented with sodium bicarbonate and monensin. Asian-Aust. J. Anim. Sci. 2009, 22, 1521-1530. [CrossRef]

60. Seo, J.K.; Kim, S.W.; Kim, M.H.; Upadhaya, S.D.; Kam, D.K.; Ha, J.K. Direct-fed microbials for ruminant animals. Asian-Australas. J. Anim. Sci. 2010, 23, 1657-1667. [CrossRef]

61. Wang, L.Z.; Zhou, M.L.; Wang, J.W.; Wu, D.; Yan, T. The effect of dietary replacement of ordinary rice with red yeast rice on nutrient utilization, enteric methane emission and rumen archaeal diversity in goats. PLoS ONE 2016, 11, e0160198. [CrossRef]

62. Martínez-Fernández, G.; Abecia, L.; Martín-García, A.I.; Ramos-Morales, E.; Hervás, G.; Molina-Alcaide, E.; Yáñez-Ruiz, D.R. In vitro-in vivo study on the effects of plant compounds on rumen fermentation, microbial abundances and methane emissions in goats. Animal 2013, 7, 1925-1934. [CrossRef] [PubMed]

63. Martínez-Fernández, G.; Abecia, L.; Martín-García, A.I.; Ramos-Morales, E.; Denman, S.E.; Newbold, C.J.; Molina-Alcaide, E.; Yáñez-Ruiz, D.R. Response of the rumen archaeal and bacterial populations to anti-methanogenic organosulphur compounds in continuous-culture fermenters. FEMS Microbiol. Ecol. 2015, 91. [CrossRef] [PubMed]

64. Mitsumori, M.; Shinkai, T.; Takenaka, A.; Enishi, O.; Higuchi, K.; Kobayashi, Y.; Nonaka, I.; Asanuma, N.; Denman, S.E.; McSweeney, C.S. Responses in digestion, rumen fermentation and microbial populations to inhibition of methane formation by a halogenated methane analogue. Br. J. Nutr. 2012, 108, 482-491. [CrossRef] [PubMed]

65. Candyrine, S.C.; Mahadzir, M.F.; Garba, S.; Jahromi, M.F.; Ebrahimi, M.; Goh, Y.M.; Samsudin, A.A.; Sazili, A.Q.; Chen, W.L.; Ganesh, S.; et al. Effects of naturally-produced lovastatin on feed digestibility, rumen fermentation, microbiota and methane emissions in goats over a 12-week treatment period. PLoS ONE 2018, 13, e0199840. [CrossRef] [PubMed]

66. Azlan, P.M.; Jahromi, M.F.; Ariff, M.O.; Ebrahimi, M.; Candyrine, S.C.; Liang, J.B. Aspergillus terreus treated rice straw suppresses methane production and enhances feed digestibility in goats. Trop. Anim. Health Prod. 2018, 50, 565-571. [CrossRef] [PubMed]

67. Soren, N.M.; Tripathi, M.K.; Bhatt, R.S.; Karim, S.A. Effect of yeast supplementation on the growth performance of Malpura lambs. Trop. Anim. Health Prod. 2013, 45, 547-554. [CrossRef] [PubMed]

68. Jeyanathan, J.; Martin, C.; Morgavi, D.P. The use of direct-fed microbials for mitigation of ruminant methane emissions: A review. Animal 2014, 8, 250-261. [CrossRef] [PubMed]

69. Chaucheyras-Durand, F.; Walker, N.D.; Bach, A. Effects of active dry yeasts on the rumen microbial ecosystem: Past, present and future. Anim. Feed Sci. Technol. 2008, 145, 5-26. [CrossRef]

70. McAllister, T.A.; Newbold, C.J. Redirecting rumen fermentation to reduce methanogenesis. Aust. J. Exp. Agric. 2008, 48, 7-13. [CrossRef] 
71. Li, Z.; Liu, N.; Cao, Y.; Jin, C.; Li, F.; Cai, C.; Yao, J. Effects of fumaric acid supplementation on methane production and rumen fermentation in goats fed diets varying in forage and concentrate particle size. J. Anim. Sci. Biotechnol. 2018, 9, 21. [CrossRef] [PubMed]

72. Puchala, R.; Min, B.R.; Goetsch, A.L.; Sahlu, T. The effect of a condensed tannin-containing forage on methane emission by goats. J. Anim. Sci. 2005, 83, 182-186. [CrossRef] [PubMed]

73. Jayanegara, A.; Leiber, F.; Kreuzer, M. Meta-analysis of the relationship between dietary tannin level and methane formation in ruminants from in vivo and in vitro experiments. J. Anim. Physiol. Anim. Nutr. 2012, 96, 365-375. [CrossRef] [PubMed]

74. Wina, E.; Muetzel, S.; Hoffmann, E.; Makkar, H.P.; Becker, K. Saponins containing methanol extract of Sapindus rarak affect microbial fermentation, microbial activity and microbial community structure in vitro. Anim. Feed Sci. Technol. 2005, 121, 159-174. [CrossRef]

75. Mao, H.L.; Wang, J.K.; Zhou, Y.Y.; Liu, J.X. Effects of addition of tea saponins and soybean oil on methane production, fermentation and microbial population in the rumen of growing lambs. Livest. Sci. 2010, 129, 56-62. [CrossRef]

76. Dong, G.Z.; Wang, X.J.; Liu, Z.B.; Wang, F. Effects of phytogenic products on in vitro rumen fermentation and methane emission in goats. J. Anim. Feed Sci. 2010, 19, 218-229. [CrossRef]

77. Denman, S.E.; Martinez-Fernandez, G.; Shinkai, T.; Mitsumori, M.; McSweeney, C.S. Metagenomic analysis of the rumen microbial community following inhibition of methane formation by a halogenated methane analog. Front. Microbiol. 2015, 6, 1087. [CrossRef] [PubMed]

78. Naqvi, S.M.; Sejian, V. Global climate change: Role of livestock. Asian J. Agric. Sci. 2011, 3, $19-25$.

79. Eckard, R.J.; Grainger, C.; De Klein, C.A. Options for the abatement of methane and nitrous oxide from ruminant production: A review. Livest. Sci. 2010, 130, 47-56. [CrossRef]

80. Hegarty, R.S.; McEwan, J.C. Genetic opportunities to reduce enteric methane emissions from ruminant livestock. In Proceedings of the 9th World Congress on Genetics Applied to Livestock Production, Leipzig, Germany, 1-6 August 2010; pp. 1-6.

81. Tarawali, S.; Herrero, M.; Descheemaeker, K.; Grings, E.; Blümmel, M. Pathways for sustainable development of mixed crop livestock systems: Taking a livestock and pro-poor approach. Livest. Sci. 2011, 139, 11-21. [CrossRef]

82. Sejian, V.; Lakritz, J.; Ezeji, T.; Lal, R. Forage and Flax seed impact on enteric methane emission in dairy cows. Res. J. Vet. Sci. 2011, 4, 1-8. [CrossRef]

83. Boadi, D.A.; Wittenberg, K.M. Methane production from dairy and beef heifers fed forages differing in nutrient density using the sulphur hexafluoride (SF6) tracer gas technique. Can. J. Anim. Sci. 2002, 82, 201-206. [CrossRef]

84. Pinares-Patiño, C.S.; Baumont, R.; Martin, C. Methane emissions by Charolais cows grazing a monospecific pasture of timothy at four stages of maturity. Can. J. Anim. Sci. 2003, 83, 769-777. [CrossRef]

85. Waghorn, G.C.; Hegarty, R.S. Lowering ruminant methane emissions through improved feed conversion efficiency. Anim. Feed Sci. Technol. 2011, 166, 291-301. [CrossRef]

86. Lascano, C.E.; Cárdenas, E. Alternatives for methane emission mitigation in livestock systems. R. Bras. Zootec. 2010, 39, 175-182. [CrossRef]

87. Ellis, J.L.; Dijkstra, J.; France, J.; Parsons, A.J.; Edwards, G.R.; Rasmussen, S.; Kebreab, E.; Bannink, A. Effect of high-sugar grasses on methane emissions simulated using a dynamic model. J. Dairy Sci. 2012, 95, 272-285. [CrossRef] [PubMed]

88. De Ramus, H.A.; Clement, T.C.; Giampola, D.D.; Dickison, P.C. Methane emissions of beef cattle on forages. J. Environ. Qual. 2003, 32, 269-277. [CrossRef]

89. Archimède, H.; Eugène, M.; Magdeleine, C.M.; Boval, M.; Martin, C.; Morgavi, D.P.; Lecomte, P.; Doreau, M. Comparison of methane production between C3 and C4 grasses and legumes. Anim. Feed Sci. Technol. 2011, 166, 59-64. [CrossRef]

90. Gerber, P.J.; Hristov, A.N.; Henderson, B.; Makkar, H.; Oh, J.; Lee, C.; Meinen, R.; Montes, F.; Ott, T.; Firkins, J.; et al. Technical options for the mitigation of direct methane and nitrous oxide emissions from livestock: A review. Animal 2013, 7, 220-234. [CrossRef]

91. Hristov, A.N.; Oh, J.; Firkins, J.L.; Dijkstra, J.; Kebreab, E.; Waghorn, G.; Makkar, H.P.; Adesogan, A.T.; Yang, W.; Lee, C.; et al. Special topics-Mitigation of methane and nitrous oxide emissions from animal operations: I. A review of enteric methane mitigation options 1. J. Anim. Sci. 2013, 91, 5045-5069. [CrossRef] 
92. Pinares-Patiño, C.S.; Hickey, S.M.; Young, E.A.; Dodds, K.G.; MacLean, S.; Molano, G.; Sandoval, E.; Kjestrup, H.; Harland, R.; Hunt, C.; et al. Heritability estimates of methane emissions from sheep. Animal 2013, 7, 316-321. [CrossRef]

93. Sudmeyer, R. Carbon Farming: Selective Breeding of Sheep for Reduced Methane Emissions, Climate Change, Agriculture and Food, Department of Primary Industries and Regional Development, Government of Western Australia. 2018. Available online: https://www.agric.wa.gov.au/climate-change/carbonfarming-selective-breeding-sheep-reduced-methane-emissions (accessed on 15 October 2018).

94. Wright, A.D.; Kennedy, P.; O’Neill, C.J.; Toovey, A.F.; Popovski, S.; Rea, S.M.; Pimm, C.L.; Klein, L. Reducing methane emissions in sheep by immunization against rumen methanogens. Vaccine 2004, 22, 3976-3985. [CrossRef]

95. Williams, Y.J.; Popovski, S.; Rea, S.M.; Skillman, L.C.; Toovey, A.F.; Northwood, K.S.; Wright, A.D. A vaccine against rumen methanogens can alter the composition of archaeal populations. Appl. Environ. Microbiol. 2009, 75, 1860-1866. [CrossRef]

96. Cook, S.R.; Maiti, P.K.; Chaves, A.V.; Benchaar, C.; Beauchemin, K.A.; McAllister, T.A. Avian (IgY) anti-methanogen antibodies for reducing ruminal methane production: In vitro assessment of their effects. Aust. J. Exp. Agric. 2008, 48, 260-264. [CrossRef]

97. Zhang, L.; Huang, X.; Xue, B.; Peng, Q.; Wang, Z.; Yan, T.; Wang, L. Immunization against rumen methanogenesis by vaccination with a new recombinant protein. PLoS ONE 2015, 10, e0140086. [CrossRef]

98. Patra, A.; Park, T.; Kim, M.; Yu, Z. Rumen methanogens and mitigation of methane emission by anti-methanogenic compounds and substances. J. Anim. Sci. Biotechnol. 2017, 8, 13. [CrossRef]

99. Lee, S.S.; Hsu, J.T.; Mantovani, H.C.; Russell, J.B. The effect of bovicin hc5, a bacteriocin from Streptococcus bovis hc5, on ruminal methane production in vitro. FEMS Microbiol. Lett. 2002, 217, 51-55. [CrossRef]

100. Santoso, B.; Mwenya, B.; Sar, C.; Gamo, Y.; Kobayashi, T.; Morikawa, R.; Kimura, K.; Mizukoshi, H.; Takahashi, J. Effects of supplementing galacto-oligosaccharides, Yucca schidigera or nisin on rumen methanogenesis, nitrogen and energy metabolism in sheep. Livest. Prod. Sci. 2004, 91, 209-217. [CrossRef]

101. Ackermann, H.W. 5500 Phages examined in the electron microscope. Arch. Virol. 2007, 152, $227-243$. [CrossRef]

102. Moss, A.R.; Jouany, J.P.; Newbold, J. Methane production by ruminants: Its contribution to global warming. Ann. Zootech. 2000, 49, 231-253. [CrossRef]

103. Boadi, D.; Benchaar, C.; Chiquette, J.; Massé, D. Mitigation strategies to reduce enteric methane emissions from dairy cows: Update review. Can. J. Anim. Sci. 2004, 84, 319-335. [CrossRef]

104. Valdez, C.; Newbold, C.J.; Hillman, K.; Wallace, R.J. Evidence for methane oxidation in rumen fluid in vitro. Ann. Zootech. 1996, 45, 351. [CrossRef]

(C) 2018 by the authors. Licensee MDPI, Basel, Switzerland. This article is an open access article distributed under the terms and conditions of the Creative Commons Attribution (CC BY) license (http:/ / creativecommons.org/licenses/by/4.0/). 
Article

\title{
Effect of Dietary Supplementation of Moringa Oleifera on the Production Performance and Fecal Methanogenic Community of Lactating Dairy Cows
}

\author{
Lifeng Dong, Tingting Zhang and Qiyu Diao* \\ Beijing Key Laboratory for Dairy Cow Nutrition, Sino-US Joint Lab on Nutrition and Metabolism of Ruminants, \\ Feed Research Institute, Chinese Academy of Agricultural Sciences, Key Laboratory of Feed Biotechnology of \\ the Ministry of Agriculture, Beijing 100081, China; donglifeng@caas.cn (L.D.); tingting5_2_0@163.com (T.Z.) \\ * Correspondence: diaoqiyu@caas.cn; Tel.: +86-010-82106055
}

Received: 25 February 2019; Accepted: 20 May 2019; Published: 22 May 2019

Simple Summary: High-quality forages such as protein-rich ingredients are essential to maximize production performance in dairy production. However, enteric methane produced by methanogenesis represents a substantial waste of feed energy for ruminants. Thus, it is important to evaluate the environmental effect when such feed ingredients are used to provide necessary nutrients. The aim of the present study was to examine the effects of dietary supplementation of Moringa oleifera on the production performance and fecal methanogenic community in lactating cows. The study's main results suggest that inclusion of Moringa oleifera improved milk fat content and changed the composition and diversity of methanogens. This study indicates that secondary metabolites from Moringa oleifera may regulate fermentation conditions and associations between some methanogens and other microbes. These findings provide basic information on the utilization of alternative forage resources for dairy cows and can help to better understand the regulation of microbial metabolic function and methane emissions.

\begin{abstract}
Development of alternative forage resources is of great importance to provide necessary nutrients and minimize greenhouse gas emissions in ruminant production. The aim of this study was to examine the effects of dietary supplementation of Moringa oleifera on the production performance and fecal methanogenic community in dairy cows using methyl-coenzyme M reductase $\alpha$-subunit gene. Sixty-four cows were allocated to one of four treatments: basal diet without $M$. oleifera (control) or low $(3 \% w / w, \mathrm{M} 3)$, medium $(6 \%, \mathrm{M} 6)$, or high $(9 \%, \mathrm{M} 9)$ supplementation with M. oleifera. This study demonstrated that different supplementation levels of Moringa oleifera in the diet achieved similar feed intake and milk production, but adding $6 \%$ of Moringa oleifera improved milk fat content. Two families, two phyla, three genera, and three species in total were identified among the four treatments. The fecal archaeal community in the control treatment was predominated by Methanobrevibacter (39.1\% of the total sequence reads) followed by Methanosphaera and Methanocorpusculum at the genus level. The increased abundance of the Methanosphaera genus and Methanosphaera sp. ISO3-F5 species was induced by secondary metabolites of Moringa oleifera in the diet. Results indicated that Moringa oleifera supplementation not only improved dairy product quality but could also potentially reduce methane emissions.
\end{abstract}

Keywords: Moringa oleifera; fecal methanogenic community; dairy cows; $m c r$ A gene sequencing technique

\section{Introduction}

Forage source and nutrient composition hold significant importance for dairy production systems due to the constant cost of commercial concentrates. This cost is a serious constraint for smallholder 
farms when the dietary protein sources are restricted or the cost is unaffordable. In the past few decades, many efforts have been made to explore less-expensive ingredients such as agricultural by-products, tree foliage, and plant leaves to supply adequate nutrients [1].

As an indigenous native tree in the Himalayas, Moringa oleifera (M. oleifera) is a perennial leafy tree that produces a high biomass in a short period and is widely distributed in tropical and subtropical areas around the world [2]. Recently, it has been increasingly considered as an alternative ingredient for animal feed because of its high content of protein, vitamins, and minerals. The average crude protein (CP) contents of M. oleifera range from 180 to $270 \mathrm{~g} \mathrm{CP} / \mathrm{kg} \mathrm{DM}$, similar to that of sesame meal (260 g CP/kg DM) [1]. In addition, saponins, tannins, and polysaccharides in M. oleifera demonstrate beneficial anti-inflammatory, antioxidant, and antimicrobial activities and can increase milk yield when dairy cows are offered dried or fresh leaves and soft twigs [3,4]. A recent study [5] found that alfalfa hay and maize silage can be partially replaced by M. oleifera silage without negative effects on nutrient digestibility and milk yield. This enhanced production performance was due to the considerable amounts of secondary metabolites in M. oleifera, which were also used as a potential feed additive to reduce greenhouse gas (GHG) emission of ruminants.

Methane $\left(\mathrm{CH}_{4}\right)$ emission from ruminants is a major contributor to atmospheric $\mathrm{CH}_{4}$ accumulation. Reduction of ruminal $\mathrm{CH}_{4}$ emissions would thus improve energy utilization efficiency and alleviate environmental issues within the dairy industry. For example, ruminal $\mathrm{CH}_{4}$ emissions were significantly decreased when M. oleifera leaves were used in an in vitro experiment [6]. Similarly, supplementation of pomegranate pulp in the diet decreased enteric $\mathrm{CH}_{4}$ emissions in dairy cows [7]. These reductions in $\mathrm{CH}_{4}$ emissions were attributed to the direct reduction of ruminal methanogenesis by active polyphenolic compounds either in M. oleifera leaves or pomegranate pulp. However, the variation and responses of fecal methanogenic community to M. oleifera supplementation in the diet of dairy cows have not been elucidated.

Archaeal methanogens are obligate anaerobes that use methanogenesis pathways to facilitate fiber digestion by converting hydrogen into $\mathrm{CH}_{4}$. Daquiado et al. [8] found the predominant species in rumen fluid and manure was Methanobrevibacter ruminantium (63.6\% and $62.4 \%$, respectively), whereas Methanocorpusculum labreanum was most abundant in rectal dung for beef cattle (53.2\%). In addition, the community structures of fecal microbiota reflect not only animal productivity but also health and food safety. Jin et al. [9] found that dietary supplementation of active dried yeast significantly increased the relative abundance of Methanocorpuschulum and Thermoplasma species but decreased Methanobrevibacter in the feces. Mohammadzadeh et al. [10] observed a decrease in the fecal methanogenic archaea abundance in goats when the diet changed from alfalfa hay to a combination of alfalfa hay and oats. Determining the fecal methanogen composition would help us understand the effect of dietary supplementation on methanogenesis and $\mathrm{CH}_{4}$ emissions. Therefore, the objective of the present study was to determine the effect of dietary supplementation of $M$. oleifera on the production performance and on the population and diversity of the fecal methanogenic community in lactating Holsteins dairy cows.

\section{Materials and Methods}

This study was conducted at the Guoxiu dairy farm located in Boading, China (latitude: $38^{\circ} 45^{\prime} 54^{\prime \prime}$ and longitude: $115^{\circ} 08^{\prime} 06^{\prime \prime}$ ) in 2017. The experiment design and animal care and handling procedures were evaluated and approved by the Animal Ethics Committee of the Chinese Academy of Agricultural Sciences (protocol number 023-2017) prior to the commencement of the experiment.

\subsection{Animals and Experimental Design}

Sixty-four multiparous lactating Holstein dairy cows (120 \pm 8.0 days in milk; $31.9 \pm 1.20 \mathrm{~kg} /$ day of milk yield at the beginning of the trial) were used in this experiment. Animals were randomly assigned to one of four treatments: (1) control, basal diet without $M$. oleifera; (2) a low supplementation of M. oleifera (3\% w/w; M3); (3) medium supplementation of M. oleifera (6\% w/w; M6); (4) high 
supplementation of $M$. oleifera ( $9 \% w / w ; \mathrm{M} 9)$. The basal diet was formulated to be isoenergetic and isonitrogenous to meet the nutrient requirements of lactating dairy cows (NY/T 34-2004, Table 1). The treatments were balanced for milk yield, body weight, and lactation period. Rachises and twigs of M. oleifera at 56 days of age were harvested in Guangdong, China $\left(23^{\circ} 8^{\prime} \mathrm{N}, 113^{\circ} 17^{\prime} \mathrm{E}\right)$; these materials were then chopped and dried on plastic sheets for 3 days for further preparation of a total mixed ration (TMR) diet. The CP, neutral detergent fiber (NDF) and acid detergent fiber (ADF) content of M. oleifera were 71.5, 743 and $552 \mathrm{~g} / \mathrm{kg}$ DM, respectively, while the ether extract (EE) and ash content was 48.6 and $78.3552 \mathrm{~g} / \mathrm{kg}$ DM, respectively. The TMR diet was offered ad libitum in amounts resulting in 5\% refusals. The whole experiment (77 days) consisted of 14 days for adaptation to the diet and 63 days for feeding period, with fecal samples collected in the last 5 days of the feeding period. Animals were fed with TMR at 07:00 and 19:00 and milked twice at 06:00 and 16:00 on a daily basis. Cows were housed in individual tie-stalls in a barn with good ventilation and had continuous access to water throughout the experiment. Artificial light was provided by suspended bulbs, and the floor was cleaned twice daily for good hygiene.

Table 1. Ingredients and nutrient composition of the experimental diets.

\begin{tabular}{lcccc}
\hline \multirow{2}{*}{ Items } & \multicolumn{4}{c}{ Dietary Moringa Oleifera Content } \\
\cline { 2 - 5 } & $\mathbf{0}$ & $\mathbf{3 \%}$ & $\mathbf{6 \%}$ & $\mathbf{9 \%}$ \\
\hline Ingredients, \% of DM & & & & \\
\hline Ground corn & 21.2 & 21.7 & 22.1 & 22.7 \\
Soybean meal & 10.5 & 11.6 & 12.7 & 13.8 \\
DDGS & 8.4 & 8.4 & 8.4 & 8.4 \\
Cottonseed meal & 7.5 & 7.5 & 7.5 & 7.5 \\
Palm fat & 7.5 & 7.5 & 7.5 & 7.5 \\
Beet pulp & 4.7 & 4.7 & 4.7 & 4.7 \\
Alfalfa hay & 20.5 & 17.1 & 13.7 & 10.2 \\
Corn silage & 16.8 & 15.7 & 14.5 & 13.4 \\
Moringa oleifera & 0.0 & 3.0 & 6.0 & 9.0 \\
Premix ${ }^{1}$ & 2.0 & 2.0 & 2.0 & 2.0 \\
Sodium hydrogen carbonate & 0.6 & 0.6 & 0.6 & 0.6 \\
Calcium hydrogen phosphate & 0.2 & 0.2 & 0.2 & 0.2 \\
Sodium chloride & 0.3 & 0.3 & 0.3 & 0.3 \\
\hline Nutrient composition ${ }^{2}$ & & & & \\
\hline CP & 178.70 & 179.00 & 179.30 & 179.60 \\
EE & 44.80 & 46.90 & 48.80 & 50.90 \\
Ash & 76.80 & 84.60 & 73.50 & 79.20 \\
NDF & 437.00 & 434.30 & 431.70 & 428.60 \\
ADF & 211.30 & 214.30 & 217.20 & 219.30 \\
NE ${ }_{\text {, MJ/kg }}^{6.60}$ & 6.61 & 6.62 & 6.63 \\
\hline
\end{tabular}

${ }^{1}$ One kilogram of premix contained the following: 100,000 IU VA; 40,000 IU VD; 1000 IU VE; $330 \mathrm{mg}$ Fe; $250 \mathrm{mg} \mathrm{Cu}$; $400 \mathrm{mg} \mathrm{Mn} ; 500 \mathrm{mg} \mathrm{Zn;} 10 \mathrm{mg} \mathrm{Se} ; 10 \mathrm{mg} \mathrm{I} ; 5 \mathrm{mg} \mathrm{Co} ;{ }^{2}$ All values were measured from the monthly total mixed ration (TMR) samples, while $\mathrm{NE}_{\mathrm{L}}$ (net energy for lactation) was calculated based on Ministry of Agriculture (MOA) of P.R. China individual feedstuffs recommendations based on chemical composition (MOA, 2004).

\subsection{Sample Collection and Measurements}

Samples of M. oleifera, TMR, and refusals were collected daily. All samples were composited and analyzed for DM (65 ${ }^{\circ} \mathrm{C}$ in a forced-air oven to a constant weight), CP (method 990.03; AOAC International, 2016), ADF and NDF (Ankom200 Fiber Analyzer, Ankom Technology, Macedon, NY, USA). Ash and EE concentration was determined with method 942.05 (AOAC International, 2016) [11]. Milk samples were recorded in the last 5 days of the feeding period and treated with 2-bromo-2-nitropropane-1-2-diol for determination of milk protein, fat, lactose, and total solids. 
Energy-corrected milk yield (ECM), standardized to $4.0 \%$ fat and 3.3\% protein, was calculated using the equation below:

$$
\operatorname{ECM}(\mathrm{kg} / \mathrm{cow} \text { per day })=\text { mikl yield }(\mathrm{kg} / \mathrm{d}) \times \frac{376 \times \text { fat } \%+209 \times \text { protein } \%+948}{3138} \text {. }
$$

Rectal fecal samples (200 g per sampling) were collected four times a day (08:00, 12:00, 16:00, and 20:00) and bulked per animal according to institutional animal care guidelines. Fecal samples were stored at $-20{ }^{\circ} \mathrm{C}$ for later DNA extraction, high-throughput sequencing, and bioinformatics analysis.

\subsection{DNA Extraction and High-Throughput Sequencing using McrA Gene}

Fecal samples were freeze-dried, and total DNA was extracted from $200 \mathrm{mg}$ samples with a QIAamp Fast DNA Stool Mini Kit (QIAGEN, CA, USA) according to the manufacturer's instructions. DNA extracts were dissolved in $200 \mu \mathrm{L}$ elution buffer and the quality and quantity of the extracted DNA were determined using a NanoDrop ND-1000 Spectrophotometer (Nyxor Biotech, Paris, France). The PCR primers used to amplify the mcrA fragments were from those of Luton et al. [12]: 5'-GGTGGTGTMGGATTCACACARTAYGCWACAGC-3' (forward) and 5'-TTCATTGCRTAGTTWGGRTAGTT-3' (reverse). The PCR was performed using the TaKaRa rTaq DNA Polymerase system and $2 \mu \mathrm{L}$ of $10 \times$ buffer, $2 \mu \mathrm{L}$ of deoxynucleotide triphosphate (dNTPs) mixture $(2.5 \mathrm{mmol} / \mathrm{L}), 0.2 \mu \mathrm{L}$ of rTaq polymerase, and $0.8 \mu \mathrm{L}$ of each primer (forward and reverse). This reaction mixture $(25 \mu \mathrm{L})$ used the following program: $95^{\circ} \mathrm{C}$ for $3 \mathrm{~min}$, followed by 30 cycles of $95^{\circ} \mathrm{C}$ for $30 \mathrm{~s}, 55^{\circ} \mathrm{C}$ for $30 \mathrm{~s}$, and $72{ }^{\circ} \mathrm{C}$ for $45 \mathrm{~s}$, and a final extension of $72{ }^{\circ} \mathrm{C}$ for $10 \mathrm{~min}$. PCR products were electrophoresed in 1\% agarose in Tris-acetate-EDTA buffer and visualized with ethidium bromide staining. Amplicons were extracted from 1\% agarose gels and purified using the AxyPrep DNA Gel Extraction Kit (Axygen Biosciences, CA, USA) according to the manufacturer's instructions and quantified using QuantiFluor-ST (Promega, Madison, WI, USA). Purified amplicons were then paired-end sequenced $(2 \times 300)$ on an Illumina MiSeq platform according to standard protocols.

\subsection{Bioinformatics Analysis of the Sequence Data}

In the present study, raw FASTQ files were demultiplexed and quality-filtered with the following criteria: (i) The 300-bp reads were truncated at any site that had an average quality score $<20$ over a 50-bp sliding window, and truncated reads < 50 bp were discarded; (ii) exact barcode matching was required, and any 2-nucleotide mismatch in primer matching and reads containing ambiguous characters were removed; and (iii) only sequences that overlapped by more than 10 bp were assembled according to their overlap sequences. The length of over $89 \%$ of the total valid sequence was between 421 and $440 \mathrm{bp}$, while around 10\% of sequences were ranged between 441 and $460 \mathrm{bp}$. Operational taxonomic units (OTUs) were clustered with 97\% similarity cutoff using Uparse algorithm (version 7.1, http://drive5.com/uparse/), and chimeric sequences were identified and removed using UCHIME. The taxonomy of each mcrA gene sequence was analyzed by the RDP Classifier against the FunGene Database using a confidence threshold of 70\% [13]. Good's coverage and rarefaction curves were determined to estimate the coverage and sampling effort. QIIME (version 1.17) was also used to calculate the archaeal population diversity (Simpson's diversity index), evenness (Shannon's diversity index), and richness (Chao1 and Ace index). Venn diagram was constructed according to Oliveros [14] to show the shared and unique OTUs among samples. Heatmap analysis and identification of significant features were also used to determine changes among samples. The data obtained in the present study have been submitted to NCBI (submission ID: SUB 3898364, BioProject ID: PRJNA449795). 


\subsection{Statistical Analyses}

Data were analyzed using SPSS software (version 22.0 for Windows, SPSS Inc., Chicago, IL, USA). Dietary DM intake, milk yield, ECM and milk composition were analyzed the using one-way ANOVA package. The model used was as follows:

$$
\mathrm{Y}_{i j}=\mu+\mathrm{A}_{i}+\mathrm{T}_{j}+\mathrm{e}_{i j}
$$

where $Y_{i}=$ the observations for the dependent variable, $\mu=$ overall mean, $\mathrm{A}_{i}=$ the random animal effect, $\mathrm{T}_{j}=$ the fixed effect of the $j$ th Moringa oleifera amount (treatment, $j=3,6$, or $9 \% w / w$ ), and $e_{i j}=$ the random residual assumed to be normally distributed with mean zero.

Relative abundance data of fecal methanogenic archaea are presented as percentages/proportions. These data were analyzed using Welch's t-test package, and the model was as follows:

$$
\mathrm{Y}_{i j}=\mu+\mathrm{S}_{i}+\mathrm{T}_{j}+\mathrm{e}_{i j}
$$

where $Y_{i}=$ the observations for the dependent variable, $\mu=$ overall mean, $S_{i}=$ the random effect of sampling, $\mathrm{T}_{j}=$ the fixed effect of treatment $j$, and $e_{i j}=$ the random residual assumed to be normally distributed with mean zero.

Treatment means were considered statistically different at $p<0.05$, and SEM values are presented with $p$ values.

\section{Results}

\subsection{Feed Intake and Milk Yield and Composition}

The DM intake, milk yield, and ECM were similar among the four treatments (Table 2). For the milk composition, fat content $(38.2 \mathrm{~g} / \mathrm{kg})$ was highest in the M6 treatment $(p<0.05)$ compared with the other three treatments. Protein, lactose, and total solid content did not differ significantly among the 4 treatments.

Table 2. Effects of supplementation of Moringa oleifera rachises and twigs on the dry matter intake, milk

\begin{tabular}{|c|c|c|c|c|c|c|}
\hline \multirow{2}{*}{ Item $^{1}$} & \multicolumn{4}{|c|}{ Treatment $^{2}$} & \multirow{2}{*}{ SEM $^{3}$} & \multirow{2}{*}{$p$-Value } \\
\hline & Control & M3 & M6 & M9 & & \\
\hline DM intake, $\mathrm{kg} /$ day & 20.6 & 20.9 & 20.7 & 19.3 & 0.53 & 0.09 \\
\hline Milk yield, kg/day & 29.6 & 29.7 & 31.0 & 28.6 & 0.46 & 0.46 \\
\hline ECM kg/day & 31.7 & 32.2 & 34.5 & 31.4 & 0.57 & 0.69 \\
\hline \multicolumn{7}{|l|}{ Milk composition, $\%$} \\
\hline Fat & $3.54^{b}$ & $3.62^{b}$ & $3.82^{\mathrm{a}}$ & $3.68^{\mathrm{ab}}$ & 0.07 & 0.04 \\
\hline Protein & 3.65 & 3.70 & 3.66 & 3.70 & 0.03 & 0.49 \\
\hline Lactose & 5.10 & 5.08 & 5.08 & 5.05 & 0.03 & 0.14 \\
\hline Total solid & 13.0 & 13.1 & 13.2 & 13.1 & 0.08 & 0.13 \\
\hline
\end{tabular}
yield and composition of Holstein dairy cows.

${ }^{1} \mathrm{DM}=$ dry matter; ${ }^{2} \mathrm{M} 3, \mathrm{M} 6$, and M9 = dietary Moringa oleifera supplementation of $3 \%, 6 \%$, and $9 \%$ w $w$; Means within rows lacking common superscript differ $(p<0.05) ;{ }^{3}$ SEM $=$ standard error of means.

\subsection{Composition and Dynamics of Fecal Methanogen Community}

A total of 450,500 high-quality sequences with an average length of $439.5 \mathrm{bp}$ were obtained. The Good's coverage indices obtained from each treatment were all above 0.999, indicating a high-quality of sampling and sequencing. The richness and diversity indices obtained for fecal samples of cows fed different levels of $M$. oleifera are presented in Table 3. Richness indices after the 4 treatments did not differ significantly, although the control group had relatively higher values of Ace and Chao (21.05 and 20.63). By contrast, Shannon's index was highest for the M9 group $(1.783 ; p<0.05)$ and 
similar among the control, M3, and M6 groups (1.653, 1.438, and 1.628, respectively). The Simpson index was lowest for the M9 group $(p<0.05)$ and did not differ significantly among the control, M3, and M6 groups.

Table 3. Effects of supplementation of Moringa oleifera rachises and twigs on the diversity indices of fecal methanogenic archaea based on mcrA gene sequences of lactating Holstein dairy cows.

\begin{tabular}{cccccccc}
\hline \multirow{2}{*}{ Item $^{1}$} & \multicolumn{5}{c}{ Treatment $^{2}$} & \multirow{2}{*}{ SEM $^{3}$} & \multirow{2}{*}{$\boldsymbol{p}$-Value } \\
\cline { 2 - 5 } & Control & M3 & M6 & M9 & & \\
\hline Ace & 21.05 & 19.78 & 15.30 & 14.35 & 1.788 & 0.510 \\
Chao & 20.63 & 19.25 & 19.75 & 18.25 & 0.569 & 0.561 \\
Shannon & $1.653^{\mathrm{b}}$ & $1.438^{\mathrm{b}}$ & $1.628^{\mathrm{b}}$ & $1.783^{\mathrm{a}}$ & 0.0570 & 0.019 \\
Simpson & $0.310^{\mathrm{a}}$ & $0.393^{\mathrm{a}}$ & $0.328^{\mathrm{a}}$ & $0.265^{\mathrm{b}}$ & 0.0199 & 0.014 \\
\hline
\end{tabular}

${ }^{1}$ Indices of Ace, Chao, Shannon, and Simpson were calculated to measure alpha diversity of the methanogens in the sample; ${ }^{2}$ M3, M6, and M9 = dietary Moringa oleifera supplementation of $3 \%, 6 \%$, and $9 \%$ w $w$; Means within rows lacking common superscript differ $(p<0.05) ;{ }^{3} \mathrm{SEM}=$ standard error of means.

A Venn diagram constructed using the OTUs for the sequences from the fecal samples is presented in Figure 1. Shared and unique OTUs were represented at a $97 \%$ similarity level among the 4 treatments. A total of 51, 50, 48, and 50 OTUs were found for the control, M3, M6, and M9 treatments, respectively, and 38 OTUs were common to all 4 treatments. In pairwise comparisons of treatments, 43 OTUs were shared between the M3 and M6 treatments, 41 between the M6 and M9 treatments, and 41 between the M3 and M9 treatments. Between the control and treatment M3, M6, or M9, respectively, 47, 44, and 44 OTUs were shared. In addition, a heatmap was constructed to determine the relationship between OTUs and experimental treatments based on the log-transformed sequence abundance and is presented based on the species level at the $97 \%$ similarity level (Figure 2). The heatmap showed a change in the abundance of Methanosphaera sp. ISO3-F5, Methanobrevibacter ruminantium, and Methanobrevibacter SM9, indicating that supplementation of $M$. oleifera in the diet resulted in archaeal populations distinct from the control, the same as shown in the abundance analysis.

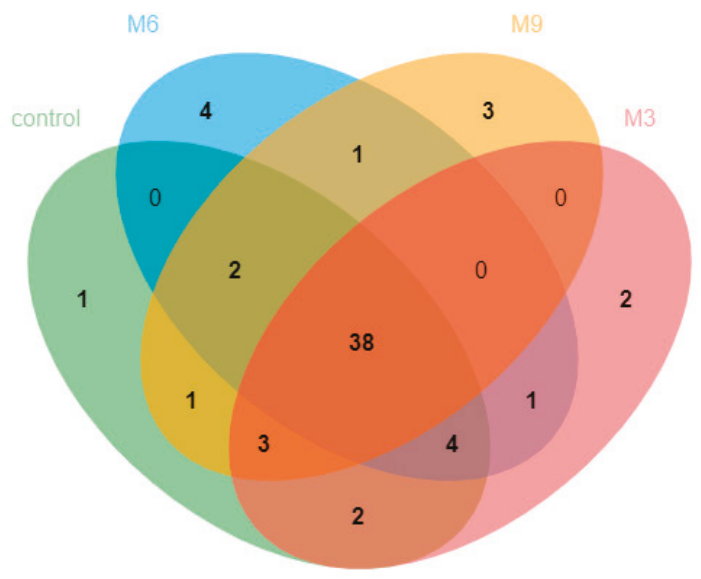

Figure 1. Venn diagram representation of the shared and exclusive Operational taxonomic units (OTUs) at 97\% similarity level of four groups: Control (without Moringa oleifera supplementation), M3 (a low dose of Moringa oleifera supplementation, 3\% w/w), M6 (a medium dose of Moringa oleifera supplementation, $6 \% w / w$ ), M9 (a high dose of Moringa oleifera supplementation, $9 \% w / w$ ) in lactating Holstein dairy cows. 


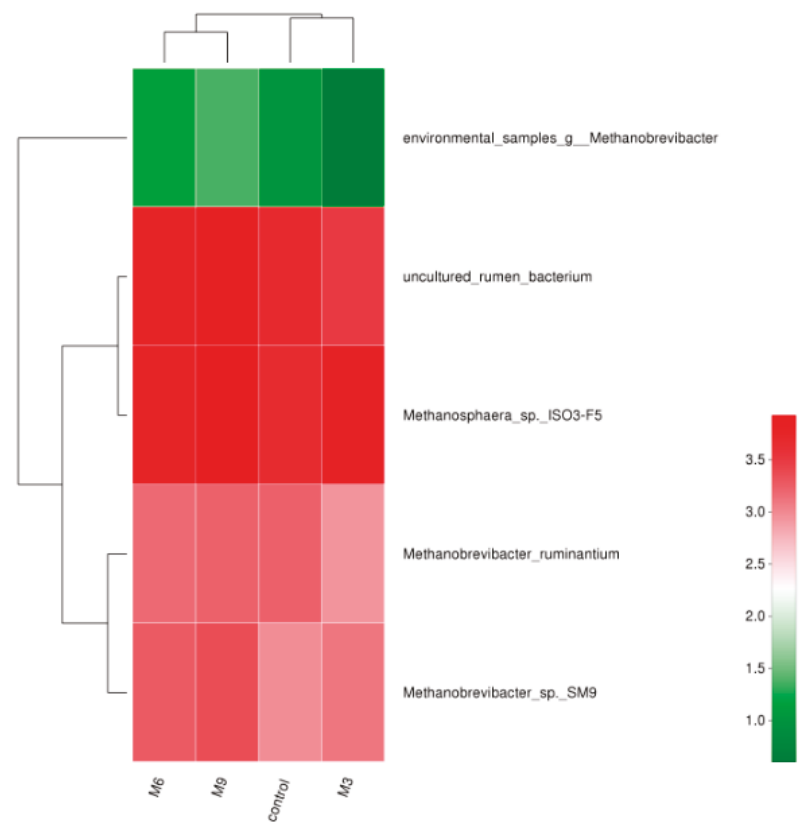

Figure 2. Heatmap under the species level of the four treatments of the lactating Holstein dairy cows fecal sample (control: without Moringa oleifera supplementation; M3: a low dose of Moringa oleifera supplementation, 3\% w/w; M6: a medium dose of Moringa oleifera supplementation, $6 \%$ w/w; M9: a high dose of Moringa oleifera supplementation, $9 \% w / w)$.

The relative abundance of fecal methanogenic archaea in the dairy cows with different supplements of $M$. oleifera based on the mcrA gene sequencing is listed by taxonomic level in Table 4; three phyla, four orders, four families, five genera, and seven species were determined. The predominant archaeal family across the four treatments in the order Methanobacteriales was Methanobacteriaceae, with species Methanosphaera sp. ISO3-F5, Methanobrevibacter sp. SM9, and Methanobrevibacter ruminantium.

Specifically, at the order level, no significant difference was observed among the four treatments in terms of Methanobacteriales and Methanomicrobiales. However, Methanobacteriales was relatively more abundant in the M3 treatment (0.677) when compared with the control (0.582), M6 (0.615), and M9 (0.606) treatments. At the genus level, the Methanocorpusculum was the third most abundant genus with an average value of $15.0 \%, 6.5 \%, 14.2 \%$, and $9.9 \%$ for the control, M3, M6, and M9 treatments, respectively. Similar values were obtained for Methanobrevibacter among the 4 treatments, whereas the abundance of Methanosphaera was significantly higher in the M3 and M9 treatments (0.297 and 0.293 , respectively, $p<0.05$ ). There was no significant difference between the control and M6 group or between M3 and M9 groups. The species abundance of Methanosphaera sp. ISO3-F5 was significantly higher in the M3 and M9 groups (0.297 and 0.291, respectively) than in the control and M6 groups (0.191 and 0.215 , respectively, $p<0.05$ ), but no significant difference was found between the control and M6 groups or between the M3 and M9 groups. The abundance of Methanobrevibacter ruminantium was significantly higher in the control than in the other three groups $(p<0.05)$, but there was no difference among the M3, M6 and M9 group. In addition, values for Methanobrevibacter SM9 were similar across the four groups but accounted for less than $10 \%$ of the total species in each group. 
Table 4. Effects of supplementation of Moringa oleifera rachises and twigs on the relative abundance of

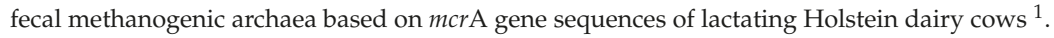

\begin{tabular}{|c|c|c|c|c|c|c|}
\hline \multirow{2}{*}{ Item } & \multicolumn{4}{|c|}{ Treatment } & \multirow{2}{*}{ SEM $^{2}$} & \multirow{2}{*}{$p$-Value } \\
\hline & Control & M3 & M6 & M9 & & \\
\hline \multicolumn{7}{|l|}{ Phylum } \\
\hline Euryarchaeota & 0.734 & 0.743 & 0.757 & 0.705 & 0.022 & 0.883 \\
\hline Uncultured rumen archaea & 0.216 & 0.150 & 0.213 & 0.272 & 0.016 & 0.456 \\
\hline Unclassified & $0.051 \mathrm{ab}$ & $0.108 \mathrm{a}$ & $0.03 \mathrm{ab}$ & $0.023 b$ & 0.015 & 0.172 \\
\hline \multicolumn{7}{|l|}{ Order } \\
\hline Methanobacteriales & 0.582 & 0.677 & 0.615 & 0.606 & 0.023 & 0.561 \\
\hline Methanomicrobiales & 0.150 & 0.065 & 0.142 & 0.099 & 0.026 & 0.676 \\
\hline Uncultured rumen archaea & 0.216 & 0.150 & 0.213 & 0.272 & 0.016 & 0.456 \\
\hline \multicolumn{7}{|l|}{ Family } \\
\hline Methanobacteriaceae & 0.582 & 0.677 & 0.615 & 0.606 & 0.023 & 0.561 \\
\hline Methanocorpusculaceae & 0.150 & 0.065 & 0.142 & 0.099 & 0.026 & 0.676 \\
\hline Uncultured rumen archaea & 0.216 & 0.150 & 0.213 & 0.272 & 0.016 & 0.456 \\
\hline \multicolumn{7}{|l|}{ Genus } \\
\hline Methanobrevibacter & 0.391 & 0.380 & 0.400 & 0.315 & 0.026 & 0.698 \\
\hline Methanosphaera & $0.191 b$ & $0.297 \mathrm{a}$ & $0.215 b$ & $0.291 \mathrm{a}$ & 0.016 & 0.016 \\
\hline Methanocorpusculum & 0.150 & 0.065 & 0.142 & 0.099 & 0.026 & 0.676 \\
\hline Uncultured rumen archaea & 0.216 & 0.150 & 0.213 & 0.272 & 0.016 & 0.456 \\
\hline \multicolumn{7}{|l|}{ Species } \\
\hline Unclassified Methanobrevibacter & 0.274 & 0.279 & 0.281 & 0.172 & 0.031 & 0.569 \\
\hline Methanosphaera sp. ISO3-F5 & $0.191 b$ & $0.297 \mathrm{a}$ & $0.215 b$ & $0.291 \mathrm{a}$ & 0.016 & 0.016 \\
\hline Unclassified Methanocorpusculum & 0.150 & 0.065 & 0.142 & 0.099 & 0.026 & 0.676 \\
\hline Uncultured rumen archaea & 0.216 & 0.150 & 0.213 & 0.272 & 0.026 & 0.456 \\
\hline Methanobrevibacter sp. SM9 & 0.038 & 0.060 & 0.065 & 0.080 & 0.007 & 0.258 \\
\hline Methanobrevibacter ruminantium & $0.078 \mathrm{a}$ & $0.041 b$ & $0.054 b$ & $0.062 b$ & 0.014 & 0.035 \\
\hline Unclassified & 0.051 & 0.108 & 0.030 & 0.023 & 0.015 & 0.172 \\
\hline
\end{tabular}

\section{Discussion}

\subsection{Feed Intake, Milk Yield and Composition}

Application of agricultural by-products in the ruminant production system has been extensively investigated because of their relatively high biomass yield and low cost. In this research, the production, and fecal methanogenic archaea were examined when lactating dairy cows were subjected to different levels of supplementation of $M$. oleifera in the diet. The milk fat content in the M6 treatment was significantly higher than that in the control and M3 treatments, although M6 treatment had relatively higher values of milk yield and ECM. Several consistent results were reported previously that supplementation of $M$. oleifera enhanced milk yield and milk composition. For example, Cohen-Zinder et al. [15] found a significant increase in milk yield, milk fat and protein content in lactating cows offered an M. oleifera diet. Azzaz et al. [3] reported that milk and total solid yield increased by 11.3 and $17.7 \%$ in lactating ewes fed a supplement of $15 \mathrm{~g} / \mathrm{kg}$ DM M. oleifera. This positive effect of M. oleifera on production performance can be attributed to improved feed intake, apparent nutrient digestibility, and ruminal fermentation conditions [4,15]. Moderate concentrations of phenolics and tannins in M. oleifera exhibited antioxidant and antimicrobial properties, which have beneficial effects in productive ruminants [16]. Aerts et al. [17] reported that ruminal methanogenesis would be inhibited by phenolics and tannins, which leading to repartition of consumed energy in $\mathrm{CH}_{4}$ and milk 
production. This was in agreement with the results of Shaani et al. [7] that improved fat yield and ECM production efficiency resulted from inhibition of $\mathrm{CH}_{4}$ production by ruminal methanogenic bacteria.

\subsection{Fecal Methanogenic Composition and Dynamics}

The composition and function of ruminal methanogens have been studied in great detail, whereas less is known in the lower gastrointestinal tract (GIT) of ruminants [18]. Previous research showed relationships between methanogens in feces and those present in the pregastric compartments $[19,20]$. In the present study, the functional $m c r A$ gene sequencing technique was used, and the results revealed the presence of Methanobrevibacter, Methanosphaera, and Methanocorpusculum in the feces of lactating dairy cows. These results were consistent with previous studies that detected two phyla and six genera in the feces of multiparous dairy cows, whereas fecal morA sequences had the closest similarity to Methanocorpusculum, Methanobacterium, and Methanobrevibacter species [9]. Jin et al. [9] found that fecal archaeal community was predominated by Methanobrevibacter ( $86.9 \%$ of the total sequence reads) and Methanocorpusculum (10.4\%). A bTEFAP pyrosequencing study reported the dominant methanogens of Methanobrevibacter, Methanophaera, and Methanobacteriaceae in the hindgut of goats [21]. In addition, Mohammadzadeh et al. [10] suggested that the fermentation characteristics as digesta pass from the rumen into the small intestine and out of the animal would affect methanogen diversity. The sequencing technique may also influence the results, although the $\mathrm{mcr}$ A gene-based approach was thought to be comparable to the 16S rRNA gene for phylogenetic studies.

Different from previous studies, however, the present study demonstrated that Methanobrevibacter sequence made up approximately $35 \%$ of the total. Guzman et al. [22] hardly detected Methanobrevibacter in the feces of calves in the first 3 days after birth. In mature cows, Methanobrevibacter represented $62 \%$ of the rumen archaea, and they were among the most important and dominant archaea in the rumen fluid. A higher percentage was also found in the hindgut of goats with Methanobrevibacter accounting for $74.8 \%$ of the total sequenced reads, while Jin et al. [9] reported that Methanobrevibacter was the dominant phylotype at the genus level accounting for over $86 \%$ of the total sequence reads. These results indicated that the presence and abundance of Methanobrevibacter may be influenced by dietary composition, enteric fermentation, and even environmental factors.

At the genus level, the relative abundance of Methanosphaera and Methanocorpusculum was generally around $20 \%$ and $15 \%$ in the fecal sample of dairy cows, higher than previously reported from the rumen and fecal samples of ruminants [19]. For example, Liu et al. [19] did not detect Methanocorpusculum in the rumen but made up only $2 \%$ of the archaeal community in the feces of sheep. Jin et al. [9] reported a very low content of Methanosphaera in the feces of lactating cows $(0.8 \%)$. The great diversity of the fecal microbiota can be attributed to various factors such as animal breeds, diet sources, and composition.

\subsection{Effect of Moringa Oleifera Supplementation on Fecal Methanogenic Archaea}

A range of studies reported that the fecal microbial relative abundance and composition were affected by types of diet or different dietary supplementations [23-25]. For example, the fecal microbial community structure was significantly changed as cattle were fed either high-grain diets or high-forage diets [24]. In our mcrA gene-based sequencing study of the methanogenic archaeal community in the feces of lactating cows, the richness indexes remained similar when $M$. oleifera was added at different levels to the diet. However, the Simpson diversity index was significantly lower compared to the control treatment. Changes in the fecal methanogen diversity might be dependent on nutrient contents and the fermentation profile of the fecal samples as a result of secondary metabolites from $M$. oleifera, similar to the alteration of the ruminal environment and microbial activity when M. oleifera was fed to ruminants $[1,9]$. For example, previous results showed that feeding $M$. oleifera plant improved nutrient digestibility and increased SCFA concentration in the rumen of goat, which resulted in the growth of propionate-producing bacterial species and inhibition of $\mathrm{CH}_{4}$-producing archaea [26]. The high protein (241-277 g/kg DM) and polyphenol content make M. oleifera a high-quality feed resource [27]. Bioactive products such as saponins $(80 \mathrm{~g} / \mathrm{kg})$ and tannins $(12 \mathrm{~g} / \mathrm{kg})$ in M. oleifera leaves have an antimicrobial 
function and play a key role in improving nutrient digestibility and fermentation efficiency [28,29]. When steers were supplemented with up to $30 \mathrm{~g} /$ day tea saponin, daily $\mathrm{CH}_{4}$ emission (g/day) was reduced by $18 \%$, and yield $\left(\mathrm{CH}_{4} / \mathrm{DM}\right.$ intake, $\left.\mathrm{g} / \mathrm{kg}\right)$ was reduced by $22 \%$ [30]. In the present study, as demonstrated in our previous experiment, the calculated saponin intake was $144 \mathrm{~g} /$ day when $9 \%$ of M. oleifera was included in the diet. We thus assumed that the composition and distribution of methanogenic archaea changed along the gastrointestinal tract, and methanogenesis and $\mathrm{CH}_{4}$ emissions would be inhibited by such a large amount of saponin intake. However, feeding saponin-containing Yucca schidigera and Quillaja saponaria powder $(10 \mathrm{~g} / \mathrm{kg} \mathrm{DM})$ differed little in $\mathrm{CH}_{4}$ emission (g/day) and yield $\left(\mathrm{CH}_{4}-\mathrm{E} / \mathrm{GE}\right.$ intake) from the basal diet [31]. This discrepancy of $\mathrm{CH}_{4}$ reduction may be attributed to the source and the actual saponin content. Further research is needed to compare responses when similar saponin sources or supplementation levels are used.

When M. oleifera was added to the diet, Methanosphaera and Methanosphaera sp. ISO3-F5 increased in abundance but Methanobrevibacter ruminantium decreased compared with the control group. Methanobrevibacter ruminantium is a strict anaerobe that can produce $\mathrm{CH}_{4}$ from $\mathrm{H}_{2}, \mathrm{CO}_{2}$, and formate and has a close syntrophic association with protozoa [32]. Secondary metabolites from M. oleifera such as saponins and tannins have antiprotozoal properties that affect cell membrane integrity [33]. Soliva et al. [34] found that approximately $30 \%$ of ciliate protozoa concentration was reduced when extracted M. oleifera was added in vitro experiment. This result was in accordance with the inhibitory effect of saponin on ruminal ciliate protozoa population in cattle or sheep [35]. In line with a range of in vivo and in vitro experiments adding different sources and levels of secondary metabolites from M. oleifera, Methanosphaera sp. ISO3-F5 increased as levels of $M$. oleifera increased. As one of the main methylotrophic methanogens, Methanosphaera sp. ISO3-F5 was found to be associated with different bacteria including members of Lachnospiraceae [36]. Thus, it would be interesting to examine the pectin content of $M$. oleifera to see its influence on Methanosphaera sp. ISO3-F5 abundance. In addition, more future work will be needed to investigate the interaction between some specific methanogens and ruminal fermentation conditions, which may help for a better understanding of rumen microbial metabolic function and development of $\mathrm{CH}_{4}$ mitigation approaches.

\section{Conclusions}

This study demonstrated that different supplementation levels of Moringa oleifera in the diet achieved similar feed intake, milk production, but adding $6 \%$ of Moringa oleifera improved milk fat content. The fecal methanogenic archaea diversity changed as the increased abundance of the Methanosphaera genus and Methanosphaera sp. ISO3-F5 species was induced by secondary metabolites of Moringa oleifera in the diet. This study provided some basic information on the utilization of Moringa oleifera as forage resources for dairy cows, and helped to elucidate the interaction between methanogens and other microbes, regulation of microbial metabolic function and methane emissions.

Author Contributions: Conceptualization, Q.D.; methodology, L.D.; data curation, T.Z.; writing—original draft preparation, L.D.; writing - review and editing, Q.D.; visualization, L.D.; supervision, Q.D; project administration, Q.D.; funding acquisition, L.D. and Q.D.

Funding: This research was funded by the Program of International S and T Cooperation (grant number 2016YFE0109000), the National Science Foundation for Young Scientists of China (grant number 31802085), the National Key Research and Development Program of China (grant number 2017YFF0211702), and Young Scientist Lifting Project (2017-2019).

Acknowledgments: The authors thank colleagues in Feed Research Institute and Century Love International Investment Group Co. Ltd., Beijing for providing kind assistance in animal experiments, sample processing, and data collection. The authors would like to thank reviewers for their suggestions and comments on this work.

Conflicts of Interest: The authors declare no conflict of interest. 


\section{References}

1. Kholif, A.E.; Gouda, G.A.; Anele, U.Y.; Galyean, M.L. Extract of Moringa oleifera leaves improves feed utilization of lactating Nubian goats. Small Rumin. Res. 2018, 158, 69-75. [CrossRef]

2. Zhang, T.T.; Si, B.W.; Deng, K.D.; Tu, Y.; Zhou, C.L.; Diao, Q.Y. Effects of feeding a Moringa oleifera rachis and twig preparation to dairy cows on their milk production and fatty acid composition, and plasma antioxidants. J. Sci. Food Agric. 2018, 98, 661-666. [CrossRef] [PubMed]

3. Azzaz, H.H.; Farahat, E.S.A.; Morsy, T.A.; Aziz, H.A.; Hadhoud, F.I.; Abd-Alla, M.S. Moringa oleifera and Echinacea purpurae as supplements for Rhamani lactating ewe's diets and their effect on rumen characteristics, nutrients digestibility, blood parameters, milk production, composition and its fatty acid profile. Asian J. Anim. Vet. Adv. 2016, 11, 684-692. [CrossRef]

4. Mendieta-Araica, B.; Sporndly, R.; Reyes-Sanchez, N.; Sporndly, E. Moringa (Moringa oleifera) leaf meal as a source of protein in locally produced concentrates for dairy cows fed low protein diets in tropical areas. Livest. Sci. 2011, 137, 10-17. [CrossRef]

5. Zeng, B.; Sun, J.J.; Chen, T.; Sun, B.L.; He, Q.; Chen, X.Y.; Zhang, Y.L.; Xi, Q.Y. Effects of Moringa oleifera silage on milk yield, nutrient digestibility and serum biochemical indexes of lactating dairy cows. J. Anim. Physiol. Anim. Nutr. 2018, 1, 75-81. [CrossRef]

6. Sarkar, S.; Mohini, M.; Nampoothiri, V.M.; Mondal, G.; Pandita, S.; Mahesh, M.S. Effect of supplementation of Moringa oleifera leaves on in vitro methane emissions and rumen fermentation on roughage based ration. In Proceedings of the XVI Biennial Animal Nutrition Conference on Innovative Approaches for Animal Feeding and Nutritional Research, Karnal, India, 6-8 February 2016.

7. Shaani, Y.; Eliyahu, D.; Mizrahi, I.; Yosef, E.; Ben-Meir, Y.; Nikbachat, M.; Solomon, R.; Mabjeesh, S.J.; Miron, J. Effect of feeding ensiled mixture of pomegranate pulp and drier feeds on digestibility and milk performance in dairy cows. J. Dairy Res. 2016, 1, 35-41. [CrossRef] [PubMed]

8. Daquiado, A.R.; Cho, K.M.; Kim, T.Y.; Kim, S.C.; Chang, H.H.; Lee, Y.B. Methanogenic archaea diversity in Hanwoo (Bos taurus coreanae) rumen fluid, rectal dung, and barn floor manure using a culture-independent method based on mcrA gene sequence. Anaerobe 2014, 27, 77-81. [CrossRef]

9. Jin, D.X.; Kang, K.; Wang, H.Z.; Wang, Z.S.; Xue, B.; Wang, L.Z.; Xu, F.; Peng, Q.H. Effects of dietary supplementation of active dried yeast on fecal methanogenic archaea diversity in dairy cows. Anaerobe 2017, 44, 78-86. [CrossRef] [PubMed]

10. Mohammadzadeh, H.; Yáñez-Ruiz, D.R.; Martínez-Fernandez, G. Molecular comparative assessment of the microbial ecosystem in rumen and faeces of goats fed alfalfa hay alone or combined with oats. Anaerobe 2014, 29, 52-58. [CrossRef]

11. AOAC International. Official Methods of Analysis, 20nd ed.; AOAC International: Rockville, MD, USA, 2016.

12. Luton, P.E.; Wayne, J.M.; Sharp, R.J.; Riley, P.W. The mcrA gene as an alternative to $16 \mathrm{~S}$ rRNA in the phylogenetic analysis of methanogen populations in landfill. Microbiol. 2002, 148, 3521-3530. [CrossRef]

13. Amato, K.R.; Yeoman, C.J.; Kent, A.; Righini, N.; Carbonero, F.; Estrada, A.; Gaskins, H.R.; Stumpf, R.M.; Yildirim, S.; Torralba, M.; et al. Habitat degradation impacts black howler monkey (Alouatta pigra) gastrointestinal microbiomes. ISME J. 2013, 7, 1344-1353. [CrossRef] [PubMed]

14. Oliveros, J.C. VENNY. An Interactive tool for Comparing Lists with Venn Diagrams; BioinfoGP of CNB-CSIC: Madrid, Spain, 2007.

15. Cohen-Zinder, M.; Leibovich, H.; Vaknin, Y.; Sagi, G.; Shabtay, A.; Ben-MEIR, Y.; Nikbachat, M.; Protnik, Y.; Yishay, M.; Miron, J. Effect of feeding lactating cows with ensiled mixture of Moringa oleifera, wheat hay and molasses, on digestibility and efficiency of milk production. Anim. Feed Sci. Technol. 2016, 211, 75-83. [CrossRef]

16. Verma, A.R.; Vijayakumar, M.; Mathela, C.S.; Rao, C.V. In vitro and in vivo antioxidant properties of different fractions of Moringa oleifera leaves. Food Chem. Toxicol. 2009, 47, 2110-2196. [CrossRef]

17. Aerts, R.J.; Barry, T.N.; McNabbm, W.C. Polyphenols and agriculture: Beneficial effects of proanthocyanidins in forages. Agric. Ecosyst. Environ. 1999, 75, 1-12. [CrossRef]

18. Faulkner, M.J.; Wenner, B.A.; Solden, L.M.; Weiss, W.P. Source of supplemental dietary copper, zinc, and manganese affects fecal microbial relative abundance in lactating dairy cows. J. Dairy Sci. 2017, 100, 1037-1044. [CrossRef] [PubMed] 
19. Liu, C.; Zhu, Z.P.; Liu, Y.F.; Guo, T.J.; Dong, H.M. Diversity and abundance of the rumen and fecal methanogens in Altay sheep native to Xinjiang and the influence of diversity on methane emissions. Arch. Microbiol. 2012, 194, 353-361. [CrossRef]

20. Zhou, M.; Chen, Y.H.; Griebel, P.J.; Guan, L.L. Methanogen prevalence throughout the gastrointestinal tract of pre-weaned dairy calves. Gut Microbes 2014, 5, 628-638. [CrossRef]

21. Min, B.R.; Solaiman, S.; Shange, R.; Eun, J.S. Gastrointestinal bacterial and methanogenic archaea diversity dynamics associated with condensed tannin-Containing pine bark diet in goats using 16S rDNA amplicon pyrosequencing. Int. J. Microbiol. 2014, 4, 1-11. [CrossRef]

22. Guzman, C.E.; Bereza-Malcolm, L.T.; Groef, B.D.; Franks, A.E. Presence of selected methanogens, fibrolytic bacteria, and proteobacteria in the gastrointestinal tract of neonatal dairy calves from birth to 72 hours. PLoS ONE 2015, 7, e0133048. [CrossRef]

23. Dowd, S.E.; Callaway, T.R.; Wolcott, R.D.; Sun, Y.; McKeehan, T.; Hagevoort, R.G.; Edrington, T.S. Evaluation of the bacterial diversity in the feces of cattle using 16S rDNA bacterial tag-encoded FLX amplicon pyrosequencing (bTEFAP). BMC Microbiol. 2008, 8, 125. [CrossRef]

24. Shanks, O.C.; Kelty, C.A.; Archibeque, S.; Jenkins, M.; Newton, R.J.; McLellan, S.L.; Huse, S.M.; Sogin, M.L. Community structures of fecal bacteria in cattle from different animal feeding operations. Appl. Environ. Microbiol. 2011, 77, 2992-3001. [CrossRef]

25. Durso, L.M.; Wells, J.E.; Harhay, G.P.; Rice, W.C.; Kuehn, L.; Bono, J.L.; Shackelford, S.; Wheeler, T.; Smith, T.P.L. Comparison of bacterial communities in faeces of beef cattle fed diets containing corn and wet distillers' grain with solubles. Lett. Appl. Microbiol. 2012, 55, 109-114. [CrossRef] [PubMed]

26. Wallace, R.J.; McEwan, N.R.; McIntosh, F.M.; Teferedegne, B.; Newbold, C.J. Natural products as manipulators of rumen fermentation. Asian Austral. J. Anim. Sci. 2002, 15, 1458-1468. [CrossRef]

27. Elghandour, M.M.Y.; Vallejo, L.H.; Salem, A.Z.M.; Mellado, M.; Camacho, L.M.; Cipriano, M.; Olafadehan, O.A.; Olivares, J.; Rogas, S. Moringa oleifera leaf meal as an environmental friendly protein source for ruminants: Biomethane and carbon dioxide production, and fermentation characteristics. J. Clean. Prod. 2017, 165, 1229-1238. [CrossRef]

28. Ferreira, P.M.P.; Farias, D.F.; de Abreu Oliveira, J.T.; de Fátima Urano Carvalho, A. Moringa oleifera: Bioactive compounds and nutritional potential. Revista de Nutrição 2008, 21, 431-437. [CrossRef]

29. Teixeira, E.M.B.; Carvalho, M.R.B.; Neves, V.A.; Silva, M.A.; Arantes-Pereira, L. Chemical characteristics and fractionation of proteins from Moringa oleifera Lam. leaves. Food Chem. 2014, 147, 51-54. [CrossRef]

30. Ramírez-Restrepoa, C.A.; Tan, C.; O’Neill, C.J.; López-Villalobos, N.; Padmanabha, J.; Wang, J.K.; McSweeney, C.S. Methane production, fermentation characteristics, and microbial profiles in the rumen of tropical cattle fed tea seed saponin supplementation. Anim. Feed. Sci. Technol. 2016, 216, 58-67. [CrossRef]

31. Holtshausen, L.; Chaves, A.V.; Beauchemin, K.A.; McGinn, S.M.; McAllister, T.A.; Odongo, N.E.; Cheeke, P.R.; Benchaar, C. Feeding saponin-containing Yucca schidigera and Quillaja saponaria to decrease enteric methane production in dairy cows. J. Dairy Sci. 2009, 92, 2809-2821. [CrossRef] [PubMed]

32. Finlay, B.J.; Esteban, G.; Clarke, K.J.; Williams, A.G.; Embley, T.M.; Hirt, R.P. Some rumen ciliates have endosymbiotic methanogens. FEMS Microbiol. Lett. 1994, 117, 157-162. [CrossRef]

33. Morgavi, D.P.; Martin, C.; Jouany, J.P.; Ranilla, M.J. Rumen protozoa and methanogenesis: Not a simple cause-effect relationship. Br. J. Nutr. 2012, 107, 388-397. [CrossRef]

34. Soliva, C.R.; Kreuzer, M.; Foidl, N.; Foidl, G.; Machnüller, A.; Hess, H.D. Feeding value of whole and extracted Moringa oleifera leaves for ruminants and their effects on ruminal fermentation in vitro. Anim. Feed Sci. Technol. 2005, 118, 47-62. [CrossRef]

35. Zhou, M.; Hernandez-Sanabria, E.; Guan, L.L. Assessment of the microbial ecology of ruminal methanogens in cattle with different feed efficiency. Appl. Environ. Microbiol. 2009, 75, 6524-6533. [CrossRef] [PubMed]

36. Henderson, G.; Cox, F.; Ganesh, S.; Jonker, A.; Young, W.; Janssen, P.H. Rumen microbial community composition varies with diet and host, but a core microbiome is found across a wide geographical range. Sci. Rep. 2015, 5, 14567. [CrossRef] [PubMed]

(C) 2019 by the authors. Licensee MDPI, Basel, Switzerland. This article is an open access article distributed under the terms and conditions of the Creative Commons Attribution (CC BY) license (http://creativecommons.org/licenses/by/4.0/). 


\title{
Effects of Tea Saponin Supplementation on Nutrient Digestibility, Methanogenesis, and Ruminal Microbial Flora in Dorper Crossbred Ewe
}

\author{
Yunlong Liu ${ }^{1}$, Tao Ma ${ }^{1}$, Dandan Chen ${ }^{1}$, Naifeng Zhang ${ }^{1}$, Bingwen $\mathrm{Si}^{1}$, Kaidong Deng ${ }^{2}$, \\ Yan Tu ${ }^{1, *}$ and Qiyu Diao ${ }^{1, *}$ \\ 1 Key Laboratory of Feed Biotechnology of the Ministry of Agriculture, Feed Research Institute, \\ Chinese Academy of Agricultural Sciences, Beijing 100081, China; liuyunlong9438@163.com (Y.L.); \\ matao@caas.cn (T.M.); chendancd@126.com (D.C.); zhangnaifeng@caas.cn (N.Z.); sibingwen@caas.cn (B.S.) \\ 2 College of Animal Science, Jinling Institute of Technology, Nanjing 210000, China; kdeng3@yeah.net \\ * Correspondence: tuyan@caas.cn (Y.T.); diaoqiyu@caas.cn (Q.D.); Tel.: +86-10-8210-6055 (Y.T.); \\ +86-10-8210-6090 (Q.D.)
}

Received: 18 December 2018; Accepted: 17 January 2019; Published: 21 January 2019

Simple Summary: Greenhouse gas emissions are a serious cause of global warming and climate change, and have become a common focus for all countries. Methane has been proven the second most commonly occurring greenhouse gas. Ruminants have been blamed for substantially contributing to methane emissions. Supplementation with tea saponin (TS) effectively decreased methane emissions and nitrogen emissions. It is not only beneficial for environmental protection, but also has potential economic benefits.

\begin{abstract}
Two experiments were conducted using Dorper $\times$ thin-tailed Han crossbred ewes. In experiment 1, eighteen ewes were randomly assigned to two dietary treatments (a basal diet, or the same basal diet supplemented with $2.0 \mathrm{~g}$ tea saponin (TS)/head/day) to investigate the effects of TS supplementation on nutrient digestibility and methane emissions. In experiment 2 , six ewes with ruminal cannulae were assigned to the same two dietary treatments as in experiment 1 to investigate the effects of TS supplementation on rumen fermentation and microbial flora. TS supplementation increased the apparent digestibility of organic matter $(\mathrm{OM})(p=0.001)$, nitrogen $(\mathrm{N})(p=0.036)$, neutral detergent fibre (NDF) $(p=0.001)$, and acid detergent fibre (ADF) $(p<0.001)$. Urinary $\mathrm{N}(p=0.001)$ and fecal $\mathrm{N}(p=0.036)$ output were reduced, and $\mathrm{N}$ retention $(p=0.001)$ and nitrogen retention/nitrogen intake ( $p=0.001)$ were increased. Supplementary TS did not decrease absolute methane emissions $(p=0.519)$ but decreased methane emissions scaled to metabolic bodyweight by $8.80 \%(p=0.006)$. Ammonia levels decreased $(p<0.001)$ and total volatile fatty acid levels increased $(p=0.018)$ in response to TS supplementation. The molar proportion of propionate increased $(p=0.007)$, whereas the acetate:propionate ratio decreased $(p=0.035)$. Supplementation with TS increased the population of Fibrobacter succinogenes ( $p=0.019)$, but the population of protozoans tended to decrease $(p=0.054)$. Supplementation with TS effectively enhanced the apparent digestibility of OM, N, NDF, and ADF, and decreased methane emissions scaled to metabolic bodyweight.
\end{abstract}

Keywords: methane emissions; nitrogen balance; reduction strategy; rumen fermentation; microbial flora; tea saponins 


\section{Introduction}

Greenhouse gas emissions are a serious cause of global warming and climate change, and have become a common focus for all countries, according to the Intergovernmental Panel on Climate Change [1]. Methane is the second most important anthropogenic greenhouse gas, which has 21 times the global warming potential of carbon dioxide [2]. Agriculture accounts for approximately $40 \%$ of the total methane emissions from anthropogenic sources, with $25 \%$ coming from enteric fermentation in livestock [3]. In ruminants, approximately $95.5 \%$ of the methane is produced by feed fermentation in the rumen [4] and is exhaled through the nose and mouth; it represents a loss of 2-12\% of the feed energy, depending on the diet [5]. Consequently, numerous efforts are underway to manipulate rumen fermentation and the rumen microbial ecosystem to reduce methane emissions. Limiting the methane emissions from ruminants is not only beneficial for environmental protection, but also has potential economic benefits [6].

Many chemical feed additives have been used to inhibit methane emissions, but these additives are either toxic to the hosts or only have a transient effect on methanogenesis [7]. By contrast, plant extracts are attractive as additives for animal feeds and animal health agents, as they are considered natural, safe, and efficient, and have no hormonal consequences or negative side effects [8]. One promising plant compound is tea saponin (TS), which is a class of pentacyclic triterpenoid glucoside compounds found in a variety of tea plants (Camelliaceae). The basic structure consists of ligands, sugars, and organic acids. Tea saponin has been reported to have an inhibitory effect on protozoa by affecting cell membrane integrity. As protozoa are known to be positively correlated with methanogenesis, tea saponin's biological properties can be used to suppress methane production [9], reduce rumen protozoan counts, and modulate rumen fermentation patterns $[10,11]$.

The rumen is a fermentation chamber where a large number of microbes, including bacteria, protozoa, and fungi, coexist and conduct complicated fermentation processes. Previous studies have been carried out on the effect of TS on methane emissions [12-14]; however, most trials were carried out in vitro [9,15], so the results do not necessarily reflect the situation in vivo [16]. Consequently, the mechanism of action of TS remains unclear. The aim of the present study was to investigate the effects of dietary TS supplementation on ruminal fermentation characteristics, digestibility, methanogenesis, and the ruminal microbial flora using sheep as in vivo model. We hypothesized that TS supplementation could reduce methane emissions by inhibiting the growth of ruminal methanogens and protozoa, and may have different effects on cellulolytic bacteria.

\section{Materials and Methods}

This study was conducted from March to May 2013 at the Experimental Station of the Chinese Academy of Agricultural Science (CAAS), Beijing, China. The experimental procedures were approved by the Animal Ethics Committee of the CAAS, and humane animal care and handling procedures were followed throughout the experiment (protocol number: AEC-CAAS-2013-01).

\subsection{Animals, Diets, and Experimental Design}

\subsubsection{Experiment 1}

Eighteen primiparous Dorper $\times$ thin-tailed Han crossbred ewes $(60.0 \pm 1.73 \mathrm{~kg}$ body weight (BW)), 12 months of age, were randomly divided, according to the principle of uniform weight, into two dietary treatment groups: a basal diet, or the same basal diet supplemented with TS at $2.0 \mathrm{~g} /$ head/day (TS was extracted from Camellia seeds, Xi'an Feida Bio-Tech Co., Ltd., Shanxi, China). The basal diets included pelleted total mixed rations (concentrate) and Chinese wildrye hay (Table 1). For the experimental diet, the TS was mixed with the pelleted concentrate. The ewes were fed $1500 \mathrm{~g}$ pelleted concentrate at $800 \mathrm{~h}$ and $200 \mathrm{~g}$ of Chinese wild rye hay at $1200 \mathrm{~h}$, daily. This feeding level fulfilled the maintenance and growth requirements of yearling ewes $(60 \mathrm{~kg} \mathrm{BW})$ according to the NRC [17]. All animals were housed in individual pens, had free access to fresh water throughout the experimental period. 
All ewes were moved into metabolism crates after a 14-day adaptation to the diets and another 7-day adaptation to the metabolism crates. The amounts of feed offered, ort, and produced feces were weighed daily and homogenized. A $10 \%$ sample was collected during an 8-day collection period, as described by $\mathrm{Ma}$ et al. [18]. Urine was collected daily in buckets containing $100 \mathrm{~mL}$ of $10 \%(\mathrm{v} / \mathrm{v}) \mathrm{H}_{2} \mathrm{SO}_{4}$. The volume was measured and a sample $\left(10 \mathrm{~mL} / \mathrm{L}\right.$ of total volume) was collected and stored at $-20{ }^{\circ} \mathrm{C}$ until analysis. Samples of feed, ort, feces, and urine were pooled to form a composite sample for each ewe.

Ruminal methane production was measured using an open-circuit respirometry system (Sable Systems International, Las Vegas, NV, USA) with three metabolism cages, each fitted with a polycarbonate head box. Measurements of methane production were staggered because only three measurement units were available. On days $0,2,4$, and 6 of each 8-day collection period, the ewes were moved in sequence from their own metabolism cages to metabolism cages equipped with head boxes for digestibility assays and methane output assessments. After a 24-h adaption period, individual methane production was measured over a 24-h period, as described by Deng et al. [19]. All ewes had been previously trained for confinement in head boxes attached to metabolism cages.

The ewes were weighed when entering and leaving the gas metabolism cages and the average body weight was used as the basis for calculating the metabolic body weight.

Table 1. Ingredients and chemical compositions of experimental diets (\% of dry matter (DM)).

\begin{tabular}{ccc}
\hline Item $^{\text {a }}$ & Total Mixed Ration & Chinese Wildrye Hay \\
\hline Ingredient, \% of DM & & \\
Corn & 17.0 & \\
Soybean meal & 12.0 & \\
Chinese wildrye hay & 68.7 & \\
CaHPO 4 & 1.35 & \\
Limestone & 0.25 & \\
NaCl & 0.50 & 91.4 \\
Premix ${ }^{\text {b }}$ & 0.24 & 90.6 \\
Chemical composition (determined) & & 17.6 \\
DM, (\% as fed) & 88.6 & 8.50 \\
OM & 80.8 & 70.7 \\
GE, MJ/kg of DM & 17.2 & 38.1 \\
CP & 12.2 & \\
NDF & 41.4 & \\
ADF & 21.8 &
\end{tabular}

\footnotetext{
a DM: dry matter; OM: organic matter; GE: gross energy; CP: crude protein; NDF: neutral detergent fibre; ADF: acid detergent fibre. ${ }^{b}$ Manufactured by Precision Animal Nutrition Research Centre, Beijing, China. The premix contained (per kg): $22.1 \mathrm{~g} \mathrm{Fe}, 2.25 \mathrm{~g} \mathrm{Cu}, 9.82 \mathrm{~g} \mathrm{Mn}, 27.0 \mathrm{~g} \mathrm{Zn}, 0.19 \mathrm{~g} \mathrm{Se}, 0.54 \mathrm{~g} \mathrm{I}, 0.09 \mathrm{~g} \mathrm{Co}, 3.2 \mathrm{~g}$ Vitamin A, $0.8 \mathrm{~g}$ Vitamin D3, and $0.4 \mathrm{~g}$ Vitamin E.
}

\subsubsection{Experiment 2}

Six ruminally cannulated Dorper $\times$ thin-tailed Han crossbred ewes $(65.2 \pm 2.0 \mathrm{~kg} \mathrm{BW})$ were divided into two groups of three, according to a crossover design, and fed one of the following diets: basal diet, or basal diet supplemented with TS ( $2.0 \mathrm{~g} / \mathrm{head} /$ day). The composition of the basal diets and the experimental regime were the same as described for Experiment 1 . The experiment lasted for 42 days and consisted of two periods lasting 21 days, including 7 days of adaptation. On days 16 and 37, two $50 \mathrm{~mL}$ samples of ruminal digesta were collected from the rumen cannula using a syringe attached to a plastic tube (20 mm internal diameter). Samples were collected at $0,1,3,6$, and $9 \mathrm{~h}$ after the morning feeding for the measurements of ruminal fermentation parameters and microbial flora populations. The $\mathrm{pH}$ was measured immediately using a pH meter (Model PB-10, Sartorius Co, Goettingen, Germany). All samples were frozen in liquid nitrogen within $5 \mathrm{~min}$ and stored at $-80^{\circ} \mathrm{C}$ until analysis. 


\subsection{Analytical Procedures}

Dry matter (DM) content was measured by drying samples in a forced-air oven at $135^{\circ} \mathrm{C}$ for $2 \mathrm{~h}$ (method 930.15; AOAC) [20]. Ash content was measured by placing samples into a muffle furnace at $550{ }^{\circ} \mathrm{C}$ for $5 \mathrm{~h}$ (method 938.08; AOAC) [20]. Organic matter (OM) was measured as the difference between DM and the ash content. Nitrogen (N) was measured according to the methods of Kjeldahl, using Se as a catalyst. Crude protein (CP) was calculated as $6.25 \times$ N. Gross energy (GE) was measured using a bomb calorimeter ( $\mathrm{C}^{200}$, IKA Works Inc., Staufen, Germany). Ether extracts (EE) were measured by the weight loss of the DM following extraction with diethyl ether in a Soxhlet extraction apparatus for $8 \mathrm{~h}$ (method 920.85; AOAC) [20]. Neutral detergent fibre (NDF) and acid detergent fibre (ADF) were measured according to $[21,22]$. NDF was measured without a heat stable amylase and expressed inclusive of residual ash. Ruminal volatile fatty acid (VFA) was measured according to the procedure described by Ma et al. [23], and ammonia $\left(\mathrm{NH}_{3}\right)$ was assessed according to Broderick and Kang [24].

The frozen samples were thawed at room temperature, and the total DNA from rumen fluid was extracted using the bead-beating method described by Zhang et al. [25]. The microbial cells were resuspended in a lysis buffer in tubes containing zirconium beads and were bead-beaten at $4600 \mathrm{rpm}$ for $3 \mathrm{~min}$ in a mini-bead beater (MM400, Retsch, Hann, Germany), followed by phenol-chloroform extraction [26]. After centrifugation of the sample at $14,000 \times \mathrm{g}$ for $15 \mathrm{~min}$ at $4{ }^{\circ} \mathrm{C}$, the supernatant was mixed with a glass milk kit (Gene Clean II Kit, ZZBio Co., Ltd., Shanghai, China) and washed before a final elution step to release the DNA from the glass milk.

Table 2 shows the amplifying primers used for quantitative polymerase chain reaction (qPCR) analysis for microbial flora [27], including total bacteria, methanogens, protozoans, Fibrobacter succinogenes, Ruminococcus flavefaciens, Ruminococcus albus, and Butyrivibrio fibrisolvens. All primers were verified using a sequencing and melting curve analysis with a $C^{1000 T M}$ Thermal Cycler and bundled software CFX ${ }^{96}$ Manager $^{\mathrm{TM}}$ software version 2.1 (Bio-Rad Laboratories, Hercules, CA, USA). The PCR products were purified by gel extraction and ligated into the pGM-T vector (Promega, Madison, WI, USA). The recombinant plasmids were extracted using a plasmid minikit (Omega, Norcross, GA, USA) according to the manufacturer's instructions and quantified by A260 measurements. Standard curves for microbes were generated with 101-107 copies of recombinant plasmids per $\mu \mathrm{L}$. The qPCR was performed using SsoFast EvaGreen Supermix (Bio-Rad) on a $C^{1000 T M}$ thermal cycler qPCR detection system, with genomic DNA as the template. All PCR amplifications used the following thermal cycling: $95^{\circ} \mathrm{C}$ for $10 \mathrm{~min}$, followed by 40 cycles of $94^{\circ} \mathrm{C}$ for $20 \mathrm{~s}, 60^{\circ} \mathrm{C}$ for annealing, extension, and collection of fluorescent signals. All samples were prepared from the ewes and each sample was assayed in triplicate.

Table 2. Primers for qPCR assay.

\begin{tabular}{|c|c|c|}
\hline Target Species & Primer Sequence $\left(5^{\prime} \rightarrow 3^{\prime}\right)^{\text {a }}$ & Amplicon \\
\hline \multirow[t]{2}{*}{ Total bacteria } & F: CGGTGAATACGTTCYCGG & 123 \\
\hline & R: GGWTACCTTGTTACGACTT & \\
\hline \multirow[t]{2}{*}{ Methanogens } & F: TTCGGTGGATCDCARAGRGC & 140 \\
\hline & R: GBARGTCGWAWCCGTAGAATCC & \\
\hline \multirow[t]{2}{*}{ Protozoans } & F: GCTTTCGWTGGTAGTGTATT & 223 \\
\hline & R: CTTGCCCTCYAATCGTWCT & \\
\hline \multirow[t]{2}{*}{ Fibrobacter succinogenes } & F: GTTCGGAATTACTGGGCGTAAA & 121 \\
\hline & R: CGCCTGCCCCTGAACTATC & \\
\hline \multirow[t]{2}{*}{ Ruminococcus flavefaciens } & F: GATGCCGCGTGGAGGAAGAAG & 286 \\
\hline & R: CATTTCACCGCTACACCAGGAA & \\
\hline \multirow[t]{2}{*}{ Ruminococcus albus } & F: GTTTTAGGATTGTAAACCTCTGTCTT & 270 \\
\hline & R: CCTAATATCTACGCATTTCACCGC & \\
\hline \multirow[t]{2}{*}{ Butyrivibrio fibrisolvens } & F: TAACATGAGAGTTTGATCCTGGCTC & 135 \\
\hline & R: CGTTACTCACCCGTCCGC & \\
\hline
\end{tabular}

a Primers were designed according to Denman and McSweeney [27]. 


\subsection{Statistical Analyses}

The data on digestibility and nitrogen balance were analysed using one-way ANOVA. Data for ruminal fermentation parameters and microbial flora measured at each sampling time were analysed using Repeated Measures and Multivariate of General Linear Model. Statistical analyses were performed by using SPSS (SPSS Inc., Chicago, IL, USA). Group differences were considered significant when $p<0.05$ and tendencies were discussed when $0.05<p<0.10$.

\section{Results}

\subsection{Nutrient Digestibility}

The intake of DM, total tract apparent digestibility of nutrients, and $\mathrm{N}$ balance are shown in Table 3. Supplementation with TS increased the apparent digestibility of OM $(p=0.001), \mathrm{N}(p=0.036)$, NDF ( $p=0.001)$, and ADF ( $p<0.001$ ) (Table 3). Daily fecal N output decreased from 10.7 to $9.90 \mathrm{~g}$ $(p=0.036)$, urinary $\mathrm{N}$ decreased from 14.9 to $12.5 \mathrm{~g}(p=0.001)$. Overall, the $\mathrm{N}$ retention and the ratio of $\mathrm{N}$ retention/ $\mathrm{N}$ intake increased $(p=0.001)$.

Table 3. Effects of tea saponin (TS) supplementation on the apparent digestibility of nutrients and nitrogen balance in ewes.

\begin{tabular}{ccccc}
\hline \multirow{2}{*}{ Item $^{\text {a }}$} & \multicolumn{2}{c}{ Treatments $^{\mathbf{b}}$} & \multirow{2}{*}{ SEM } & \multirow{2}{*}{-Value } \\
\cline { 2 - 3 } & CON & TS & & \\
\hline Apparent digestibility, \% & & & & \\
OM & 60.3 & 66.1 & 0.99 & 0.001 \\
N & 66.6 & 69.2 & 0.63 & 0.036 \\
NDF & 37.9 & 48.5 & 1.79 & 0.001 \\
ADF & 35.0 & 48.3 & 2.07 & $<0.001$ \\
Fecal N, g/d & 10.7 & 9.90 & 0.20 & 0.036 \\
Urinary N, g/d & 14.9 & 12.5 & 0.42 & 0.001 \\
N retention, g/d & 6.54 & 9.78 & 0.56 & 0.001 \\
N retention/N intake, \% & 20.3 & 30.4 & 1.74 & 0.001 \\
\hline
\end{tabular}

a DM: dry matter; OM: organic matter; GE: gross energy; CP: crude protein; NDF: neutral detergent fibre; ADF: acid detergent fibre. ${ }^{b}$ Control $(\mathrm{CON})$ ewes were fed a basal diet; TS ewes were fed the same basal diet supplemented with tea saponin (TS).

\subsection{Ruminal Fermentation and Methanogenesis}

The methane production, ruminal $\mathrm{pH}$, and ruminal concentrations of ammonia and VFA are shown in Table 4. Supplementation of TS did not affect daily methane production by the ewes $(p>0.05)$, but the methane output, scaled to $\mathrm{BW}^{0.75}$, decreased from 2.84 to 2.59 ( $p=0.006$ ) (Table 4). Ruminal $\mathrm{pH}$ was similar between the two treatments $(p=0.912)$. TS supplementation decreased ammonia production from 10.7 to $8.3 \mathrm{mmol} / \mathrm{L}(p<0.001)$, while total VFA increased from 101.6 to $118.1 \mathrm{mmol} / \mathrm{L}$ $(p=0.018)$. The molar proportions of propionate $(p=0.007)$, isobutyrate $(p=0.001)$, butyrate $(p=0.002)$, and isovalerate $(p=0.001)$ were increased by TS supplementation. No difference was observed in the molar proportion of acetate $(p=0.171)$ and valerate $(p=0.107)$. The molar proportion of the ratio of acetate to propionate decreased from $5.23 \%$ to $4.50 \%(p=0.035)$. 
Table 4. Effects of tea saponin (TS) supplementation on daily methane production and ruminal fermentation in ewes.

\begin{tabular}{ccccc}
\hline \multirow{2}{*}{ Item $^{\text {a }}$} & \multicolumn{2}{c}{ Treatments } & & \\
& CON & TS & & \\
\cline { 2 - 4 } & SEM & & \\
\hline DM intake, g/d & 1512.5 & 1512.6 & 0.04 & 0.593 \\
BW $^{0.75}, \mathrm{~kg}$ & 21.4 & 24.2 & 0.52 & $<0.001$ \\
Methane production & & & & \\
L & 61.1 & 62.2 & 0.77 & 0.519 \\
L/kg BW 0.75 & 2.86 & 2.57 & 0.05 & 0.001 \\
L/kg DMI & 40.4 & 41.1 & 0.51 & 0.519 \\
pH & 5.98 & 5.96 & 0.05 & 0.912 \\
Ammonia, mmol/L & 10.7 & 8.30 & 0.33 & $<0.001$ \\
Total VFA, mmol/L & 101.6 & 118.1 & 3.56 & 0.018 \\
Molar proportions, \% & & & & \\
Acetate & 74.0 & 80.0 & 2.17 & 0.171 \\
Propionate & 14.4 & 18.7 & 0.82 & 0.007 \\
Isobutyrate & 1.34 & 2.04 & 0.12 & 0.001 \\
Butyrate & 9.62 & 14.2 & 0.76 & 0.002 \\
Isovalerate & 1.39 & 2.16 & 0.13 & 0.001 \\
Valerate & 0.89 & 1.06 & 0.05 & 0.107 \\
Acetate:propionate & 5.23 & 4.50 & 0.17 & 0.035 \\
\hline
\end{tabular}

${ }^{a}$ BW: bodyweight; DMI: dry matter intake; VFA: volatile fatty acids. ${ }^{b}$ Control (CON) ewes were fed a basal diet; TS ewes were fed the same basal diet supplemented with tea saponin (TS).

\subsection{Ruminal Microbial Flora}

The effect of TS supplementation on ruminal microbial population is shown in Table 5. Supplementation of TS tended to decrease the population of protozoans $(p=0.054)$ and increased the populations of $F$. succinogenes $(p=0.019)$, whereas population of total bacteria, methanogen, $R$. flavefaciens, $R$. albus, and B. fibrisolvens did not change.

Table 5. Effects of tea saponin (TS) supplementation on ruminal microbial population.

\begin{tabular}{ccccc}
\hline Microbial Population, & \multicolumn{2}{c}{ Treatments $^{\text {a }}$} & \multirow{2}{*}{ SEM } & \multirow{2}{*}{$\boldsymbol{p}$-Value } \\
\cline { 2 - 3 } per $\mathbf{m L}$ of Ruminal Fluid & CON & TS & & \\
\hline Total bacteria, $\times 10^{9}$ & 7.77 & 8.23 & 0.40 & 0.569 \\
Protozoans, $\times 10^{7}$ & 5.44 & 4.59 & 0.22 & 0.054 \\
Methanogens, $\times 10^{7}$ & 7.09 & 6.18 & 0.45 & 0.318 \\
F. succinogenes, $\times 10^{5}$ & 4.36 & 5.41 & 0.23 & 0.019 \\
R. flavefaciens, $\times 10^{8}$ & 4.06 & 4.40 & 0.19 & 0.372 \\
R. albus, $\times 10^{7}$ & 5.30 & 5.02 & 0.16 & 0.385 \\
B. fibrisolvens, $\times 10^{8}$ & 6.31 & 6.49 & 0.12 & 0.476 \\
\hline
\end{tabular}

${ }^{\text {a }}$ Control (CON) ewes were fed a basal diet; TS ewes fed the same basal diet supplemented with tea saponin (TS).

\section{Discussion}

\subsection{Effect of Tea Saponin on Apparent Digestibility and Nitrogen Balance}

The effect of TS on nutrient digestibility has been poorly studied. In the present experiment, supplementation with TS increased the apparent digestibility of OM, N, NDF, and ADF. Tea saponins have an important effect on nutrient digestibility [5], whereas saponins from other sources, such as Quillaja saponaria or Yucca schidigera, are reported to have no effect on diet digestibility [10,28]. The lower $\mathrm{N}$ outputs in the urine and feces in the TS group in the present study are consistent with the higher apparent digestibility of dietary $\mathrm{N}$, and may reflect the reduction in protozoan numbers [29]. A related study reported that supplementation with TS improved in vitro OM digestibility [8] 
Similarly, Guyader et al. [14] reported a numerical increase in NDF and ADF digestibility in dairy cows; this outcome may be related to the numerically lower dry matter intake (DMI) of lactating dairy cows fed this plant extract, given that a reduction of DMI can be associated with lower rumen filling and greater fiber digestibility. In the present experiment, DMI was not modified in ewes supplemented with TS in DM. Overall, the increase in nutrient digestibility is not related to DMI; it could be explained by the increase in the population of $F$. succinogenes, generally considered the primary organisms responsible for the degradation of plant cell walls in the rumen [30], and by the decrease in the protozoan population.

Nitrogen retention in ruminants has significant benefits for ruminant survival, health, production, and ruminal protection [31]. In the present study, TS supplementation decreased fecal $\mathrm{N}$ and urinary $\mathrm{N}$ outputs, resulting in a significant $\mathrm{N}$ retention. The decrease in urinary $\mathrm{N}$ output could be attributed to the decrease in the protozoan population, as previously confirmed by Van Soest [32]. Protozoa contribute to $10-40 \%$ of the total rumen nitrogen, so a reduction in this population would mean less predation and lysis of bacteria and, consequently, a lower release of the products of protein breakdown. Jouany [29] assumed that urinary $\mathrm{N}$ always decreases with defaunation, due to both the decreased ammonia concentration in the ruminal fluid and the increased capture of urea $\mathrm{N}$ for microbial protein synthesis prior to its delivery to the large intestine for recycling in the blood. Koening et al. [33] also reported increases in microbial protein entering the post-digestive tract from the rumen and a promotion of nitrogen utilization.

\subsection{Effect of Tea Saponin on Methane Production}

In the present study, TS supplementation resulted in an $8.8 \%$ decrease in the daily methane emissions, scaled to metabolic BW. TS has been reported to reduce methane production by inhibiting the proliferation of rumen protozoa and perhaps by inhibiting interspecies hydrogen transfer between the protozoa and methanogens, although inhibitory effects on hydrogen-producing bacteria are also possible [34]. Similar results were reported in other studies using TS as a plant extract additive to reduce methane emissions. For example, Guo et al. [12] determined that the mechanism of TS inhibition of methane production involved inhibition of the expression of $m c r A$, a key gene encoding the methyl-coenzyme $\mathrm{M}$ reductase enzyme involved in methane synthesis. Hess et al. [35] showed that TS can act directly on methanogens to reduce methane production to levels consistent with those reported by Whitelaw et al. [36] and Dohme et al. [37]. In our study, supplementation with TS had no significant effect on the population of methanogens, but it decreased the population of protozoans. A similar observation was made by Hess et al. [35], who reported a 54\% decrease in protozoan counts and a $20 \%$ decline in in vitro methane emissions, with no effect on methanogens. These researchers suggested that defaunation reduced methane emissions because of the lower $\mathrm{H}_{2}$ supply, which reduced the activity per methanogen. In the present study, TS supplementation increased the molar proportion of propionate ( 1 mole $\mathrm{H}_{2}$ consumed per mole propionate) and decreased the acetate:propionate ratio, indicating a transformation of the rumen from acetate fermentation to propionate fermentation. This switch would lead to a reduction in $\mathrm{H}_{2}$ availability for methanogenic archaea [38]. Overall, the observed reduction in methane output, scaled to $\mathrm{BW}^{0.75}$, may be related to the size of the protozoan population and the VFA patterns.

\subsection{Effect of Tea Saponin on Ruminal Fermentation}

Supplementation with TS modified the fermentation patterns, resulting in changes in rumen $\mathrm{pH}$, ammonia release, and total VFA content. Ruminal $\mathrm{pH}$ is an important index of normal rumen function, and the rumen $\mathrm{pH}$ values ( $\mathrm{pH}$ 5.96-5.98) in the present study were within the normal range for efficient rumen function [39]. Supplementation with TS significantly decreased the ruminal concentration of ammonia but increased the levels of total VFA. Wina et al. [40] suggested that decreases in rumen ammonia concentration were an indirect result of the decreased protozoan numbers caused by addition of TS. Similar to our results, most studies have shown that TS supplementation increased the molar proportion of propionate [13,41,42], although Ramírez-Restrepo et al. [43] reported that butyrate 
concentration increased and propionate concentration decreased at their highest TS supplementation level. Guyader et al. [44] reported that supplementation with TS decreased the acetate:propionate ratio in an in vitro experiment, in agreement with the results of $\mathrm{Hu}$ et al. [9,15] and Guo et al. [12] but a subsequent in vivo experiment in lactating cows showed an increase in the acetate:propionate ratio. Overall, the change in the molar proportions of propionate and butyrate and in the acetate:propionate ratio suggested that TS supplementation could modify rumen fermentation profiles by changing the microbial population or the rate of passage of digesta through the rumen.

\subsection{Effect of Tea Saponin on Microbial Flora}

Supplementation with TS tended to decrease the population of protozoans in the present study, in agreement with the findings of Mao et al. [45] and Zhou et al. [13], who also showed that the rumen protozoan numbers were lower in sheep supplemented with TS. A toxic effect of TS towards protozoa has also been reported previously $[9,12,44]$ in vitro. Wallace et al. [31] indicated that TS might kill or damage protozoa by forming complexes with sterols on the protozoan membrane surface, leading to membrane impairment and eventual disintegration. However, several reports have shown no effect of saponin on protozoa, and some have showed an increase in protozoan numbers [41]. These differences may reflect differences in the experimental diets and the TS dosages. Methanogenic archaea have been observed on the exterior surfaces of rumen protozoa [46]. About $10 \%$ to $20 \%$ of methanogens live in association with protozoa [47], so a reduction in protozoan numbers would also be expected to reduce methanogen numbers, and thereby decrease methane emissions. However, in vitro [12] and in vivo [45] experiments have shown that TS addition has little effect on the methanogen population, which is consistent with the present findings. Similarly, previous studies indicated that the relative abundance of methanogens in sheep was unaffected by TS supplementation [13,45]. However, the activity of the methanogens could be reduced, as Guo et al. [12] found that TS supplementation inhibited the expression of the mcrA gene.

In the present study, we also used qPCR to quantify four main cellulolytic bacteria and found a selective effect of TS supplementation on rumen bacteria. Unlike the case for F. succinogenes, the populations of $R$. flavefaciens, R. albus, and B. fibrisolvens were unchanged by TS supplementation. Several studies have examined the effects of TS on ruminal microbial flora, but the results have been inconsistent. For example, Guo et al. [12] reported that number of F. succinogenes increased significantly with the addition of TS in vitro, in agreement with our results. Conversely, in vivo TS supplementation has been reported to have no effect on the populations of $R$. flavefaciens or F. succinogenes [45]. Zhou et al. [13] also reported no changes in the population of $F$. succinogenes. The rumen is a complex system where billions of microbes live, so the effects of TS supplementation on ruminal microbial populations deserve further study.

In order to avoid the adverse effects of stress on entering and leaving the gas metabolism cage, the ewes were weighed twice, before and after the start of the experiment, the average body weight was taken as the basis for the calculation of metabolic body weight. Of course, we considered that body weight may be related to methane emissions, so we used metabolic body weight to eliminate this factor. Converting the average body weight into metabolic body weight is equivalent to unifying the body weight and eliminating the influence of body weight. The relative (per $\mathrm{kg}$ metabolic BW) methane emissions are more indicative of differences in methane emissions between different diets.

\section{Conclusions}

In the present study, dietary TS supplementation effectively enhanced OM, N, NDF, and ADF digestibility and reduced daily methane emissions $\left(\mathrm{L} / \mathrm{kg} \mathrm{BW}^{0.75}\right)$ in ewes. These effects were probably due to decreases in the population of ruminal protozoans and modifications in the VFA profile in response to TS. Further investigation is necessary to explain the mechanisms by which TS exerts these effects on methanogenesis and ruminal microbial flora. 
Author Contributions: Conceptualization, T.M. and Q.D.; methodology, Y.T.; software, Y.L.; validation, Y.T., N.Z. and Q.D.; formal analysis, T.M.; investigation, D.C.; resources, Q.D.; data curation, D.C.; writing-original draft preparation, Y.L.; writing—review and editing, T.M. and K.D.; visualization, T.M.; supervision, B.S.; project administration, B.S.; funding acquisition, Q.D.

Funding: This work was supported by the [China Agriculture Research System] under Grant [CARS-38] and [National Natural Science Foundation of China] under Grant [No: 41705129]. All authors participated in writing the final draft of the manuscript and agreed on the final format.

Conflicts of Interest: We certify that there are no conflicts of interest with any financial organization regarding the material discussed in the manuscript.

\section{References}

1. IPCC (Intergovernmental Panel on Climate Change). Climate change: Synthesis report. In Contribution of Working Groups I, II and III to the Fifth Assessment Report of the Intergovernmental Panel on Climate Change; Pachauri, R.K., Meyer, L.A., Eds.; IPCC: Geneva, Switzerland, 2014; p. 151.

2. UNFCC (United Nations Framework Convention on Climate Change). Greenhouse Gas Inventory Data; UNFCC: Bonn, Germany, 2006.

3. Olivier, J.G.J.; Aardenne, J.A.; Dentener, F.; Ganzeveld, L.; Peters, J.A.H.W. Recent trends in global greenhouse gas emissions: Regional trends and spatial distribution of key sources. In Proceedings of the Non- $\mathrm{CO}_{2}$ Greenhouse Gases (NCGG-4), Utrecht, The Netherlands, 4-6 July 2005; pp. 325-330.

4. AGO (Australian Greenhouse Office). National Greenhouse Gas Inventory 2001 with Methodology Supplements; AGO: Canberra, Australia, 2003.

5. Johnson, K.A.; Johnson, D.E. Methane emissions from cattle. J. Anim. Sci. 1995, 73, 2483-2492. [CrossRef] [PubMed]

6. Alford, A.R.; Hegarty, R.S.; Parnell, P.F.; Cacho, O.J.; Herd, R.M.; Griffith, G.R. The impact of breeding to reduce residual feed intake on enteric methane emissions from the Australian beef industry. Aust. J. Exp. Agric. 2006, 46, 813-820. [CrossRef]

7. Moss, A.R.; Jouany, J.P.; Newbold, C.J. Methane production by ruminants: Its contribution to global warming. Ann. Zootech. 2000, 49, 231-235. [CrossRef]

8. Wei, M.L.; Ren, L.P.; Zhou, Z.M.; Meng, Q.X. Effect of addition of three plant extracts on gas production, ruminal fermentation, methane production and ruminal digestibility based on an in vitro technique. J. Anim. Vet. Adv. 2012, 11, 4304-4309.

9. Hu, W.L.; Wu, Y.M.; Liu, J.X.; Guo, Y.Q.; Ye, J.A. Tea saponins affect in vitro fermentation and methanogenesis in faunated and defaunated rumen fluid. J. Zhejiang Univ. Sci. B 2005, 6, 787-792. [CrossRef]

10. Lila, Z.A.; Mohammed, N.; Kanda, S.; Kamada, T.; Itabashi, H. Effect of sarsaponin on ruminal fermentation with particular reference to methane production in vitro. J. Dairy Sci. 2003, 86, 3330-3336. [CrossRef]

11. Wang, C.J.; Wang, S.P.; Zhou, H. Influences of flavomycin, ropadiar, and saponin on nutrient digestibility, rumen fermentation, and methane emission from sheep. Anim. Feed Sci. Technol. 2009, 148, 157-166. [CrossRef]

12. Guo, Y.Q.; Liu, J.X.; Lu, Y.; Zhu, W.Y.; Denman, S.E.; McSweeney, C.S. Effect of tea saponin on methanogenesis, microbial community structure and expression of $m c r A$ gene, in cultures of rumen microorganisms. Lett. Appl. Microbiol. 2008, 47, 421-426. [CrossRef]

13. Zhou, Y.Y.; Mao, H.L.; Jiang, F.; Wang, J.K.; Liu, J.X.; McSweeney, C.S. Inhibition of rumen methanogenesis by tea saponins with reference to fermentation pattern and microbial communities in Hu sheep. Anim. Feed Sci. Technol. 2011, 166-167. [CrossRef]

14. Guyader, J.; Eugène, M.; Doreau, M.; Morgavi, D.P.; Gérard, C.; Loncke, C.; Martin, C. Nitrate but not tea saponin feed additives decreased enteric methane emissions in nonlactating cows. J. Anim. Sci. 2015, 93, 5367-5377. [CrossRef]

15. Hu, W.L.; Wu, Y.M.; Liu, J.X.; Guo, Y.Q.; Ye, J.A. Effect of tea saponins on in vitro ruminal fermentation and growth performance in growing Boer goat. Arch. Anim. Nutr. 2006, 60, 89-97. [CrossRef]

16. Macome, F.M.; Pellikaan, W.F.; Hendriks, W.H.; Warner, D.; Schonewille, J.T.; Cone, J.W. In vitro gas and methane production in rumen fluid from dairy cows fed grass silages differing in plant maturity, compared to in vivo data. J. Anim. Physiol. Anim. Nutr. 2018, 102, 843-852. [CrossRef] [PubMed] 
17. NRC (Nutrient Requirements of Small Ruminants). Sheep, Goats, Cervids and New World Camelids; National Academy Press: Washington, DC, USA, 2007.

18. Ma, T.; Chen, D.D.; Tu, Y.; Zhang, N.F.; Si, B.W.; Deng, K.D.; Diao, Q.Y. Effect of dietary supplementation with resveratrol on nutrient digestibility, methanogenesis and ruminal microbial flora in sheep. J. Anim. Physiol. Anim. Nutr. 2015, 99, 676-683. [CrossRef] [PubMed]

19. Deng, K.D.; Jiang, C.G.; Tu, Y.; Zhang, N.F.; Liu, J.; Ma, T.; Zhao, Y.G.; Xu, G.S.; Diao, Q.Y. Energy requirements of Dorper crossbred ewe lambs. J. Anim. Sci. 2014, 92, 2161-2169. [CrossRef] [PubMed]

20. AOAC (Association of Official Analytical Chemists). Official Methods of Analysis, 15th ed.; AOAC: Washington, DC, USA, 1990.

21. Van Soest, P.J.; Robertson, J.B.; Lewis, B.A. Methods for dietary fiber, neutral detergent fiber and non-starch polysaccharides in relation to animal nutrition. J. Dairy Sci. 1991, 74, 3583-3597. [CrossRef]

22. Goering, H.G.; Van Soest, J.P. Forage fiber analysis. In Agricultural Handbook; UPSDA: Washington, DC, USA, 1970; Volume 379.

23. Ma, T.; Deng, K.D.; Tu, Y.; Zhang, N.F.; Jiang, C.G.; Liu, J.; Zhao, Y.G.; Diao, Q.Y. Effect of dietary forage-to-concentrate ratios on urinary excretion of purine derivatives and microbial nitrogen yields in the rumen of Dorper crossbred sheep. Livest. Sci. 2014, 160, 37-44. [CrossRef]

24. Broderick, G.A.; Kang, J.H. Automated simultaneous determination of ammonia and total amino acids in ruminal fluid and in vitro media. J. Dairy Sci. 1980, 63, 64-75. [CrossRef]

25. Zhang, C.M.; Guo, Y.Q.; Yuan, Z.P.; Wu, Y.M.; Wang, J.K.; Liu, J.X.; Zhu, W.Y. Effect of octadeca carbon fatty acids on microbial fermentation, methanogenesis and microbial flora in vitro. Anim. Feed Sci. Technol. 2008, 146, 259-269. [CrossRef]

26. Zoetendal, E.G.; Akkermans, A.D.; De Vos, W.M. Temperature gradient gel electrophoresis analysis of $16 \mathrm{~S}$ rRNA from human fecal samples reveals stable and host-specific communities of active bacteria. Appl. Environ. Microb. 1998, 64, 3854-3859.

27. Denman, S.E.; McSweeney, C.S. Development of a real-time PCR assay for monitoring anaerobic fungal and cellulolytic bacterial populations within the rumen. FEMS Microbiol. Ecol. 2006, 58, 572-582. [CrossRef]

28. Holtshausen, L.; Chaves, A.V.; Beauchemin, K.A.; McGinn, S.M.; McAllister, T.A.; Odongo, N.E.; Cheeke, P.R.; Benchaar, C. Feeding saponin-containing Yucca schidigera and Quillaja saponaria to decrease enteric methane production in dairy cows. J. Dairy Sci. 2009, 92, 2809-2821. [CrossRef] [PubMed]

29. Jouany, J.P. Effect of rumen protozoa on nitrogen utilization by ruminants. J. Nutr. 1996, 126, 1335S-1346S. [CrossRef] [PubMed]

30. Michalet-Doreau, B.; Fernandez, I.; Peyron, C.; Millet, L.; Fonty, G. Fibrolytic activities and cellulolytic bacterial community structure in the solid and liquid phases of rumen contents. Reprod. Nutr. Dev. 2001, 41, 187-194. [CrossRef] [PubMed]

31. Wallace, R.J.; McEwan, N.R.; McIntosh, F.M.; Teferedegne, B.; Newbold, C.J. Natural products as manipulators rumen fermentation. Asian Australas. J. Anim. 2002, 15, 1458-1468. [CrossRef]

32. Van Soest, P.J. Nutritional Ecology of the Ruminant, 2nd ed.; Cornell University Press: New York, NY, USA, 1994; p. 470.

33. Koening, K.M.; Newbold, C.J.; Mcintosh, F.M.; Rode, L.M. Effects of protozoa on bacterial nitrogen recycling in the rumen. J. Dairy Sci. 2000, 78, 2431-2445.

34. Attwood, G.; McSweeney, C.S. Methanogen genomics to discover targets for methane mitigation technologies and options for alternative $\mathrm{H}_{2}$ utilisation in the rumen. Aust. J. Exp. Agric. 2008, 48, 28-37. [CrossRef]

35. Hess, H.D.; Kreuzer, M.; Diaz, T.E.; Lascano, C.E.; Carulla, J.E.; Soliva, C.R.; Machmuller, A. Saponin rich tropical fruits affect fermentation and methanogenesis in faunated and defaunated rumen fluid. Anim. Feed Sci. Technol. 2003, 109, 79-94. [CrossRef]

36. Whitelaw, F.G.; Eadie, J.M.; Bruce, L.A.; Shand, W.J. Methane formation in faunated and ciliate-free cattle and its relationship with rumen volatile fatty acid proportions. Br. J. Nutr. 1984, 52, 261-275. [CrossRef]

37. Dohme, F.; Machmüller, A.; Estermann, B.L.; Pfister, P.; Wasserfallen, A.; Kreuzer, M. The role of the rumen ciliateprotozoa for methane suppression caused by coconut oil. Lett. Appl. Microbiol. 1999, 29, 187-192. [CrossRef]

38. Guyader, J.; Eugène, M.; Meunier, B.; Doreau, M.; Morgavi, D.P.; Silberberg, M.; Rochette, Y.; Gérard, C.; Loncke, C.; Martin, C. Additive methane-mitigating effect between linseed oil and nitrate fed to cattle. J. Anim. Sci. 2015, 93, 3564-3577. [CrossRef] 
39. Yoon, I.K.; Stern, M.D. Effect of Saccharomyces cerevisiae and Aspergillus oryzae cultures on ruminal fermentation in dairy cows. J. Dairy Sci. 1996, 79, 411-417. [CrossRef]

40. Wina, E.; Muetzel, S.; Becker, K. The impact of saponins or saponin-containing plant materials on ruminant production-areview. J. Agric. Food Chem. 2005, 53, 8093-8105. [CrossRef]

41. Santoso, B.; Kilmaskossu, A.; Sambodo, P. Effect of saponin from Biophytum petersianum Klotzsch on ruminal fermentation: Microbial protein synthesis and nitrogen utilization in goats. Anim. Feed Sci. Technol. 2007, 137, 58-68. [CrossRef]

42. Poungchompu, O.; Wanapat, M.; Wachirapakorn, C.; Wanapat, S.; Cherdthong, A. Manipulation of ruminal fermentation and methane production by dietary saponins and tannins from mangosteen peel and soapberry fruit. Arch. Anim. Nutr. 2009, 63, 389-400. [CrossRef] [PubMed]

43. Ramírez-Restrepo, C.A.; Tan, C.; O’Neil, C.J.; López-Villalobos, N.; Padmanabha, J.; Wang, J.K.; McSweeney, C.S. Methane production, fermentation characteristics, and microbial profiles in the rumen of tropical cattle fed tea saponin supplementation. Anim. Feed Sci. Technol. 2016, 216, 58-67.

44. Guyader, J.; Eugène, M.; Doreau, M.; Morgavi, D.P.; Gérard, C.; Loncke, C.; Martin, C. Tea saponin reduced methanogenesis in vitro but increased methane yield in lactating dairy cows. J. Dairy Sci. 2017, 100, 1845-1855. [CrossRef] [PubMed]

45. Mao, H.L.; Wang, J.K.; Zhou, Y.Y.; Liu, J.X. Effects of addition of tea saponins and soybean oil on methane production, fermentation and microbial population in the rumen of growing lambs. Livest. Sci. 2010, 129, 56-62. [CrossRef]

46. Vogels, G.D.; Hoppe, W.F.; Stumm, C.K. Association of methanogenic bacteria with rumen ciliates. Appl. Environ. Microbiol. 1980, 40, 608-612.

47. Tokur, M.; Chagan, I.; Ushida, K.; Kojima, Y. Phylogenetic study of methanogens associated with rumen ciliates. Curr. Microbiol. 1999, 39, 123-128. [CrossRef]

(C) 2019 by the authors. Licensee MDPI, Basel, Switzerland. This article is an open access article distributed under the terms and conditions of the Creative Commons Attribution (CC BY) license (http:/ / creativecommons.org/licenses/by/4.0/). 


\title{
Methane Emissions and the Use of Desmanthus in Beef Cattle Production in Northern Australia
}

\author{
Bénédicte Suybeng ${ }^{1}$, Edward Charmley ${ }^{2}$, Christopher P. Gardiner ${ }^{1}$, Bunmi S. Malau-Aduli ${ }^{3}$ and \\ Aduli E. O. Malau-Aduli ${ }^{1, *}$ \\ 1 Animal Genetics and Nutrition, Veterinary Sciences Discipline, College of Public Health, Medical and \\ Veterinary Sciences, Division of Tropical Health and Medicine, James Cook University, Townsville, \\ QLD 4811, Australia \\ 2 CSIRO Agriculture and Food, Private Mail Bag Aitkenvale, Australian Tropical Sciences and Innovation \\ Precinct, James Cook University, Townsville, QLD 4811, Australia \\ 3 College of Medicine and Dentistry, Division of Tropical Health and Medicine, James Cook University, \\ Townsville, QLD 4811, Australia \\ * Correspondence: aduli.malauaduli@jcu.edu.au; Tel.: +61-747-815-339
}

Received: 10 May 2019; Accepted: 6 August 2019; Published: 9 August 2019

Simple Summary: An in-depth review of Australia's tropical beef cattle production system is presented with emphasis on the use of Desmanthus, a tropical legume, as a nutritional supplementation strategy for the abatement and mitigation of methane emissions. It also identifies current knowledge gaps in in vivo methane emissions research.

\begin{abstract}
The Australian beef industry is a major contributor to the economy with an estimated annual revenue generation of over seven billion dollars. The tropical state of Queensland accounted for $48 \%$ of Australian beef and veal production in 2018. As the third biggest beef exporter in the world, Australia supplies 3\% of the world's beef exports and its agricultural sector accounts for an estimated $13.2 \%$ of its total greenhouse gas emissions. About $71 \%$ of total agricultural emissions are in the form of methane and nitrous oxide. In this review, an overview of the carbon footprint of the beef cattle production system in northern Australia is presented, with emphasis on the mitigation of greenhouse gases. The review also focuses on the tropical legume, Desmanthus, one of the more promising nutritional supplements for methane abatement and improvement of animal growth performance. Among the review's findings is the need to select environmentally well-adapted and vigorous tropical legumes containing tannins that can persistently survive under the harsh northern Australian conditions for driving animal performance, improving meat quality and reducing methane emissions. The paper argues that the use of appropriate legumes such as Desmanthus, is a natural and preferred alternative to the use of chemicals for the abatement of methane emanating from tropical beef cattle production systems. It also highlights current gaps in knowledge and new research opportunities for in vivo studies on the impact of Desmanthus on methane emissions of supplemented tropical beef cattle.
\end{abstract}

Keywords: methane emission; tropical beef cattle; Desmanthus; supplementation; growth performance; ruminant nutrition; legumes

\section{Introduction}

Global climate change is principally caused by greenhouse gas (GHG) emissions that result in warming of the atmosphere [1]. According to the Australian National Greenhouse Accounts [2], 13.2\% of GHG emissions emanate from agriculture, with methane and nitrous oxide accounting for $71 \%$ of 
total agricultural emissions [3]. In 2017, Australia produced an estimated 51,543.56 $\mathrm{Gg} \mathrm{CO}_{2}$-e of $\mathrm{CH}_{4}$ from enteric fermentation [3].

The world population is predicted to increase from 7.6 to 9.8 billion by 2050 [4]. Consequently, the world has to match the increased demand for food from a larger and more affluent population to its supply in an environmentally sustainable manner [5]. Livestock products constitute an important source of food for global food security by providing $33 \%$ and $17 \%$ of world protein and kilocalorie consumption, respectively [6]. Climate change constitutes a risk to livestock production due to its impact on the feed quality of crops and forages, animal performance, milk production, water availability, animal reproduction, livestock diseases and biodiversity [6]. Therefore, the challenge is to find ways to increase livestock productivity without compromising household food security while sustainably improving the natural resource base [7].

Beef cattle productivity in north Queensland is beset with climatic and nutritional challenges, due to prolonged drought, high climate variability, inadequate feed resources, low-quality pastures and the poor body condition of cattle [8]. In this seasonally dry, low-elevation, heavy textured soils and inland tropical region of north Queensland, there is an overwhelming need for integrating more productive, nutritious and persistent summer-growing legumes into existing low quality, grass-dominant pastures [8].

Existing cultivars lack the capacity to adapt to seasonally waterlogged duplex soils, infertile light-textured soils, heavy cracking clays and low rainfall conditions [9]. Gardiner [10] evaluated the performance characteristics of Desmanthus in contrasting tropical environments and found that it thrived and spred on heavier vertisol soils. Hall and Walker [9] conducted a study over a 15-year period in six different environments in the seasonally dry tropics of north Queensland and found that on cracking clay soils, Desmanthus species and Clitoria ternatea were the most persistent and productive legumes among 118 legume accessions.

Further evaluation and development of Desmanthus under commercial grazing management will be highly beneficial to northern Australian beef cattle graziers for improved productive and reproductive performances, better animal body condition and higher meat quality, particularly in the live cattle trade where northern Australia is the main gateway to this key business export market. The State of Queensland accounts for about $43 \%$ of the Australian cattle population [11] and has a $\mathrm{CH}_{4}$ emission from ruminants that has been estimated to account for 3\% of Australia's GHG [3]. Australia has a target to reduce its emissions by $5 \%$ below the 2000 level by 2020 and $26-28 \%$ below 2005 emissions by 2030. The Government allocated $\$ 2.55$ billion to the Emissions Reduction Fund (ERF) to help livestock producers use modern farming methods to store carbon in vegetation and soils towards reducing GHG [12]. Research into contemporary, scientific and sustainable ways to produce high quality beef in tropical Northern Australia with low methane emissions are paramount to Australia being competitive in the international market. Desmanthus spp. are among the most promising sown legume species for the vastly undeveloped semi-arid clay soil regions across northern Australia.

This review focusses on the carbon footprint of the beef cattle industry in northern Australia, explores mechanisms and methods of enteric methane production and abatement with a focus on Desmanthus as a potential pasture legume for mitigating methane emissions. Finally, the current knowledge gaps that could underpin future research are also reviewed.

\section{Carbon Footprint from the Beef Industry in Queensland}

\subsection{The Australian Beef Cattle Market}

Australia is the third biggest beef exporter in the world, supplying $3 \%$ of the world's beef exports with 1,500,000 tons of carcass weight exported annually. The Australian beef cattle industry accounted for $\$ 11.4$ billion in 2017-2018 [11]. Furthermore, the beef cattle industry employed 191,800 people in 2016-2017. Therefore, the beef industry plays a central role in the Australian economy, especially in the state of Queensland, where its 11.1 million head of cattle accounted for $48.1 \%$ of the Australian beef and veal production in 2017-2018 [11]. 


\subsection{The Different Sectors Included in the Carbon Footprint of the Beef Industry in Queensland}

The total net emissions attributed to agriculture in Queensland was 18,672.5 $\mathrm{Gg} \mathrm{CO}_{2}$-e in 2017 [3]. The beef industry in Queensland is the largest agricultural industry in the state [13]. Sources of GHG emissions from a typical beef enterprise comprise enteric fermentation in cattle $\left(\mathrm{CH}_{4}\right.$ and $\left.\mathrm{N}_{2} \mathrm{O}\right)$, burning of vegetation (intentional or accidental), energy use (electricity and fuel), land clearing, loss of pasture and decline in soil carbon [13,14]. A study conducted by Eady et al. [14] in two beef farms in Queensland showed that the carbon footprint of beef products at the farm gate ranged from 17.5-22.9 $\mathrm{kg} \mathrm{CO}-\mathrm{e} / \mathrm{kg}$ liveweight at Gympie and 11.6-15.5 kg CO $2-\mathrm{e} / \mathrm{kg}$ liveweight in the Arcadia Valley. They also found that enteric fermentation represented about 80\% (74\% at Arcadia Valley and 85\% at Gympie) of the overall 'cradle-to-farm gate' GHG emissions [14]. The last figures can be linked with the 70\% $\left(12,995.97 \mathrm{Gg} \mathrm{CO}_{2}\right.$-e) of agriculture GHG emissions coming from enteric fermentation from grazing beef cattle in Queensland in 2017 [3].

\subsection{The Principal Causes Inducing Enteric Methane Emissions}

\subsubsection{Rumen Microbial Fermentation}

The rumen is a dynamic and complex ecosystem composed essentially of anaerobic bacteria, protozoa, anaerobic fungi, methanogenic archaea and phages [15]. The microbes interact with each other and have a symbiotic relationship with the host. The breakdown of plant cell wall carbohydrates that are inedible by humans provides energy to the host [16]. Methane is produced exclusively by methanogenic archaea [15] via the hydrogenotrophic pathway using $\mathrm{CO}_{2}$ as the carbon source and $\mathrm{H}_{2}$ as the main electron donor, and less so through the utilization of methyl groups (methylotrophic pathway), or even less commonly from acetate (acetoclastic pathway) [15]. The methanogenesis reaction uses $\mathrm{H}_{2}$ to reduce $\mathrm{CO}_{2}$ to $\mathrm{CH}_{4}: \mathrm{CO}_{2}+4 \mathrm{H}_{2}=\mathrm{CH}_{4}+2 \mathrm{H}_{2} \mathrm{O}$ [17].

The main products of rumen microbial fermentation, as depicted in Figure 1, are volatile fatty acids (VFA) (acetic, propionic and butyric acids), carbon dioxide and methane [18]. In the rumen, the VFA formed are absorbed and used as a source of energy. On the contrary, $\mathrm{CO}_{2}$ and $\mathrm{CH}_{4}$ are eliminated by eructation from the rumen. Over $80 \%$ of the methane is synthesised in the rumen and the lower digestive tract produces the rest [18]. Northern beef cattle in Australia can generate about 32.2 to $184 \mathrm{~g}$ of methane per day [19], which represents an important energy loss to the animal ranging from $2 \%$ to $12 \%$ of gross energy intake depending on the nature of the diet [20]. Under a high forage diet, these losses are on the average, $7.2 \%$ of gross energy intake; $6.3 \%$ for an intermediate forage and $3.84 \%$ for a low forage (feedlot) [21].

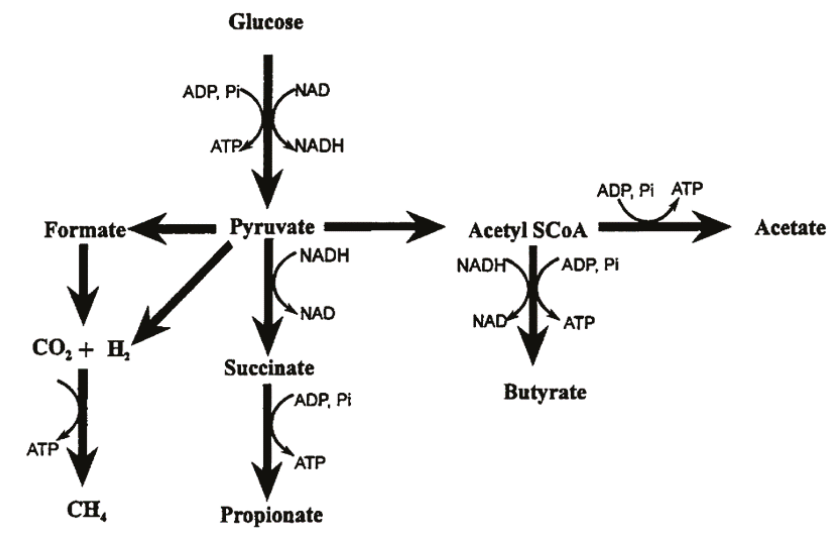

Figure 1. Principal end-products of carbohydrate fermentation in the rumen [18]. 


\subsubsection{Low Animal Performance Increases Methane Production}

Less efficient cattle can take longer to reach market weight and might only breed two out of three seasons. The longer an animal takes to reach market weight, the longer that animal is producing methane, with very little beef being marketed in return [20,22]. Arthur et al. [23] estimated genetic and phenotypic parameters for feed intake in Angus bulls and heifers, and showed that the feed conversion ratio defined by the amount of feed consumed divided by live weight gain was correlated genetically $(-0.62)$ and phenotypically $(-0.74)$ with the average daily gain (ADG). For instance, Charmley et al. [22] showed that by maintaining a liveweight (LW) gain of $0.5 \mathrm{~kg} /$ day for steers in the northern spear grass region by adding supplements to the pasture diet would reduce the turn-off age of the Japanese Ox market from 4 years (526 kg LW) to 2.3 years (650 kg LW). Gross margin budget and cashflow analyses for a 100 -cow herd showed a $61 \%$ internal rate of return over a 25 -year investment period, despite the higher cost for purchasing efficient bulls. It represents an annual benefit per cow of A \$8.76 [24]. Low animal productivity is associated with high methane output per unit of product (methane intensity) and low pasture quality is associated with high methane output per unit of dry matter intake [12]. For that reason, northern Australian beef herds are estimated to produce more methane than the more intensive systems in southern Australia [20]. For instance, Eady [25] showed that the GHG emissions of beef produced from cattle supply chain from Northern Australia to the Indonesian market were higher $(26 \mathrm{~kg} \mathrm{CO} 2$ equivalent/ $\mathrm{kg}$ liveweight) than beef produced in Southern Australian systems, where GHG emissions ranged from 5.4 to $14.5 \mathrm{~kg} \mathrm{CO}$ equivalent/kg liveweight for finished steers. They attributed it to the higher reproduction rate, faster turn-off and lower methane emissions per unit of feed intake permitted by a high pasture quality in the southern systems [25].

\subsubsection{Northern Australian Forage Diet Influences Rumen Microbiome and Methane Production}

In northern Australia, comprising the Kimberley and Pilbara districts of Western Australia, the Northern Territory and Queensland above the Tropic of Capricorn, the beef industry is dominated by large pastoral properties [10]. This part of Australia is characterised by a vast array of heavy clay or vertosol soils, where the range of available sown pasture legumes has long been regarded as being deficient [26]. There are also vast areas of light textured soils where the legume Stylosanthes has been successfully introduced. Pasture production is highly seasonal, with a wet season (November to April) characterised by growth, and a senescent period during the dry season. This induces a marked seasonal pattern of pasture availability and quality [27]. The prevailing pasture species are mainly C4 grasses, which have lower nutritional value than temperate grasses, and result in lower animal productivity than in temperate regions [28,29]. During the wet, hot summers, these pastures grow quickly and persist through the dry winter seasons as mature grasses [30-32]. The low livestock productivity in northern Australia is especially due to low protein content and low digestibility during the dry season [33]. The low digestibility (45\% organic matter) and nitrogen content (less than $7 \mathrm{~g}$ $\mathrm{N} / \mathrm{kg}$ dry matter (DM)) of these grasses during the dry season results in poor forage intakes and low annual growth rate of young cattle [30-32]. Animals tend to put on weight in the wet season and lose weight in the dry season. In northern Australia, it is not uncommon for 4-6 years old steers to be marketed [34]. Consequently, depending on the time of the year, liveweight gains in Northern Australia are around 70-240 kg/year for native pastures [35] compared to 250-300 kg/year for temperate pastures [36]. Growth rate is directly related to metabolisable energy intake, and can be markedly increased by replacing the feed base or by giving supplements to the animals [36].

Archimede et al. [37] showed that ruminants fed C4 grass produced 17\% more methane as L/kg organic matter intake than those fed C3 grass. Likewise, Perry et al. [29] found that steers fed a wet season pasture (crude protein $(\mathrm{CP})=90 \mathrm{~g} / \mathrm{kg} \mathrm{DM})$ or a high quality hay $(\mathrm{CP}=88 \mathrm{~g} / \mathrm{kg} \mathrm{DM}$ ) produced 5-10 $\mathrm{g} \mathrm{CH}_{4} / \mathrm{kg}$, digested less dry matter intake (DMI) and had about $3 \%$ less digestible energy intake than steers fed low quality hay $(\mathrm{CP}=25 \mathrm{~g} / \mathrm{kg} \mathrm{DM})$. They observed shorter rumen retention times in high quality hay fed steers, which decreased methane production per kilogram of DMI compared with low quality hay and the dry season pasture. This phenomenon can be explained with an increased rumen 
outflow rate [38]. The rise in rumen outflow rates is associated with higher concentrations of dissolved $\mathrm{H}_{2}$ that increase the growth rate of methanogens. The greater cellulose and hemicellulose content in tropical C4 grasses rather than neutral detergent soluble carbohydrates in grain diets results in higher methane emissions and a shift in rumen fermentation pathways from propionate to acetate [12,29]. The production of methane in the rumen is associated with the production of VFA. The formation of both acetic and butyric acids is accompanied by the production of $\mathrm{H}_{2}$ and $\mathrm{CO}_{2}$, whereas propionic acid production requires a net uptake of $\mathrm{H}_{2}$, which can reduce methanogenesis [38]. The production of propionic acid instead of acetic acid can be realised by replacing structural carbohydrates (forage) with easily fermented carbohydrates [38].

\section{Mitigation Techniques against Methane Emission}

\subsection{The Use of Chemicals for Rumen Manipulation to Reduce Methane Production}

\subsubsection{The Use of Chemicals to Control Protozoa, the Main Hydrogen Producer}

Some techniques such as defaunation and the utilisation of ionophores, have been used to control protozoa, the major producers of $\mathrm{H}_{2}$ from the rumen [39], so that less $\mathrm{H}_{2}$ is accessible for $\mathrm{CH}_{4}$ formation.

\section{Defaunation}

Defaunation techniques comprise synthetic chemicals such as copper sulphate, dioctylsodium sulfosuccinate, calcium peroxide, detergents and natural compounds, such as vitamin A, steroidal hormones or non-protein amino acids [40]. Dohme et al. [41] showed that defaunation using coconut oil immediately reduced methane formation by about $40 \%$ in vitro using non-lactating Brown Swiss cow fed hay. However, like other inhibitors of methanogenesis, numerous defaunation agents are toxic to the animal [42]. Moreover, defaunation techniques on-farm are currently non-existent [40].

Ionophores

Ionophores are classified as antibiotics and are synthetized by soil microorganisms that can modify the movement of cations, such as calcium, potassium and sodium through cell membranes. The ionophores that are particularly used to reduce methane emissions are monensin and lasalocid [43]. Guan et al. [44] showed that supplementing ionophores to 36 Angus yearling steers decreased enteric $\mathrm{CH}_{4}$ emissions (expressed as litres per kilogram) by $30 \%$ for the first two weeks for animals on a highly concentrated diet and by $27 \%$ for the first four weeks for animals on high and low-concentrate diets, respectively. They also indicated that alternative feeding of cattle with monensin and lasalocid in comparison to only monensin did not result in further decreases or longer periods of depressed enteric methane emissions. In contrast, McCaughey et al. [45], observed no difference in methane production in pasture-fed steers supplemented with $270 \mathrm{mg} / \mathrm{d}$ monensin controlled release capsule. According to Russell and Houlihan [46], the possibility of transmission of antibiotic resistance from animals to man through ionophores in animal feeds is not likely to happen. However, the use of monensin in cattle as a feed additive to increase growth and feed efficiency was phased out by the European Union Council Regulation in January 2006, but it has been re-evaluated and authorized as a feed additive for the control of coccidiosis in poultry [47].

Another technique using probiotics has also been developed. Although the mechanism used to decrease $\mathrm{CH}_{4}$ production is not yet clear, it may be due to the utilisation of metabolic $\mathrm{H}_{2}$ by acetogenic bacteria to produce acetate [40] or by decreasing the numbers of rumen ciliate protozoa [48]. Probiotics are microbial feed additives that affect fermentation in the rumen. The most widely used probiotics are yeasts such as Saccharomyces cerevisiae and Lactobacillus sporogenes [40]. McGinn et al. [49] found that a commercial yeast product (procreatin-7 yeast) fed to growing beef cattle induced a $3 \%$ reduction in $\mathrm{CH}_{4}$ production (g/g DMI). The use of probiotics appears to be an interesting method, but results have been unconvincing or yet to be confirmed in vivo [50]. 


\subsubsection{The Use of Chemicals to Control the Methanogen Numbers}

Methane inhibitors are chemical compounds with inhibitory effects on rumen archaea [40]. Studies using methane inhibitors such as chloroform, 3-nitrooxypropanol (3-NOP), carbon tetrachloride, methylene chloride, bromoethanesulphonate or bromochloromethane showed significant reductions in $\mathrm{CH}_{4}$ production [51-54]. For instance, Martinez Fernandez et al. [54] showed that methane production (in $\mathrm{g} / \mathrm{kg}$ DMI) reduced by $38 \%$ in animals supplemented with $3-\mathrm{NOP}$ and by $30 \%$ for Brahman steers supplemented with chloroform compared with the control group (Chloris gayana). Mathison et al. [42] indicated that methane inhibitors can reduce $\mathrm{CH}_{4}$ emissions on short-term basis by preventing the accumulation of $\mathrm{H}_{2}$ in the rumen, but because of microbial adaptation, the effects are rapidly neutralized and feed intake often depressed [42].

Overall, the utilisation of chemicals for rumen manipulation with subsequent mitigation of methane emission appears promising, but requires considerable further development due to inconclusive results (probiotics, ionophores), microbial adaptation (defaunation, methane inhibitors) and prohibited use of antibiotics in some countries [40].

\subsection{The Use of Diet Manipulation to Reduce Methane Production}

\subsubsection{The Use of Concentrates to Reduce Methane Production}

Supplements are frequently used in grazing systems when availability and/or quality of pasture is limiting animal performance. To promote good animal health, supplementary feeding should satisfy the animals' needs for protein, energy, roughage and minerals. This can be a regular part of the production cycle during the dry season. The use of supplements depends on the enterprise's production objectives and seasonal conditions [42]. Table 1 sums up the typical tropical supplements for critical seasons used in northern Australia, often chosen for their low cost [55-57].

Table 1. Typical tropical animal supplements for critical seasons $[55,56]$.

\begin{tabular}{ccc}
\hline Animal Nutrient Needs & Supplement & Critical Season \\
\hline Energy & Grains, molasses & Dry \\
Protein & Urea & Dry \\
Roughage & Silage, hay & Dry and wet \\
Minerals & Phosphorus & Wet \\
\hline
\end{tabular}

Purnomoadi et al. [58] found that offering concentrates to Indonesian Ongole crossbred young bulls twice a day significantly reduced methane production $\left(32.76 \mathrm{CH}_{4} \mathrm{~g} / \mathrm{kg} \mathrm{DMI}\right.$ ) compared to other bulls fed concentrate only once a day $\left(36.33 \mathrm{CH}_{4} \mathrm{~g} / \mathrm{kg} \mathrm{DMI}\right)$. The same study also showed that increasing the feeding frequency of concentrates resulted in a better feed utilisation (lower feed conversion rate) and increased animal productivity with a higher ADG (0.44 vs. $0.38 \mathrm{~kg} /$ day) [58]. This phenomenon can be explained by the change in fermented substrate from fibre to starch and the decline in ruminal $\mathrm{pH}$, inducing a reduction in the proportion of dietary energy converted to $\mathrm{CH}_{4}$ thereby increasing the level of concentrates in the diet [59]. Although increasing dietary concentrates may sometimes increase total carbon footprint by increasing the amount of emissions associated with total production, the use of pesticides, fertilisers and transportation infrastructure are indirect contributing factors [59].

\subsubsection{The Use of Legumes to Reduce Methane Production}

Interest in secondary plant compounds as possible methane mitigation strategy is rising, as plant preparations are viewed as natural alternatives to chemical additives, which are prone to negative perception from consumers [50]. The production of methane from rumen fermentation is generally lower with legumes than grass forages, principally due to the lower fibre content inducing a more rapid rate of passage through the rumen [59].

One of the plant extracts used to reduce methane emissions belongs to the tannin families [50]. 
Tannins are polyphenolic compounds of plant origin. There are two main types: Hydrolysable tannins (HT) (polyesters of gallic acid and various sugars) and condensed tannins (CT) (polymers of flavonoids) as depicted in Figure 2 [60]. Tannins are broadly distributed in the plant kingdom and are known to protect against infection, insects or animal herbivory [40]. Tannins have the ability to form complexes with dietary proteins, minerals and polymers, such as hemicellulose, cellulose and pectin, thus delaying digestion; this confers tannins with their anti-nutritive property [61].<smiles>Oc1cc(O)c2c(c1)O[C@H](c1ccc(O)c(O)c1)[C@H](O)C2</smiles>

Catechin (yields cyanidin pigments)<smiles>Oc1cc(O)c2c(c1)O[C@H](c1cc(O)c(O)c(O)c1)[C@H](O)C2</smiles>

Gallocatechin (yields delphiridin pigments)<smiles>O=C(O)c1cc(O)c(O)c(O)c1</smiles>

Gallic acid

Figure 2. Monomeric units of condensed (catechin and gallocatechin) and hydrolysable tannins (gallic and ellagic acid) [62].

Several legumes have been studied for their methane reduction properties. Hess et al. [63] showed that extracted tannins and legumes with high tannin levels from Calliandra calothyrsus induced a reduction in methane emissions, but also reduced the feeding value of the diet. The same observation was made by Tiemann et al. [64], who reported a reduction in $\mathrm{CH}_{4}$ production by up to $24 \%$ when an herbaceous high-quality legume (Vigna unguiculata) was replaced with tannin-rich plants (Calliandra calothyrsus or Flemingia macrophylla). They concluded that this reduction was mainly due to a reduction in fibre digestion and organic matter.

Leucaena leucocephala, a leguminous shrub that is abundant in the tropics, contains a significant amount of CT (33 to $61 \mathrm{~g} / \mathrm{kg} \mathrm{DM}$ ) [65] and a high protein content of 200 to $250 \mathrm{~g} / \mathrm{kg}$ DM [66]. Leucaena contains mimosine ranging from 40 to $120 \mathrm{~g} / \mathrm{kg}$ DM [67], and mimosine is an anti-nutritive compound that can be toxic at high DM intake $[65,67]$. However, in vitro $[65,68,69]$ and in vivo $[70,71]$ studies showed that the addition of Leucaena in the diet induces methane reduction. Soltan et al. [71] conducted an in vivo study with Santa Inês sheep and showed that Leuceana, compared to Bermuda grass (Cynodon dactylon) in the diet, decreased $\mathrm{CH}_{4}$ emissions and enhanced intake, body nitrogen retention, faecal nitrogen excretion and the elimination of urinary purine derivatives (a sign of the synthesis and availability of microbial proteins). In order to test the effect of tannins on methane production, they added polyethylene glycol (PEG), a tannin inhibitor, at a ratio of 1:1 PEG:Leucaena into the diet and did not see any significant difference in methane reduction with or without PEG. They suggested that there was no clear efficiency of tannins on methane emissions in sheep. Jones and Mangan [72] showed that the interchange reaction of PEG with an already formed tannin-protein complex depends 
on the quantity of tannins and complex age before PEG addition. They explained that any increase in both factors decreases the exchange. McSweeney et al. [73] showed that PEG addition (10 mg PEG/50 $\mathrm{mg}$ plant substrate) to in vitro fermentation can be used to analyse the effect of tannins on nitrogen digestibility. Bhatta et al. [74] showed that tannins suppress methanogenesis by reducing methanogenic populations in the rumen by either direct inhibition of methanogens or indirect interference with the protozoal population, resulting in a decrease in the number of methanogens symbiotically associated with the protozoal population. Beauchemin et al. [75] found that supplementing quebracho tannin extract linearly decreased the proportion of acetate, resulting in a linear decrease of the acetate to propionate ratio.

The antimethanogenic activity of tannin-containing plants has been credited mostly to the condensed tannin group because hydrolysable tannins are more toxic for the animal [76]. However, a study conducted by Jayanegara et al. [77] showed that HT had a greater effect in reducing $\mathrm{CH}_{4}$ emissions and had less negative effects on digestibility than CT. They attributed this observation to the lower risk of toxicity of CT than HT [59]. Ruminants consuming forage plants containing a high level of HT (Terminalia oblongata and the Indonesian shrub Clidemia hirta) showed toxicity symptoms through simple phenolics liberated in the gut [78] beyond the capacity of the liver to detoxify [79]. McMahon et al. [80] reported that high tannin concentrations exceeding 40 to $50 \mathrm{~g} / \mathrm{kg}$ dry matter in forages may diminish protein and dry matter digestibility in ruminants. Several experiments showed that a level of HT lower than $20 \mathrm{~g} / \mathrm{kg}$ DM did not cause detrimental effects on production parameters [77]. At low to moderate concentrations, CT raises dietary protein quantity, in particular, the essential amino acids. CT (polyphenolics) are able to form complexes with proteins in the rumen under the near-neutral condition of $\mathrm{pH} 6.5$ and protect them from deamination, thus reducing nitrogen availability to rumen microorganisms [60,72]. However, at $\mathrm{pH} 2.5$ in the abomasum and abomasal end of the duodenum, the complex becomes disrupted and unstable, thereby permitting protein degradation by acidic proteases [72].

In summary, legumes and plant extracts such as tannins, seem to be good alternatives for methane abatement as they are perceived to be more natural than the other methods [50]. However, the addition of plant extracts does not always show conclusive results. For instance, the addition of Leucaena can be toxic due to high mimosine content [67], and Calliandra can decrease feed digestibility [64]. Only Desmanthus, a tropical legume containing $\mathrm{CT}$, has so far shown promising results in reducing methane emissions [68,81] and improving animal growth performance [82-85].

\section{The Use of Legumes to Increase Pasture Quality and Animal Performance in Northern Australia}

\subsection{The Use of Legumes to Increase Pasture quality}

\subsubsection{Ability to Fix Nitrogen}

Legumes are rich in nitrogen because they have the capacity to biologically fix nitrogen and transform it into leguminous protein [86]. For instance, Wetselaar [87] measured the amount of nitrogen fixed by four legumes: Townsville Lucerne (Stylosanthes humilis), guar (Cyamopsis tetragonoloba), cowpea (cv. Poon) and peanut (cv. Natal common) on Tippera clay loam in three growing seasons. They showed that the total amount of $\mathrm{N}$ added to the soil-plant system in three seasons by the four legumes was 220, 220, 270 and $125 \mathrm{~kg} / \mathrm{ha}$ respectively. Another study on Tippera clay loam soil in the Northern Territory displayed a higher nitrogen uptake by $30 \mathrm{~kg} / \mathrm{ha}$ after the first year, and by $55 \mathrm{~kg} / \mathrm{ha}$ after the third year of maize crops on a Caribbean stylo (Stylosanthes hamata cv. Verano) legume ley compared to a grass ley [88]. The presence of Rhizobium bacteria-legume symbioses is capable of fixing nitrogen under dry conditions that benefits not only the legumes, but associated grasses also [89].

Northern Australian graziers are concerned about the 'rundown' of buffel grass, which constitutes the dominant sown species in the area. Buffel grass pastures older than 10-20 years since establishment have declined by up to $50 \%$ in all districts. This decrease is principally related to the lack of nitrogen in 
the soil. Economic analysis suggests that the best solution to overcome this 'rundown' is to establish a range of adapted pasture legumes into existing grass-only pastures in order to introduce more nitrogen. Seeding legumes into a predominantly grass pasture can enable a regain of $30-50 \%$ of lost production from pasture rundown and improve economic returns [90].

\subsubsection{Ability to Extract Moisture and Nutrients from the Soil}

Legumes have taproots that allow for moisture and nutrient extraction from deep down the soil profile. This assists with more drought tolerance, greener and productive longevity than grasses [91]. Thus, forage legumes can have significant impacts on the environment, including nitrogen fixation, improvement of soil quality, protection from water and wind erosions [92] and improvement of carbon accumulation [93].

\subsection{The Use of Legumes to Increase Animal Productivity}

Studies have shown that legumes increase animal productivity due to improved crude protein content and feed digestibility [10,94]. For instance, liveweight gains of $190 \mathrm{~kg} /$ head/year were observed on improved Townsville Stylosanthes legumes compared to $80 \mathrm{~kg} / \mathrm{head} / \mathrm{year}$ on native pastures at a stocking rate of one beast per 2.4 hectares [8]. Bowen et al. [95] conducted a study on 21 sites located in the Fitzroy river catchment (Queensland) across 12 commercial beef cattle properties. They showed that tropical legume forages constituted high quality diets (Leucaena-grass (120 and 59), lablab (115 and 59), and butterfly pea-grass (97 and 59), g CP/kg DM) and dry matter digestibility (DMD) in comparison with perennial grass pastures that had $66 \mathrm{~g} \mathrm{CP} / \mathrm{kg}$ DM and 55\% DMD. These high quality diets resulted in an annual per ha liveweight gain of $2.6 \mathrm{~kg}$ when cattle grazed paddocks containing Leucaena and Butterfly peas with perennial C4 grass which was 1.6 times higher than for cattle grazing only perennial grass pastures. Coates et al. [9] found that the introduction of legumes such as stylo pastures improved annual liveweight gains ( $0.45 \mathrm{~kg} /$ day), decreased turn-off age by at least 3-6 months, extended cattle growth into the late wet season and minimised dry season liveweight loss [95].

Thus, it seems the sowing of legumes in grass improves pasture quality and animal performance. Throughout the long annual dry seasons of northern Australia, the semiarid clay soil region has no sown pasture legumes with recognized adaptation and persistence [96]. Therefore, to help meet beef cattle production requirements, farmers use nutritional supplementation strategies [97], agistment or selling of stock to reduce stocking rates [55].

\subsection{Northern Australian Legumes}

Northern Australian legumes such as Crotalaria spp., Cullen spp., Glycine spp., Indigofera spp., Rhynchosia spp., Sesbania spp. and Vigna spp. are often described as grazing intolerant [98], toxic and/or unpalatable [10]. Some legumes such as Stylosanthes with its cultivars Seca (S. scabra) and Verano (S. hamata) have been incorporated into native grass pastures on light textured soils such as black spear grass (Heteropogon contortus). This legume has been shown to be beneficial in increasing cattle liveweight gains in the range of 30-60 kg/head/year and improving stocking rates $[9,10]$. In semi-arid northern regions with textured clay soils (vertisols), the stylos are not usually well adapted and few other sown legume species have shown persistence in such environments [10]. Leucaena is another notable success in the development of exotic species in northern Australia, especially after the discovery by Raymond Jones that a bacterium (Synergistes jonesii) could degrade DHP (3-hydroxy-4(IH) pyridone), a breakdown product of mimosine, the anti-nutritional toxic agent in Leucaena $[98,99]$. The search for legumes broadly adapted to the Australian subtropics had limited success. Twining tropical legumes including C. pascuorum, Clitoria ternatea (butterfly pea), Sirano (Macroptilium atropurpureum) and Centrosema mole (centro) did not persist under grazing and could not regenerate from seeds when the first-established plants died [98]. Some other legumes were persistent but suffered from other deficiencies such as limited environmental adaptation to the wide range of the Australian subtropical environment, low palatability and weedy characteristics that reduced their attractiveness [98]. However, Desmanthus, a legume native to the Americas has been shown 
to persist under heavy grazing on clay soils [14]. In the 1990s, various Desmanthus accessions persisted for more than two decades in abandoned trial sites across remote northern and central west Queenslands' semi-arid clay soil regions [26]. The Commonwealth Scientific and Industrial Research Organisation and Queensland Department of Primary Industries have introduced numerous accessions of Desmanthus over the past 50 years [100].

\section{Desmanthus as a Potential Pasture Species for Ruminants}

\subsection{Performance Characteristics of Desmanthus}

Desmanthus is included in the Dichrostachys group of the tribe Mimoseae [101]. It can grow on a wide range of soil types from coastal sands to rocky limestone and saline soils. Desmanthus spp. are often selected for their persistence on heavy clay such as alkaline soils, but will grow on lighter soils of neutral to alkaline $\mathrm{pH}$ [102]. In exotic locations such as Queensland, with its average annual rainfall of $616 \mathrm{~mm}$ (1900 to 2015) [103], Desmanthus is well adapted and capable of thriving in a 550-1000 mm average rainfall environment [102]. The plant grows better in humid-tropical locations with annual average temperatures ranging from 22 to $28^{\circ} \mathrm{C}$. The legume can be defoliated by heavy frost, but is able to regrow from crowns when the moisture and heat conditions are sufficient [103]. Its deep roots enable it to be grown with stoloniferous grasses such as buffel grass (Cenchrus ciliaris), Bambatsi panic (Panicum coloratum var. makarikariense) and Queensland bluegrass (Dichanthium sericeum). Minor damages in seed crops by psyllid insects (Accizia spp.) in northern Australia and by seed-eating bruchid beetle (5 Acanthoscelides spp. and Stator sp.) have been reported [102]. Jones and Brandon [104] studied the persistence and productivity of eight accessions of Desmanthus virgatus under grazing at five levels of presentation yield at the end of the growing season in subtropical and subcoastal Queensland from 1989 to 1996 . After surface sowing Desmanthus at $4 \mathrm{~kg} / \mathrm{ha}$ in 1989, they found that the yields averaged $0.7 \mathrm{t} / \mathrm{ha}$ at the highest grazing pressure and $4.7 \mathrm{t} / \mathrm{ha}$ at the lowest grazing pressure [104]. The best of these varieties has been selected, evaluated, propagated and commercialised by Agrimix Pty Ltd. (James Cook University's commercialisation partner, Virginia, QLD, Australia), as Progardes ${ }^{\text {TM }}$ which stands for PROtein, GARdiner and Desmanthus; and includes new selections of the species D. bicornutus, D. leptophyllus and D. virgatus. The five selected cultivars are: JCU1 (D. leptophyllus), JCU 2, 3, 5 (D. virgatus) and JCU 4 (D. bicornutus) [10]. The different species give a large collection of early to late maturity types, habits (herbaceous to suffructicose), edaphic and climatic tolerances [104]. Progardes $^{\mathrm{TM}}$ seeds have been sown in about 20,000 ha of commercial paddocks across northern New South Wales, Northern Territory and principally Queensland, using several sowing techniques such as aerial seeding, seeding following a blade plough and stick raking [10]. Desmanthus has an average crude protein content of $21 \%$ [105] with $20.2 \%$ crude protein in the leaf, $11.9 \%$ in the stem and $17 \%$ in the pods of Progardes ${ }^{\mathrm{TM}}$ Desmanthus [106]. On the contrary, Australian native grasses (bluegrass, spear grass) have average crude protein levels between 10\% at the beginning and $5 \%$ at the end of the wet season [101]. During the dry or winter season, Desmanthus dies back to the base, and each year, when moisture and/or temperature conditions are favourable, new stems sprout [101]. A shallow planting depth (0.5-2.0 cm in at least 50-60 cm depth of good moist soil [103]) and weed control have been

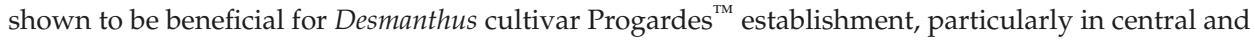
southern Queensland. In general, the end of the dry season/start of the wet season is a good period to sow Desmanthus seeds and enable grazing during the summer/autumn in northern Queensland [10]. However, due to unpredictable annual rainfall, it is advisable to plant $3 \mathrm{~kg}$ of Progardes ${ }^{\mathrm{TM}}$ seeds/ha as a combination of half-hard and half-soft (scarified) seeds. Scarification has been used in the horticultural industry to improve the rate of seed germination by chemically or physically altering the seed coat. The purpose is to increase the diffusion rates of water and gases into the seeds [107]. Scarification of Progardes ${ }^{\mathrm{TM}}$ by hot water or with a mechanical abrasive disc for commercial batches enhances germination from $10 \%$ to $70-80 \%$ (with scarification) [10]. Its seed yield range varies between 400 and $600 \mathrm{~kg} / \mathrm{ha}$ from direct harvesting [102,108]. The ability of Desmanthus to spread and become a 
potential weed is limited. Late flowering cultivars such as cv. Bayamo produce limited seeds while early flowering cultivars have high seed yields resulting in high soil seed reserves. These reserves lead to a thickening of the planted areas with a slow spread from the original plantings [102,108]. However, hard seeds of leguminous species are known to resist digestion and can be dispersed by ruminants in faeces (endozoochory). Gardiner et al. [109] found that most JCU2 seeds fed to sheep passed through the animals in $48 \mathrm{~h}$ with only $9 \%$ of the fed seeds recovered, with about $60 \%$ remaining viable.

Consequently, Desmanthus seems to be a promising legume in northern Australia due to its high DM productivity, seed production, tolerance of heavy grazing in alkaline, sodic, saline and heavy clay soils and its persistence in low rainfall environments [102].

\subsection{Desmanthus as a Potential Pasture to Reduce Methane Production}

As depicted in Table 2, Vandermeulen et al. [81] evaluated organic matter degradability (OMD) and methane production via in vitro incubation of ruminal fluid from grazing Brahman (Bos indicus) steers on Rhodes grass (as control), Desmanthus bicornutus, D. leptophyllus and D. virgatus harvested from Agrimix Pty. Ltd. commercial plots. They showed that $D$. leptophyllus had a significantly lower methane emission per unit of fermented organic matter during winter in comparison to the control and other Desmanthus species. For instance, after $72 \mathrm{~h}$ of incubation, $29.56 \mathrm{~mL} \mathrm{CH}_{4} / \mathrm{g} \mathrm{OM}$ (organic matter) fermented was emitted in the presence of D. leptophyllus; $38.72 \mathrm{~mL} \mathrm{CH}_{4} / \mathrm{g} \mathrm{OM}$ was fermented for the control; and 39.90 and $32.94 \mathrm{~mL} \mathrm{CH}_{4} / \mathrm{g}$ OM fermented for D. virgatus and D. bicornutus respectively [81]. They also found a negative correlation between HT concentration in Desmanthus forages and $\mathrm{CH}_{4}$ emission per g of OM fermented. Consequently, they hypothesised a possible anti-methanogenic property of HT [81]. Durmic et al. [68] in their study comparing fermentation parameters and nutritive values between plant species and across seasons, showed that Desmanthus leptophyllus produced less methane than Leucaena, and had reduced volatile fatty acid concentrations.

\subsection{Desmanthus as a Potential Pasture to Increase Animal Production}

Gardiner and Parker [83] showed that steers grazing a mixed buffel grass-Progardes ${ }^{\mathrm{TM}}$ pasture in central Queensland gained an extra $40 \mathrm{~kg}$ liveweight over a 90-day period in comparison to steers on a buffel grass-only based diet during the dry season (Table 2). Another study conducted in central Queensland has shown that cattle grazing paddocks containing buffel grass with Progardes ${ }^{\mathrm{TM}}$ at a population density of 7 plants $/ \mathrm{m}^{2}$ had an additional gain of $40 \mathrm{~kg} /$ head compared to steers grazing only buffel grass [82]. A 56-day feeding trial with 24 growing goats showed that supplementing animals with $40 \%$ D. bicornutus and alfalfa induced an average daily gain of $60.9 \mathrm{~g} /$ day compared to $82.3 \mathrm{~g} /$ day on alfalfa only [97]. Rangel and Gardiner [85] showed the potential advantage of providing $30 \%$ Desmanthus to sheep on a Mitchell grass hay diet. They observed reduced weight loss, higher feed intake and wool growth exceeding $19 \%$ over the 6 week experimental duration. Sheep showed a positive nitrogen balance and significantly enhanced weight gains and intakes by supplementing $D$. leptophyllus to a Flinders grass diet [84].

Table 2. Effects of Desmanthus on methane production, growth performance and rumen fermentation ${ }^{a}$.

\begin{tabular}{|c|c|c|c|c|c|}
\hline $\begin{array}{l}\text { Desmanthus } \\
\text { Species }\end{array}$ & Experiment & Dosage & $\begin{array}{l}\text { Control } \\
\text { Dosage }\end{array}$ & Effects & References \\
\hline $\begin{array}{l}\text { D. bicornutus, } \\
\text { D. leptophyllus } \\
\text { or D. virgatus }\end{array}$ & $\begin{array}{l}\text { In vitro } \\
\text { (Brahman } \\
\text { steers rumen } \\
\text { fluid) }\end{array}$ & $\begin{array}{l}1 \mathrm{~g} \text { Desmanthus }+125 \\
\mathrm{~mL} \text { rumen fluid }\end{array}$ & $\begin{array}{l}1 \mathrm{~g} \text { Rhodes grass } \\
\text { forage }+125 \\
\mathrm{~mL} \text { rumen fluid }\end{array}$ & $\downarrow \mathrm{ME}, \mathrm{VFA}$ & [81] \\
\hline D. leptophyllus & $\begin{array}{l}\text { In vitro (sheep } \\
\text { rumen fluid) }\end{array}$ & $\begin{array}{l}10 \mathrm{~mL} \text { of } 1: 1.3 \text { or } \\
1: 1.5 \text { dilution of } \\
\text { inoculum:buffer }+ \\
0.1 \mathrm{~g} \text { Desmanthus }\end{array}$ & $\begin{array}{l}10 \mathrm{~mL} \text { of } 1: 1.3 \\
\text { or } 1: 1.5 \text { dilution } \\
\text { of } \\
\text { inoculum:buffer } \\
+0.1 \mathrm{~g} \text { grass }\end{array}$ & $\downarrow \mathrm{ME}, \mathrm{VFA}$ & [68] \\
\hline
\end{tabular}


Table 2. Cont.

\begin{tabular}{|c|c|c|c|c|c|}
\hline $\begin{array}{l}\text { Desmanthus } \\
\text { Species }\end{array}$ & Experiment & Dosage & $\begin{array}{l}\text { Control } \\
\text { Dosage }\end{array}$ & Effects & References \\
\hline Progardes $^{\mathrm{TM}}$ & Steers & $\begin{array}{l}\text { Paddock with buffel } \\
\text { grass and } \\
\text { Progardes }^{\mathrm{TM}}\end{array}$ & $\begin{array}{l}\text { Paddock with } \\
\text { buffel grass }\end{array}$ & $\uparrow \mathrm{LW}$ & [83] \\
\hline Progardes $^{\mathrm{TM}}$ & Steers & $\begin{array}{l}\text { Paddock Progardes }{ }^{\mathrm{TM}} \\
\left(7 \text { plants } / \mathrm{m}^{2}\right) \text { and } \\
\text { buffel grass }\end{array}$ & $\begin{array}{l}\text { Paddock with } \\
\text { buffel grass }\end{array}$ & $\uparrow \mathrm{LW}$ & [82] \\
\hline D. bicornutus & Goats & $\begin{array}{l}40 \% \text { Desmanthus in } \\
\text { the diet }+ \text { alfalfa }\end{array}$ & Alfalfa & $\downarrow \mathrm{LW}$ & [110] \\
\hline $\begin{array}{l}\text { D. virgatus, } D \text {. } \\
\text { pubescens or } D \text {. } \\
\text { leptophyllus }\end{array}$ & Sheep & $\begin{array}{l}30 \% \text { Desmanthus + } \\
\text { Mitchell grass hay }\end{array}$ & Mitchell grass & $\begin{array}{l}\uparrow \mathrm{LW}, \\
\uparrow \text { Intake, } \\
\uparrow \text { Wool growth }\end{array}$ & [85] \\
\hline D. leptophyllus & Sheep & \multicolumn{2}{|c|}{$\begin{array}{l}\text { Ad libitum flinders grass hay }+D \text {. } \\
\text { leptophyllusor either D. leptophyllus or } \\
\text { flinders grass hay }\end{array}$} & $\begin{array}{l}\uparrow \mathrm{LW}, \\
\uparrow \text { positive } \mathrm{N} \\
\text { balance with } \\
\text { Desmanthus }\end{array}$ & [84] \\
\hline
\end{tabular}

${ }^{\text {a ME}}$, methane emissions; VFA, volatile fatty acids; LW, liveweight, $\downarrow$, decrease; $\uparrow$, increase.

\section{Implications, Future Research and Conclusions}

Australia as the third biggest beef exporter in the world, and particularly the state of Queensland, that produced almost half of Australia's beef and veal in 2017-2018 [11], is heavily reliant on the beef industry. Enteric fermentation in livestock represents three quarters of the agricultural GHG emissions in the form of methane and nitrous oxide, and methane production represents a significant energy loss to the animal (2 to $12 \%$ of gross energy) [3,20]. The Australian government allocated $\$ 2.55$ billion to the Emissions Reduction Fund in 2018 [26]. This was to encourage livestock producers to use innovative methods to store carbon in vegetation and soils for reducing GHG. Queensland is most concerned by enteric fermentation emissions because its beef production is the largest agricultural industry in the state [13]. Its enteric fermentation coming from grazing beef cattle represents $70 \%$ of agricultural GHG emissions [3] and also represents about $80 \%$ of the overall 'cradle-to-farm gate' GHG emissions [14]. However, prolonged drought, high climate variability, low quality pastures and heavy textured soils in north Queensland constitute a challenge for beef cattle productivity characterised by the poor body condition of cattle [97]. Selection of environmentally well-adapted and vigorous legumes that can persist in the harsh climatic conditions of northern Australia is a good solution for alleviating various nutritional problems faced by livestock in this tropical part of Australia. Legumes enable an increase in animal production due to higher protein content and digestibility in comparison to native tropical grasses [10]. The roots of legumes enable ready access to deep water, introduce nitrogen in the soil and stabilize associated grasses [89]. The tropical legume, Desmanthus, seems to be a promising legume, due to its high DM productivity, seed production, tolerance of heavy grazing in alkaline, sodic, saline and heavy clay soils and its persistence in low rainfall environments [102]. For future studies using Desmanthus, it is important to keep in mind its establishment limitations on heavy soils due to its small sized seeds that can also constitute a risk for short-term pastures $(<3$ years) [102]. Furthermore, Desmanthus containing condensed tannins, showed promising results in decreasing methane emissions [68,81] and improving animal growth performance [82-85]. The legume also seems to be a good alternative for methane abatement, because it is a better natural alternative to chemical methods and concentrate supplementation [50]. However, no study has been conducted on the impact of Desmanthus on in vivo methane emissions in northern Australia. Thus, further studies should be conducted in vivo to test the effects of Desmanthus on methane emissions from supplemented live cattle in northern Australia. 
Author Contributions: Conceptualization, A.E.O.M.-A., E.C., C.P.G., B.S.M.-A. and B.S.; methodology, A.E.O.M.-A., E.C., C.P.G., B.S.M.-A. and B.S.; software, A.E.O.M.-A.; validation, A.E.O.M.-A., E.C., C.P.G. and B.S.M.-A.; formal analysis, B.S.; investigation, B.S.; resources, A.E.O.M.-A., E.C., C.P.G. and B.S.M.-A.; data curation, writing—original draft preparation, B.S.; writing—reviewing and editing, A.E.O.M.-A., E.C., C.P.G. and B.S.M.-A.; supervision, A.E.O.M.-A., E.C., C.P.G. and B.S.M.-A.; project administration, A.E.O.M.-A., C.P.G; funding acquisition, A.E.O.M.-A., C.P.G. and E.C.

Funding: This research was funded by the Cooperative Research Centre for Developing Northern Australia (CRC-DNA) Projects [grant number CRC P-58599] from the Australian Government's Department of Industry, Innovation and Science, and a PhD scholarship funded by the College of Public Health, Medical and Veterinary Sciences, James Cook University, Queensland, Australia, awarded to the first named author.

Acknowledgments: The authors gratefully acknowledge James Cook University's (JCU) College of Public Health, Medical and Veterinary Sciences, the Cooperative Research Centre for Developing Northern Australia (CRC-DNA), Meat and Livestock Australia (MLA) and the Commonwealth Scientific and Industrial Research Organisation (CSIRO)-JCU-Agrimix Joint Research Project.

Conflicts of Interest: The authors declare no conflict of interest. The funders had no role in the design of the study; collection, analyses, or interpretation of data; in the writing of the manuscript, or in the decision to publish the results.

\section{References}

1. Intergovernmental Panel on Climate Change. Climate change 2007: The physical science basis. Agenda 2007, 6,333 .

2. Australia's National Greenhouse Accounts. Quarterly Update of Australia's National Greenhouse Gas Inventory: June 2018; Australian Government Department of the Environment and Energy: Canberra, Australia, 2018. Available online: http://www.environment.gov.au/climate-change/climate-science-data/greenhouse-gasmeasurement/publications/quarterly-update-australias-national-greenhouse-gas-inventory-june-2018 (accessed on 17 March 2019).

3. Australian Greenhouse Emissions Information System. In National Greenhouse Gas Inventory-Kyoto Protocol Classifications; Australian Government Department of the Environment and Energy: Canberra, Australia, 2017. Available online: http://ageis.climatechange.gov.au/ (accessed on 26 July 2019).

4. United Nations. World Population Projected to Reach 9.8 Billion in 2050, and 11.2 Billion in 2100. 2017. Available online: https://www.un.org/development/desa/en/news/population/world-population-prospects2017.html (accessed on 17 March 2019).

5. Godfray, H.C.J.; Beddington, J.R.; Crute, I.R.; Haddad, L.; Lawrence, D.; Muir, J.F.; Toulmin, C. Food security: The challenge of feeding 9 billion people. Science 2010, 327, 812-818. [CrossRef]

6. Rojas-Downing, M.M.; Nejadhashemi, A.P.; Harrigan, T.; Woznicki, S.A. Climate change and livestock: Impacts, adaptation, and mitigation. Clim. Risk Manag. 2017, 16, 145-163. [CrossRef]

7. Wright, I.A.; Tarawali, S.; Blümmel, M.; Gerard, B.; Teufel, N.; Herrero, M. Integrating crops and livestock in subtropical agricultural systems. J. Sci. Food Agric. 2012, 92, 1010-1015. [CrossRef]

8. Winks, L. Townsville stylo research at Swan's Lagoon. Trop. Grassl. 1973, 7, 201.

9. Hall, T.J.; Walker, R.W. Pasture legume adaptation to six environments of the seasonally dry tropics of north Queensland. Trop. Grassl. 2005, 39, 182-196.

10. Gardiner, C.P. Developing and commercializing new pasture legumes for clay soils in the semi-arid rangelands of northern Australia: The new Desmanthus cultivars JCU 1-5 and the Progardes story. In Tropical Forage Legumes: Harnessing the Potential of Desmanthus and Other Genera for Heavy Clay Soils; Lazier, J.R., Ahmad, N., Eds.; CABI: Wallingford, UK, 2016; pp. 283-304.

11. MLA. Fast Facts Australia's Beef Industry. 2018. Available online: https://www.mla.com.au/globalassets/ mla-corporate/prices--markets/documents/trends--analysis/fast-facts--maps/mla_beef-fast-facts-2018.pdf (accessed on 17 March 2019).

12. Commonwealth of Australia. Emissions Reduction Fund-Overview. 2019. Available online: http://www.environment.gov.au/system/files/resources/cef73480-9dea-4436-bb15-4882345ae9a5/files/erffactsheet-overview.pdf (accessed on 17 March 2019).

13. Bray, S.; Willcocks, J. Net Carbon Position of the Queensland Beef Industry; Queensland Department of Employment, Economic Development and Innovation: Brisbane, Australia, 2009. 
14. Eady, S.; Viner, J.; MacDonnell, J. On-farm greenhouse gas emissions and water use: Case studies in the Queensland beef industry. Anim. Prod. Sci. 2011, 51, 667-681. [CrossRef]

15. Morgavi, D.; Forano, E.; Martin, C.; Newbold, C. Microbial ecosystem and methanogenesis in ruminants. Animal 2010, 4, 1024-1036. [CrossRef] [PubMed]

16. Huws, S.A.; Creevey, C.J.; Oyama, L.B.; Mizrahi, I.; Denman, S.E.; Popova, M.; Hess, M. Addressing global ruminant agricultural challenges through understanding the rumen microbiome: Past, present, and future. Front. Microbiol 2018, 9, 2161. [CrossRef]

17. Czerkawski, J.W. An Introduction to Rumen Studies; Elsevier: Amsterdam, The Netherlands, 2013.

18. Immig, I. The rumen and hindgut as source of ruminant methanogenesis. Environ. Monit. Assess. 1996, 42, 57-72. [CrossRef] [PubMed]

19. Charmley, E.; Williams, S.R.O.; Moate, P.J.; Hegarty, R.S.; Herd, R.M.; Oddy, V.H.; Hannah, M.C. A universal equation to predict methane production of forage-fed cattle in Australia. Anim. Prod. Sci. 2016, 56, 169-180. [CrossRef]

20. Johnson, K.A.; Johnson, D.E. Methane emissions from cattle. J. Anim. Sci. 1995, 73, 2483-2492. [CrossRef] [PubMed]

21. Gavrilova, O.; Leip, A.; Dong, H.; MacDonald, J.D.; Alfredo, C.; Bravo, G.; Widiawati, Y. 2019 Refinement to the 2006 IPCC Guidelines for National Greenhouse Gas Inventories. Available online: https://www.ipccnggip.iges.or.jp/public/2019rf/index.html (accessed on 26 July 2019).

22. Charmley, E.; Stephens, M.L.; Kennedy, P.M. Predicting livestock productivity and methane emissions in northern Australia: Development of a bio-economic modelling approach. Aust. J. Exp. Agric. 2008, 48, 109-113. [CrossRef]

23. Arthur, P.; Archer, J.; Johnston, D.; Herd, R.; Richardson, E.; Parnell, P. Genetic and phenotypic variance and covariance components for feed intake, feed efficiency, and other postweaning traits in Angus cattle. J. Anim. Sci. 2001, 79, 2805-2811. [CrossRef] [PubMed]

24. Exton, S.; Herd, R.; Davies, L.; Archer, J.; Arthur, P. Commerical Benefits to the Beef Industry from Genetic Improvement in Net Feed Efficiency. Asian Australas. J. Anim. 2000, 13, 338-341.

25. Eady, S.J. Undertaking a Life Cycle Assessment for the Livestock Export Trade; Meat \& Livestock Australia Limited: North Sydney, Australia, 2011.

26. Pengelly, B.C.; Conway, M.J. Pastures on cropping soils: Which tropical pasture legume to use? Trop. Grassl. 2000, 34, 162-168.

27. Tothill, J.C.; Gillies, C. The Pasture Lands of Northern Australia: Their Condition, Productivity and Sustainability; Tropical Grasslands Society of Australia: St Lucia, Australia, 1992.

28. Hattersley, P. The distribution of C 3 and C 4 grasses in Australia in relation to climate. Oecologia 1983, 57, 113-128. [CrossRef] [PubMed]

29. Perry, L.; Al Jassim, R.; Gaughan, J.; Tomkins, N. Effect of feeding forage characteristic of wet-or dry-season tropical C4 grass in northern Australia, on methane production, intake and rumen outflow rates in Bos indicus steers. Anim. Prod. Sci. 2017, 57, 2033-2041. [CrossRef]

30. Hennessy, D.; Williamson, P.; Nolan, J.; Kempton, T.; Leng, R. The roles of energy-or protein-rich supplements in the subtropics for young cattle consuming basal diets that are low in digestible energy and protein. J. Agric. Sci.-Camb. 1983, 100, 657-666. [CrossRef]

31. McLennan, S.R. Developing Profitable Strategies for Increasing Growth Rates of Cattle Grazing Tropical Pastures; Meat \& Livestock Australia Limited: North Sydney, Australia, 1997; Project DAQ, 100.

32. Shaw, N.; Bisset, W. Characteristics of a bunch spear grass (Heteropogon contortus (L). BEAUV.) pasture grazed by cattle in subtropical Queensland. Aust. J. Agric. Res. 1955, 6, 539-552. [CrossRef]

33. Poppi, D.P.; McLennan, S.R. Nutritional research to meet future challenges. Anim. Prod. Sci. 2010, 50, 329-338. [CrossRef]

34. Poppi, D.P.; McLennan, S.R. Protein and energy utilization by ruminants at pasture. J. Anim. Sci. 1995, 73, 278-290. [CrossRef] [PubMed]

35. Bortolussi, G.; McIvor, J.G.; Hodgkinson, J.; Coffey, S.; Holmes, C. The northern Australian beef industry, a snapshot. 3. Annual liveweight gains from pasture based systems. Aust. J. Agric. Res. 2005, 45, 1093-1108. [CrossRef] 
36. Poppi, D.P.; McLennan, S.R. Nutrition R\&D: Past, present and future. In Proceedings of the Northern Beef Update Research Conference, Southbank Convention Centre, Townsville, Australia, 21-22 March 2007; Pattie, B., Restall, B., Eds.;

37. Archimède, H.; Eugène, M.; Magdeleine, C.M.; Boval, M.; Martin, C.; Morgavi, D.; Doreau, M. Comparison of methane production between C3 and C4 grasses and legumes. Anim. Feed Sci. Technol. 2011, 166, 59-64. [CrossRef]

38. Benchaar, C.; Pomar, C.; Chiquette, J. Evaluation of dietary strategies to reduce methane production in ruminants: A modelling approach. Can. J. Anim. Sci. 2001, 81, 563-574. [CrossRef]

39. Joblin, K. Ruminal acetogens and their potential to lower ruminant methane emissions. Aust. J. Agric. Res. 1999, 50, 1307-1314. [CrossRef]

40. Broucek, J. Options to methane production abatement in ruminants: A review. J. Anim. Plant Sci. 2018, 28, 348-364.

41. Dohme, F.; Machmüller, A.; Estermann, B.; Pfister, P.; Wasserfallen, A.; Kreuzer, M. The role of the rumen ciliate protozoa for methane suppression caused by coconut oil. Lett. Appl. Microbiol. 1999, 29, 187-192. [CrossRef]

42. Mathison, G.; Okine, E.; McAllister, T.; Dong, Y.; Galbraith, J.; Dmytruk, O. Reducing methane emissions from ruminant animals. J. Appl. Anim. Res. 1998, 14, 1-28. [CrossRef]

43. Iqbal, M.F.; Cheng, Y.-F.; Zhu, W.-Y.; Zeshan, B. Mitigation of ruminant methane production: current strategies, constraints and future options. World J. Microb. Biot. 2008, 24, 2747-2755. [CrossRef]

44. Guan, H.; Wittenberg, K.; Ominski, K.; Krause, D. Efficacy of ionophores in cattle diets for mitigation of enteric methane. J. Anim. Sci. 2006, 84, 1896-1906. [CrossRef] [PubMed]

45. McCaughey, W.; Wittenberg, K.; Corrigan, D. Methane production by steers on pasture. Can. J. Anim. Sci. 1997, 77, 519-524. [CrossRef]

46. Russell, J.B.; Houlihan, A.J. Ionophore resistance of ruminal bacteria and its potential impact on human health. FEMS Microbiol. Rev. 2003, 27, 65-74. [CrossRef] [PubMed]

47. European Medicines Agency Veterinary Medicines and Inspections. Committee for Medical Products for Veterinary Use. 2007. Available online: https://www.ema.europa.eu/documents/mrl-report/monensin-cattleincluding-dairy-cows-summary-report-committee-veterinary-medicinal-products_en.pdf (accessed on 17 March 2019).

48. Newbold, C.; McIntosh, F.; Wallace, R. Changes in the microbial population of a rumen-simulating fermenter in response to yeast culture. Can. J. Anim. Sci. 1998, 78, 241-244. [CrossRef]

49. McGinn, S.; Beauchemin, K.; Coates, T.; Colombatto, D. Methane emissions from beef cattle: Effects of monensin, sunflower oil, enzymes, yeast, and fumaric acid. J. Anim. Sci. 2004, 82, 3346-3356. [CrossRef] [PubMed]

50. Martin, C.; Morgavi, D.; Doreau, M. Methane mitigation in ruminants: From microbe to the farm scale. Animal 2010, 4, 351-365. [CrossRef] [PubMed]

51. Martinez-Fernandez, G.; Denman, S.E.; Yang, C.; Cheung, J.; Mitsumori, M.; McSweeney, C.S. Methane inhibition alters the microbial community, hydrogen flow, and fermentation response in the rumen of cattle. Front. Microbiol. 2016, 7, 1122. [CrossRef] [PubMed]

52. McCrabb, G.; Berger, K.; Magner, T.; May, C.; Hunter, R. Inhibiting methane production in Brahman cattle by dietary supplementation with a novel compound and the effects on growth. Aust. J. Agric. Res. 1997, 48, 323-329. [CrossRef]

53. Van Nevel, C.; Demeyer, D. Control of rumen methanogenesis. Environ. Monit. Assess. 1996, 42, 73-97. [CrossRef]

54. Martinez Fernandez, G.; Duval, S.M.; Kindermann, M.; Schirra, H.J.; Denman, S.E.; McSweeney, C.S. 3-NOP vs. Halogenated compound: Methane production, ruminal fermentation and microbial community response in forage fed cattle. Front. Microbiol. 2018, 9, 1582. [CrossRef] [PubMed]

55. Supplementary Feeding. 2019. Available online: https://www.mla.com.au/Research-and-development/ Feeding-finishing-nutrition/Supplementary-feeding (accessed on 17 March 2019).

56. Department of Agriculture Forestry and Fisheries. Supplementation Feeding: Some Basic Considerations. 2019. Available online: https://www.daf.qld.gov.au/business-priorities/agriculture/disaster-recovery/ drought/managing/supplementation-feeding-considerations (accessed on 17 March 2019). 
57. McLennan, S.R.; Dunster, P.; O'rourke, P.; Murphy, G. Comparison of dry season urea supplements containing salt, sulfur or molasses for steers grazing native pasture in the dry tropics of northern Queensland. Aust. J. Exp. Agric. 1981, 21, 457-463. [CrossRef]

58. Purnomoadi, A.; Rianto, E.; Kurihara, M. Reduction of methane production from Ongole Crossbreed cattle in Indonesia by increasing the concentrate feeding frequency. In Greenhouse Gas Control Technologies; Elsevier: Amsterdam, The Netherlands, 2005; Volume 7, pp. 2513-2516.

59. Beauchemin, K.A.; Kreuzer, M.; O'mara, F.; McAllister, T.A. Nutritional management for enteric methane abatement: A review. Aust. J. Exp. Agric. 2008, 48, 21-27. [CrossRef]

60. McSweeney, C.; Palmer, B.; McNeill, D.; Krause, D. Microbial interactions with tannins: Nutritional consequences for ruminants. Anim. Feed Sci. Techol. 2001, 91, 83-93. [CrossRef]

61. Woodward, S.; Waghorn, G.; Thomson, N. Supplementing dairy cows with oils to improve performance and reduce methane-does it work? In Proceedings of the New Zealand Society of Animal Production, Napier, New Zealand, 26-28 June 2006; Volume 66, pp. 176-181.

62. Patra, A.K.; Saxena, J. Exploitation of dietary tannins to improve rumen metabolism and ruminant nutrition. J. Sci. Food Agric. 2011, 91, 24-37.

63. Hess, H.D.; Tiemann, T.T.; Noto, F.; Carulla, J.E.; Kreuzer, M. Strategic use of tannins as means to limit methane emission from ruminant livestock. In International Congress Series; Elsevier: Amsterdam, The Netherlands, 2006; Volume 1293, pp. 164-167.

64. Tiemann, T.T.; Lascano, C.E.; Wettstein, H.-R.; Mayer, A.C.; Kreuzer, M.; Hess, H.D. Effect of the tropical tannin-rich shrub legumes Calliandra calothyrsus and Flemingia macrophylla on methane emission and nitrogen and energy balance in growing lambs. Animal 2008, 2, 790-799. [CrossRef]

65. Tan, H.; Sieo, C.; Abdullah, N.; Liang, J.; Huang, X.; Ho, Y. Effects of condensed tannins from Leucaena on methane production, rumen fermentation and populations of methanogens and protozoa in vitro. Anim. Feed Sci. Techol. 2011, 169, 185-193. [CrossRef]

66. Brewbaker, J.L. Leucaena: A multipurpose tree genus for tropical agroforestry. In Agroforestry: A Decade of Development; Steppler, H.A., Ramachandran Nair, P.K., Eds.; International Council for Research in Agroforestry: Nairobi, Kenya, 1987; pp. 289-323.

67. Dalzell, S.; Burnett, D.; Dowsett, J.; Forbes, V.; Shelton, H. Prevalence of mimosine and DHP toxicity in cattle grazing Leucaena leucocephala pastures in Queensland, Australia. Anim. Prod. Sci. 2012, 52, 365-372. [CrossRef]

68. Durmic, Z.; Ramírez-Restrepo, C.A.; Gardiner, C.; O’Neill, C.J.; Hussein, E.; Vercoe, P.E. Differences in the nutrient concentrations, in vitro methanogenic potential and other fermentative traits of tropical grasses and legumes for beef production systems in northern Australia. J. Sci. Food Agric. 2017, 97, 4075-4086. [CrossRef] [PubMed]

69. Soltan, Y.A.; Morsy, A.S.; Sallam, S.M.; Lucas, R.C.; Louvandini, H.; Kreuzer, M.; Abdalla, A.L. Contribution of condensed tannins and mimosine to the methane mitigation caused by feeding Leucaena leucocephala. Arch. Anim. Nutr. 2013, 67, 169-184. [CrossRef] [PubMed]

70. Harrison, M.T.; McSweeney, C.; Tomkins, N.W.; Eckard, R.J. Improving greenhouse gas emissions intensities of subtropical and tropical beef farming systems using Leucaena leucocephala. Agric. Syst. 2015, 136, 138-146. [CrossRef]

71. Soltan, Y.; Morsy, A.; Sallam, S.; Louvandini, H.; Abdalla, A. Comparative in vitro evaluation of forage legumes (prosopis, acacia, atriplex, and leucaena) on ruminal fermentation and methanogenesis. J. Anim. Feed Sci. 2012, 21, 759-772. [CrossRef]

72. Jones, W.T.; Mangan, J.L. Complexes of the condensed tannins of sainfoin (Onobrychis viciifolia Scop.) with fraction 1 leaf protein and with submaxillary mucoprotein, and their reversal by polyethylene glycol and $\mathrm{pH}$. J. Sci. Food Agric. 1977, 28, 126-136. [CrossRef]

73. McSweeney, C.; Palmer, B.; Bunch, R.; Krause, D. In vitro quality assessment of tannin-containing tropical shrub legumes: Protein and fibre digestion. Anim. Feed Sci. Techol. 1999, 82, 227-241. [CrossRef]

74. Bhatta, R.; Uyeno, Y.; Tajima, K.; Takenaka, A.; Yabumoto, Y.; Nonaka, I.; Kurihara, M. Difference in the nature of tannins on in vitro ruminal methane and volatile fatty acid production and on methanogenic archaea and protozoal populations. J. Dairy Sci. 2009, 92, 5512-5522. [CrossRef] [PubMed]

75. Beauchemin, K.; McGinn, S.; Martinez, T.; McAllister, T. Use of condensed tannin extract from quebracho trees to reduce methane emissions from cattle. J. Anim. Sci. 2007, 85, 1990-1996. [CrossRef] [PubMed] 
76. Field, J.; Kortekaas, S.; Lettinga, G. The tannin theory of methanogenic toxicity. Biol. Waste 1989, 29, 241-262. [CrossRef]

77. Jayanegara, A.; Goel, G.; Makkar, H.P.; Becker, K. Divergence between purified hydrolysable and condensed tannin effects on methane emission, rumen fermentation and microbial population in vitro. Anim. Feed Sci. Techol. 2015, 209, 60-68. [CrossRef]

78. Murdiati, T.B.; McSweeney, C.S.; Lowry, J. Complexing of toxic hydrolysable tannins of yellow-wood (Terminalia oblongata) and harendong (Clidemia hirta) with reactive substances: An approach to preventing toxicity. J. Appl. Toxicol. 1991, 11, 333-338. [CrossRef]

79. Makkar, H.; Francis, G.; Becker, K. Bioactivity of phytochemicals in some lesser-known plants and their effects and potential applications in livestock and aquaculture production systems. Animal 2007, 1, 1371-1391. [CrossRef] [PubMed]

80. McMahon, L.R.; McAllister, T.A.; Berg, B.P.; Majak, W.; Acharya, S.N.; Popp, J.D.; Cheng, K.-J. A review of the effects of forage condensed tannins on ruminal fermentation and bloat in grazing cattle. Can. J. Anim. Sci. 2000, 80, 469-485. [CrossRef]

81. Vandermeulen, S.; Singh, S.; Ramírez-Restrepo, C.A.; Kinley, R.D.; Gardiner, C.P.; Holtum, J.A.; Bindelle, J. In vitro assessment of ruminal fermentation, digestibility and methane production of three species of Desmanthus for application in northern Australian grazing systems. Crop Pasture Sci. 2018, 69, 797-807. [CrossRef]

82. Collins, J.; Gardiner, C.P.; Kempe, N.; Hannah, I. Successful Pasture Development at Cungelella: A grazier, a researcher and a seed company's perspective. In Proceedings of the Northern Beef Research Update Conference, Rockhampton, Australia, 15-18 August 2016; North Australia Beef Research Council: Gympie, Australia, 2016.

83. Gardiner, C.P.; Parker, A. Steer liveweight gains on ProgardesTM/buffel pastures in Qld. In Proceedings of the 2nd Australian and New Zealand Societies of Animal Production Joint Conference, Lincoln University, Christchurch, New Zealand, 2-5 July 2012.

84. Ngo, T.; Parker, A.; Gardiner, C.P. The effects of diet preference on feed intake, digestibility and nitrogen balance of sheep given Flinders grass (Iseilema spp.) hay and/or Desmanthus leptophyllus cv. JCU 1 ad libitum. In Proceedings of the TropAg2017: International Tropical Agriculture Conference, Brisbane, Australia, 20-22 November 2017.

85. Rangel, J.; Gardiner, C.P. Stimulation of wool growth by Desmanthus spp. as a supplement to a diet of Mitchell grass hay. Trop. Grassl. 2009, 43, 106-111.

86. Gardiner, C.; Kempe, N.; Hannah, I. New pasture legumes for clay soils in dry environments. North. Muster 2012, 30, 27-28.

87. Wetselaar, R. Estimation of nitrogen fixation by four legumes in a dry monsoonal area of north-western Australia. Aust. J. Exp. Agric. 1967, 7, 518-522. [CrossRef]

88. Jones, R.; Probert, M.; Dalgliesh, N.; McCown, R. Nitrogen inputs from a pasture legume in rotations with cereals in the semi-arid tropics of northern Australia: Experimentation and modelling on a clay loam soil. Aust. J. Exp. Agric. 1996, 36, 985-994. [CrossRef]

89. Zahran, H.H. Rhizobium-legume symbiosis and nitrogen fixation under severe conditions and in an arid climate. Microbiol. Mol. Biol. Rev. 1999, 63, 968-989. [PubMed]

90. Peck, G.; Buck, S.; Hoffmann, A.; Holloway, C.; Johnson, B.; Lawrence, D.; Paton, C. Review of Productivity Decline in Sown Grass Pastures; Meat \& Livestock Australia Limited: North Sydney, Australia, 2011; p. 86.

91. Sturz, A.; Christie, B.; Matheson, B.; Nowak, J. Biodiversity of endophytic bacteria which colonize red clover nodules, roots, stems and foliage and their influence on host growth. Biol. Fertil. Soils 1997, 25, 13-19. [CrossRef]

92. Rao, I.M.; Peters, M.; Castro, A.; Schultze-Kraft, R.; White, D.; Fisher, M.; Rudel, T. LivestockPlus: The sustainable intensification of forage-based agricultural systems to improve livelihoods and ecosystem services in the tropics. Trop. Grassl. 2015, 3, 59-82. [CrossRef]

93. Peters, M.; Herrero, M.; Fisher, M.; Erb, K.-H.; Rao, I.; Subbarao, G.V.; Searchinger, T. Challenges and opportunities for improving eco-efficiency of tropical forage-based systems to mitigate greenhouse gas emissions. Trop. Grassl. 2013, 1, 156-167. 
94. Mero, R.N.; Udén, P. Promising tropical grasses and legumes as feed resources in Central Tanzania V. Effect of supplementing Cenchrus ciliaris hay with leaves from four legumes on intake and digestibility by growing Mpwapwa bulls. Anim. Feed Sci. Techol. 1998, 70, 111-122. [CrossRef]

95. Bowen, M.; Chudleigh, F.; Buck, S.; Hopkins, K. Productivity and profitability of forage options for beef production in the subtropics of northern Australia. Anim. Prod. Sci. 2016, 58, 332-342. [CrossRef]

96. Gardiner, C.P.; Swan, S.J. Abandoned pasture legumes offer potential economic and environmental benefits in semiarid clay soil rangelands. In Proceedings of the 15th Biennial Conference Proceedings 'A Climate of Change in the Rangelands', Charters Towers, Australia, 28 September-2 October 2008.

97. CSIRO. Nutrient Requirements of Domesticated Ruminants; CSIRO publishing: Clayton, VIC, Australia, 2007.

98. Clements, R.J.; Henzell, E.F. Pasture research and development in northern Australia: An ongoing scientific adventure. Trop. Grassl. 2010, 44, 221-230.

99. Jones, R.; Lowry, J. Australian goats detoxify the goitrogen 3-hydroxy-4 (1H) pyridone (DHP) after rumen infusion from an Indonesian goat. Experientia 1984, 40, 1435-1436. [CrossRef]

100. Pengelly, B.C.; Liu, C.J. Genetic relationships and variation in the tropical mimosoid legume Desmanthus assessed by random amplified polymorphic DNA. Genet. Resour. Crop Evol. 2001, 48, 93-101. [CrossRef]

101. Luckow, M. Monograph of Desmanthus (leguminosae-mimosoideae). In Systematic Botany Monographs; Anderson, C., Ed.; The American Society of Plant Taxonomists: Laramie, WY, USA, 1993; Volume 38, pp. 1-166.

102. Tropical Forages. Desmanthus Leptophyllus. Available online: http://www.tropicalforages.info/key/forages/ Media/Html/entities/desmanthus_leptophyllus.htm (accessed on 26 July 2019).

103. State of the Environment. Average Rainfall. 2017. Available online: https://www.stateoftheenvironment.des. qld.gov.au/2015/climate/climate-observations/average-rainfall (accessed on 26 July 2019).

104. Jones, R.; Brandon, N. Persistence and productivity of eight accessions of Desmanthus virgatus under a range of grazing pressures in subtropical Queensland. Trop. Grassl. 1998, 32, 145-152.

105. Department of Agriculture Forestry and Fisheries. Pasture Management for the Inland Burnett, 3rd ed.; DAFF: Brisbane, Australia, 2014.

106. Gardiner, C.P.; Kempe, N.; Hannah, I.; McDonald, J. PROGARDES TM: A legume for tropical/subtropical semi-arid clay soils. Trop. Grassl. 2013, 1, 78-80. [CrossRef]

107. Pandrangi, S.; Elwell, M.; Anantheswaran, R.; LaBorde, L. Efficacy of sulfuric acid scarification and disinfectant treatments in eliminating Escherichia coli O157: H7 from alfalfa seeds prior to sprouting. J. Food Sci. 2003, 68, 613-617. [CrossRef]

108. Clem, B. Desmanthus. 2009. Available online: https://keys.lucidcentral.org/keys/v3/pastures/Html/ Desmanthus.htm (accessed on 26 July 2019).

109. Gardiner, C.; Wright, C.; Coventry, M. The germination, passage and viability of Desmanthus virgatus (L.) Willenow seed through sheep and its implication for dispersal in tropical rangelands. In Proceedings of the 16th Australian Society of Agronomy Conference, Armidale, NSW, Australia, 14-18 October 2012.

110. Kanani, J.; Lukefahr, S.; Stanko, R. Evaluation of tropical forage legumes (Medicago sativa, Dolichos lablab, Leucaena leucocephala and Desmanthus bicornutus) for growing goats. Small Rumin. Res. 2006, 65, 1-7. [CrossRef]

(C) 2019 by the authors. Licensee MDPI, Basel, Switzerland. This article is an open access article distributed under the terms and conditions of the Creative Commons Attribution (CC BY) license (http://creativecommons.org/licenses/by/4.0/). 


\title{
Effect of Encapsulated Nitrate and Microencapsulated Blend of Essential Oils on Growth Performance and Methane Emissions from Beef Steers Fed Backgrounding Diets
}

\author{
Aklilu W. Alemu ${ }^{1}$, Atmir Romero-Pérez ${ }^{1, \dagger}{ }^{,}$Rafael C. Araujo ${ }^{2}$ and Karen A. Beauchemin ${ }^{1, *}$ \\ 1 Lethbridge Research and Development Centre, Agriculture and Agri-Food Canada, Lethbridge, \\ AB T1J 4B1, Canada; aklilu.alemu@canada.ca (A.W.A.); atmir@umam.mx (A.R.-P.) \\ 2 GRASP Ind. \& Com. LTDA, Curitiba, Paraná, Brazil 81260-000/EW I Nutrition GmbH, \\ 49429 Visbek, Germany; rafael@grasp.ind.br \\ * Correspondence: karen.beauchemin@canada.ca; Tel.: +1-403-317-2235 \\ † Current address: Departamento de Nutrición Animal y Bioquímica, Universidad Nacional Autónoma de \\ México, Ciudad de Mexico 04510, Mexico.
}

Received: 3 December 2018; Accepted: 1 January 2019; Published: 10 January 2019

Simple Summary: The use of supplemental dietary nitrate $\left(\mathrm{NO}_{3}{ }^{-}\right)$to minimize enteric methane $\left(\mathrm{CH}_{4}\right)$ emissions from ruminants is hindered by potential toxicity effects. In the current study, the potential effects of feeding encapsulated $\mathrm{NO}_{3}{ }^{-}(\mathrm{EN})$, microencapsulated blend of essential oils (MBEO), and their combination on growth performance and enteric $\mathrm{CH}_{4}$ emissions of beef cattle were evaluated. There was no interaction effect between feeding $\mathrm{EN}$ and $\mathrm{MBEO}$ on $\mathrm{CH}_{4}$ emissions and the presence of MBEO did not affect the potential of EN to reduce $\mathrm{CH}_{4}$. Feeding MBEO increased $\mathrm{CH}_{4}$ emissions without affecting animal performance. Inclusion of EN as a replacement for urea reduced $\mathrm{CH}_{4}$ emissions without incurring any adverse effects on cattle health and performance.

\begin{abstract}
A long-term study (112 days) was conducted to examine the effect of feeding encapsulated nitrate $\left(\mathrm{NO}_{3}{ }^{-}\right)$, microencapsulated blend of essential oils (EO), and their combination on growth performance, feeding behavior, and enteric methane $\left(\mathrm{CH}_{4}\right)$ emissions of beef cattle. A total of 88 crossbred steers were purchased and assigned to one of four treatments: (i) control, backgrounding high-forage diet supplemented with urea $\left(1.17 \%\right.$ in dietary DM); (ii) encapsulated $\mathrm{NO}_{3}{ }^{-}$(EN), control diet supplemented with $2.5 \%$ encapsulated $\mathrm{NO}_{3}{ }^{-}$as a replacement for urea $\left(1.785 \% \mathrm{NO}_{3}{ }^{-}\right.$ in the dietary DM); (iii) microencapsulated blend of $\mathrm{EO}$ (MBEO), control diet supplemented with $150 \mathrm{mg} / \mathrm{kg}$ DM of microencapsulated blend of EO and pepper extract; and (iv) EN + MBEO, control diet supplemented with EN and MBEO. There was no interaction $(p \geq 0.080)$ between EN and MBEO on average dry matter intake (DMI), average daily gain (ADG), gain to feed ratio (G:F), feeding behavior, and $\mathrm{CH}_{4}$ emission (using GreenFeed system), implying independent effects of feeding EN and MBEO. Feeding MBEO increased $\mathrm{CH}_{4}$ production (165.0 versus $183.2 \mathrm{~g} /$ day; $p=0.005$ ) and yield (18.9 versus $21.4 \mathrm{~g} / \mathrm{kg}$ DMI; $p=0.0002)$ but had no effect $(p \geq 0.479)$ on average DMI, ADG, G:F, and feeding behavior. However, feeding EN had no effect on ADG and G:F ( $p \geq 0.119)$ but reduced DMI ( 8.9 versus $8.4 \mathrm{~kg} /$ day; $p=0.003$ ) and $\mathrm{CH}_{4}$ yield (21.5 versus $18.7 \mathrm{~g} / \mathrm{kg}$ DMI; $p<0.001$ ). Feeding EN slowed $(p=0.001)$ the feeding rate $(\mathrm{g}$ of $\mathrm{DM} / \mathrm{min})$ and increased $(p=0.002)$ meal frequency (events/day). Our results demonstrate that supplementing diets with a blend of EO did not lower $\mathrm{CH}_{4}$ emissions and there were no advantages of feeding MBEO with EN. Inclusion of EN as a replacement for urea reduced $\mathrm{CH}_{4}$ emissions but had no positive impact on animal performance.
\end{abstract}

Keywords: backgrounded cattle; encapsulated nitrate; essential oil; methane 


\section{Introduction}

Over the past decades, livestock research has been focused on developing strategies to reduce the environmental impacts of ruminant animals [1]. As enteric methane $\left(\mathrm{CH}_{4}\right)$ emission is the major contributor of total emissions in ruminant farming, different mitigation strategies including feed additives (e.g., inhibitors, ionophores, plant bioactive compounds, electron receptors, dietary lipids), feed (e.g., high starch grains, lipids), and feeding management (e.g., forage quality and management, feed processing, feeding frequency, precision feeding) have been directed towards minimizing enteric $\mathrm{CH}_{4}$ emissions [1].

Feeding nitrate $\left(\mathrm{NO}_{3}{ }^{-}\right)$to ruminant animals as a replacement for urea has received attention as a promising methane-mitigating approach, as several studies have shown that feeding $\mathrm{NO}_{3}{ }^{-}$ can decrease enteric $\mathrm{CH}_{4}$ [2-7]. Similarly, a recent in vitro experiment [8] and metabolism study using beef heifers [9] at our lab were also in line with the previous reports. Conversely, reduction in enteric $\mathrm{CH}_{4}$ was not observed from feedlot animals managed outdoors and supplemented with encapsulated $\mathrm{NO}_{3}{ }^{-}$at 1.25 and $2.5 \%$ on a dry matter (DM) basis $[10,11]$. Furthermore, despite its positive effects on $\mathrm{CH}_{4}$ reduction, feeding $\mathrm{NO}_{3}{ }^{-}$could pose a potential risk of $\mathrm{NO}_{3}{ }^{-} /$nitrite $\left(\mathrm{NO}_{2}{ }^{-}\right)$ toxicity to animals. Nitrate intoxication can occur when the concentration of $\mathrm{NO}_{2}{ }^{-}$(reduced form of $\mathrm{NO}_{3}{ }^{-}$) accumulates in the rumen and is absorbed into the blood stream, increasing methemoglobin $(\mathrm{MetHb})$ level. When ample hemoglobin $(\mathrm{Hb})$ is converted to $\mathrm{MetHb}$, the animal suffers from oxygen starvation [12]. A slow release form of $\mathrm{NO}_{3}{ }^{-}$(encapsulated $\mathrm{NO}_{3}{ }^{-}$) was developed to ensure the slow release of $\mathrm{NO}_{3}{ }^{-}$to rumen microbes and minimize potential toxicity [7-11].

Bacterial resistance to multiple antibiotics is a worldwide health problem. As such, following the prohibition of the use of growth-promoting antibiotics in animal feeds by the European Union (1831/2003) [13], interest in the use of essential oils (EO) as potential alternatives to antibiotics and studying their effects and mechanisms on ruminal fermentation has been the focus of livestock research [14,15]. Large numbers of in vitro and in vivo studies have investigated the potential effects of EO on modifying rumen function [14-16]. However, the mode of action remain poorly understood [17]. Furthermore, in addition to its impact on rumen function, EO have been shown to have antioxidant, anti-inflammatory, immune modulation, mucolytic, as well as thermoregulation and blood oxygenation properties $[14,18,19]$ and minimize stress in feedlot cattle [20]. These impacts have not been studied in detail yet. Hori et al. [21] reported that capsaicin (an alkaloid from chili pepper) increased peripheral blood flow with positive impact on body thermoregulation. Recently, Silva et al. [19,22] reported that the use of a blend of EO (Activo ${ }^{\circledR}$ Premium) increased milk efficiency, digestible organic matter intake, and $\mathrm{O}_{2}$ saturation of $\mathrm{Hb}$ in dairy cows. The improved oxygenation of blood may be beneficial for cattle fed $\mathrm{NO}_{3}{ }^{-}$. Using the same product for sheep, Soltan et al. [23] reported a reduction in $\mathrm{CH}_{4}$ emissions without affecting dry matter intake (DMI) and nutrient digestibility. Overall, research on the effects of EO in beef cattle diets is fairly limited $[17,24]$.

Therefore, the current study aimed to explore the effects of feeding encapsulated $\mathrm{NO}_{3}{ }^{-}$(EN) and a microencapsulated blend of $\mathrm{EO}(\mathrm{MBEO})$ alone or in combination on feed consumption and behavior, animal performance, and enteric $\mathrm{CH}_{4}$ emissions from feedlot beef steers fed a high-forage diet. Because the mode of action of $\mathrm{NO}_{3}{ }^{-}$and $\mathrm{EO}$ differ, we hypothesized that feeding $\mathrm{NO}_{3}{ }^{-}$in combination with $\mathrm{EO}$ would improve animal performance and reduce enteric $\mathrm{CH}_{4}$ production.

\section{Materials and Methods}

All experimental procedures were reviewed and approved by the Animal Care and Use Committee at the Lethbridge Research and Development Centre (ACC 1626) under the guidelines of the Canadian Council on Animal Care [25] and the Veterinary Drug Directorate of Health Canada (DSTS No. 197834). 


\subsection{Animals and Experimental Design}

A total of 88 crossbred steers (mean arrival BW of $287 \pm 19 \mathrm{~kg}$ ) were purchased from the local auction market. The experiment was conducted as a completely randomized design in a $2 \times 2$ factorial arrangement of treatments. A total of 22 animals per treatment were assigned and housed in four large adjacent pens $\left(17 \times 12.7 \mathrm{~m} ; 10 \mathrm{~m}^{2}\right.$ per animal). The four treatments (Table 1$)$ were: (i) control, a typical backgrounding high-forage diet ( $800 \mathrm{~g} / \mathrm{kg}$ DM corn silage) supplemented with urea $(1.17 \%$ in dietary DM); (ii) EN, control diet supplemented with $2.5 \%$ encapsulated calcium ammonium $\mathrm{NO}_{3}{ }^{-}$ in dietary DM providing $1.785 \% \mathrm{NO}_{3}{ }^{-}$in the dietary DM (GRASP Ind. \& Com. LTDA, Curitiba, Brazil); (iii) MBEO, control diet supplemented with $150 \mathrm{mg} / \mathrm{kg}$ DM of commercial microencapsulated blend of EO and pepper extract (Activo ${ }^{\circledR}$ Premium, GRASP Ind. \& Com. LTDA, Curitiba, Brazil); and (iv) $\mathrm{EN}+\mathrm{MBEO}$, control diet supplemented with $2.5 \%$ encapsulated calcium ammonium $\mathrm{NO}_{3}{ }^{-}$in dietary DM and $150 \mathrm{mg} / \mathrm{kg}$ in the dietary DM of MBEO. The commercial blend of EO was a blend of natural and identical to natural terpenoids (carvacrol), phenylpropanoids (cinnamaldehyde and eugenol), and alkaloids (capsaicin from capsicum oleoresin) and fed to the animals according to the manufacturer's recommended level. It was mixed with ground barley before feeding, and the blend was fed at the rate of $75 \mathrm{~g} /$ day to provide the full dose starting day 1 . Encapsulated $\mathrm{NO}_{3}{ }^{-}$was added directly into the total mixed ration (TMR) daily and contained $85.6 \% \mathrm{DM}, 17.6 \% \mathrm{~N}, 19.6 \% \mathrm{Ca}$, and $71.4 \% \mathrm{NO}_{3}{ }^{-}$on a DM basis. Diets were formulated to be isonitrogenous, although chemical analysis indicated that the TMR containing EN were slightly lower in crude protein $(C P)$ content (13.1 versus $14.3 \%$ DM; Table 1). The TMR were offered twice daily at $0900 \mathrm{~h}$ and $1600 \mathrm{~h}$. Due to the high amount of $\mathrm{Ca}$ in encapsulated $\mathrm{NO}_{3}{ }^{-}$, the concentration of limestone was reduced in the EN and EN + MBEO diets to provide a similar Ca level across the diets.

The experiment was conducted over a total of 112 days (28 days adaptation and 84 days of measurement), with the measurement period conducted in three consecutive periods of four weeks. In order to avoid the risk of intoxication, animals that received diets containing encapsulated $\mathrm{NO}_{3}{ }^{-}$ were acclimatized gradually using a step-up protocol during the first 28 days of adaptation; $0.625 \%$, $1.25 \%, 1.875 \%$, and $2.5 \% \mathrm{NO}_{3}{ }^{-}$in dietary DM. Each pen was equipped with five automated feeding stations (GrowSafe System Ltd., Airdrie, AB, Canada) to measure individual daily feed intake and feeding behavior. Animals were fitted with radio-frequency identification (RFID) ear tags to record feeding events of individual animals. Standard feedlot management procedures were implemented. Pens were bedded with straw and animals were implanted with steroids following the Standard Operating Procedure (SOP code: GEN. 1001) at Lethbridge Research and Development Centre. However, ionophores and antibiotics for liver abscess control were not added to the diets.

Table 1. Feed ingredients and chemical composition of the experimental diets with no additives (control, $-\mathrm{EN}$, and -MBEO), or supplemented with encapsulated nitrate $(+\mathrm{EN})$, microencapsulated blend of essential oils (+MBEO), and combination of EN and MBEO (+EN +MBEO).

\begin{tabular}{|c|c|c|c|c|}
\hline \multirow{2}{*}{ Item } & \multicolumn{2}{|c|}{$-\mathrm{EN}^{1}$} & \multicolumn{2}{|c|}{$+\mathrm{EN}$} \\
\hline & $-\mathrm{MBEO}^{1}$ & +MBEO & -MBEO & $+\mathrm{MBEO}$ \\
\hline \multicolumn{5}{|l|}{ Ingredients, $\%$ of dry matter (DM) } \\
\hline Corn silage ${ }^{2}$ & 80 & 80 & 80 & 80 \\
\hline Barley grain, dry rolled ${ }^{3}$ & 10 & 10 & 10 & 10 \\
\hline Supplement & 10 & 9.99 & 7.5 & 7.48 \\
\hline Canola meal & 3.70 & 3.70 & 3.70 & 3.70 \\
\hline Limestone & 1.55 & 1.55 & 0.43 & 0.43 \\
\hline Salt $(\mathrm{NaCl})$ & 0.11 & 0.11 & 0.11 & 0.11 \\
\hline Urea & 1.17 & 1.17 & 0.24 & 0.24 \\
\hline LeRDC beef feedlot premix ${ }^{4}$ & 0.05 & 0.05 & 0.05 & 0.05 \\
\hline Molasses, dried & 0.05 & 0.05 & 0.05 & 0.05 \\
\hline Barley ground & 3.31 & 3.31 & 2.85 & 2.85 \\
\hline Canola oil & 0.07 & 0.05 & 0.07 & 0.06 \\
\hline EN & 0.0 & 0.0 & 2.5 & 2.5 \\
\hline MBEO & 0.0 & 0.015 & 0.0 & 0.015 \\
\hline
\end{tabular}


Table 1. Cont.

\begin{tabular}{|c|c|c|c|c|}
\hline \multirow{2}{*}{ Item } & \multicolumn{2}{|c|}{$-\mathrm{EN}^{1}$} & \multicolumn{2}{|c|}{$+\mathrm{EN}$} \\
\hline & - MBEO $^{1}$ & +MBEO & -MBEO & $+\mathrm{MBEO}$ \\
\hline \multicolumn{5}{|c|}{ Chemical composition (\% of DM) } \\
\hline DM (as-is) & 44.0 & 44.0 & 43.8 & 43.8 \\
\hline OM & 93.9 & 93.9 & 92.5 & 92.5 \\
\hline $\mathrm{CP}$ & 14.3 & 14.3 & 13.1 & 13.1 \\
\hline NDF & 42.0 & 42.0 & 41.2 & 41.1 \\
\hline $\mathrm{ADF}$ & 28.1 & 28.1 & 27.9 & 27.9 \\
\hline Starch & 29.8 & 29.8 & 29.3 & 29.3 \\
\hline $\mathrm{NO}_{3}^{-}$ & 0.12 & 0.16 & 1.66 & 1.68 \\
\hline $\mathrm{GE}(\mathrm{Mcal} / \mathrm{kg} \mathrm{DM})^{5}$ & 5.39 & 5.39 & 5.32 & 5.29 \\
\hline
\end{tabular}

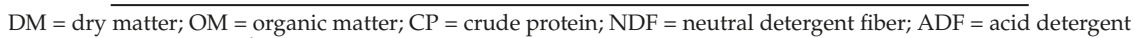
fiber; $\mathrm{NO}_{3}{ }^{-}=$nitrate. ${ }^{1} \mathrm{EN}=$ Encapsulated nitrate $(\mathrm{EN})$ was manufactured by GRASP Ind. \& Com. LTDA, Curitiba, Paraná, Brazil; DM, 85.6\%; N, 17.6\%; Ca, $19.6 \%$; and $\mathrm{NO}_{3}{ }^{-}, 71.4 \%$ on a DM basis. The source of nitrate was the double salt of calcium ammonium nitrate decahydrate $\left[5 \mathrm{Ca}\left(\mathrm{NO}_{3}\right)_{2} \bullet \mathrm{NH}_{4} \mathrm{NO}_{3} \bullet 10 \mathrm{H}_{2} \mathrm{O}\right] ; \mathrm{MBEO}=$ Commercial microencapsulated blend of natural and identical to natural terpenoids (carvacrol), phenylpropanoids (cinnamaldehyde and eugenol), and alkaloids (capsaicin from capsicum oleoresin) manufactured by GRASP Ind. \& Com. LTDA, Curitiba, Paraná, Brazil. ${ }^{2}$ DM, 32\% $( \pm 1.3$ SD) on as-is basis and OM, 96\% ( \pm 0.1 SD); $\mathrm{CP}, 8 \%( \pm 0.2 \mathrm{SD})$; NDF, $47.3 \%( \pm 2.1 \mathrm{SD}) ; \mathrm{ADF}, 32.8 \%( \pm 3.8 \mathrm{SD})$; starch, $28 \%( \pm 3.6 \mathrm{SD})$ on a DM basis. ${ }^{3} \mathrm{OM}$, $98 \%$ ( $\pm 0.5 \mathrm{SD}) ; \mathrm{CP}, 14 \%$ ( $\pm 0.8 \mathrm{SD}) ; \mathrm{NDF}, 16.6 \%$ ( $\pm 1.8 \mathrm{SD})$; starch, $55 \%( \pm 1.6 \mathrm{SD})$ on a DM basis. ${ }^{4}$ Lethbridge Research and Development Centre (LeRDC) beef feedlot vitamin-mineral premix contained (on a DM basis) CaCO ${ }_{3}$, $34.83 \% ; \mathrm{ZnSO}_{4}, 28.37 \%$; $\mathrm{CuSO}_{4}, 10.31 \%$; ethylenediamine dihydriodide ( $80 \%$ concentration), $0.15 \%$; selenium $1 \%$ $\left(10,000 \mathrm{mg} \mathrm{Se} / \mathrm{kg}, \mathrm{Na}_{2} \mathrm{SeO}_{3}\right), 5.04 \% ; \mathrm{CoCO}_{3}, 0.08 \% ; \mathrm{MnSO}_{4}, 14.61 \%$; vitamin A (500,000,000 IU / kg), $1.72 \%$; vitamin $\mathrm{D}(500,000,000 \mathrm{IU} / \mathrm{kg}), 0.17 \%$; and vitamin E (500,000 IU $/ \mathrm{kg}), 4.73 \% .{ }^{5}$ Gross energy (GE, Mcal/kg DM); corn silage, 5.60 ( $\pm 0.35 \mathrm{SD})$; dry rolled barley grain, 4.91 ( $\pm 0.05 \mathrm{SD})$; control and MBEO supplement, 4.24 ( $\pm 0.15 \mathrm{SD})$; and EN supplement, $4.69( \pm 0.18 \mathrm{SD})$.

\subsection{Sample Collection}

Body weight (BW) was measured before feeding (nonfasted BW) on 2 consecutive days at the start and end of the experiment and once at the end of each period (4 weeks) to calculate average daily gain (ADG). Feed ingredients, TMR offered, and orts were sampled weekly and composited by period for further chemical and particle size analyses. Blood samples from all animals were collected before feeding from the jugular vein into two sodium and one lithium heparinized tubes (10-mL) and one $\mathrm{K}_{2}$ EDTA Vacutainer ${ }^{\circledR}$ tube (8-mL; Becton Dickinson Breda, Etten-Leur, The Netherland) on weeks 0 (experimental day 28, which was end of the adaptation period and beginning of Period 1), 4, 8, and 12 to determine acid-base balance, blood gases, total $\mathrm{Hb}$, MetHb, packed cell volume (PCV), and $\mathrm{NO}_{3}{ }^{-}$ and $\mathrm{NO}_{2}{ }^{-}$concentrations. Whole blood was analyzed within $30 \mathrm{~min}$ for total $\mathrm{Hb}$ and MetHb levels.

\subsection{Emission Measurements}

Methane and hydrogen were measured using the GreenFeed emission monitoring (GEM) system (C-Lock Inc., Rapid City, SD, USA). The GEM system was placed in one of the pens and animals were moved rotationally (conveyer belt approach) once a week, such that a new pen of cattle could access the system each week. Thus, once the animals were adapted to the GEM system (28 days), each treatment group had access to the system for seven days within a period, totaling three weeks of measurement per treatment group (pen) during the 84-day period. This approach allowed us to eliminate any possible pen effect because all animals spent the same amount of time in each pen.

The GEM system allows free movement of animals (in and out of the system) and gasses are measured only when the animal's head is in the "head chamber" unit as determined by a proximity sensor. The system is equipped with RFID reader to recognize individual animal visits by its electronic ear tag. Upon visiting the system, animals were provided with pellets from the overhead hopper (as bait) to keep them in the unit for sufficient eructation time to achieve a representative measurement. The pellet was composed of ground barley, canola meal, canola oil, dried molasses, and salt $(\mathrm{NaCl})$ with a composition of $14.6 \% \mathrm{CP}, 42.1 \%$ starch, $19.6 \%$ neutral detergent fiber (NDF), $11.8 \%$ acid detergent fiber (ADF), and $4.8 \mathrm{Mcal} / \mathrm{kg}$ DM gross energy (GE, DM basis). Maximum daily pellet drops per 
animal was set to 36 drops in the GEM system ( 6 visits per day $\times 6$ drops per visit) to restrict the amount of pellet consumption. Animals could visit the system anytime during the day, but they were eligible for pellet drops only during the 6 visits. Thus, animals were required to wait for $4 \mathrm{~h}$ before getting their next pellet drop. The interval between pellet drops was set to $35 \mathrm{~s}$ to keep the animal for 3 to $7 \mathrm{~min}$ in the hood of the GEM system.

Once the animal's head was in the hood of the GEM system, air was drawn passed the nose and mouth of the animal at about 25 to $40 \mathrm{~L} / \mathrm{s}$ into the collection pipe. The system measured $\mathrm{CH}_{4}$ and hydrogen continuously, concomitantly with air flow, temperature, atmospheric pressure, and relative humidity. Each gas was analyzed by a separate nondispersive infrared analyzer that was calibrated weekly. Daily $\mathrm{CH}_{4}$ emissions for individual animals were calculated by aggregating and averaging the visit flux by time of day, or "bin" over the study period, whereas hydrogen was calculated using an "arithmetic averaging method", a straight averaging of the visit fluxes [26].

Eating behavior of the individual animal was analyzed from the GrowSafe feed bunk data. A meal was defined as a visit to the bunk, followed by an absence from the bunk for $300 \mathrm{~s}$ or greater. Meal size was calculated from the amount of feed consumed during a visit. Feeding rate was calculated by dividing the amount of feed consumed by meal duration (time spent at feeder), and head down duration per meal was calculated by dividing meal duration by number of meals per day.

\subsection{Sample Analyses}

Ingredient, TMR, and ort samples were composited by period and treatment. A portion of TMR and ort samples was used to determine particle size distribution using the Penn State Particle Separator with 3 screens $(18,8$, and $1.18 \mathrm{~mm})$ [27]. Composited samples of ingredients, TMR, and orts were analyzed for DM content by drying at $55^{\circ} \mathrm{C}$ for $72 \mathrm{~h}$. Samples were ground through a 1-mm screen using a Wiley mill (A. H. Thomas, Philadelphia, PA, USA) for chemical analyses. Subsamples were further ground with a ball grinder (mixer mill MM200, Retsch, Haan, Germany) and analyzed for nitrogen $(\mathrm{N})$ using flash combustion (Carlo Erba Instruments, Milan, Italy). Crude protein of ingredients was calculated by multiplying the N content by 6.25. The NDF and ADF of ingredients were determined with a FIWE 6 fiber analyzer $\left(\operatorname{VELP}^{\circledR}\right.$ Scientifica, Via Stazione, Italy), using the principles described by Van Soest et al. [28], including $\alpha$-amylase and sodium sulfite for the NDF analysis. The GE content of ingredients and TMR was determined using a bomb calorimeter (model E2k; CAL2k, Johannesburg, South Africa). Nitrate in TMR and orts was extracted (method 968.07) [29] and the concentrations were determined using a $\mathrm{NO}_{3}{ }^{-} / \mathrm{NO}_{2}{ }^{-}$Colorimetric Assay Kit (detection limit for $\mathrm{NO}_{3}{ }^{-}$and $\mathrm{NO}_{2}{ }^{-}$was $2 \mu \mathrm{mol} / \mathrm{L}$ in the original sample; Cayman Chemical Co., Ann Arbor, MI, USA).

Blood gas and electrolytes were determined using IDEXX VetStat ${ }^{\circledR}$ electrolyte and blood gas analyzer (IDEXX Laboratories, Westbrook, ME, USA). Hemoglobin and MetHb were determined using an aliquot of fresh whole blood $(5 \mu \mathrm{L})$ from the individual animal, collected using sodium heparinized tubes (GEM OPL; Instrumentation Laboratory Company, Lexington, MA, USA). The remaining blood from sodium heparinized tube was centrifuged (AccuSpin 3/3R; Fisher Scientific, Pittsburgh, PA, USA) at $3000 \times \mathrm{g}$ for $20 \mathrm{~min}$ at $4{ }^{\circ} \mathrm{C}$ to obtain plasma samples for $\mathrm{NO}_{3}{ }^{-}$and $\mathrm{NO}_{2}{ }^{-}$determination $\left(\mathrm{NO}_{3}{ }^{-} / \mathrm{NO}_{2}{ }^{-}\right.$Colorimetric Assay Kit; Cayman Chemical Co., Ann Arbor, MI, USA). Hematocrit samples taken in EDTA Vacutainer ${ }^{\circledR}$ tubes were used to determine PCV (\%) using a microcapillary reader (model MH, International Equipment Co., Boston, MA, USA).

\subsection{Statistical Analysis}

Data were analyzed as a $2 \times 2$ factorial design using the MIXED procedure of SAS (SAS Inst., Inc., Cary, NC, Canada) considering animal as experimental unit. Normality of distribution and homogeneity of variance was determined using the Univariate procedure of SAS. Subsequently, data were analyzed using the following model: $y_{i j k}=\mu+E N_{i}+M B E O_{j}+E N \times M B E O_{i j}+e_{i j k}$; where $y_{i j k}$ is the observation $k$ in level $i$ of $\mathrm{EN}$ and level $j$ of MBEO, $\mu$ is the overall mean, $E N_{i}$ is the effect of $i$ th EN 
treatment (control and $\mathrm{MBEO}$ versus $\mathrm{EN}$ and $\mathrm{EN}+\mathrm{MBEO}), M B E O_{j}$ is the effect of $j$ th $\mathrm{MBEO}$ treatment (control and $E N$ versus $\mathrm{MBEO}$ and $\mathrm{EN}+\mathrm{MBEO}$ ), $E N \times M B E O_{i j}$ is the interaction of the $i$ th $\mathrm{EN}$ and $j$ th MBEO treatment, and $e_{i j k}$ is residual error. Period was used as a repeated measure in the model. In the case of significant interactions, the PDIFF option was included in the LSMEANS statement to account for multiple comparisons. Different time-series covariance structures were evaluated and the best one (unstructured covariance order one) was selected based on the lowest Akaike and Bayesian information criteria. Statistical significance was declared at $p \leq 0.05$.

\section{Results}

Analyzed average $\mathrm{NO}_{3}{ }^{-}$concentration in the $\mathrm{EN}$ diets $\left(16.7 \pm 1.10 \mathrm{~g} \mathrm{NO}_{3}{ }^{-} / \mathrm{kg}\right.$ dietary DM) was very close to the formulated level of $17.85 \mathrm{~g} \mathrm{NO}_{3}^{-} / \mathrm{kg}$ dietary DM. Average daily consumption of $\mathrm{NO}_{3}{ }^{-}$was higher $(p<0.001)$ for EN but not affected by MBEO and EN $\times$ MBEO (Table 2). However, when daily $\mathrm{NO}_{3}{ }^{-}$intake was plotted over the experimental periods, an interaction effect $(p<0.01)$ was observed where animals fed $\mathrm{MBEO}$ consumed more $\mathrm{NO}_{3}{ }^{-}$at the beginning of the experiment (period 1) and less at the end compared with animals fed EN (Figure 1).

Final BW was reduced ( $p=0.012$ ) by $4.1 \%$ for EN (444 versus $463 \mathrm{~kg}$ ) but it was not affected by MBEO $(p=0.336)$ and $\mathrm{EN} \times \operatorname{MBEO}(p=0.835$; Table 2$)$. Over the experimental period, animals gained 135, 119, and $113 \mathrm{~kg}$ for the control, MBEO, and EN, respectively. Interaction effects between $\mathrm{EN}$ and MBEO on ADG and G:F were not consistent throughout the experimental period; significant interactions ( $p \leq 0.009$ ) were observed for day 29 to 56 and day 57 to 84 but no effect $(p \geq 0.20)$ occurred for the other days. However, the lack of interaction between EN and MBEO on average DMI $(p=0.479)$, ADG $(p=0.08)$, and average G:F ( $p=0.240)$ indicates the independent effect of the two additives (Table 2). Feeding EN reduced average DMI by 6.0\% (8.9 versus 8.4 for $-\mathrm{EN}$ and $+\mathrm{EN}$, respectively; $p=0.003)$ but had no effect on ADG ( $p=0.12)$ and average $\mathrm{G}: \mathrm{F}(p=0.43)$. However, average DMI, ADG, as well as average G:F were not affected by MBEO $(p \geq 0.48)$.

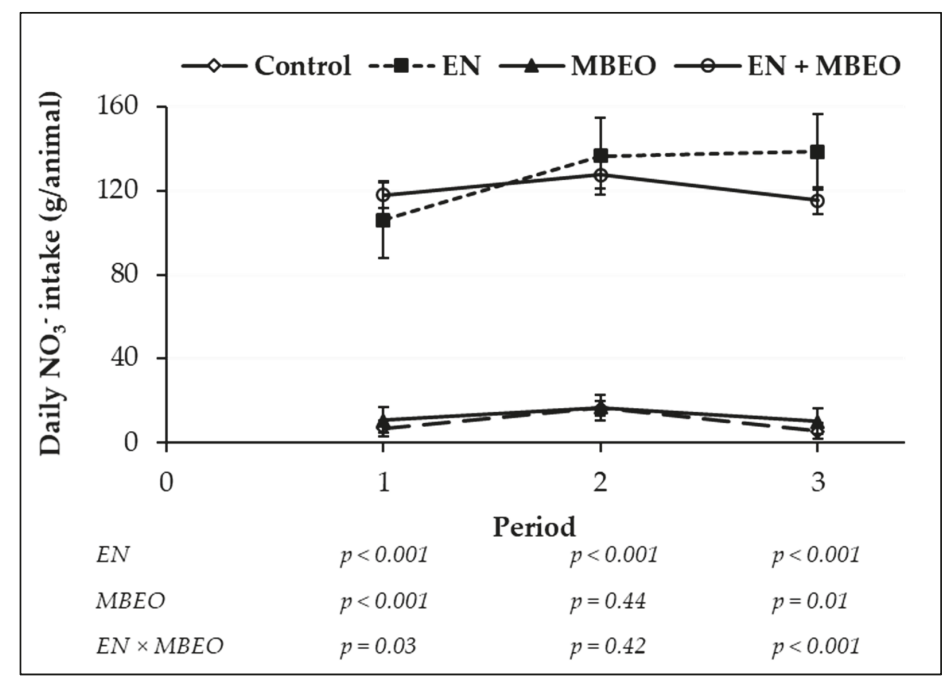

Figure 1. Nitrate intake of backgrounding beef steers fed a high-forage diet with no additives (control, -EN - MBEO) or supplemented with encapsulated nitrate (EN), microencapsulated blend of essential oils (MBEO), and combination of EN and MBEO (EN + MBEO). Error bars indicate standard deviation. For the statistical analysis, EN represents the main effect of encapsulated nitrate (-EN - MBEO and $-\mathrm{EN}+\mathrm{MBEO}$ ) versus (+EN $-\mathrm{MBEO}$ and $+\mathrm{EN}+\mathrm{MBEO})$; $\mathrm{MBEO}$ represents the main effects of microencapsulated blend of essential oils $(-\mathrm{EN}-\mathrm{MBEO}$ and $+\mathrm{EN}-\mathrm{MBEO})$ versus $(-\mathrm{EN}+\mathrm{MBEO}$ and $+\mathrm{EN}+\mathrm{MBEO}) ; \mathrm{EN}+\mathrm{MBEO}$ represents the interaction between main effects of EN and MBEO. 
Table 2. Body weight, average daily gain, dry matter intake, feed efficiency, and feeding behavior of backgrounding beef steers fed a high-forage diet with no additives (control, -EN - MBEO), or supplemented with encapsulated nitrate $(+\mathrm{EN})$, microencapsulated blend of essential oils (+MBEO), and combination of EN and MBEO (+EN +MBEO).

\begin{tabular}{|c|c|c|c|c|c|c|c|c|c|}
\hline \multirow[b]{2}{*}{ Item $^{2}$} & \multicolumn{2}{|c|}{$-\mathrm{EN}^{1}$} & \multicolumn{2}{|c|}{$+\mathrm{EN}^{1}$} & \multirow[b]{2}{*}{ SEM } & \multicolumn{4}{|c|}{$p$-Value } \\
\hline & -MBEO & +MBEO & -MBEO & +MBEO & & EN & MBEO & $\begin{array}{l}\text { EN } \times \\
\text { MBEO }\end{array}$ & Period \\
\hline Number of animals & 22 & 22 & 22 & 22 & -- & -- & -- & -- & -- \\
\hline \multicolumn{10}{|l|}{ Body weight, kg } \\
\hline Initial & 332 & 331 & 331 & 331 & 5.03 & 0.939 & 0.953 & 0.989 & --- \\
\hline day 28 & 371 & 363 & 359 & 356 & 5.59 & 0.088 & 0.348 & 0.604 & --- \\
\hline day 56 & 397 & 395 & 387 & 382 & 6.12 & 0.060 & 0.541 & 0.839 & --- \\
\hline day 84 & 439 & 426 & 413 & 407 & 6.92 & 0.002 & 0.184 & 0.561 & --- \\
\hline Final (d 112) & 467 & 458 & 446 & 441 & 7.60 & 0.012 & 0.336 & 0.835 & --- \\
\hline \multicolumn{10}{|l|}{ ADG (kg/day) } \\
\hline day 1 to 28 & 1.417 & 1.137 & 0.986 & 0.910 & 0.060 & $<0.0001$ & 0.004 & 0.093 & -- \\
\hline day 29 to 56 & $0.934^{b}$ & $1.136^{\mathrm{a}}$ & $\begin{array}{c}1.010 \\
\mathrm{a}, \mathrm{b}\end{array}$ & $0.916^{b}$ & 0.050 & 0.153 & 0.281 & 0.004 & --- \\
\hline day 57 to 84 & $1.497^{\mathrm{a}}$ & $1.110^{b}$ & $0.917^{b}$ & $0.909^{b}$ & 0.055 & $<0.0001$ & 0.001 & 0.001 & --- \\
\hline day 85 to 112 & 0.998 & 1.153 & 1.190 & 1.173 & 0.053 & 0.049 & 0.200 & 0.111 & --- \\
\hline \multicolumn{10}{|l|}{ DMI (kg/day) ${ }^{3}$} \\
\hline day 1 to 28 & 7.71 & 7.53 & 7.05 & 7.12 & 0.180 & 0.004 & 0.768 & 0.489 & --- \\
\hline day 29 to 56 & 7.85 & 8.31 & 7.82 & 7.69 & 0.180 & 0.072 & 0.359 & 0.100 & -- \\
\hline day 57 to 84 & 9.35 & 8.81 & 8.67 & 8.47 & 0.197 & 0.011 & 0.063 & 0.388 & --- \\
\hline day 85 to 112 & 9.47 & 9.53 & 8.95 & 8.73 & 0.180 & 0.001 & 0.673 & 0.447 & -- \\
\hline \multicolumn{10}{|l|}{$\mathrm{G}: \mathrm{F}$} \\
\hline day 1 to 28 & 0.184 & 0.150 & 0.139 & 0.127 & 0.007 & $<0.0001$ & 0.002 & 0.123 & -- \\
\hline day 29 to 56 & $0.118^{b}$ & $0.136^{\mathrm{a}}$ & $\begin{array}{c}0.129 \\
\mathrm{a}, \mathrm{b}\end{array}$ & $0.118^{b}$ & 0.006 & 0.504 & 0.571 & 0.009 & -- \\
\hline day 57 to 84 & $0.160^{\mathrm{a}}$ & $0.126^{b}$ & $0.106^{c}$ & $0.105^{c}$ & 0.005 & $<0.0001$ & 0.002 & 0.002 & --- \\
\hline day 85 to 112 & 0.105 & 0.121 & 0.132 & 0.134 & 0.005 & 0.0001 & 0.088 & 0.182 & --- \\
\hline \multicolumn{10}{|l|}{ Average (day 29 to 112 ) } \\
\hline DMI $(\mathrm{kg} / \text { day })^{3}$ & 8.93 & 8.87 & 8.47 & 8.28 & 0.176 & 0.003 & 0.479 & 0.713 & $<0.0001$ \\
\hline ADG (kg/day) & 1.065 & 1.157 & 1.073 & 1.018 & 0.042 & 0.119 & 0.657 & 0.080 & 0.0001 \\
\hline G:F & 0.123 & 0.128 & 0.125 & 0.121 & 0.004 & 0.432 & 0.921 & 0.240 & 0.811 \\
\hline $\begin{array}{c}\text { Average daily } \mathrm{NO}_{3}{ }^{-} \text {consumed } \\
\text { (g/animal })^{4}\end{array}$ & 9.43 & 12.43 & 127.20 & 120.37 & 5.030 & $<0.001$ & 0.723 & 0.370 & 0.160 \\
\hline \multicolumn{10}{|l|}{ Feeding behavior ${ }^{5}$} \\
\hline Total meal duration, min/day & 183.6 & 183.4 & 188.2 & 186.6 & 4.71 & 0.410 & 0.849 & 0.883 & $<0.0001$ \\
\hline $\begin{array}{l}\text { Head down duration per meal, } \\
\mathrm{min} / \text { meal }\end{array}$ & 9.6 & 9.3 & 10.2 & 9.6 & 0.68 & 0.572 & 0.519 & 0.793 & 0.323 \\
\hline Head down duration, min/day & 80.9 & 84.0 & 97.1 & 91.6 & 4.83 & 0.016 & 0.810 & 0.377 & $<0.0001$ \\
\hline Feeding/meal frequency, events/day & 9.2 & 9.6 & 10.4 & 10.4 & 0.30 & 0.002 & 0.495 & 0.440 & $<0.0001$ \\
\hline Feeding rate, $\mathrm{g} \mathrm{DM} / \mathrm{min}$ & 46.2 & 46.1 & 42.7 & 41.1 & 1.29 & 0.001 & 0.514 & 0.553 & $<0.0001$ \\
\hline
\end{tabular}

${ }^{1}$ EN represents the main effect of encapsulated nitrate (-EN $-\mathrm{MBEO}$ and $\left.-\mathrm{EN}+\mathrm{MBEO}\right)$ versus $(+\mathrm{EN}-\mathrm{MBEO}$ and $+\mathrm{EN}+\mathrm{MBEO})$; $\mathrm{MBEO}$ represents the main effects of microencapsulated blend of essential oils ( $-\mathrm{EN}-\mathrm{MBEO}$ and $+\mathrm{EN}-\mathrm{MBEO})$ versus $(-\mathrm{EN}+\mathrm{MBEO}$ and $+\mathrm{EN}+\mathrm{MBEO}) ;+\mathrm{EN}+\mathrm{MBEO}$ represents the interaction between main effects of EN and MBEO. ${ }^{2}$ Animals that received diets containing encapsulated $\mathrm{NO}_{3}{ }^{-}$were acclimatized gradually using a step-up protocol during the first 28 days of adaptation; $0.625 \%, 1.25 \%, 1.875 \%$, and $2.5 \% \mathrm{NO}_{3}{ }^{-}$in dietary DM. Animals that received MBEO were supplemented with $150 \mathrm{mg} / \mathrm{kg}$ DM microencapsulated blend of EO since the beginning of the experiment. ${ }^{3}$ Dry matter intake for animals that visited the GreenFeed emission monitoring system included the amount of pellet consumed while visiting the system. ${ }^{4} \mathrm{NO}_{3}{ }^{-}$consumption was calculated from $\mathrm{NO}_{3}{ }^{-}$analysis of TMR and ort samples. ${ }^{5}$ A meal was defined as a visit to the bunk, followed by an absence from the bunk for $300 \mathrm{~s}$ or greater. Total meal duration = total time spent at feeder, head down duration per meal = meal duration/number of meals per day, feeding rate $=\mathrm{DM}$ consumed by time at feeder (DMI/meal duration). $\mathrm{a}, \mathrm{b}, \mathrm{c}$ Means within a row for each treatment with different lower case letter are significantly different $(p \leq 0.05)$.

Feeding or eating behavior was not affected ( $p \geq 0.377$ ) by MBEO and EN $\times$ MBEO (Table 2). However, feeding EN reduced feeding rate ( $\mathrm{g} \mathrm{DM} / \mathrm{min} ; p=0.001)$, which resulted in longer head down duration ( $\mathrm{min} /$ day; $p=0.016)$ during meals and greater $(p=0.002)$ meal frequency per day.

Inclusion of EN and MBEO in the diet did not change $(p \geq 0.128)$ particle size distribution of TMR or the large $(\geq 18 \mathrm{~mm}$ ) and medium $(8$ to $18 \mathrm{~mm}$ ) particles of orts (Table 3 ). However, there was an interaction $(p<0.04)$ between EN and MBEO for the small (1.2 to $8 \mathrm{~mm}$ ) and bottom (fine, $<1.2 \mathrm{~mm}$ ) 
particles of orts because inclusion of EN induced selective sorting in favor of fine particles to a greater extent when MBEO was not added.

Table 3. Particle size distribution of total mixed ration (TMR) and orts $(n=3)$ from beef steers fed a backgrounding diet with no additives (control, - EN - MBEO), or supplemented with encapsulated nitrate $(+\mathrm{EN})$, microencapsulated blend of essential oils (+MBEO), and combination of EN and MBEO $(+\mathrm{EN}+\mathrm{MBEO})$.

\begin{tabular}{|c|c|c|c|c|c|c|c|c|c|}
\hline \multirow[b]{2}{*}{ Item } & \multicolumn{2}{|c|}{$-\mathrm{EN}^{1}$} & \multicolumn{2}{|c|}{$+\mathrm{EN}^{1}$} & \multirow[b]{2}{*}{ SEM } & \multicolumn{4}{|c|}{$p$-Value } \\
\hline & - MBEO & +MBEO & - MBEO & +MBEO & & EN & MBEO & $\begin{array}{l}\text { EN } \times \\
\text { MBEO }\end{array}$ & Period \\
\hline \multicolumn{10}{|l|}{ TMR, \% (as-is basis) } \\
\hline Large $(\geq 18 \mathrm{~mm})$ & 2.57 & 3.93 & 3.43 & 3.23 & 0.331 & 0.817 & 0.128 & 0.056 & 0.020 \\
\hline Medium (8 to $18 \mathrm{~mm})$ & 61.58 & 66.65 & 65.19 & 66.61 & 1.917 & 0.462 & 0.219 & 0.451 & 0.413 \\
\hline Small (1.2 to $8 \mathrm{~mm})$ & 31.99 & 28.13 & 29.63 & 28.89 & 1.430 & 0.706 & 0.388 & 0.510 & 0.707 \\
\hline Bottom (<1.2 mm) & 2.92 & 1.83 & 1.41 & 2.02 & 0.554 & 0.479 & 0.766 & 0.401 & 0.269 \\
\hline \multicolumn{10}{|l|}{ Orts, $\%$ (as-is basis) } \\
\hline Large $(\geq 18 \mathrm{~mm})$ & 11.48 & 14.27 & 12.65 & 9.52 & 3.886 & 0.732 & 0.973 & 0.586 & 0.115 \\
\hline Medium ( 8 to $18 \mathrm{~mm})$ & 57.26 & 62.71 & 61.01 & 58.86 & 2.211 & 0.982 & 0.483 & 0.136 & 0.111 \\
\hline Small $(1.2$ to $8 \mathrm{~mm})$ & $29.65^{a}$ & $24.11^{b}$ & $24.02^{b}$ & $30.70^{\mathrm{a}}$ & 0.775 & 0.564 & 0.49 & 0.0001 & 0.001 \\
\hline Bottom $(<1.2 \mathrm{~mm})$ & $1.71^{\mathrm{a}}$ & $0.79 \mathrm{a}, \mathrm{b}$ & $0.49^{b}$ & $0.78^{\mathrm{a}, \mathrm{b}}$ & 0.232 & 0.039 & 0.225 & 0.04 & 0.017 \\
\hline Orts, $\%$ of total offered (DM basis) & 1.08 & 1.01 & 1.36 & 2.62 & 0.477 & 0.096 & 0.259 & 0.215 & 0.037 \\
\hline
\end{tabular}

Animal visits to the GEM system and the impacts of feeding EN and MBEO on enteric $\mathrm{CH}_{4}$ and hydrogen emissions and yield are presented in Table 4. An interaction between EN and MBEO was observed for the number of animals that visited the GEM system $(p=0.021)$, but there were no treatment effects $(p \geq 0.089)$ on the average number of good visits or visit duration. The effect of EN and $\mathrm{MBEO}$ on $\mathrm{CH}_{4}$ emissions was independent as indicated by the lack of interaction effects $(p \geq 0.174)$ for these variables. Feeding EN reduced enteric $\mathrm{CH}_{4}$ emissions by $17.6 \%$ (190.9 versus $157.3 \mathrm{~g} /$ day for $-\mathrm{EN}$ and $+\mathrm{EN}$, respectively; $p<0.0001)$, whereas feeding MBEO increased $\mathrm{CH}_{4}$ emissions by $11.0 \%$ (165.0 versus $183.2 \mathrm{~g} /$ day for $-\mathrm{MBEO}$ and $+\mathrm{MBEO}$, respectively; $p=0.005)$. Similarly, $\mathrm{CH}_{4}$ yield (emissions corrected for intake) was 13.0\% lower for EN (21.5 versus $18.7 \mathrm{~g} / \mathrm{kg}$ DMI for $-\mathrm{EN}$ and + EN, respectively; $p<0.0001$ ) but $13.6 \%$ higher for MBEO (18.9 versus $21.4 \mathrm{~g} / \mathrm{kg}$ DMI for $-\mathrm{MBEO}$ and $+\mathrm{MBEO}$, respectively; $p=0.0002$ ). When $\mathrm{CH}_{4}$ emission was expressed in terms of energy loss, feeding EN resulted in a $10.8 \%$ lower loss of GE as $\mathrm{CH}_{4}$ (5.37 versus $4.79 \%$ of GE intake for - EN and $+\mathrm{EN}$, respectively; $p=0.001$ ), whereas feeding MBEO resulted in $10.6 \%$ more loss of GE as $\mathrm{CH}_{4}$ ( 4.83 versus $5.34 \%$ GE intake for $-\mathrm{MBEO}$ and $+\mathrm{MBEO}$, respectively; $p=0.002$ ). Correspondingly, an interaction ( $p=0.02)$ was observed between additives for daily hydrogen production because addition of EN increased hydrogen production to a greater extent when MBEO was not added. However, when corrected for DMI and expressed as yield, feeding EN increased hydrogen yield by $57.3 \%$ ( 0.052 versus $0.081 \mathrm{~g} / \mathrm{kg}$ DMI for $-\mathrm{EN}$ and $+\mathrm{EN}$, respectively; $p<0.001)$, whereas MBEO and $\mathrm{EN} \times \mathrm{MBEO}$ had no effect $(p \geq 0.12)$.

The diurnal pattern of $\mathrm{CH}_{4}$ production and animal visits to the GEM system by hour are presented in Figure 2. Hourly $\mathrm{CH}_{4}$ emissions increased after morning (1000 h) and afternoon $(1600 \mathrm{~h})$ feeding and production rate for $+\mathrm{EN}$ was consistently lower throughout the day relative to $-\mathrm{EN}$. Furthermore, $+\mathrm{EN}$ reduced $\mathrm{CH}_{4}$ emissions consistently throughout the experimental period, implying that the effectiveness of EN did not decline over time (Figure 3). Animals frequented the GEM system to the greatest extent at midnight $(0000 \mathrm{~h})$ and the lowest number of visits was observed between $0300 \mathrm{~h}$ and $0400 \mathrm{~h}$ for all treatments. 
Table 4. Visitation to the GreenFeed emissions monitoring (GEM) system, pellet consumption, and emission and yield of $\mathrm{CH}_{4}$ and hydrogen from backgrounding beef animals fed a high-forage diet with no additives (control, $-\mathrm{EN},-\mathrm{MBEO})$ or supplemented with encapsulated nitrate (+EN), microencapsulated blend of essential oils (+MBEO), and combination of EN and MBEO (+EN +MBEO).

\begin{tabular}{|c|c|c|c|c|c|c|c|c|c|}
\hline \multirow[b]{2}{*}{ Item } & \multicolumn{2}{|c|}{$-\mathrm{EN}^{1}$} & \multicolumn{2}{|c|}{$+\mathrm{EN}^{1}$} & \multirow[b]{2}{*}{ SEM } & \multicolumn{4}{|c|}{$p$-Value } \\
\hline & -MBEO & +MBEO & - MBEO & +MBEO & & EN & MBEO & $\begin{array}{l}\text { EN } \times \\
\text { MBEO }\end{array}$ & Period \\
\hline \multicolumn{10}{|l|}{ GEM system visitation } \\
\hline Number of animals that visited & $18^{\mathrm{a}}$ & $16^{\mathrm{b}}$ & $17^{\mathrm{a}, \mathrm{b}}$ & $18^{\mathrm{a}}$ & 0.5 & 0.741 & 0.339 & 0.021 & 0.010 \\
\hline Good visits per animal per period ${ }^{2}$ & 33.0 & 33.1 & 33.3 & 34.3 & 1.66 & 0.647 & 0.743 & 0.807 & 0.210 \\
\hline Visit duration (min:s) & $4: 06$ & 4:07 & $4: 39$ & $4: 18$ & 0.12 & 0.089 & 0.210 & 0.389 & $<0.0001$ \\
\hline Pellet consumed, kg DM/day & 0.79 & 0.84 & 0.82 & 0.88 & 0.030 & 0.262 & 0.065 & 0.911 & $<0.0001$ \\
\hline $\mathrm{DMI}^{3}, \mathrm{~kg} /$ day & 9.02 & 8.89 & 8.56 & 8.30 & 0.207 & 0.010 & 0.322 & 0.713 & $<0.0001$ \\
\hline GE intake, Mcal/day & 46.64 & 47.30 & 44.83 & 43.56 & 1.075 & 0.009 & 0.766 & 0.353 & $<0.0001$ \\
\hline \multicolumn{10}{|l|}{$\mathrm{CH}_{4}$} \\
\hline g/day & 184.14 & 197.69 & 145.89 & 168.78 & 6.533 & $<0.0001$ & 0.005 & 0.458 & $<0.0001$ \\
\hline $\mathrm{g} / \mathrm{kg}$ of DMI & 20.69 & 22.35 & 17.00 & 20.46 & 0.683 & $<0.0001$ & 0.0002 & 0.174 & $<0.0001$ \\
\hline$\%$ of GE intake & 5.19 & 5.55 & 4.46 & 5.12 & 0.169 & 0.001 & 0.002 & 0.350 & 0.0002 \\
\hline \multicolumn{10}{|l|}{ Hydrogen $^{4}$} \\
\hline g/day & $0.428^{c}$ & $0.455^{c}$ & $0.734^{\mathrm{a}}$ & $0.639^{b}$ & 0.0265 & $<0.0001$ & 0.192 & 0.022 & $<0.0001$ \\
\hline $\mathrm{g} / \mathrm{kg}$ of DMI & 0.050 & 0.053 & 0.084 & 0.078 & 0.0031 & $<0.0001$ & 0.571 & 0.123 & $<0.0001$ \\
\hline
\end{tabular}

${ }^{1} \mathrm{EN}$ represents the main effect of encapsulated nitrate ( $-\mathrm{EN}-\mathrm{MBEO}$ and $\left.-\mathrm{EN}+\mathrm{MBEO}\right)$ versus $(+\mathrm{EN}-\mathrm{MBEO}$ and $+\mathrm{EN}+\mathrm{MBEO})$; $\mathrm{MBEO}$ represents the main effects of microencapsulated blend of essential oils $(-\mathrm{EN}-\mathrm{MBEO}$ and $+\mathrm{EN}-\mathrm{MBEO})$ versus $(-\mathrm{EN}+\mathrm{MBEO}$ and $+\mathrm{EN}+\mathrm{MBEO}) ;+\mathrm{EN}+\mathrm{MBEO}$ represents the interaction between main effects of EN and MBEO. ${ }^{2}$ Good visits were selected based on the distance of the animal's head from the proximity sensor and the duration that the animal's head in the "head chamber". Good visits were used to calculate the average daily $\mathrm{CH}_{4}$ emissions. ${ }^{3} \mathrm{DM}$ intake included both TMR and pellet consumption. ${ }^{4}$ Hydrogen emission was calculated using the "arithmetic averaging method", a straight-forward averaging of the visit fluxes defined as the sum of the visit fluxes divided by the number of measurements [26]. ${ }^{a, b, c}$ Means within a row for each treatment with different lower case letter are significantly different $(p \leq 0.05)$.

There was no interaction $(p \geq 0.20)$ between EN and MBEO on blood partial pressure of carbon dioxide $\left(\mathrm{pCO}_{2}\right)$ and oxygen $\left(\mathrm{pO}_{2}\right)$, total concentration of $\mathrm{CO}_{2}\left(\mathrm{tCO}_{2}\right)$, saturation of $\mathrm{O}_{2}\left(\mathrm{SatO}_{2}\right)$ and $\mathrm{CO}_{2}\left(\mathrm{SatCO}_{2}\right)$, bicarbonate $\left(\mathrm{HCO}_{3}{ }^{-}\right)$, total $\mathrm{Hb}$, base excess $(\mathrm{BE}), \mathrm{pH}$, and packed cell volume $(\mathrm{PCV})$ (Table 5). However, an interaction between the additives was observed for blood $\mathrm{MetHb}(p=0.008)$ and plasma $\mathrm{NO}_{3}{ }^{-}-\mathrm{N}(p=0.003)$ contents, because blood MetHb and plasma $\mathrm{NO}_{3}{ }^{-}-\mathrm{N}$ increased to a lesser extent when MBEO was added. None of the animals showed visual signs of methemoglobinemia throughout the experiment, observing a maximum individual MetHb concentration of $4.1 \%$ of total $\mathrm{Hb}$ for the $+\mathrm{EN}+\mathrm{MBEO}$ treatment, a level that is not a threat to animal health and wellbeing. Furthermore, feeding $\mathrm{EN}(+\mathrm{EN})$ increased $(p=0.05)$ blood $\mathrm{HCO}_{3}{ }^{-}$and total $\mathrm{CO}_{2}$ relative to treatment without EN. Feeding MBEO had no effect on all measured blood parameters. Plasma $\mathrm{NO}_{3}{ }^{-}-\mathrm{N}$ concentration for the EN and EN + MBEO treatments was reduced over the experimental period (Figure 4a); however, plasma $\mathrm{NO}_{2}{ }^{-}-\mathrm{N}$ concentrations reached maximum at the fourth week of the experimental period for all the treatments and sharply reduced thereafter (Figure $4 \mathrm{~b}$ ). 


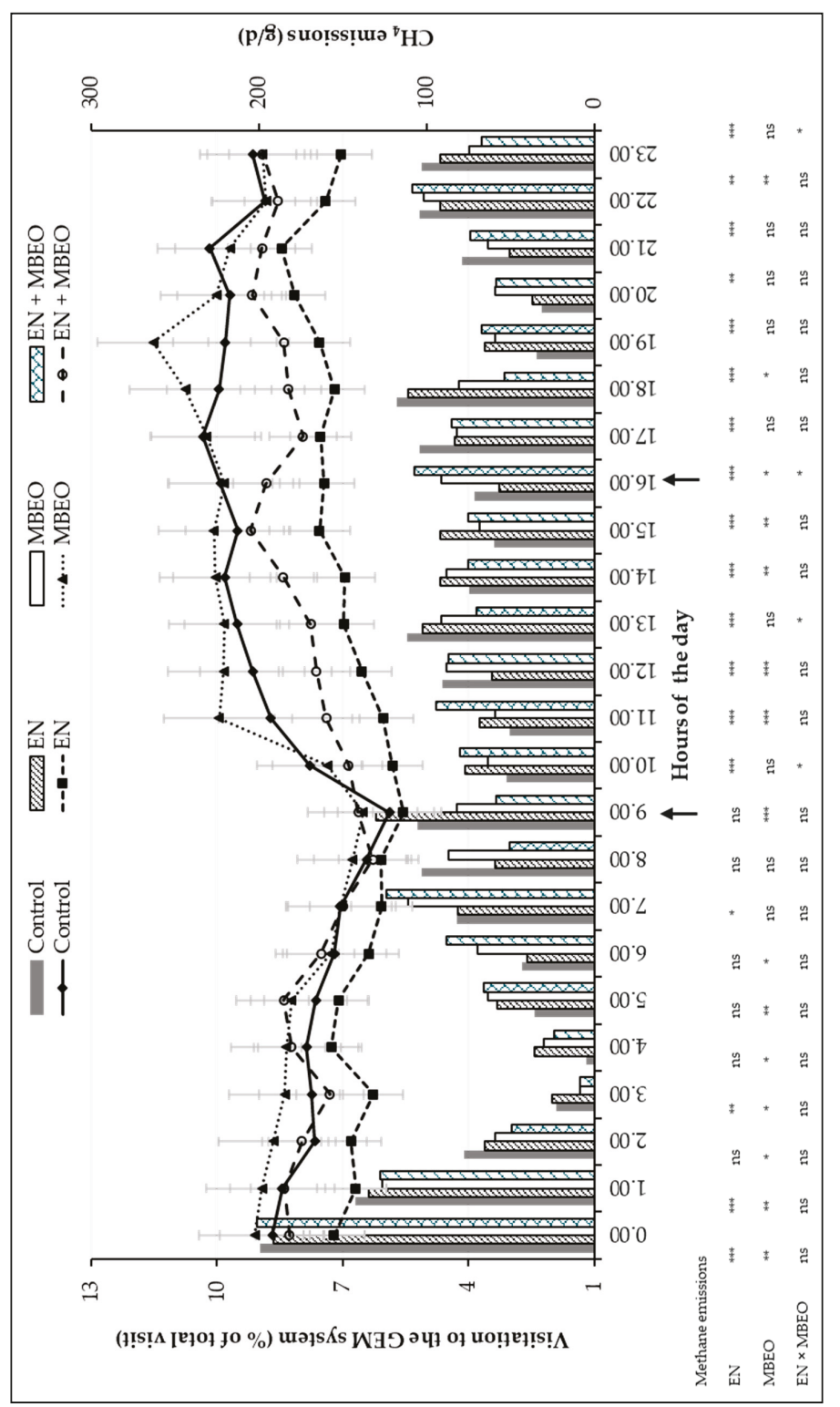

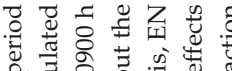
过 म

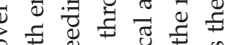

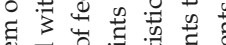

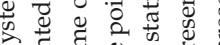

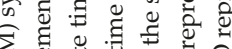

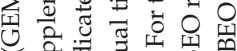
क के द्वें मे $\Sigma$ tᄒ o

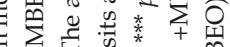

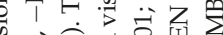

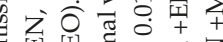
व

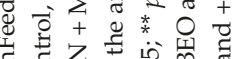

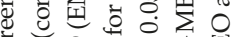

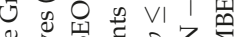

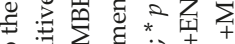

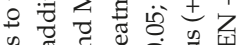
क

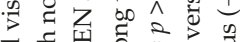

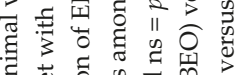
完苛

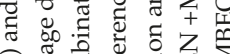

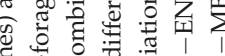
马 늠

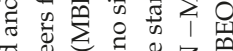
.궝 क पै

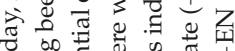
कo

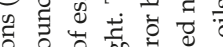

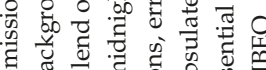

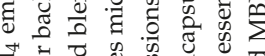

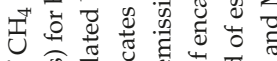

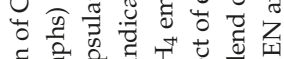

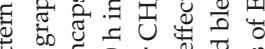
表

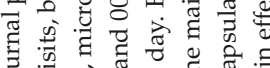
मे

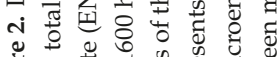
ज屯

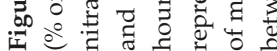




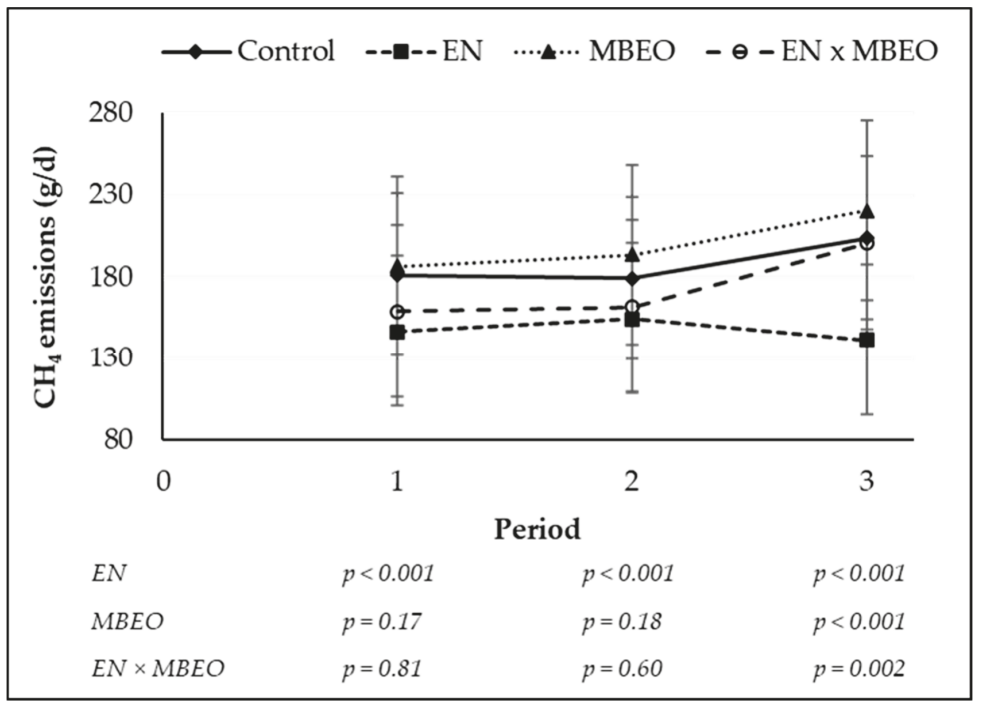

Figure 3. Enteric $\mathrm{CH}_{4}$ emissions over the experimental period for beef steers consuming a high-forage diet with no additives (control, - EN - MBEO) or supplemented with encapsulated nitrate (EN), microencapsulated blend essential oils (MBEO), and combination of EN and MBEO (EN + MBEO). Error bars indicate standard deviation. For the statistical analysis, EN represents the main effect of encapsulated nitrate ( $-\mathrm{EN}-\mathrm{MBEO}$ and $-\mathrm{EN}+\mathrm{MBEO})$ versus $(+\mathrm{EN}-\mathrm{MBEO}$ and $+\mathrm{EN}+\mathrm{MBEO})$; MBEO represents the main effects of microencapsulated blend of essential oils ( $-\mathrm{EN}-\mathrm{MBEO}$ and $+\mathrm{EN}$ $-\mathrm{MBEO}$ ) versus $(-\mathrm{EN}+\mathrm{MBEO}$ and $+\mathrm{EN}+\mathrm{MBEO}) ; \mathrm{EN}+\mathrm{MBEO}$ represents the interaction between main effects of EN and MBEO.

Table 5. Jugular blood acid-base balance of beef steers $(n=22)$ fed a high forage backgrounding diet with no additives (control, $-\mathrm{EN},-\mathrm{MBEO})$ or supplemented with encapsulated nitrate (+EN), microencapsulated blend of essential oils (+MBEO), and combination of EN and MBEO (+EN +MBEO).

\begin{tabular}{|c|c|c|c|c|c|c|c|c|c|}
\hline \multirow{2}{*}{ Item $^{2}$} & \multicolumn{2}{|c|}{$-\mathrm{EN}^{1}$} & \multicolumn{2}{|c|}{$+\mathrm{EN}^{1}$} & \multirow{2}{*}{ SEM } & \multicolumn{4}{|c|}{$p$-Value } \\
\hline & -MBEO & $+\mathrm{MBEO}$ & -MBEO & +MBEO & & EN & MBEO & $\mathrm{EN} \times \mathrm{MBEO}$ & Period \\
\hline $\mathrm{pCO}_{2}, \mathrm{mmHg}$ & 40.91 & 39.55 & 41.39 & 41.82 & 0.974 & 0.165 & 0.632 & 0.364 & $<0.0001$ \\
\hline $\mathrm{tCO}_{2}, \mathrm{mmol} / \mathrm{L}^{3}$ & 29.30 & 29.55 & 30.43 & 30.49 & 0.506 & 0.048 & 0.762 & 0.844 & $<0.0001$ \\
\hline $\mathrm{HCO}_{3}-, \mathrm{mmol} / \mathrm{L}^{3}$ & 28.06 & 28.34 & 29.15 & 29.20 & 0.486 & 0.051 & 0.724 & 0.813 & $<0.0001$ \\
\hline $\mathrm{BE}, \mathrm{mmol} / \mathrm{L}^{3}$ & 4.82 & 5.28 & 5.49 & 5.65 & 0.380 & 0.180 & 0.424 & 0.691 & 0.209 \\
\hline $\mathrm{pH}$ & 7.48 & 7.50 & 7.48 & 7.49 & 0.008 & 0.857 & 0.334 & 0.200 & 0.0001 \\
\hline $\mathrm{pO}_{2}, \mathrm{mmHg}$ & 42.79 & 43.03 & 41.88 & 44.03 & 1.127 & 0.968 & 0.294 & 0.402 & 0.0077 \\
\hline $\mathrm{SatO}_{2}, \%$ total $\mathrm{Hb}$ & 78.00 & 79.15 & 77.27 & 78.91 & 1.223 & 0.694 & 0.261 & 0.844 & $<0.001$ \\
\hline PCV,$\%$ & 43.03 & 43.40 & 43.49 & 43.83 & 0.571 & 0.444 & 0.539 & 0.979 & 0.0001 \\
\hline Total Hb, g/dL & 16.15 & 15.98 & 16.42 & 16.29 & 0.210 & 0.170 & 0.479 & 0.934 & $<0.0001$ \\
\hline MetHb, g/100 g Hb & $0.70^{b}$ & $0.87^{b}$ & $1.45^{\mathrm{a}}$ & $1.22^{\mathrm{a}}$ & 0.053 & $<0.0001$ & 0.710 & 0.008 & 0.0003 \\
\hline Min., g/100 g Hb & 0.00 & 0.25 & 0.20 & 0.55 & --- & --- & --- & --- & --- \\
\hline $\begin{array}{c}\text { Max., g/100 g Hb } \\
\text { Plasma }\end{array}$ & 1.95 & 2.53 & 3.40 & 4.10 & --- & --- & -- & -- & -- \\
\hline $\mathrm{NO}_{3}{ }^{-}-\mathrm{N}, \mathrm{mg} / \mathrm{L}$ & $0.082^{c}$ & $0.076^{\mathrm{c}}$ & $1.135^{\mathrm{a}}$ & $0.812^{b}$ & 0.052 & $<0.0001$ & 0.002 & 0.003 & $<0.0001$ \\
\hline $\mathrm{NO}_{2}{ }^{-}-\mathrm{N}, \mu \mathrm{g} / \mathrm{L}$ & 2.536 & 2.621 & 2.178 & 1.971 & 0.129 & 0.0002 & 0.636 & 0.260 & $<0.0001$ \\
\hline
\end{tabular}

${ }^{1}$ EN represents the main effect of encapsulated nitrate ( $-\mathrm{EN}-\mathrm{MBEO}$ and $\left.-\mathrm{EN}+\mathrm{MBEO}\right)$ versus $(+\mathrm{EN}-\mathrm{MBEO}$ and $+\mathrm{EN}+\mathrm{MBEO})$; $\mathrm{MBEO}$ represents the main effects of microencapsulated blend of essential oils $(-\mathrm{EN}-\mathrm{MBEO}$ and $+\mathrm{EN}-\mathrm{MBEO}$ ) versus $(-\mathrm{EN}+\mathrm{MBEO}$ and $+\mathrm{EN}+\mathrm{MBEO}) ;+\mathrm{EN}+\mathrm{MBEO}$ represents the interaction between main effects of EN and MBEO. ${ }^{2} \mathrm{pCO}_{2}$, partial pressure of carbon dioxide; $\mathrm{tCO}_{2}$, total concentration of $\mathrm{CO}_{2} ; \mathrm{HCO}_{3}^{-}$, bicarbonate; $\mathrm{BE}$, base excess; $\mathrm{pO}_{2}$, partial pressure of $\mathrm{O}_{2}$; $\mathrm{SatO}_{2}, \mathrm{O}_{2}$ saturation as percent of oxygen based on total hemoglobin saturation capacity; $\mathrm{PCV}$, packed cell volume; $\mathrm{Hb}$, hemoglobin; $\mathrm{MetHb}$, methemoglobin; $\mathrm{NO}_{3}{ }^{-}$, nitrate and $\mathrm{NO}_{2}{ }^{-}$, nitrite. ${ }^{3}$ These parameters were calculated from parameters measured by VetStat analyzer. ${ }^{\mathrm{a}, \mathrm{b}, \mathrm{c}}$ Means within a row for each treatment with different lower case letter are significantly different $(p \leq 0.05)$. 

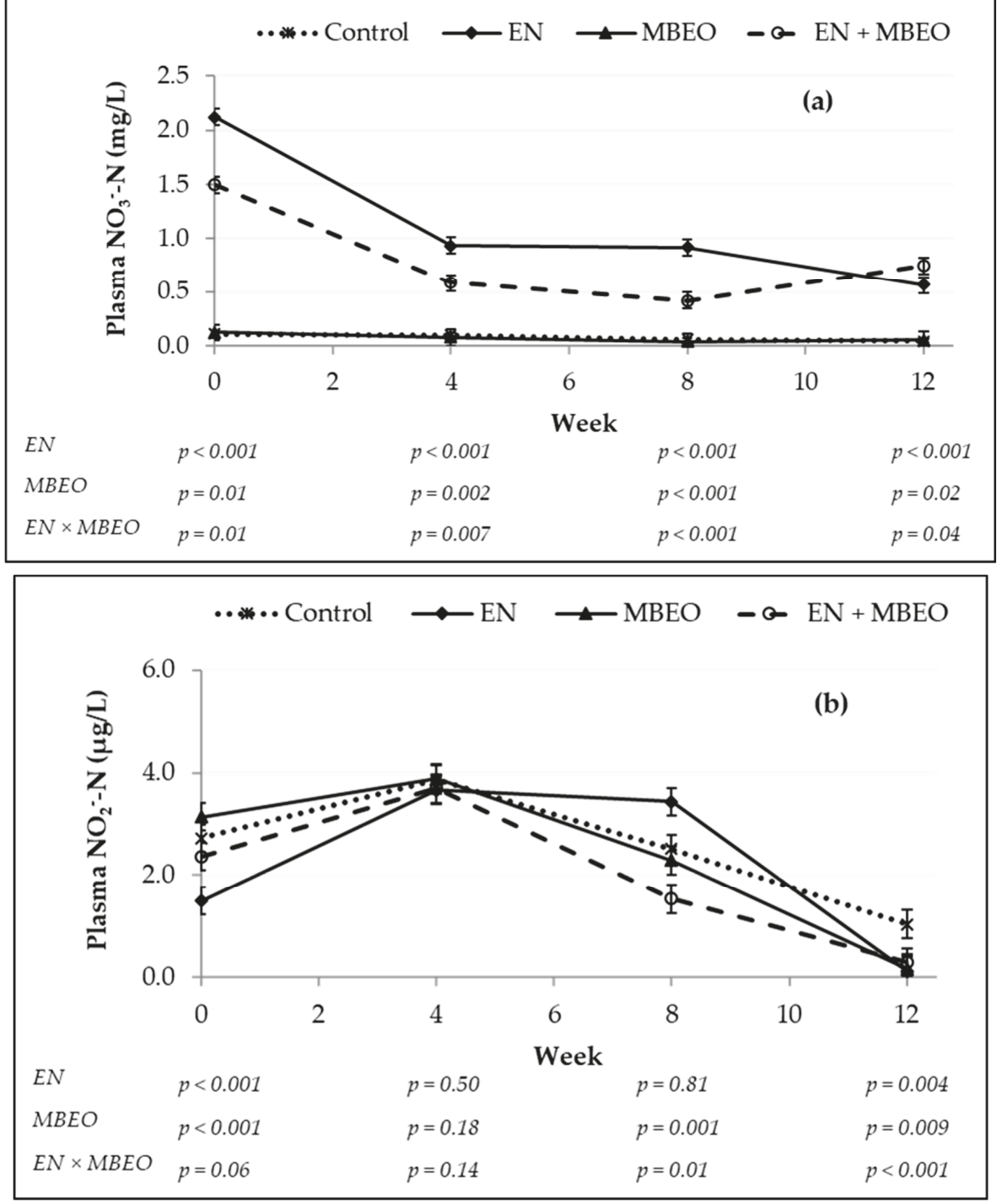

Figure 4. Plasma $\mathrm{NO}_{3}{ }^{-}-\mathrm{N}$ (a) and $\mathrm{NO}_{2}{ }^{-}-\mathrm{N}($ b) concentration before morning feeding in beef steers $(n=22)$ consuming a high-forage diet with no additives (control, $-\mathrm{EN},-\mathrm{MBEO}$ ) or supplemented with encapsulated nitrate (EN), microencapsulated blend essential oils (MBEO), and combination of EN and MBEO (EN + MBEO). Week zero indicates the end of adaptation period (experimental day 28). Error bars indicate standard deviation. For the statistical analysis, EN represents the main effect of encapsulated nitrate ( $-\mathrm{EN}-\mathrm{MBEO}$ and $-\mathrm{EN}+\mathrm{MBEO})$ versus $(+\mathrm{EN}-\mathrm{MBEO}$ and $+\mathrm{EN}+\mathrm{MBEO})$; MBEO represents the main effects of microencapsulated blend of essential oils ( $-\mathrm{EN}-\mathrm{MBEO}$ and $+\mathrm{EN}$ $-\mathrm{MBEO})$ versus $(-\mathrm{EN}+\mathrm{MBEO}$ and $+\mathrm{EN}+\mathrm{MBEO}) ; \mathrm{EN}+\mathrm{MBEO}$ represents the interaction between main effects of EN and MBEO. 


\section{Discussion}

Supplementation of $\mathrm{NO}_{3}{ }^{-}$in ruminant diets has been proposed as an alternative to increase non-protein nitrogen intake while effectively minimizing enteric $\mathrm{CH}_{4}$ emissions [30]. However, it is also well documented that over-consumption of $\mathrm{NO}_{3}{ }^{-}$can be toxic to animals [12]. Encapsulation of $\mathrm{NO}_{3}{ }^{-}$has been used $[7,29]$ to ensure slow release of $\mathrm{NO}_{3}{ }^{-}$in the rumen and increase the efficiency of microbes to fully reduce $\mathrm{NO}_{3}{ }^{-}$to ammonia, thus minimizing the risk of $\mathrm{NO}_{3}{ }^{-} / \mathrm{NO}_{2}{ }^{-}$toxicity.

Essential oils have been shown to favorably affect rumen fermentation in vitro, but the observed responses have not translated into improved production characteristics in the few existing studies with beef cattle [17]. Furthermore, previous studies have reported that the immune modulation, antioxidant, thermoregulation, and blood oxygenation properties of EO may improve animal productivity and energetics $[14,18]$. Despite the use of $\mathrm{NO}_{3}{ }^{-}$and $\mathrm{EO}$ in ruminant diets, previous studies have not explored their possible interaction on enteric $\mathrm{CH}_{4}$ mitigation and animal productivity. The main finding in the current study is that the effects of EN were mostly independent from those of MBEO, as most of the variables examined showed a lack of significant interaction between EN and MBEO, thus considering the responses to these additives as generally independent.

\subsection{Nitrate}

In the literature, the impact of feeding $\mathrm{NO}_{3}{ }^{-}$to ruminants on DMI varies among studies. For example, using unencapsulated $\mathrm{NO}_{3}{ }^{-}$(2\% in diet DM) Lund et al. [31] reported $11 \%$ reduction in DMI for dairy cattle fed a high-forage diet (58\% DM). Similarly, Hulshof et al. [2] used unencapsulated $\mathrm{NO}_{3}{ }^{-}(2.2 \%$ in dietary DM) and observed a decrease in DMI of $6 \%$ in beef cattle fed high-forage diets $(60 \% \mathrm{DM})$. Encapsulation of $\mathrm{NO}_{3}{ }^{-}$ensures not only slow release in the rumen [8] but also has a potential to minimize its negative impact on feed intake caused by its organoleptic properties [32]. This has been the case in some previous reports that used encapsulated $\mathrm{NO}_{3}{ }^{-}[7,10]$ but not in others [11].

In our study, the lack of effects of EN on ADG and G:F were in agreement with Lee et al. [10] and El-Zaiat et al. [7]. Lee et al. [10] supplemented encapsulated $\mathrm{NO}_{3}{ }^{-}(2.5 \%$ in dietary DM) to beef cattle fed a high-forage diet (65\% DM corn silage) and reported no effect on DMI and feed efficiency. Whereas with the same inclusion rate in a high concentrate diet ( $80 \% \mathrm{DM}$ of barley grain), the same authors observed a $7.5 \%$ reduction in DMI and 11\% improvement in feed efficiency for finishing beef cattle [11]. Changes in feeding and eating behavior following $\mathrm{NO}_{3}{ }^{-}$supplementation may contribute to DMI and feed efficiency responses [32,33]. For example, Lee et al. [10] observed significant sorting of the TMR for large particles, which increased the proportion of small particles and decreased the proportion of large particles in orts, as well as a considerable increase in $\mathrm{NO}_{3}{ }^{-}$concentration in orts. Conversely, in our study, feeding EN induced sorting in favor of fine particles but had no effect on either the large and medium particles of orts or the total amount of orts ( $\%$ of total offered). The reduction in feeding rate (g DM/min) for EN was manifested in longer head down duration during meals and more frequent meals per day. These changes in feeding behavior of cattle fed EN were consistent with Velazco et al. [34], where $\mathrm{NO}_{3}{ }^{-}$-fed cattle consumed a large number of meals per day and smaller in size when compared to cattle fed a control diet.

Previous studies reported a reduction in enteric $\mathrm{CH}_{4}$ production in several species and categories of animals due to $\mathrm{NO}_{3}{ }^{-}$feeding $[1,30]$. Reductions in $\mathrm{CH}_{4}$ yield ranging between $4 \%$ (with $1 \% \mathrm{NO}_{3}{ }^{-}$ in diet DM; $[9,10]$ ) and 33\% (with 2.7\% $\mathrm{NO}_{3}{ }^{-}$in diet DM; [7]) have been reported for ruminants fed high-forage diets supplemented with encapsulated $\mathrm{NO}_{3}{ }^{-}$. The observed reduction in $\mathrm{CH}_{4}$ yield in our study for $+\mathrm{EN}(13.0 \%)$ was within the range of $12.2 \%$ and $18.3 \%$ reduction reported for beef heifers fed a forage diet (50\% DM barley silage) supplemented with encapsulated $\mathrm{NO}_{3}{ }^{-}$at $2 \%$ and $3 \%$ in diet DM, respectively [9]. Lower rate of reduction (6.2\%) was also reported for backgrounding steers fed a high-forage diet (65\% DM corn silage) supplemented with encapsulated $\mathrm{NO}_{3}{ }^{-}(2.5 \%$ in diet DM [10]). Little is known about the factors that may interfere with the efficiency of $\mathrm{NO}_{3}{ }^{-}$reduction in the rumen. Encapsulation of $\mathrm{NO}_{3}{ }^{-}$[8], amount of $\mathrm{NO}_{3}{ }^{-}$ingested, and intake rate of $\mathrm{NO}_{3}{ }^{-}[32,35]$, 
type of diet (e.g., roughage inclusion, $\mathrm{N}$ and $\mathrm{S}$ concentrations $[10,11,35]$ as well as type of animals [35]) affect ruminal $\mathrm{NO}_{3}{ }^{-}$utilization, and consequently, $\mathrm{CH}_{4}$ reduction. Furthermore, duration of feeding a dietary additive may affect its efficacy in reducing enteric $\mathrm{CH}_{4}$ production over time [36]; however, there was no decline in the effectiveness of EN over time in the current study (Figure 3).

Multiple in vitro [8] and in vivo studies [4,5,31] have reported an increase in hydrogen production after feeding $\mathrm{NO}_{3}{ }^{-}$. Similarly, a significant $(p<0.001)$ increase in hydrogen production and yield was observed for the EN treatment in our study. It is generally believed that $\mathrm{NO}_{3}{ }^{-}$reduction is a thermodynamically favorable process relative to methanogenesis in which $\mathrm{NO}_{3}{ }^{-}$acts as a hydrogen sink [37]. However, considering the observed increase in hydrogen production following $\mathrm{NO}_{3}{ }^{-}$ supplementation in previous studies as well as in the current study, the earlier hypothesis needs to be re-examined. Perhaps the direct toxicity of $\mathrm{NO}_{3}{ }^{-}$and its reduced intermediate $\left(\mathrm{NO}_{2}{ }^{-}\right)$on rumen microbes [3] may contribute as an additional mode of action in decreasing enteric $\mathrm{CH}_{4}$ production. Furthermore, hydrogen is an energy-dense gas (142 kJ/g of hydrogen, [38]) and its emission by animals could partially offset the energy gain by the decrease in $\mathrm{CH}_{4}$ production. For example, the calculated energy lost in hydrogen production for the $+\mathrm{EN}$ treatment was $23.3 \mathrm{kcal}$ per day or $6.9 \%$ of the observed $\mathrm{CH}_{4}$ decrease with the use of EN.

The increased concentration of plasma $\mathrm{NO}_{3}{ }^{-}$and $\mathrm{NO}_{2}{ }^{-}$following supplementation of $\mathrm{NO}_{3}{ }^{-}$in the diets of ruminants implies that $\mathrm{NO}_{3}{ }^{-}$is not fully reduced to ammonia. Lee et al. [10,32] observed a dose-response increase in blood $\mathrm{NO}_{3}{ }^{-}$and $\mathrm{NO}_{2}{ }^{-}$when encapsulated $\mathrm{NO}_{3}{ }^{-}$was fed. The observed increase in blood $\mathrm{NO}_{3}{ }^{-}$concentration for the EN treatment in our study was comparable to previous reports $[10,33]$. Furthermore, $\mathrm{NO}_{2}{ }^{-}$was present in the blood in a detectable range (2 to $3 \mu \mathrm{g} / \mathrm{L}$ of $\mathrm{NO}_{2}{ }^{-} \mathrm{N}$ ) but did not elevate blood MetHb levels (less than $4.1 \%$ of total $\mathrm{Hb}$ ) to the threshold that is considered to cause subclinical methemoglobinemia (30 to $40 \%$ [12]). Feeding $\mathrm{NO}_{3}{ }^{-}$at 2 to $3 \%$ of dietary DM has been widely reported without any toxicity issues [30]. Although $\mathrm{NO}_{3}{ }^{-}$consumption was relatively consistent over the experimental periods, blood $\mathrm{NO}_{3}{ }^{-}$and $\mathrm{NO}_{2}{ }^{-}$concentrations gradually decreased during the study, which could be due to a combination of factors, including a possible gradual improvement in microbial capacity to reduce dietary $\mathrm{NO}_{3}{ }^{-}$[39], physiological change of the experimental animals [8], and change in the feeding behavior $[8,10,40]$. The lower feeding rate ( $\mathrm{g} \mathrm{DM} / \mathrm{min}$ ) and higher meal frequency per day for EN may have helped to spread out the availability of $\mathrm{NO}_{3}{ }^{-}$to rumen microbes over a longer period, thus reducing the size of $\mathrm{NO}_{3}{ }^{-}$pulses occurring in the rumen, which in turn would have lowered the concentration of $\mathrm{NO}_{3}{ }^{-}$and $\mathrm{NO}_{2}{ }^{-}$in rumen fluid and blood.

\subsection{Essential Oils}

The lack of effect of MBEO on average DMI and feed efficiency observed in our study is consistent with previous in vivo studies that supplemented EO or blend of EO to beef cattle. For example, Beauchemin and McGinn [41] reported that growing beef cattle fed a high-forge diet (75\% DM whole-grain barley silage) supplemented with $1 \mathrm{~g}$ /day blend of EO (Crina ${ }^{\circledR}$ Ruminants, mixture of thymol, eugenol, vanillin, limonene, and guaiacol) did not show any difference in DMI and feed efficiency. Similarly, using that same product (Crina ${ }^{\circledR}$ Ruminants) at 1 and $2 \mathrm{~g} /$ day, Tomkins et al. [39] found no differences in DMI and animal performance for steers fed Rhodes grass hay (ad libitum). For beef animals on finishing diets, a study conducted by Yang et al. [20] tested the effects of 3 doses $(0.4,0.8,1.6 \mathrm{~g} /$ day) of cinnamaldehyde or monensin on feedlot cattle performance, and reported that none of the treatments affected performance variables. Furthermore, Meyer et al. [42] reported no effect on DMI and feed efficiency for feedlot steers over a 115-day finishing period when fed a blend of EO (thymol, eugenol, vanillin, guaiacol, and limonene) at $1 \mathrm{~g} /$ animal/day. However, the authors reported improved efficiency for diets containing a blend of $\mathrm{EO}$ and tylosin. Furthermore, using higher doses ( 3.5 and $7 \mathrm{~g} / \mathrm{animal} /$ day) of a blend of $\mathrm{EO}\left(\mathrm{MixOil}^{\circledR}\right.$, extracts from oregano, garlic, lemon, rosemary, thyme, eucalyptus, and sweet orange), Rivaroli et al. [43] reported no effects on DMI and animal performance parameters for crossbred bulls fed high-grain finishing diets for 120-days. A similar 
lack of effect has been observed in other animal species, including sheep [44] and dairy cows [18,42]. Overall, the results from our study are consistent with the literature that suggests supplementation of diets with EO has no effects on DMI and performance of beef cattle.

Only few in vivo studies investigated the effect of $\mathrm{EO}$ on enteric $\mathrm{CH}_{4}$ emission with conflicting results $[16,17]$. Furthermore, due to the variation in type of diets, dose rate, and the range of EO and EO compounds used, it is challenging to make a direct comparison of $\mathrm{CH}_{4}$ emission outputs among studies. Reduction in enteric $\mathrm{CH}_{4}$ emissions following supplementation of $\mathrm{EO}$ and blend of $\mathrm{EO}$ has been reported for sheep [23,44] and buffalo [45], although others reported no effect on $\mathrm{CH}_{4}$ emissions for beef $[41,46]$ and dairy cattle [47]. However, in the current study, enteric $\mathrm{CH}_{4}$ emissions and yield were increased by $11.0 \%$ and $13.6 \%$, respectively. It is difficult to explain the observed increase in $\mathrm{CH}_{4}$ production. However, several factors, including the wide range of non-specific antibacterial activity of EO that may favor methanogenesis [15] or positive impacts of EO on ruminal feed degradability [19,48], may play a role.

Information on the effect of $\mathrm{EO}$ on the process of methanogenesis in ruminants is ambiguous $[49,50]$. The impact of $\mathrm{EO}$ on $\mathrm{CH}_{4}$ emissions may be attributed to direct impact on methanogenic archaea (changing community structure or activity of methanogenesis pathway) and indirect impact on microbial metabolic processes contributing to methanogenesis [17]. Essential oils can also affect some protozoa that are symbiotically associated with archaea. Using meta-analysis, Khiaosa-ard and Zebeli [51] reported a dose-response effect of EO on reducing protozoa, whereas Cobellis et al. [17] reported no effect of EO on protozoa in most in vivo studies in ruminants. Furthermore, the antimicrobial activity of EO varies with the quantity used, chemical composition (both components present and their proportion), interaction among EO components, and chemical configurations $[52,53]$. Additive, antagonistic, and synergistic effects have been observed between components of $\mathrm{EO}[15,52]$. The Activo ${ }^{\circledR}$ Premium used in the MBEO treatment contained carvacol, eugenol, capsaicin, cinnamaldehyde, and pepper extract with diverse antimicrobial activities. For example, carvacrol has shown a negative effect on Gram-negative bacteria [54], whereas eugenol has shown a broad antibacterial activity by affecting both Gram-negative and Gram-positive bacteria [14,55].

Although reduction in DM digestibility following supplementation of EO has been reported in most in vitro studies, in vivo studies have been inconsistent [17]. Yang et al. [48] fed garlic (5 g/cow per day) and juniper berry ( $2 \mathrm{~g} / \mathrm{cow}$ per day) to dairy cows consuming a ration containing forage $(40 \% \mathrm{DM})$ and reported a 12 to $15 \%$ increase in rumen DM and OM digestibility. However, total tract digestibility of DM, OM, fiber, and starch were not affected. They suggested that the increased ruminal digestibility was due to an $11 \%$ increase in dietary protein digestibility in the rumen compared with control. In another study, Silva et al. [19] fed Activo ${ }^{\circledR}$ Premium at the rate of $150 \mathrm{mg} / \mathrm{kg}$ DM to dairy cows consuming a diet containing corn silage $(48 \% \mathrm{DM})$ and observed an increase in total tract $\mathrm{OM}$ digestibility. It has also been reported that the effects of $\mathrm{EO}$ and $\mathrm{EO}$ blends are rumen $\mathrm{pH}$ and diet dependent [14]. Benchaar et al. [56] reported that supplementation of $750 \mathrm{mg}$ Crina ${ }^{\circledR}$ Ruminants per day to dairy cows tended to increase total VFA concentration in the rumen of lactating cows when the diet contained alfalfa silage, but tended to decrease total VFA concentration when the diet contained corn silage. Overall, further long-term in vivo studies are required to determine the potential of using $\mathrm{EO}$ in ruminant diets to lower enteric $\mathrm{CH}_{4}$ production.

Although studies report anti-inflammatory, immune modulation, antioxidant, thermoregulation, and blood oxygenation properties of EO [14,18], blood parameters measured in our study did not differ for the MBEO and EN + MBEO treatments. Recent findings suggest that due to their phenolic nature, some EO are likely less susceptible to microbial degradation in the rumen and exhibit activities post-ruminally by binding to specific receptors expressed in neurons, intestines, and other cells [18,57]. However, Oh et al. [18] stated that these impacts of EO are likely dependent on the type and physiological status of the experimental animals, as well as the type of diets. In dairy cattle, providing EO either in the diet or by direct infusion into the abomasum had an effect on the immune system of the animals, post-ruminal nutrient use, and animal physiology [18]. Silva et al. [19,22] fed 
Activo ${ }^{\circledR}$ Premium at $150 \mathrm{mg} / \mathrm{kg}$ diet DM to dairy cows in mid-lactation for 8 weeks and reported increased $\mathrm{O}_{2}$ saturation of $\mathrm{Hb}$ and a greater proportion of $\mathrm{O}_{2}$ transported by blood in relation to total gases for cows fed a blend of EO compared with a control. Furthermore, for feedlot cattle fed a finishing diet containing dry-rolled barley grain (86\% DM), Yang et al. [20] reported that supplementation with cinnamaldehyde (0.4 to $1.6 \mathrm{~g}$ /day per animals) reduced stress and increased DMI during the early feeding period when stress is greater. In our study, animals were fed a high-forage diet (80\% DM) and were likely under minimal stress.

\section{Conclusions}

The effects of feeding EN as a replacement for urea and MBEO alone or in combination with $\mathrm{EN}$ on animal performance and enteric $\mathrm{CH}_{4}$ emissions from beef steers fed a high-forage diet were investigated. Our results demonstrate that there were no advantages of feeding EN with MBEO. Supplementing diets with MBEO neither improved animal performance nor lowered $\mathrm{CH}_{4}$ emissions. However, EN reduced $\mathrm{CH}_{4}$ emissions and altered feeding behavior, whereas it had no impact on animal health and performance. Accordingly, the use of EN could have important implications for the Canadian beef sector in particular and global ruminant agriculture in general. In 2016, $\mathrm{CH}_{4}$ emissions from enteric fermentation represented 3.5\% of the Canadian national greenhouse gas inventory, with beef cattle production accounting for $80 \%$ of the emissions. A $30 \%$ adoption rate of EN by beef producers, combined with $17.6 \%$ reduction of enteric $\mathrm{CH}_{4}$ emissions following the use of EN, would result in $4 \%$ less total enteric emissions and $1.8 \%$ less agricultural emissions in Canada.

Author Contributions: Conceptualization, A.W.A., A.R.-P., R.C.A., and K.A.B.; methodology, A.W.A., A.R.-P., R.C.A., and K.A.B.; software, A.W.A.; validation, A.W.A., A.R.-P., and K.A.B.; formal analysis, A.W.A., A.R.-P., and K.A.B.; investigation, A.W.A., A.R.-P., R.C.A., and K.A.B.; resources, A.W.A., A.R.-P., R.C.A., and K.A.B.; data curation, A.W.A., A.R.-P., and K.A.B.; writing-original draft preparation, A.W.A.; writing-review and editing, A.W.A., A.R.-P., R.C.A., and K.A.B.; supervision, K.A.B.; project administration, A.W.A., A.R.-P., and K.A.B.; funding acquisition, K.A.B.

Funding: This research was funded by Emissions Reduction Alberta and Agriculture and Agri-Food Canada.

Acknowledgments: Special thanks to the staff of the Research Feedlot and Controlled Environment Facilities for animal care and lab technicians (K. Andrews, B. Farr, L. Holtshausen, N. Johnson, R. Roth, and D. Vedres) for sample analyses.

Conflicts of Interest: The authors declare no conflict of interest.

\section{References}

1. Hristov, A.N.; Oh, J.; Lee, C.; Meinen, R.; Montes, F.; Ott, T.; Firkins, J.; Rotz, A.; Dell, C.; Adesogan, A.; et al. Mitigation of Greenhouse Gas Emissions in Livestock Production-A Review of Technical Options for non-CO $\mathrm{CO}_{2}$ Emissions; Gerber, P.J., Henderson, B., Makkar, H.P.S., Eds.; FAO Animal Production and Health Paper No. 177; FAO: Rome, Italy, 2013.

2. Hulshof, R.B.A.; Berndt, A.; Gerrits, W.J.J.; Dijkstra, J.; van Zijderveld, S.M.; Newbold, J.R.; Perdok, H.B. Dietary nitrate supplementation reduces methane emission in beef cattle fed sugarcane-based diets. J. Anim. Sci. 2012, 90, 2317-2323. [CrossRef]

3. Van Zijderveld, S.M.; Gerrits, W.J.J.; Apajalahti, J.A.; Newbold, J.R.; Dijkstra, J.; Leng, R.A.; Perdok, H.B. Nitrate and sulfate: Effective alternative hydrogen sinks for mitigation of ruminal methane production in sheep. J. Dairy Sci. 2010, 93, 5856-5866. [CrossRef] [PubMed]

4. Van Zijderveld, S.M.; Gerrits, W.J.J.; Dijkstra, J.; Newbold, J.R.; Hulshof, R.B.A.; Perdok, H.B. Persistency of methane mitigation by dietary nitrate supplementation in dairy cows. J. Dairy Sci. 2011, 94, 4028-4038. [CrossRef] [PubMed]

5. Guyader, J.; Eugene, M.; Meunier, B.; Doreau, M.; Morgavi, D.P.; Silberberg, M.; Rochette, Y.; Gerard, C.; Loncke, C.; Martin, C. Additive methane-mitigating effect between linseed oil and nitrate fed to cattle. J. Anim. Sci. 2015, 93, 3564-3577. [CrossRef] [PubMed]

6. Nolan, J.V.; Hegarty, R.S.; Hegarty, J.; Godwin, I.R.; Woodgate, R. Effects of dietary nitrate on fermentation, methane production and digesta kinetics in sheep. Anim. Prod. Sci. 2010, 50, 801-806. [CrossRef] 
7. El-Zaiat, H.M.; Araujo, R.C.; Soltan, Y.A.; Morsy, A.S.; Louvandini, H.; Pires, A.V.; Patino, H.O.; Correa, P.S.; Abdalla, A.L. Encapsulated nitrate and cashew nut shell liquid on blood and rumen constituents, methane emission, and growth performance of lambs. J. Anim. Sci. 2014, 92, 2214-2224. [CrossRef] [PubMed]

8. Lee, C.; Araujo, R.C.; Koenig, K.M.; Beauchemin, K.A. In situ and in vitro evaluations of a slow release form of nitrate for ruminants: Nitrate release rate, rumen nitrate metabolism and the production of methane, hydrogen, and nitrous oxide. Anim. Feed Sci. Technol. 2017, 231, 97-106. [CrossRef]

9. Lee, C.; Araujo, R.C.; Koenig, K.M.; Beauchemin, K.A. Effects of encapsulated nitrate on enteric methane production and nitrogen and energy utilization in beef heifers. J. Anim. Sci. 2015, 93, 2391-2404. [CrossRef] [PubMed]

10. Lee, C.; Araujo, R.C.; Koenig, K.M.; Beauchemin, K.A. Effects of encapsulated nitrate on growth performance, nitrate toxicity, and enteric methane emissions in beef steers: Backgrounding phase. J. Anim. Sci. 2017, 95, 3700-3711. [CrossRef]

11. Lee, C.; Araujo, R.C.; Koenig, K.M.; Beauchemin, K.A. Effects of encapsulated nitrate on growth performance, carcass characteristics, nitrate residues in tissues, and enteric methane emissions in beef steers: Finishing phase. J. Anim. Sci. 2017, 95, 3712-3726. [CrossRef]

12. Bruning-Fann, C.S.; Kaneene, J.B. The effects of nitrate, nitrite and N-nitroso compounds on human health-A review. Vet. Hum. Toxicol. 1993, 35, 521-538. [PubMed]

13. European Commission (EC). Regulation EC No 1831/2003 of the European Parliament and Council of 22 September 2003 on additives for use in animal nutrition. Off. J. Eur. Commun. 2003, L268, 29-43.

14. Calsamiglia, S.; Busquet, M.; Cardozo, P.W.; Castillejos, L.; Ferret, A. Invited review: Essential oils as modifiers of rumen microbial fermentation. J. Dairy Sci. 2007, 90, 2580-2595. [CrossRef]

15. Benchaar, C.; McAllister, T.A.; Chouinard, P.Y. Digestion, ruminal fermentation, ciliate protozoal populations, and milk production from dairy cows fed cinnamaldehyde, quebracho condensed tannin, or Yucca schidigera saponin extracts. J. Dairy Sci. 2008, 91, 4765-4777. [CrossRef] [PubMed]

16. Patra, A.K. Effects of essential oils on rumen fermentation, microbial ecology and ruminant production. Asian J. Anim. Vet. Adv. 2011, 6, 416-428. [CrossRef]

17. Cobellis, G.; Trabalza-Marinucci, M.; Yu, Z. Critical evaluation of essential oils as rumen modifiers in ruminant nutrition: A review. Sci. Total Environ. 2016, 545-546, 556-568. [CrossRef] [PubMed]

18. Oh, J.; Wall, E.H.; Bravo, D.M.; Hristov, A.N. Host-mediated effects of phytonutrients in ruminants: A review. J. Dairy Sci. 2017, 100, 5974-5983. [CrossRef] [PubMed]

19. Silva, R.B.; Pereira, R.A.N.; Araujo, R.C.; Pereira, M.N. Response of lactating cows to a blend of essential oils and pepper extract. J. Anim. Sci. 2015, 93, 45 (abstract).

20. Yang, W.Z.; Ametaj, B.N.; Benchaar, C.; Beauchemin, K.A. Dose response to cinnamaldehyde supplementation in growing beef heifers: Ruminal and intestinal digestion. J. Anim. Sci. 2010, 88, 680-688. [CrossRef]

21. Hori, T. Capsaicin and central control of thermoregulation. Pharmacol. Ther. 1984, 26, 389-416. [CrossRef]

22. Silva, R.B.; Silva, W.R.; Oliveira, C.D.S.; Lacreta Junior, A.C.C.; Chalfun, L.H.L.; Araujo, R.C.; Pereira, R.A.N.; Pereira, M.N. Supplementation of lactating cows with a blend of essential oils and capsaicin or monensin: Thermoregulation and blood variables. J. Dairy Sci. 2017, 100 (Suppl. 2), 321-322.

23. Soltan, Y.A.; Natel, A.S.; Araujo, R.C.; Morsy, A.S.; Abdalla, A.L. Progressive adaptation of sheep to a microencapsulated blend of essential oils: Ruminal fermentation, methane emission, nutrient digestibility, and microbial protein synthesis. Anim. Feed Sci. Technol. 2018, 237, 8-18. [CrossRef]

24. Araujo, R.C.; Daley, D.R.; Goodall, S.R.; Jalali, S.; Guimarães Bisneto, O.A.; Budde, A.M.; Wagner, J.J.; Engle, T.E. The effects of a microencapsulated blend of essential oils supplemented alone or in combination with monensin on performance and carcass characteristics of growing and finishing beef steers. Prof. Anim. Sci. 2019, under review.

25. Canadian Council on Animal Care. CCAC Guidelines on: The Care and Use of Farm Animals in Research, Teaching and Testing; Canadian Council on Animal Care: Ottawa, ON, Canada, 2009.

26. Manafiazar, G.; Zimmerman, S.; Basarab, J.A. Repeatability and variability of short-term spot measurement of methane and carbon dioxide emissions from beef cattle using GreenFeed emissions monitoring system. Can. J. Anim. Sci. 2016, 97, 118-126. [CrossRef] 
27. Kononoff, P.J.; Heinrichs, A.J.; Buckmaster, D.R. Modification of the Penn State forage and total mixed ration particle separator and the effects of moisture content on its measurements. J. Dairy Sci. 2003, 86, 1858-1863. [CrossRef]

28. Van Soest, P.J.; Robertson, J.B.; Lewis, B.A. Methods for dietary fiber, neutral detergent fiber, and nonstarch polysaccharides in relation to animal nutrition. J. Dairy Sci. 1991, 74, 3583-3597. [CrossRef]

29. AOAC. Official Methods of Analysis, 18th ed.; AOAC Int.: Gaithersburg, MD, USA, 2005.

30. Lee, C.; Beauchemin, K.A. A review of feeding supplementary nitrate to ruminant animals: Nitrate toxicity, methane emissions, and production performance. Can. J. Anim. Sci. 2014, 94, 557-570. [CrossRef]

31. Lund, P.; Dahl, R.; Yang, H.J.; Hellwing, A.L.; Cao, B.B.; Weisbjerg, M.R. The acute effect of addition of nitrate on in vitro and in vivo methane emission in dairy cows. Anim. Prod. Sci. 2014, 54, 1432-1435. [CrossRef]

32. Lee, C.; Araujo, R.C.; Koenig, K.M.; Beauchemin, K.A. Effects of encapsulated nitrate on eating behavior, rumen fermentation, and blood profile of beef heifers fed restrictively or ad libitum. J. Anim. Sci. 2015, 93, 2405-2418. [CrossRef]

33. Lee, C.; Araujo, R.C.; Koenig, K.M.; Beauchemin, K.A. Effects of feed consumption rate of beef cattle offered a diet supplemented with nitrate ad libitum or restrictively on potential toxicity of nitrate. J. Anim. Sci. 2015, 93, 4956-4966. [CrossRef]

34. Velazco, J.I.; Cottle, D.J.; Hegarty, R.S. Methane emissions and feeding behaviour of feedlot cattle supplemented with nitrate or urea. Anim. Prod. Sci. 2014, 54, 1737-1740. [CrossRef]

35. Leng, R.A. The Potential of Feeding Nitrate to Reduce Enteric Methane Production in Ruminants. A Report to Department of Climate Change. Commonwealth Government of Australia, Canberra. 2008. Available online: https:/ / pdfs.semanticscholar.org/2c17/65afdfff583c9d72aec94d3a4facc894e064.pdf (accessed on 20 August 2018).

36. Moate, P.J.; Jacobs, J.L.; Hannah, M.C.; Morris, G.L.; Beauchemin, K.A.; Hess, P.S.; Eckard, R.J.; Liu, Z.; Rochfort, S.; Wales, W.J.; et al. Adaptation responses in milk fat yield and methane emissions of dairy cows when wheat was included in their diet for 16 weeks. J. Dairy Sci. 2018, 101, 7117-7132. [CrossRef] [PubMed]

37. Ungerfeld, E.M. A theoretical comparison between two ruminal electron sinks. Front. Microbiol. 2013, 4, 1-15. [CrossRef] [PubMed]

38. Afeefy, H.Y.; Liebman, J.F.; Stein, S.E. Neutral thermochemical data. In NIST Chemistry WebBook, NIST Standard Reference Database; Linstrom, P.J., Mallard, W.G., Eds.; National Institute of Standards and Technology: Gaithersburg, MD, USA, 1998; Volume 69.

39. Shi, C.X.; Meng, Q.X.; Hou, X.Z.; Ren, L.P.; Zhou, Z.M. Response of ruminal fermentation, methane production and dry matter digestibility to microbial source and nitrate addition level in an in vitro incubation with rumen microbes obtained from wethers. J. Anim. Vet. Adv. 2012, 11, 3334-3341. [CrossRef]

40. Nolan, J.V.; Godwin, I.R.; de Raphélis-Soissan, V.; Hegarty, R.S. Managing the rumen to limit the incidence and severity of nitrite poisoning in nitrate-supplemented ruminants. Anim. Prod. Sci. 2016, 56, 1317-1329. [CrossRef]

41. Beauchemin, K.A.; McGinn, S.M. Methane emissions from beef cattle: Effects of fumaric acid, essential oil, and canola oil. J. Anim. Sci. 2006, 84, 1489-1496. [CrossRef] [PubMed]

42. Meyer, N.F.; Erickson, G.E.; Klopfenstein, T.J.; Greenquist, M.A.; Luebbe, M.K.; Williams, P.; Engstrom, M.A. Effect of essential oils, tylosin, and monensin on finishing steer performance, carcass characteristics, liver abscesses, ruminal fermentation, and digestibility. J. Anim. Sci. 2009, 87, 2346-2354. [CrossRef] [PubMed]

43. Rivaroli, D.C.; do Prado, R.M.; Ornaghi, M.G.; Mottin, C.; Ramos, T.R.; Barrado, A.G.; Jorge, A.M.; do Prado, I.N. Essential oils in the diet of crossbred ( $\frac{1}{2}$ Angus vs. $\frac{1}{2}$ Nellore) bulls finished in feedlot on animal performance, feed efficiency and carcass characteristics. J. Agric. Sci. 2017, 9, 205-2015. [CrossRef]

44. Wang, C.J.; Wang, S.P.; Zhou, H. Influences of flavomycin, ropadiar, and saponin on nutrient digestibility, rumen fermentation, and methane emission from sheep. Anim. Feed Sci. Technol. 2009, 148, 157-166. [CrossRef]

45. Yatoo, M.A.; Chaudhary, L.C.; Agarwal, N.; Chaturvedi, V.B.; Kamra, D.N. Effect of feeding of blend of essential oils on methane production, growth, and nutrient utilization in growing buffaloes. Asian-Aust. J. Anim. Sci. 2018, 31, 672-676. [CrossRef]

46. Tomkins, N.W.; Denman, S.E.; Pilajun, R.; Wanapat, M.; McSweeney, C.S.; Elliott, R. Manipulating rumen fermentation and methanogenesis using an essential oil and monensin in beef cattle fed a tropical grass hay. Anim. Feed Sci. Technol. 2015, 200, 25-34. [CrossRef] 
47. Benchaar, C. Diet supplementation with cinnamon oil, cinnamaldehyde, or monensin does not reduce enteric methane production of dairy cows. Animal 2016, 10, 418-425. [CrossRef] [PubMed]

48. Yang, W.Z.; Benchaar, C.; Ametaj, B.N.; Chaves, A.V.; He, M.L.; McAllister, T.A. Effects of garlic and juniper berry essential oils on ruminal fermentation and on the site and extent of digestion in lactating cows. J. Dairy Sci. 2007, 90, 5671-5681. [CrossRef]

49. Szumacher-Strabel, M.; Cieślak, A. Potential of phytofactors to mitigate rumen ammonia and methane production. J. Anim. Feed Sci. 2010, 19, 319-337. [CrossRef]

50. Patra, A.K.; Saxena, J. A new perspective on the use of plant secondary metabolites to inhibit methanogenesis in the rumen. Phytochemistry 2010, 71, 1198-1222. [CrossRef] [PubMed]

51. Khiaosa-ard, R.; Zebeli, Q. Meta-analysis of the effects of essential oils and their bioactive compounds on rumen fermentation characteristics and feed efficiency in ruminants. J. Anim. Sci. 2013, 91, 1819-1830. [CrossRef]

52. Burt, S. Essential oils: Their antibacterial properties and potential applications in foods-A review. Int. J. Food Microbiol. 2004, 94, 223-253. [CrossRef] [PubMed]

53. Patra, A.K.; Yu, Z. Essential oils affect populations of some rumen bacteria in vitro as revealed by microarray (RumenBactArray) analysis. Front. Microbiol. 2015, 6, 297. [CrossRef] [PubMed]

54. Lambert, R.; Skandamis, P.N.; Coote, P.J.; Nychas, G.J. A study of the minimum inhibitory concentration and mode of action of oregano essential oil, thymol and carvacrol. J. Appl. Microbiol. 2001, 91, 453-462. [CrossRef]

55. Benchaar, C.; Greathead, H. Essential oils and opportunities to mitigate enteric methane emissions from ruminants. Anim. Feed Sci. Technol. 2011, 166, 338-355. [CrossRef]

56. Benchaar, C.; Petit, H.V.; Berthiaume, R.; Ouellet, D.R.; Chiquette, J.; Chouinard, P.Y. Effects of essential oils on digestion, ruminal fermentation, rumen microbial populations, milk production, and milk composition in dairy cows fed alfalfa silage or corn silage. J. Dairy Sci. 2007, 90, 886-897. [CrossRef]

57. Vriens, J.; Nilius, B.; Vennekens, R. Herbal compounds and toxins modulating TRP channels. Curr. Neuropharmacol. 2008, 6, 79-96. [CrossRef] [PubMed]

(C) 2019 by the authors. Licensee MDPI, Basel, Switzerland. This article is an open access article distributed under the terms and conditions of the Creative Commons Attribution (CC BY) license (http:/ / creativecommons.org/licenses/by/4.0/). 
Article

\title{
Effects of Dietary Forage Proportion on Feed Intake, Growth Performance, Nutrient Digestibility, and Enteric Methane Emissions of Holstein Heifers at Various Growth Stages
}

\author{
Lifeng Dong, Binchang Li and Qiyu Diao * \\ Feed Research Institute, Chinese Academy of Agricultural Sciences/Beijing Key Laboratory for Dairy Cow \\ Nutrition/Key Laboratory of Feed Biotechnology, Ministry of Agriculture/Sino-US Joint Lab on Nutrition and \\ Metabolism of Ruminant, Beijing 100081, China; donglifeng@email.ulster.ac.uk or donglifeng@caas.cn (L.D.); \\ 118394151270@163.com (B.L.) \\ * Correspondence: diaoqiyu@caas.cn; Tel.: +86-010-82106055
}

Received: 18 July 2019; Accepted: 23 September 2019; Published: 26 September 2019

Simple Summary: Enteric methane $\left(\mathrm{CH}_{4}\right)$ emission from ruminants is a large source of anthropogenic greenhouse gas production, which is an inevitable by-product when feedstuff is digested and fermented in the rumen, representing approximately $7 \%$ of dietary energy loss. Although the Chinese government has committed to reduce $\mathrm{CH}_{4}$ emissions under the requirement of the Copenhagen Accord (2009), there is lack of accurate $\mathrm{CH}_{4}$ emission data from young cows as the guideline of IPCC gives little consideration to the variations of geographic conditions, animal physiology stages, and dietary components of dairy production system. Our study investigated the effects of different dietary forage-to-concentrate on feed intake, growth performance, nutrient digestibility, and enteric $\mathrm{CH}_{4}$ emissions of Holstein heifers under various growth stage, and developed the prediction equations using production and emission data. Our results demonstrated that enteric $\mathrm{CH}_{4}$ emission was significantly affected by dietary composition and physiological condition; results obtained from the current study will be of great importance for development of regional or national emission inventories and mitigation approaches for heifers at specific growth stage.

\begin{abstract}
Enteric methane $\left(\mathrm{CH}_{4}\right)$ emissions from young ruminants contribute to a substantial proportion of atmospheric $\mathrm{CH}_{4}$ accumulation. Development of emission inventory and mitigation approaches needs accurate estimation of individual emission from animals under various physiological conditions and production systems. This research investigated the effect of different dietary concentrate contents on feed intake, growth performance, nutrient digestibility and $\mathrm{CH}_{4}$ emissions of heifers at various stages, and also developed linear or non-linear prediction equations using data measured by sulphur hexafluoride tracer technique. Increasing dietary concentrate contents increased feed intake and growth rate, enhanced nutrient digestibility, and reduced enteric $\mathrm{CH}_{4}$ emissions. Heifers at the age of 9, 12, and 15 months with an average weight of 267.7, 342.1, and $418.6 \mathrm{~kg}$ produced 105.2, 137.4, and $209.4 \mathrm{~g} /$ day of $\mathrm{CH}_{4}$, and have an average value of $\mathrm{CH}_{4}$ energy per gross energy intake $\left(\mathrm{Y}_{\mathrm{m}}\right)$ 0.054, 0.064, 0.0667, respectively. Equations relating $\mathrm{CH}_{4}$ emission values with animal and feed characteristics were developed with high determination coefficients for heifers at different growth stages. Dietary concentrate contents had significant influence on overall performance of heifers. These data can be used to develop regional or national emission inventories and mitigation approaches for heifers under various production regimes in China.
\end{abstract}

Keywords: methane; heifer; forage-to-concentrate ratio; prediction equation; sulphur hexafluoride tracer technique 


\section{Introduction}

Enteric methane $\left(\mathrm{CH}_{4}\right)$ is a final product of ruminal fermentation via methanogenesis, which contributes substantially to atmospheric $\mathrm{CH}_{4}$ accumulation. As dietary structural carbohydrates (e.g., cellulose and hemicellulose) are degraded by ruminal microorganisms, $\mathrm{CH}_{4}$ emission represents up to $12 \%$ loss of dietary energy ingested in the rumen [1]. Thus, reducing enteric $\mathrm{CH}_{4}$ emissions will help improve energy utilization efficiency and alleviate environmental pressures for dairy production regimes. According to the national report, $\mathrm{CH}_{4}$ emissions in 2005 from agriculture sector accounts for $25.5 \mathrm{Tg}$, of which approximately $57 \%$ is from rumen fermentation within ruminant production system in China [2]. As dairy population and milk production increased by 24 and 58 times, respectively, from 1961 to 2010, it is projected that the total $\mathrm{CH}_{4}$ emissions in 2030 will reach $52.1 \mathrm{Tg}$ [3]. Meanwhile, in response to the domestic and international pressures on sustainable development, the Chinese government has made the commitment to reduce greenhouse gases (GHG), which has been incorporated in to the 2009 Copenhagen Accord [4]. Although Tier-2 methodology from International Panel on Climate Change (IPCC) guidelines is commonly used in many countries for the quantification of $\mathrm{CH}_{4}$ emission inventories [5], it gives little consideration to the variations of geographic conditions, animal physiology stages, and dietary components [6,7]. In addition, this methodology tries to calculate the $\mathrm{CH}_{4}$ emission for the whole dairy population using a default value derived from lactating cows. In China, approximately $60 \%$ of the dairy population is milking cows, and the remainder is heifers (i.e., 5.68 million of heifers) [8]. Different physiological conditions and varied composition and abundance of ruminal methanogens demonstrated great difference of $\mathrm{CH}_{4}$ emission of lactating cow and heifer, indicating the importance of quantifying the individual emissions for these animals [3]. However, limited studies have examined the effects of dietary components on $\mathrm{CH}_{4}$ emissions of heifers under different physiological conditions. Therefore, the objective of the current study is to assess the effect of different dietary concentrate contents on the enteric $\mathrm{CH}_{4}$ emissions of Holstein heifers at various stage, and develop prediction equations using data collected using sulphur hexafluoride $\left(\mathrm{SF}_{6}\right)$ tracer technique.

\section{Materials and Methods}

\subsection{Animals, Experimental Design, and Diets}

This study was conducted in 2018 at the Zhongiiayonghong dairy farm located in Fangshan district, (Beijing, China, latitude: N39 $39^{\prime} 6^{\prime \prime}$ and longitude: E116 $\left.12^{\prime} 21^{\prime \prime}\right)$. Forty-five Chinese Holstein heifers with an initial body weight $(\mathrm{BW})$ of $264.9 \pm 25.6 \mathrm{~kg}$ (mean $\pm \mathrm{SD}$ ) were used in this study with three measurements taken at age of 9,12 , and 15 months, respectively. In each experiment stage, heifers were balanced by date of birth, age and BW and offered randomly assigned to 1 of 3 treatments $(n=15)$ in which animals were individually offered diets containing 30 , 40, and $50 \%$ of concentrate (C $30, C 40$, and C50, respectively). Each experimental period was 32 days in length, including 18 days for adaptation, followed by 8 days for gas measurement and 6 days for nutrient digestibility. Heifers were housed individually with free access to feed and water throughout the whole experiment. All animal care and handling procedures were reviewed and approved by the Animal Ethics Committee of Chinese Academy of Agricultural Sciences (protocol number 019-2018) prior to the start of the experiment.

In period 1, cows received their diet as a total mixed rations (TMR) that composted of corn silage, wildrye, and a typical ration of concentrate on Chinese commercial farms. In period 2 and 3, alfalfa was included in the diet based on the ration of period 1 (Table 1). The TMR were prepared daily using a feed mixer (Belle Engineering Ltd., Derbyshire, UK) and distributed ad libitum ( $5 \%$ refusals, on an as-fed basis). All diets in three periods were formulated to meet the recommendation of Ministry of Agriculture of P. R. China. For all of the three periods, cows were fed twice daily between 0600 and $0800 \mathrm{~h}$, and 1600 and $1800 \mathrm{~h}$. Feed refusals were collected and weighted to determine the daily feed intake. 
Table 1. Ingredient and chemical composition of diets in the current study.

\begin{tabular}{ccccccc}
\hline \multirow{2}{*}{ Item } & \multicolumn{7}{c}{ Period 1 (9 months) } & \multicolumn{3}{c}{ Periods 2 and 3 (12 and 15 months) } \\
\cline { 2 - 7 } & C30 & C40 & C50 & C30 & C40 & C50 \\
\hline Ingredient & & & & & & \\
Corn silage & 42 & 36 & 30 & 42 & 36 & 30 \\
Chinese wildrye hay & 28 & 24 & 20 & 14 & 12 & 10 \\
Alfalfa & - & - & - & 14 & 12 & 10 \\
Concentrate & 30 & 40 & 50 & 30 & 40 & 50 \\
Nutrient, DM basis & & & & & & \\
Dry matter & 93.6 & 93.5 & 93.6 & 93.9 & 93.7 & 93.3 \\
Organic matter, \% & 91.8 & 91.7 & 91.2 & 93.1 & 92.8 & 92.2 \\
Gross energy, MJ kg-1 & 18.0 & 18.1 & 18.1 & 16.8 & 16.7 & 16.6 \\
Crude protein, \% & 15.7 & 17.8 & 18.7 & 14.1 & 14.5 & 14.7 \\
Ether extract, \% & 4.1 & 4.0 & 4.0 & 3.7 & 3.8 & 3.8 \\
Ash, \% & 8.2 & 8.3 & 8.8 & 6.9 & 7.2 & 7.8 \\
Neutral detergent fiber, \% & 37.8 & 34.2 & 31.4 & 36.8 & 32.6 & 29.3 \\
Acid detergent fiber, \% & 15.6 & 14.0 & 12.0 & 19.8 & 17.5 & 14.8 \\
Ca, \% & 0.5 & 0.5 & 0.5 & 0.3 & 0.5 & 0.6 \\
P, \% & 0.2 & 0.3 & 0.3 & 0.2 & 0.2 & 0.3
\end{tabular}

C30 = diet containing $30 \%$ of concentrate, C40 = diet containing $40 \%$ of concentrate, C50 = diet containing $50 \%$ of concentrate; Concentrates were purchased from a commercial company (Beijing Sanyuan Breeding Technology Corporation, Beijing, China), which mainly comprise corn, wheat bran, soybean meal, calcium hydrophosphate, limestone and salt. The nutrient content is: crude protein $\geq 17 \%$, ether extract $\geq 2.5 \%$, crude fiber $\leq 9.0 \%, \mathrm{Ca}=0.5-1.5 \%$, $\mathrm{P}=0.4-1.0 \%, \mathrm{NaCl}=0.5-2.0 \%$, Lysine $\geq 0.6 \%$.

\subsection{Enteric Methane Emission Measurement}

Enteric $\mathrm{CH}_{4}$ emissions were measured from individual cows using the $\mathrm{SF}_{6}$ tracer technique with minor modification of Deighton et al. [9]. Generally, empty permeation tubes were filled with $450 \mathrm{~mL}$ of $99.999 \%$ pure $\mathrm{SF}_{6}$ by immersing in liquid nitrogen. The release rate was determined by incubating the permeation tubes in an oven at $39^{\circ} \mathrm{C}$ and weighting each one twice a week for 4 weeks. The calculated releasing rate of the $\mathrm{SF}_{6}$ tubes ranged from 3.13 to 3.84 (mean, $3.28 \pm 0.175$ ) $\mathrm{mg} / \mathrm{day}$ in period 1, from 3.10 to $3.70(3.32 \pm 0.266) \mathrm{mg} /$ day in period 2, and from 3.10 to $3.60(3.20 \pm 0.167) \mathrm{mg} / \mathrm{day}$ in period 3, respectively. Each cow was randomly administrated with one $\mathrm{SF}_{6}$ tube using a balling gun three weeks before the commence of the experiment.

A back-mounted harness was used to support the canister (volume $=1.85 \mathrm{~L}$ ) for continuously sample collection; the canisters were washed by flushing $99.999 \%$ pure nitrogen and evacuated to over $98 \mathrm{kPa}$ vacuum. The sampling rate of canister was approximately $0.25 \mathrm{~mL} / \mathrm{min}$ by crimping a stainless-steel capillary tube within the sampling tubing. Canisters were removed after $24 \mathrm{~h}$ and residual vacuum was recorded before addition of nitrogen gas. Background gas samples of $\mathrm{SF}_{6}$ and $\mathrm{CH}_{4}$ were also collected daily by using six additional canisters that were either placed on the back of animals or about $2.0 \mathrm{~m}$ above ground level of the experimental barn.

Gas samples were analyzed using a gas chromatography system (GC126, Shanghai Precision Instruments Co., Ltd., Shanghai, China) equipped with a flame-ionization detector (FID) and an electron-capture detector (ECD). The ECD operated at $300{ }^{\circ} \mathrm{C}$ with a molecular sieve $0.5 \mathrm{~nm}$ column and the FID at $150{ }^{\circ} \mathrm{C}$ with a Porapack N 80-100 mesh column (Shanghai Precision Instruments Co., Ltd., Shanghai, China) for determination of $\mathrm{SF}_{6}$ and $\mathrm{CH}_{4}$, respectively. Ultra-high purity nitrogen gas $(99.999 \%$ ) was used as carrier gas at $40 \mathrm{~mL} / \mathrm{min}$ flow and analysis was performed after calibration with standard gases for $\mathrm{SF}_{6}$ and $\mathrm{CH}_{4}$. The daily $\mathrm{CH}_{4}$ emission was calculated as follows:

$$
\mathrm{CH}_{4}=\mathrm{SF}_{6} \times\left[\left(\mathrm{CH}_{4 \text { sample }}-\mathrm{CH}_{4 \text { background }}\right) /\left(\mathrm{SF}_{6 \text { sample }}-\mathrm{SF}_{6 \text { background }}\right)\right] \times(16 / 146) \times 1000
$$

where $\mathrm{CH}_{4}$ is the calculated emission $(\mathrm{g} / \mathrm{d}) ; \mathrm{SF}_{6}$ is the measured releasing rate of each $\mathrm{SF}_{6}$ permeation tube (mg/day); the concentration of $\mathrm{CH}_{4}$ sample and $\mathrm{CH}_{4}$ background are expressed in ppm and 
concentration of $\mathrm{SF}_{6}$ sample and $\mathrm{SF}_{6}$ background in ppt; 6 and 146 are the molecular mass $(\mathrm{g} / \mathrm{mol})$ of $\mathrm{CH}_{4}$ and $\mathrm{SF}_{6}$, respectively; the factor of 1,000 is used to calculate $\mathrm{CH}_{4}$ in units of $\mathrm{g} / \mathrm{day}$.

\subsection{Nutrient Digestibility and Laboratory Analyses}

During the last $6 \mathrm{~d}$ of each experimental period (digestibility experiment), 5 cows out of each treatment were moved to metabolic stalls for nutrient digestibility measurement using a modified method of acid-insoluble ash (AIA) [10]. Generally, rectal feces were collected from the rectum to obtain representative samples (day 1: 1000 and 2200 h; day 2: 0200 and 1400 h; day 3: 0500 and 1700 h; day 4: 0800 and 2000 h; day 5: 1100 and 2300 h; day 6: 0600 and 1800 h). Fresh samples over the 6 days period from each cow were composited and analyzed by using $2 \mathrm{~N} \mathrm{HCl}$. The equation used to calculate digestibility was as follows:

Nutrient digestibility $=100-[100 \times($ ADIA in DM consumed, $\% /$ ADIA in feces, $\%) /($ nutrient in feces, $\% /$ nutrient in consumed DM, \%)]

in which ADIA = acid detergent insoluble ash.

Representative feed samples were collected during adaptation and experimental period for chemical composition determinations. Dietary gross energy (GE) content was determined by bomb calorimetry (1108 Oxygen bomb, Parr Instruments, Moline, IL, USA). Dry matter, neutral detergent fiber (NDF), acid detergent fiber (ADF), crude fat, and ash were determined using AOAC International (2006), and crude protein (CP) was measured using combustion analyzer (Leco FP-528 N, Fullerton, CA, USA).

\subsection{Statistical Analyses}

The effect of dietary concentration levels on growth performance, nutrient digestibility and enteric $\mathrm{CH}_{4}$ emissions was evaluated using two analytical approaches as described by Dong et al. [1]. Generally, the ANOVA procedure was used with the three treatments fitted as a fixed effect and animals within each treatment fitted as random effects during the analysis. Other necessary variables such as initial BW and date of birth were fitted as covariates, when appropriate, for evaluation of enteric $\mathrm{CH}_{4}$ emissions. Prediction equations were developed using restricted maximum likelihood model as treatments were fitted as a fixed effect. Significant effects were noted at $p<0.05$. The statistical program used in the current study was Genstat 14.2 (14th edition; Lawes Agricultural Trust, Rothamsted, UK).

\section{Results}

\subsection{Effects on Nutrient Intake and Growth Performance}

Dietary ingredients and chemical composition are presented in Table 1 . The diets are planned to differ in concentrate contents and feed analysis indicated that NDF and ADF decreased with increasing concentrate feed contents in any of periods one to three. Accordingly, the opposite happened with the NFC fraction of the diets.

Nutrients and energy intake and growth performance are presented in Table 2. Overall, DM, OM, $\mathrm{NFC}$, and GE intake increased with increasing concentrate contents in any of periods one to three $(p<0.05)$; however, these values did not differ significantly between the C40 and C50 treatments in period one or between C30 and C40 treatments in period two $(p>0.05)$. Dietary NDF intake was similar among the three treatments in period one ( 2.12 vs. 2.21 vs. 2.17 for C $30, C 40$ and C50 treatment, respectively, $p>0.05)$, whereas heifers in C30 treatments consumed more NDF than the other two treatments in periods two and three $(p<0.05)$. Weight gain increased with increasing concentrate feed contents in the diet $(p<0.05)$ with an average ADG value of $1.26,1.16$, and $0.97 \mathrm{~kg} /$ day for heifers in periods one to three, respectively. 
Table 2. Effects of different dietary concentrate levels on the growth performance of Holstein heifers at age of 9,12 and 15 months.

\begin{tabular}{|c|c|c|c|c|c|}
\hline \multirow{2}{*}{ Item } & \multicolumn{3}{|c|}{ Treatments } & \multirow{2}{*}{ SEM } & \multirow{2}{*}{$p$-Value } \\
\hline & $\mathrm{C} 30$ & $\mathrm{C} 40$ & $\mathrm{C} 50$ & & \\
\hline \multicolumn{6}{|c|}{9 months } \\
\hline Age, month & 9.5 & 9.5 & 9.4 & 1.46 & 0.987 \\
\hline BW, kg & $246.2^{\mathrm{b}}$ & $274.3^{\mathrm{a}}$ & $282.7^{\mathrm{a}}$ & 5.16 & 0.046 \\
\hline DM intake, $\mathrm{kg} /$ day & $5.61^{\mathrm{b}}$ & $6.47^{\mathrm{a}}$ & $6.90^{\mathrm{a}}$ & 0.164 & $<0.01$ \\
\hline OM intake, kg/day & $5.15^{\mathrm{b}}$ & $5.94^{\mathrm{a}}$ & $6.30^{\mathrm{a}}$ & 0.152 & 0.007 \\
\hline NDF intake, kg/day & 2.12 & 2.21 & 2.17 & 0.093 & 0.07 \\
\hline NFC intake, kg/day & $1.92^{\mathrm{b}}$ & $2.31^{\mathrm{a}}$ & $2.57^{\mathrm{a}}$ & 0.041 & 0.024 \\
\hline GE intake, MJ/day & $100.8^{\mathrm{b}}$ & $117.4^{\mathrm{a}}$ & $124.9^{\mathrm{a}}$ & 2.74 & $<0.01$ \\
\hline ADG, kg/day & $1.10^{\mathrm{b}}$ & $1.33^{\mathrm{a}}$ & $1.36^{\mathrm{a}}$ & 0.085 & 0.448 \\
\hline \multicolumn{6}{|c|}{12 months } \\
\hline Age, month & 11.7 & 11.6 & 12.4 & 0.72 & 0.477 \\
\hline $\mathrm{BW}, \mathrm{kg}$ & $326.8^{\mathrm{b}}$ & $336.0^{\mathrm{b}}$ & $363.6^{\mathrm{a}}$ & 10.27 & 0.036 \\
\hline DM intake, $\mathrm{kg} /$ day & $6.98^{\mathrm{b}}$ & $7.06^{\mathrm{b}}$ & $7.18^{\mathrm{a}}$ & 0.233 & 0.001 \\
\hline OM intake, kg/day & $6.50^{\mathrm{b}}$ & $6.56^{\mathrm{b}}$ & $6.62^{\mathrm{a}}$ & 0.227 & 0.017 \\
\hline NDF intake, kg/day & $2.57^{\mathrm{a}}$ & $2.30^{\mathrm{b}}$ & $2.10^{\mathrm{b}}$ & 0.100 & 0.038 \\
\hline NFC intake, $\mathrm{kg} /$ day & $2.69^{\mathrm{b}}$ & $2.96^{\mathrm{b}}$ & $3.19^{\mathrm{a}}$ & 0.106 & 0.001 \\
\hline GE intake, MJ/day & $115.9^{\mathrm{b}}$ & $117.9^{\mathrm{b}}$ & $124.6^{\mathrm{a}}$ & 0.500 & $<0.01$ \\
\hline ADG, kg/day & $0.97^{\mathrm{b}}$ & $1.14^{\mathrm{b}}$ & $1.39^{\mathrm{a}}$ & 0.062 & 0.010 \\
\hline \multicolumn{6}{|c|}{15 months } \\
\hline Age, month & 14.7 & 14.6 & 14.9 & 0.33 & 0.965 \\
\hline $\mathrm{BW}, \mathrm{kg}$ & $402.2^{\mathrm{b}}$ & $424.4^{\mathrm{a}}$ & $429.3^{\mathrm{a}}$ & 8.82 & 0.945 \\
\hline DM intake, $\mathrm{kg} /$ day & $7.44^{\mathrm{c}}$ & $7.78^{\mathrm{b}}$ & $7.96^{\mathrm{a}}$ & 0.234 & 0.014 \\
\hline OM intake, $\mathrm{kg}$ /day & $6.86^{\mathrm{c}}$ & $7.22^{\mathrm{b}}$ & $7.42^{\mathrm{a}}$ & 0.126 & $<0.01$ \\
\hline NDF intake, $\mathrm{kg} /$ day & $2.93^{\mathrm{a}}$ & $2.53^{\mathrm{b}}$ & $2.18^{\mathrm{c}}$ & 0.228 & 0.031 \\
\hline NFC intake, kg/day & $3.06^{\mathrm{b}}$ & $3.26^{\mathrm{a}}$ & $3.30^{\mathrm{a}}$ & 0.179 & $<0.01$ \\
\hline GE intake, MJ/day & $124.9^{\mathrm{c}}$ & $129.9^{\mathrm{b}}$ & $132.2^{\mathrm{a}}$ & 1.69 & $<0.01$ \\
\hline ADG, kg/day & $0.87^{\mathrm{b}}$ & $0.99^{\mathrm{a}}$ & $1.05^{\mathrm{a}}$ & 0.026 & 0.005 \\
\hline
\end{tabular}

$\mathrm{BW}=$ body weight, $\mathrm{OM}=$ organic matter, $\mathrm{NDF}=$ neutral detergent fiber, $\mathrm{ADF}=$ acid detergent fiber, $\mathrm{NFC}=$ non-fibrous carbohydrate, $\mathrm{GE}=$ gross energy, $\mathrm{ADG}=$ average daily gain, $\mathrm{C} 30=$ diet containing $30 \%$ of concentrate, $\mathrm{C} 40=$ diet containing $40 \%$ of concentrate, $\mathrm{C} 50=$ diet containing $50 \%$ of concentrate, $\mathrm{SEM}=$ standard error of means. ${ }^{\mathrm{a}, \mathrm{b}, \mathrm{c}}$ values within a row with different superscripts differ significantly at $p<0.05$.

\subsection{Effects on Apparent Nutrient Digestibility}

Apparent nutrient digestibility data are presented in Table 3. Overall, CP and NDF digestibility increased with increasing concentrate feed contents throughout the three experimental periods $(p<0.05)$. However, DM and OM digestibility remained similar among the three treatments in period one, whereas both values increased linearly as concentrate increased in periods two and three $(p<0.05)$. Dietary ADF digestibility was unaffected by different concentrate contents in period two with a value of 68.4, 69.4 and 71.1 for C30, C40 and C50 treatments, respectively ( $p>0.05)$. Moreover, there was an increasing trend in digestibility of average DM (74.47 vs. 75.50 vs. 78.47$)$, OM (76.43 vs. 79.20 vs. 80.50$)$ and ADF (68.42 vs. 69.63 vs. 74.00 ) for period one to three, respectively. 
Table 3. Effects of different dietary concentration level on apparent nutrient digestibility of Holstein cows at age of 9,12 and 15 months.

\begin{tabular}{|c|c|c|c|c|c|}
\hline \multirow{2}{*}{ Item } & \multicolumn{3}{|c|}{ Treatments } & \multirow{2}{*}{ SEM } & \multirow{2}{*}{$p$-Value } \\
\hline & C30 & $\mathrm{C} 40$ & C50 & & \\
\hline \multicolumn{6}{|c|}{9 months } \\
\hline Dry matter & 73.3 & 74.8 & 75.3 & 1.00 & 0.710 \\
\hline Organic matter & 75.3 & 76.8 & 77.2 & 1.00 & 0.740 \\
\hline Crude protein & $65.6^{\mathrm{C}}$ & $69.3^{\mathrm{b}}$ & $76.5^{\mathrm{a}}$ & 1.53 & 0.003 \\
\hline Neutral detergent fiber & $69.2^{c}$ & $72.4^{\mathrm{b}}$ & $76.9^{\mathrm{a}}$ & 1.52 & 0.012 \\
\hline Acid detergent fiber & $63.0^{c}$ & $69.4^{\mathrm{b}}$ & $72.9^{\mathrm{a}}$ & 1.87 & 0.041 \\
\hline \multicolumn{6}{|c|}{12 months } \\
\hline Dry matter & $73.5^{\mathrm{b}}$ & $74.7^{\mathrm{b}}$ & $78.3^{\mathrm{a}}$ & 0.96 & 0.017 \\
\hline Organic matter & $77.1^{\mathrm{b}}$ & $78.6^{\mathrm{b}}$ & $81.9^{\mathrm{a}}$ & 0.92 & 0.047 \\
\hline Crude protein & $65.6^{\mathrm{b}}$ & $69.3^{\mathrm{b}}$ & $76.5^{\mathrm{a}}$ & 1.53 & 0.002 \\
\hline Neutral detergent fiber & $60.8^{\mathrm{b}}$ & $65.4^{\mathrm{a}}$ & $66.9^{\mathrm{a}}$ & 1.66 & 0.029 \\
\hline Acid detergent fiber & 68.4 & 69.4 & 71.1 & 1.46 & 0.141 \\
\hline \multicolumn{6}{|c|}{15 months } \\
\hline Dry matter & $75.7^{\mathrm{b}}$ & $76.5^{\mathrm{b}}$ & $83.2^{\mathrm{a}}$ & 1.04 & $<0.01$ \\
\hline Organic matter & $77.9^{\mathrm{b}}$ & $78.7^{\mathrm{b}}$ & $84.9^{\mathrm{a}}$ & 0.99 & $<0.01$ \\
\hline Crude protein & $72.7^{\mathrm{b}}$ & $72.2^{\mathrm{b}}$ & $79.6^{\mathrm{a}}$ & 1.10 & $<0.01$ \\
\hline Neutral detergent fiber & $73.1^{\mathrm{b}}$ & $75.4^{\mathrm{a}}$ & $76.7^{\mathrm{a}}$ & 0.92 & 0.028 \\
\hline Acid detergent fiber & $71.3^{\mathrm{b}}$ & $73.5^{\mathrm{b}}$ & $77.2^{\mathrm{a}}$ & 1.11 & 0.046 \\
\hline
\end{tabular}

C30 = diet containing 30\% of concentrate; C40 = diet containing 40\% of concentrate; C50 = diet containing $50 \%$ of concentrate, SEM = standard error of means. ${ }^{a, b, c}$ values within a row with different superscripts differ significantly at $p<0.05$.

\subsection{Effects on Enteric $\mathrm{CH}_{4}$ Emission}

Enteric $\mathrm{CH}_{4}$ emission data of each experiment period are presented in Table 4. Daily $\mathrm{CH}_{4}$ production and $\mathrm{CH}_{4}$-E were significantly affected by treatments that both sets of parameters decreased linearly with increasing concentrate feed contents in the diets in any periods of one to three $(p<0.05)$.

Table 4. Effects of different dietary concentration level on enteric methane $\left(\mathrm{CH}_{4}\right)$ emissions of Holstein cows at age of 9,12 and 15 months.

\begin{tabular}{|c|c|c|c|c|c|}
\hline \multirow{2}{*}{ Item } & \multicolumn{3}{|c|}{ Treatments } & \multirow{2}{*}{ SEM } & \multirow{2}{*}{$p$-Value } \\
\hline & C30 & $\mathrm{C} 40$ & C50 & & \\
\hline \multicolumn{6}{|c|}{9 months } \\
\hline $\mathrm{CH}_{4}, \mathrm{~g} /$ day & $114.90^{\mathrm{a}}$ & $107.10^{\mathrm{b}}$ & $93.66^{c}$ & 2.584 & $<0.01$ \\
\hline $\mathrm{CH}_{4} / \mathrm{MBW}, \mathrm{g} / \mathrm{kg}^{0.75}$ & $1.68^{\mathrm{a}}$ & $1.59^{\mathrm{b}}$ & $1.42^{\mathrm{C}}$ & 0.031 & 0.002 \\
\hline $\mathrm{CH}_{4} / \mathrm{DM}$ intake, $\mathrm{g} / \mathrm{kg}$ & $20.57^{\mathrm{a}}$ & $16.56^{\mathrm{b}}$ & $13.57^{c}$ & 0.643 & $<0.01$ \\
\hline $\mathrm{CH}_{4} / \mathrm{OM}$ intake, $\mathrm{g} / \mathrm{kg}$ & $26.15^{\mathrm{a}}$ & $21.39^{b}$ & $17.15^{\mathrm{c}}$ & 0.734 & $<0.01$ \\
\hline $\mathrm{CH}_{4} / \mathrm{NDF}$ intake, $\mathrm{g} / \mathrm{kg}$ & $60.66^{\mathrm{a}}$ & $47.55^{\mathrm{b}}$ & $35.40^{c}$ & 2.99 & $<0.01$ \\
\hline $\mathrm{CH}_{4}-\mathrm{E}, \mathrm{MJ} /$ day & $6.40^{\mathrm{a}}$ & $5.96^{\mathrm{b}}$ & $5.21^{\mathrm{c}}$ & 0.131 & $<0.01$ \\
\hline $\mathrm{CH}_{4}$-E/GE intake & $0.0686^{\mathrm{a}}$ & $0.0552^{\mathrm{b}}$ & $0.0454^{\mathrm{c}}$ & 0.00264 & $<0.01$ \\
\hline \multicolumn{6}{|c|}{12 months } \\
\hline $\mathrm{CH}_{4}, \mathrm{~g} /$ day & $159.68^{a}$ & $133.16^{b}$ & $119.32^{c}$ & 5.054 & $<0.01$ \\
\hline $\mathrm{CH}_{4} / \mathrm{MBW}, \mathrm{gkg}^{0.75}$ & $2.09^{\mathrm{a}}$ & $1.71^{\mathrm{b}}$ & $1.50^{\mathrm{c}}$ & 0.079 & 0.001 \\
\hline $\mathrm{CH}_{4} / \mathrm{DM}$ intake, $\mathrm{g} / \mathrm{kg}$ & $22.88^{\mathrm{a}}$ & $18.85^{b}$ & $16.63^{c}$ & 0.903 & $<0.01$ \\
\hline $\mathrm{CH}_{4} / \mathrm{OM}$ intake, $\mathrm{g} / \mathrm{kg}$ & $27.13^{\mathrm{a}}$ & $22.65^{b}$ & $20.40^{c}$ & 0.958 & $<0.01$ \\
\hline $\mathrm{CH}_{4} / \mathrm{NDF}$ intake, $\mathrm{g} / \mathrm{kg}$ & $63.77^{\mathrm{a}}$ & $55.81^{b}$ & $54.60^{\mathrm{b}}$ & 1.744 & 0.019 \\
\hline $\mathrm{CH}_{4}-\mathrm{E}, \mathrm{MJ} / \mathrm{day}^{-1}$ & $7.89^{\mathrm{a}}$ & $7.41^{\mathrm{b}}$ & $6.64^{c}$ & 0.281 & $<0.001$ \\
\hline $\mathrm{CH}_{4}$-E/GE intake & $0.0742^{\mathrm{a}}$ & $0.0618^{\mathrm{b}}$ & $0.0558^{\mathrm{b}}$ & 0.00321 & $<0.001$ \\
\hline
\end{tabular}


Table 4. Cont.

\begin{tabular}{|c|c|c|c|c|c|}
\hline \multirow{2}{*}{ Item } & \multicolumn{3}{|c|}{ Treatments } & \multirow{2}{*}{ SEM } & \multirow{2}{*}{$p$-Value } \\
\hline & $\mathrm{C} 30$ & $\mathrm{C} 40$ & C50 & & \\
\hline \multicolumn{6}{|c|}{15 months } \\
\hline $\mathrm{CH}_{4}, \mathrm{~g} /$ day & $219.58^{\mathrm{a}}$ & $214.86^{\mathrm{b}}$ & $193.77^{c}$ & 4.17 & $<0.01$ \\
\hline $\mathrm{CH}_{4} / \mathrm{MBW}, \mathrm{g} / \mathrm{kg}^{0.75}$ & $2.39^{\mathrm{a}}$ & $2.26^{\mathrm{a}}$ & $2.02^{\mathrm{b}}$ & 0.058 & 0.013 \\
\hline $\mathrm{CH}_{4} / \mathrm{DM}$ intake, $\mathrm{g} / \mathrm{kg}$ & $23.17^{\mathrm{a}}$ & $19.94^{b}$ & $16.92^{\mathrm{c}}$ & 0.776 & $<0.01$ \\
\hline $\mathrm{CH}_{4} / \mathrm{OM}$ intake, $\mathrm{g} / \mathrm{kg}$ & $24.95^{\mathrm{a}}$ & $21.54^{b}$ & $18.20^{c}$ & 0.837 & $<0.01$ \\
\hline $\mathrm{CH}_{4} / \mathrm{NDF}$ intake, $\mathrm{g} / \mathrm{kg}$ & $69.39^{\mathrm{a}}$ & $67.12^{\mathrm{b}}$ & $64.83^{c}$ & 1.312 & 0.039 \\
\hline $\mathrm{CH}_{4}-\mathrm{E}, \mathrm{MJ} /$ day & $12.77^{\mathrm{a}}$ & $11.96^{\mathrm{b}}$ & $10.78^{c}$ & 0.232 & $<0.01$ \\
\hline $\mathrm{CH}_{4}-\mathrm{E} / \mathrm{GE}$ intake & $0.0769^{\mathrm{a}}$ & $0.0665^{\mathrm{b}}$ & $0.0568^{\mathrm{c}}$ & 0.00374 & $<0.01$ \\
\hline
\end{tabular}

$\mathrm{MBW}=$ metabolic body weight, $\mathrm{DM}=$ dry matter, $\mathrm{OM}=$ organic matter, $\mathrm{NDF}=$ neutral detergent fiber, $\mathrm{CH}_{4}-\mathrm{E}=$ methane energy, $\mathrm{GE}=$ gross energy, $\mathrm{C} 30=$ diet containing $30 \%$ of concentrate; $\mathrm{C} 40=$ diet containing $40 \%$ of concentrate; $\mathrm{C} 50=$ diet containing $50 \%$ of concentrate, $\mathrm{SEM}=$ standard error of means. ${ }^{\mathrm{a}, \mathrm{b}, \mathrm{c}}$ values within a row with different superscripts differ significantly at $p<0.05$.

Individual $\mathrm{CH}_{4}$ intensity including $\mathrm{CH}_{4} / \mathrm{DM}$ intake, $\mathrm{CH}_{4} / \mathrm{OM}$ intake, and $\mathrm{CH}_{4} / \mathrm{NDF}$ intake decreased linearly with increasing dietary concentrate feed contents throughout the three experiment periods, whereas no difference was observed for $\mathrm{CH}_{4} / \mathrm{NDF}$ intake between $\mathrm{C} 40$ and $\mathrm{C} 50$ (55.81 vs. $54.60 \mathrm{~g} / \mathrm{kg})$ treatments in period two $(p>0.05) . \mathrm{CH}_{4}$-E per gross energy intake $\left(\mathrm{Y}_{\mathrm{m}}\right)$ decreased significantly $(p<0.05)$ with increasing concentrate contents in any periods of one to three. Furthermore, although comparison of the effect of experimental periods on $\mathrm{CH}_{4}$ emissions was the objective of this study, the average of $Y_{m}$ value was $0.0564,0.0639$, and 0.0667 in periods one to three, respectively.

\subsection{Development of Prediction Equations}

Prediction equations of $\mathrm{CH}_{4}$ emissions in each period are presented in Tables 4 and 5. Growth and feed intake parameters were used to develop these relationships, which were significantly correlated $(p<0.01)$ with coefficient of determination values ranging from 0.27 to 0.74 .

Table 5. Prediction equations of methane $\left(\mathrm{CH}_{4}\right)$ emission for Holstein heifers at age of 9, 12, and 15 months.

\begin{tabular}{|c|c|c|c|c|}
\hline Item & Equations & SE & $\mathbf{R}^{2}$ & Eq. \\
\hline \multirow[t]{2}{*}{$\mathrm{CH}_{4}$} & $=0.13_{(0.106)} \times \mathrm{BW}+68.6_{(29.15)}$ & 0.330 & 0.47 & $(1)$ \\
\hline & $=24.21_{(1.133)} \times \mathrm{DM}$ intake $-51.3_{(7.34)}$ & 0.999 & 0.67 & $(2)$ \\
\hline $\mathrm{CH}_{4}-\mathrm{E}$ & $=0.08_{(0.004)} \times$ GE intake $-2.72_{(0.467)}$ & 0.999 & 0.69 & (3) \\
\hline \multirow[t]{2}{*}{$\mathrm{CH}_{4}$} & $=0.19_{(0.151)} \times \mathrm{BW}+78.6_{(49.64)}$ & 0.461 & 0.42 & $(4)$ \\
\hline & $=36.27_{(6.712)} \times \mathrm{DM}$ intake $-87.8_{(12.24)}$ & 0.782 & 0.71 & (5) \\
\hline $\mathrm{CH}_{4}-\mathrm{E}$ & $=0.11_{(0.012)} \times \mathrm{GE}$ intake $-4.65_{(1.785)}$ & 0.766 & 0.72 & $(6)$ \\
\hline \multirow{2}{*}{$\mathrm{CH}_{4}$} & $=0.29_{(0.161)} \times \mathrm{BW}+84.9_{(68.61)}$ & 0.461 & 0.46 & (7) \\
\hline & $=51.72(4.640) \times \mathrm{DM}$ intake $-193.9_{(22.49)}$ & 0.979 & 0.74 & $(8)$ \\
\hline $\mathrm{CH}_{4}-\mathrm{E}$ & $=0.18_{(0.042)} \times$ GE intake $-9.70_{(2.071)}$ & 0.973 & 0.67 & (9) \\
\hline
\end{tabular}

$\mathrm{CH}_{4}$-E = methane energy (MJ/day), BW = body weight $(\mathrm{kg}), \mathrm{DM}=$ dry matter (kg/day), GE = gross energy (MJ/day); $\mathrm{SE}=$ standard error

Overall, relationships obtained in period three had highest values of determination values when compared with those from the other two periods. The strongest relationship was observed between $\mathrm{CH}_{4}$ emission and DM intake in period three (Equation (8) in Table 5, $\mathrm{R}^{2}=0.74$ ), whereas $\mathrm{CH}_{4}$ production was relatively poor related with BW for heifers in period 1 (Equation (1) in Table 5, $\left.\mathrm{R}^{2}=0.47\right)$. Furthermore, emissions data derived from all three periods were pooled to develop overall $\mathrm{CH}_{4}$ prediction equations (Figures 1 and 2). Feed intake and BW were significantly correlated with $\mathrm{CH}_{4}$ emission $(p<0.01)$ and coefficient of determination value was 0.727 and 0.802 for linear and non-linear equations, respectively. Furthermore, a range of linear and non-linear prediction models 
were developed using the whole data sets of animal production and feed intake values (Equations (10) to (20), Table 6). Generally, improved values of $R^{2}$ can be observed with more variables were incorporated in to the models. For example, highest value of $\mathrm{R}^{2}$ of 0.820 was observed for the models relating $\mathrm{CH}_{4}$-E to BW, DM intake, and NFC intake $(p<0.01)$, whereas a relatively low value of $\mathrm{R}^{2}$ of 0.593 was observed for Equation (12), which relates $\mathrm{CH}_{4}$-E to DM intake and NDF intake $(p<0.01)$. However, there was no such trends for non-linear models as highest value of $\mathrm{R}^{2}$ was observed for the relationship between $\mathrm{CH}_{4}$-E and NDF intake (Equation (18)).

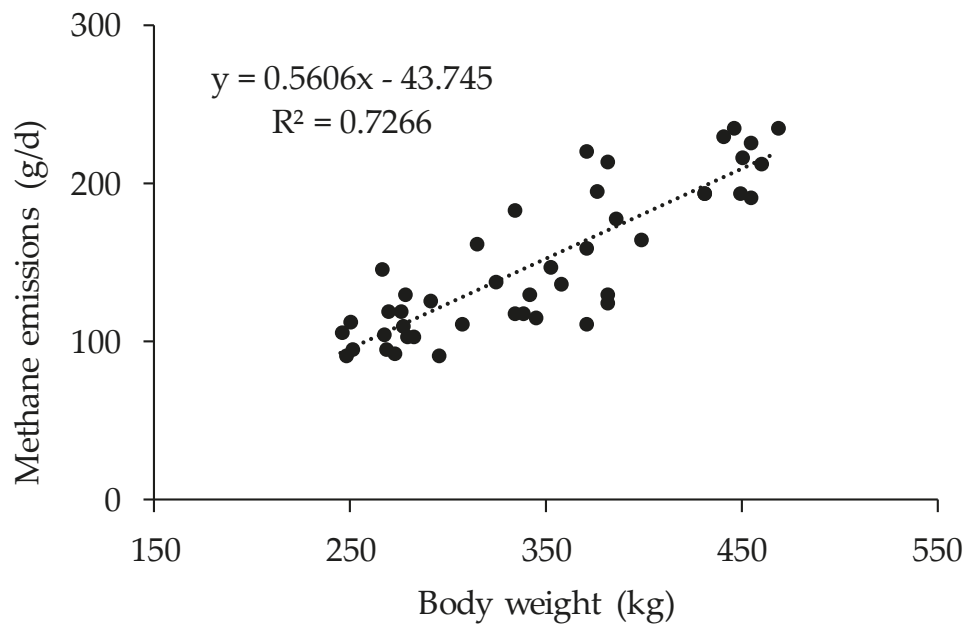

Figure 1. Linear relationship between body weight and enteric methane emissions of Holstein heifers.

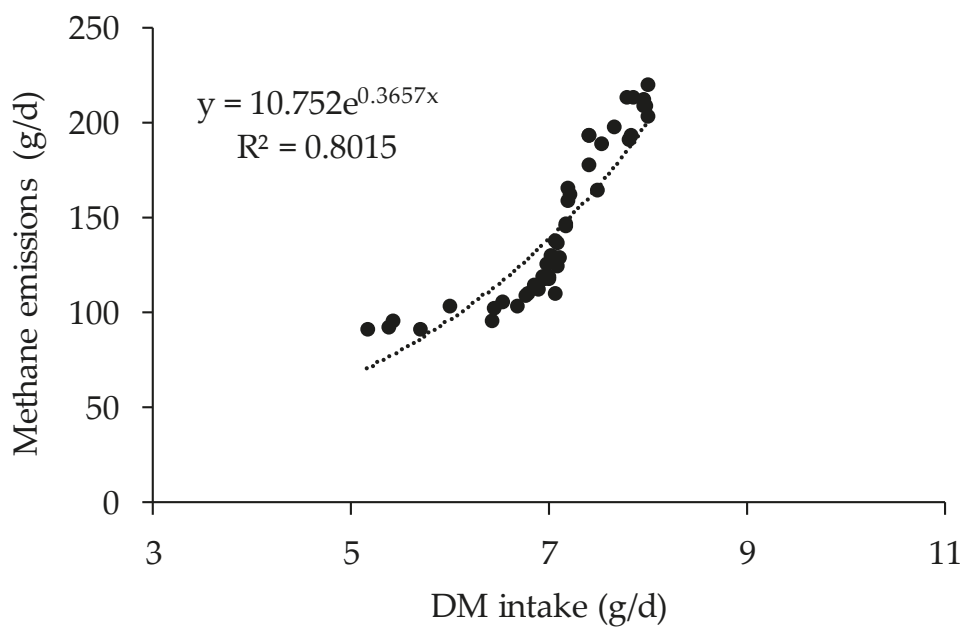

Figure 2. Non-linear relationship between dry matter intake and enteric methane emissions of Holstein heifers. 
Table 6. Development of methane prediction models for Holstein heifers using the whole data sets.

\begin{tabular}{|c|c|c|c|c|}
\hline Item $^{1}$ & Equations & SE & $\mathbf{R}^{2}$ & Eq. \\
\hline \multirow{6}{*}{$\mathrm{CH}_{4}-\mathrm{E}(\mathrm{MJ} /$ day $)$} & Linear models & & & \\
\hline & $\begin{array}{c}0.026(0.0043) \times \mathrm{BW}(\mathrm{kg})+0.69(0.431) \times \mathrm{DM} \text { intake }(\mathrm{kg} / \text { day })- \\
5.564(1.1940)\end{array}$ & 0.337 & 0.742 & $(10)$ \\
\hline & $\begin{array}{c}3.18(0.408) \times \mathrm{DM} \text { intake }(\mathrm{kg} / \text { day })+1.74(0.598) \times \mathrm{NDF} \text { intake } \\
(\mathrm{kg} / \text { day })-9.426(2.6003)\end{array}$ & 0.682 & 0.593 & $(11)$ \\
\hline & $\begin{array}{c}1.75(0.399) \times \mathrm{DM} \text { intake }(\mathrm{kg} / \mathrm{d})-2.71(0.648) \times \mathrm{NFC} \text { intake } \\
(\mathrm{kg} / \text { day })-8.552(2.4150)\end{array}$ & 0.549 & 0.655 & (12) \\
\hline & $\begin{array}{c}0.024(0.0041) \times \mathrm{BW}(\mathrm{kg})+1.22(0.456) \times \mathrm{DM} \text { intake }(\mathrm{kg} / \text { day })+ \\
1.15(0.459) \times \mathrm{NDF} \text { intake }(\mathrm{kg} / \text { day })-5.389(2.0681)\end{array}$ & 0.261 & 0.777 & (13) \\
\hline & $\begin{array}{c}0.023(0.0037) \times \mathrm{BW}(\mathrm{kg})+0.28(0.038) \times \mathrm{DM} \text { intake }(\mathrm{kg} / \text { day })- \\
2.04(0.486) \times \mathrm{NFC} \text { intake }(\mathrm{kg} / \text { day })-4.872(1.8634) \\
\text { Non-linear models }\end{array}$ & 0.132 & 0.820 & (14) \\
\hline \multirow{6}{*}{$\mathrm{CH}_{4}-\mathrm{E}(\mathrm{MJ} /$ day $)$} & $5.564(1.1206) \times \exp (0.0276(0.0037) \times \mathrm{DM}$ intake $(\mathrm{kg} /$ day $))$ & 0.396 & 0.461 & (15) \\
\hline & $4.333(1.0177) \times \mathrm{DM}$ intake $(\mathrm{kg} /$ day $){ }^{0.232(0.0452)}$ & 0.601 & 0.446 & (16) \\
\hline & $2.465(0.7452) \times \exp (0.0075(0.0008) \times \mathrm{NDF}$ intake $(\mathrm{kg} / \mathrm{d}))$ & 0.452 & 0.411 & (17) \\
\hline & $2.204(0.6514) \times \mathrm{NDF}$ intake $(\mathrm{kg} / \text { day })^{0.084(0.0072)}$ & 0.377 & 0.489 & $(18)$ \\
\hline & $0.926(0.0452) \times \exp (0.0672(0.00121) \times$ NFC intake $(\mathrm{kg} /$ day $))$ & 0.514 & 0.385 & (19) \\
\hline & $0.527(0.0271) \times \mathrm{NDF}$ intake $(\mathrm{kg} / \text { day })^{0.541(0.0362)}$ & 0.602 & 0.434 & (20) \\
\hline
\end{tabular}

${ }^{1} \mathrm{CH}_{4}$-E = methane energy, $\mathrm{BW}$ = body weight, $\mathrm{DM}=$ dry matter, NDF = neutral detergent fiber, NFC = non-fibrous carbohydrate; $\mathrm{SE}=$ standard error.

\section{Discussion}

\subsection{Effects on Feed Intake and Growth Performance}

A number of studies have demonstrated that increasing dietary concentrate contents would increase feed intake of heifers, although they are typically fed high-fiber diets due to physiological and economic considerations [11]. In accordance with the previous studies, moving from 2.09 to $3.59 \mathrm{~kg} / \mathrm{day}$ and 2.23 to $3.98 \mathrm{~kg} /$ day from of concentrate treatments increased DM intake by 0.20 and $0.52 \mathrm{~kg} /$ day in period two and three, respectively. Aguerre at al. [12] reported a significant increase of NDF intake from 5.4 to $6.5 \mathrm{~kg} /$ day as dietary forage-to-concentrate increased from 47:53 to 68:32. However, although only a numerical change was observed in NDF intake, NFC intake increased significantly as concentrate contents increased from 30 to $50 \%$ in period one. In the current study, alfalfa was introduced into the diets in the last two periods. This high-quality forage would be responsible for the significant increase of feed intake for the C50 treatments due to its good palatability and high level of digestibility [13]. Consequently, increased ADG were achieved in the current study as a direct result of higher energy density of the higher concentrate diets and increased feed intake [14].

\subsection{Effects on Apparent Nutrient Digestibility}

Generally, nutrient digestibility increased with increased concentrate supplementation for heifers in any periods of the present study. Moody et al. [15] reported that increasing dietary corn silage contents reduced DM digestibility of Holstein heifers either at the age of 6 or 12 months. Jiao et al. [16] found similar digestibility values of DM, NDF and ADF to our results for heifers at various ages. Different from our findings, Moody et al. [15] reported that NDF digestibility decreased as concentrate proportion increased in the diet, and concluded that this significant reduction of NDF digestibility may be due to the variations of passage of different forage in the diet and growth condition of animals [17]. However, as corn silage was commonly used in each experimental period, only alfalfa was introduced into the period two and three of the present study. This inclusion of different forage types might explain different nutrient digestibility among the three treatments in any period of one to three. Sarwar et al. [18] reported little difference of nitrogen digestibility for Holstein cows fed diets varying in proportion of NDF. Recent studies conducted by Drewnoski and Poore [19] and Trotta et al. [20] found that increasing dietary concentrate level increased the total tract $\mathrm{CP}$ digestibility from 53.1 to $58.1 \%$ for beef cattle. The current study showed that there was a positive relationship between 
dietary concentrate level and CP digestibility, which had similar trends to the digestibility values of other nutrients. Nousiainene et al. [21] suggested that increased CP digestibility was associated with improved diet digestibility, which may be resulted from increased dietary CP concentrate and a dilution of metabolic and endogenous fecal nitrogen. However, these authors also suggested that the amount of dietary CP concentration instead of amount of concentrate was related to changes of dietary CP digestibility. Dietary CP content increased from 15.7 to $18.7 \%$ (period 1) or from 14.1 to $14.7 \%$ (period 2) with concentrate level increasing from 30 to $50 \%$ in the present study. However, it still needs further study to elucidate the direct relationship between nutrient digestibility and dietary composition as some cofounding factors need to be considered during analysis. However, it is worth noting that the nutrient digestibility values in the present study were obtained using acid-insoluble ash as internal marker, as this method has been extensively recognized for determination of diet digestibility due to reliable digestibility estimates [22,23]. Previously, the standard procedure for measuring total-tract apparent digestibility involved total collection of feces and urine, whereas alternative approaches including acid-insoluble ash and indigestible NDF were proposed and used as they required a small number of animals and produced accurate results [24,25]. Nevertheless, nutrient digestibility values obtained in the present study were consistent with the previous studies, which indicated that acid-insoluble ash method may be a suitable and convenient method although the total collection should still be considered the best choice [26].

\subsection{Effects on Enteric Methane Emissions}

Due to the large population of China's dairy industries, it is becoming increasingly important to quantify $\mathrm{CH}_{4}$ emissions for cows at different ages and under various production systems. However, until recently, several studies investigated the effects of dietary concentrate contents on $\mathrm{CH}_{4}$ emissions for heifers. Boland et al. [27] reported similar $\mathrm{CH}_{4}$ emissions (121 vs. $132 \mathrm{~g} /$ day) for grazing beef heifer that consumed different herbage masses. Jiao et al. [16] examined $\mathrm{CH}_{4}$ emissions from heifer and steer at various growth stage, and reported an average daily $\mathrm{CH}_{4}$ emission of 93.5, 159.5, 175.0, and $188.5 \mathrm{~g} /$ day for young stock at the age of $6,12,18$, and 22 months under confined condition. These values are similar to the recent study of Morrison et al. [28] who measured $\mathrm{CH}_{4}$ emissions from grazing heifers using the $\mathrm{SF}_{6}$ tracer technique. However, emission data for heifers at the age of 15 months were higher than those for confined heifer and steer or for young stock in grazing condition [28].

As enteric $\mathrm{CH}_{4}$ emission represents the final production of ruminal fermentation via methanogenesis, it can be significantly affected by a range of factors including animal physiological state, dietary components, and measurement technique. Increased concentrate proportion resulted in reduced $\mathrm{CH}_{4}$ emissions in the current study. These values were consistent with studies of Muñoz et al. [29], who also decreased $\mathrm{CH}_{4}$ production with increasing concentrate level up to 6 and $5 \mathrm{~kg}$ of concentrate per day, respectively. Generally, inclusion of high level of concentrate in the diet represents higher content of readily fermentable substance (e.g., starch) than that of high forage diets. Previous studies demonstrated that starch-rich diets reduced ruminal $\mathrm{pH}$ and $\mathrm{H}_{2}$ concentration, and shifted fermentation patter towards to an increased propionate formation, which would depress the activity of methanogens and consequently reduce $\mathrm{CH}_{4}$ emissions [30,31]. Moreover, the composition and structure of ruminal methanogens was demonstrated to differ across heifer physiological stages, which would affect the enteric $\mathrm{CH}_{4}$ emissions of heifers [32]. Although the main objective of the current was not to examine the archaeal community in the rumen, results showed an increasing trend in $\mathrm{CH}_{4}$ emissions as the growth of heifer advanced, which would reflect the changes and distribution of ruminal methanogens.

Regional or national enteric $\mathrm{CH}_{4}$ emission inventories in many countries are currently estimated using the Tier-2 methodology from International Panel on Climate Change (IPCC) guidelines. As with Tier-2 approaches, default prediction values for $Y_{m}$ from adult dairy cows in the 1997 (0.060) [33] and 2006 (0.065) [5] IPCC guidelines were recommended for the $\mathrm{CH}_{4}$ estimation of the whole dairy population. However, adoption of a default and fixed value has becoming a major concern because it can vary considerably with varying geographic conditions, cow breed and physiological stages, and 
dietary characteristics [6,7]. Boadi et al. [34] reported an $Y_{m}$ value of 0.067 or 0.076 for yearling heifers either fed ad-libitum or under restricted feeding condition. Morrison et al. [28] calculated $Y_{m}$ values for calves, yearling heifer, and in-calf heifer with an average age of 8.5, 14.5 and 20.5 months, and found that the calculated $Y_{m}$ was $0.057,0.0675,0.059$ for each period. In accordance with those results from confined lactating cows or heifers at pasture, a range of $Y_{m}$ values between 0.0454 and 0.0769 were obtained across all heifer ages in the current study, which lied within the range (0.036-0.114) obtained under diverse production systems [35]. Therefore, these prediction factors achieved on a regional production basis in China can be used and improve the prediction accuracy for cows at specific developmental stages. Furthermore, variations of $Y_{m}$ values were also examined when heifers were fed different concentrate contents in the diet. As report previously, variations of dietary components such as starch: NDF ratios can change the rumen fermentation environment and methanogenesis functions, which consequently affect the $\mathrm{CH}_{4}$ emissions. In the present study, $\mathrm{Y}_{\mathrm{m}}$ values decreased from 0.0686 to $0.0454,0.0742$ to $0.0558,0.0769$ to 0.0568 when concentrate intake increased from 1.68 to $3.45,2.09$ to $3.59,2.23$ to $3.98 \mathrm{~kg} /$ day in period 1 to 3 , respectively. These results are consistent with the grazing studies of van Wyngaard et al. [35], who reported that $Y_{m}$ of lactating Jersey cows significantly decreased from 0.0891 to 0.0785 when the concentrate increased from 0 to $8 \mathrm{~kg} /$ day.

\subsection{Prediction Equations for Enteric Methane Emissions}

Enteric $\mathrm{CH}_{4}$ emission predictions have been widely developed based on mathematical or statistical association of nutrient intake, dietary nutrient composition and digestibility and other animal factors with enteric $\mathrm{CH}_{4}$ emissions [36]. In agreement with previous studies, DM and GE intake were the best predictors of $\mathrm{CH}_{4}$ emissions in this study with values of $\mathrm{R}^{2}$ ranging from 0.67 to 0.74 . Similar $\mathrm{R}^{2}$ values of 0.68 with DM intake and 0.70 with GE intake were reported for beef cattle measured using respiration calorimeters [37]. Appuhamy et al. [7] evaluated performance of more than 40 empirical models in predicting enteric $\mathrm{CH}_{4}$ emissions, and suggested that DM intake alone may be sufficient to achieve satisfactory prediction accuracy inventory purposes [38]. A meta-analysis conducted by Charmley et al. [39] showed that a large data set including both dairy and beef cattle can significantly enhance the relationship between DM intake and $\mathrm{CH}_{4}$ emissions, with a high value of determination coefficient and an intercept close to zero when DM intake ranged from 2 to $28 \mathrm{~kg} /$ day. The data was pooled together and a linear or nonlinear relationship was observed between BW, DM intake and $\mathrm{CH}_{4}$ emissions in the current study. However, curvilinear relationship between DM intake and $\mathrm{CH}_{4}$ production was observed when dairy cows were fed relatively high proportion of concentrate [40]. It was suggested that linear relationship between $\mathrm{DM}$ intake and $\mathrm{CH}_{4}$ production can be achieved when the concentrate level was below 30\% [39]. Yan et al. [37] reported that the coefficient of determination for the relationship between DM intake and $\mathrm{CH}_{4}$ emissions were highly affected by several factors including growth stage, dietary concentrations of protein and carbohydrate fractions. For example, coefficients for DM intake increased from 24.21 to 51.72 for heifers at the age of 9 to 15 months, although this difference did not reach significance. Moreover, lower values of $R^{2}$ from 0.42 to 0.47 were observed when animal characteristic such as BW was used as a single predictor variable. Jiao et al. [16] reported an increase of $0.252 \mathrm{~kg} /$ day $\mathrm{CH}_{4}$ for an increase of $1 \mathrm{~kg}$ of heifer $\mathrm{BW}$, which was similar to our findings that an average increase of $0.203 \mathrm{~kg} / \mathrm{day} \mathrm{CH}_{4}$ was observed for each unit increase of BW.

Although linear models can be mathematically developed using dietary intake and composition variables, enteric $\mathrm{CH}_{4}$ emissions may not follow a linear trend as generation of $\mathrm{CH}_{4}$ can be affected by ruminal function and fermentation dynamics. Among the non-linear models developed using the whole data sets of the present study, a highest $R^{2}$ value of 0.82 was observed when BW, DM intake and NFC intake were incorporate in to the equation. However, a range of relative lower values of $R^{2}$ were also found for those exponential or power equations. This result was in consistent with the previous research of Mills et al. [41] and Patra et al. [42], who found minor difference in RMSE percentage between the linear and non-linear models. Although non-linear models required more variables to obtained the accurate methane emissions results, Mills et al. [41] suggested that 
non-linear models would be better for quantifying $\mathrm{CH}_{4}$ production in a wide range of production variables; especially, as they could be more appropriate when extreme values were obtained during the practical application [42]. The slopes of dietary DM and NDF intake were positively related to enteric $\mathrm{CH}_{4}$ emissions, whereas increasing dietary NFC intake may reduce $\mathrm{CH}_{4}$ emission. Diets rich in non-structural carbohydrates such as starch and sugars are converted to propionate in the rumen with less hydrogen and $\mathrm{CH}_{4}$ production. However, fermentation of fibrous materials would favour the formation of acetate and butyrate, which would have positive impact on $\mathrm{CH}_{4}$ emissions.

\section{Conclusions}

It is concluded that increasing dietary concentrate contents improves feed intake and growth performance, and nutrient digestibility. Enteric methane emissions decrease significantly with increasing concentrate contents. A range of $\mathrm{CH}_{4}$ conversion factors are derived from the current study, reflecting the variations of animal and dietary characteristics under the typical production regimes in China. Together with prediction equations, these data will be of great importance for development of regional or national emission inventories and mitigation approaches for heifers at specific growth stage.

Author Contributions: Conceptualization, Q.D.; methodology, L.D.; data curation, B.L.; writing—original draft preparation, L.D.; writing—review and editing, Q.D.; visualization, L.D.; supervision, Q.D.; project administration, Q.D.; funding acquisition, L.D. and Q.D.

Funding: This research was funded by Program of International S\&T Cooperation (2016YFE0109000), National Science Foundation for Young Scientists of China (31802085), National Key Research and Development Program of China (2017YFF0211702 and 2017YFF0211701), and Young Scientist Lifting Project (2017-2019).

Acknowledgments: The authors thank colleagues in Feed Research Institute and Century Love International Investment Group Co. Ltd., Beijing for providing kind assistance in animal experiments, sample processing, and data collection. The authors would like to thank reviewers for their suggestions and comments on this work.

Conflicts of Interest: The authors declare no conflict of interest.

\section{References}

1. Dong, L.F.; Ferris, C.P.; McDowell, D.A.; Yan, T. Effects of diet forage proportion on maintenance energy requirement and the efficiency of metabolizable energy use for lactation by lactating dairy cows. J. Dairy Sci. 2015, 98, 1-10. [CrossRef] [PubMed]

2. Second National Communication on Climate Change of China (SNCCCC). National Development and Reform Commission of the People's Republic of China. Available online: http://www.ccchina.gov.cn/archiver/ ccchinaen/UpFile/Files/Default/20130218145208096785.pdf/ (accessed on 2 December 2015).

3. Zhu, G.D.; Ma, X.Y.; Gao, Z.L.; Ma, W.Q.; Li, J.G.; Cai, Z.J. Characterizing $\mathrm{CH}_{4}$ and $\mathrm{N}_{2} \mathrm{O}$ emissions from an intensive dairy operation in summer and fall in China. Atmos. Environ. 2014, 38, 245-253. [CrossRef]

4. Yang, Y.; Zhang, J.J.; Wang, C. Forecasting China's Carbon Intensity-Is China on Track to Comply with Its Copenhagen Commitment? Energy J. 2018, 39, 63-86. [CrossRef]

5. Intergovernmental Panel on Climate Change (IPCC). 2006 IPCC Guidelines for National Greenhouse Gas Inventories. In Prepared by the National Greenhouse Gas Inventories Programme; Eggleston, H.S., Buendia, L., Miwa, K., Ngara, T., Tanabe, K., Eds.; IGES: Hayama, Japan, 2006.

6. Bannink, A.; van Schijndel, M.W.; Dijkstra, J. A model of enteric fermentation in dairy cows to estimate methane emission for the Dutch National Inventory Report using the IPCC Tier 3 approach. Anim. Feed Sci. Technol. 2011, 166, 603-618. [CrossRef]

7. Appuhamy, J.A.D.R.N.; France, J.; Kebreab, E. Models for predicting enteric methane emissions from dairy cows in North America, Europe, and Australia and New Zealand. Glob. Chang. Biol. 2016, 22, 3039-3056. [CrossRef]

8. Xue, B.; Wang, L.Z.; Yan, T. Methane emission inventories for enteric fermentation and manure management of yak, buffalo and dairy and beef cattle in China from 1988 to 2009. Agric. Ecosyst. Environ. 2014, 195, 202-210. [CrossRef] 
9. Deighton, M.H.; Williams, S.R.O.; Hannah, M.C.; Eckard, R.J.; Boland, T.M.; Wales, W.J.; Moate, P.J. A modified sulphur hexafluoride tracer technique enables accurate determination of enteric methane emissions from ruminants. Anim. Feed Sci. Technol. 2014, 197, 47-63. [CrossRef]

10. Van Keulen, J.; Young, B.A. Evaluation of acid-insoluble ash as a natural marker in ruminant digestibility studies. J. Anim. Sci. 1997, 44, 282-287. [CrossRef]

11. Kljak, K.; Heinrichs, B.S.; Heinrichs, A.J. Fecal particle dry matter and fiber distribution of heifers fed ad libitum and restricted with low and high forage quality. J. Dairy Sci. 2019, 102, 4694-4703. [CrossRef]

12. Aguerre, M.J.; Wattiaux, M.A.; Powell, J.M.; Broderick, G.A.; Arndt, C. Effect of forage-to-concentrate ratio in dairy cow diets on emission of methane, carbon dioxide, and ammonia, lactation performance, and manure excretion. J. Dairy Sci. 2011, 94, 3081-3093. [CrossRef]

13. Kljak, K.; Pino, F.; Heinrichs, A.J. Effect of forage to concentrate ratio with sorghum silage as a source of forage on rumen fermentation, $\mathrm{N}$ balance, and purine derivative excretion in limit-fed dairy heifers. J. Dairy Sci. 2017, 100, 213-223. [CrossRef]

14. Reynolds, C.K.; Tyrrell, H.F.; Reynolds, P.J. Effects of diet forage-to-concentrate ratio and intake on energy metabolism in growing beef heifers: Net nutrient metabolism by visceral tissues. J. Nutr. 1991, 121, 1004-1015. [CrossRef]

15. Moody, M.L.; Zanton, G.I.; Daubert, J.M.; Heinrichs, A.J. Nutrient utilization of differing forage-to-concentrate ratios by growing Holstein heifers. J. Dairy Sci. 2007, 90, 5580-5586. [CrossRef] [PubMed]

16. Jiao, H.P.; Dale, A.J.; Carson, A.F.; Murray, S.; Gordon, A.W.; Ferris, C.P. Effect of concentrate feed level on methane emissions from grazing dairy cows. J. Dairy Sci. 2014, 97, 7043-7053. [CrossRef]

17. Nakamura, T.; Owen, F.G. High amounts of soyhulls for pelleted concentrate diets. J. Dairy Sci. 1989, 72, 988-994. [CrossRef]

18. Sarwar, M.; Firkins, J.L.; Eastridge, M.L. Effects of varying forage and concentrate carbohydrates on nutrient digestibilities and milk production by dairy cows. J. Dairy Sci. 1992, 75, 1533-1542. [CrossRef]

19. Drewnoski, M.E.; Poore, M.H. Effect of supplementation frequency on ruminal fermentation and digestion by steers fed medium-quality hay and supplemented with a soybean hull and corn gluten feed blend. J. Anim. Sci. 2012, 90, 881-891. [CrossRef]

20. Trotta, R.J.; Klotz, J.L.; Harmon, D.L. Effects of source and level of dietary energy supplementation on in vitro digestibility and methane production from tall fescue-based diets. Anim. Feed Sci. Technol. 2018, 242, 41-47. [CrossRef]

21. Nousiainen, J.; Rinne, M.; Huhtanen, P. A meta-analysis of feed digestion in dairy cows. 1. The effects of forage and concentrate factors on total diet digestibility. J. Dairy Sci. 2009, 92, 5019-5030. [CrossRef]

22. Huhtanen, P.; Kaustell, K.; Jaakkola, S. The use of internal markers to predict total digestibility and duodenal flow of nutrients in cattle given six different diets. Anim. Feed Sci. Technol. 1994, 48, 211-227. [CrossRef]

23. Rice, E.M.; Aragona, K.M.; Moreland, S.C.; Erickson, P.S. Supplementation of sodium butyrate to postweaned heifer diets: Effects on growth performance, nutrient digestibility, and health. J. Dairy Sci. 2019, 102, 1-10. [CrossRef]

24. Nikkhah, A.; Alikhani, M.; Amanlou, H. Effects of Feeding Ground or Steam-Flaked Broom Sorghum and Ground Barley on Performance of Dairy Cows in Midlactation. J. Dairy Sci. 2004, 87, 122-130. [CrossRef]

25. Lee, C.; Hristov, A.N. Evaluation of acid-insoluble ash and indigestible neutral detergent fiber as total-tract digestibility markers in dairy cows fed corn silage-based diets. J. Dairy Sci. 2013, 96, 5295-5299. [CrossRef]

26. De Marco, M.; Miraglia, N.; Peiretti, P.G.; Bergero, D. Apparent digestibility of wheat bran and extruded flax in horses determined from the total collection of feces and acid-insoluble ash as an internal marker. Animal 2012, 6, 227-231. [CrossRef]

27. Boland, T.M.; Quinlan, C.; Pierce, K.M.; Lynch, M.B.; Kenny, D.A.; Kelly, A.K.; Purcell, P.J. The effect of pasture pregrazing herbage mass on methane emissions, ruminal fermentation, and average daily gain of grazing beef heifers. J. Anim. Sci. 2013, 91, 3867-3874. [CrossRef]

28. Morrison, S.J.; McBride, J.; Gordon, A.W.; Wylie, A.R.G.; Yan, T. Methane Emissions from Grazing Holstein-Friesian Heifers at Different Ages Estimated Using the Sulfur Hexafluoride Tracer Technique. Eng. 2017, 3, 753-759. [CrossRef]

29. Muñoz, C.; Hube, S.; Morales, J.M.; Yan, T.; Ungerfeld, E.M. Effects of concentrate supplementation on enteric methane emissions and milk production of grazing dairy cows. Livest. Sci. 2015, 175, 37-46. [CrossRef] 
30. Zhang, X.M.; Wang, M.; Wang, R.; Ma, Z.Y.; Long, D.L.; Mao, H.X.; Wen, J.N.; Bernard, L.A.; Beauchemin, K.A.; Tan, Z.L. Urea plus nitrate pretreatment of rice and wheat straws enhances degradation and reduced methane production in in vitro ruminal culture. J. Sci. Food Agric. 2018, 98, 5205-5211. [CrossRef]

31. Lan, W.; Yang, C.L. Ruminal methane production: Associated microorganisms and the potential of applying hydrogen-utilizing bacteria for mitigation. Sci. Total Environ. 2019, 654, 1270-1283. [CrossRef]

32. Cunha, C.S.; Marcondes, M.I.; Veloso, C.M.; Mantovani, H.C.; Pereira, L.G.R.; Tomich, T.R.; Dill-McFarland, K.A.; Suen, G. Compositional and structural dynamics of the ruminal microbiota in dairy heifers and its relationship to methane production. J. Sci. Food Agric. 2019, 99, 210-218. [CrossRef]

33. Intergovernmental Panel on Climate Change (IPCC). Revised 1996 IPCC Guidelines for National Greenhouse Gas Inventories; Intergovernmental Panel on Climate Change, IPCC/OECD/IEA: Bracknell, UK, 1997.

34. Boadi, D.A.; Wittenberg, K.M. Methane production from dairy and beef heifers fed forages differing in nutrient density using the sulphur hexafluoride $\left(\mathrm{SF}_{6}\right)$ tracer gas technique. Can. J. Anim. Sci. 2011, 82, 201-206. [CrossRef]

35. Van Wyngaard, J.D.V.; Meeske, R.; Erasmus, L.J. Effect of concentrate level on enteric methane emissions, production performance, and rumen fermentation of Jersey cows grazing kikuyu-dominant pasture during summer. J. Dairy Sci. 2018, 101, 1-13. [CrossRef]

36. Hristov, A.N.; Kebreab, E.; Niu, M.; Oh, J.; Bannink, A.; Bayat, A.R.; Boland, T.B.; Brito, A.F.; Casper, D.P.; Crompton, L.A.; et al. Uncertainties in enteric methane inventories, measurement techniques, and prediction models. J. Dairy Sci. 2018, 101, 1-20. [CrossRef]

37. Yan, T.; Porter, M.G.; Mayne, C.S. Prediction of methane emission from beef cattle using data measured in indirect open-circuit respiration calorimeters. Animal 2009, 3, 1455-1462. [CrossRef]

38. Hess, P.S.A.; Eckard, R.J.; Jacobs, J.L.; Hannah, M.C.; Moate, P.J. Comparison of five methods for the estimation of methane production from vented in vitro systems. J. Sci. Food Agric. 2019, 99, 109-116. [CrossRef]

39. Charmley, E.; Williams, S.R.O.; Moate, P.J.; Hegarty, R.S.; Herd, R.M.; Oddy, V.H.; Reyenga, P.; Staunton, K.M.; Anderson, A.; Hannah, M.C. A universal equation to predict methane production of forage-fed cattle in Australia. Anim. Prod. Sci. 2016, 56, 169-180. [CrossRef]

40. Knapp, J.R.; Laur, G.L.; Vadas, P.A.; Weiss, W.P.; Tricarico, J.M. Enteric methane in dairy cattle production: Quantifying the opportunities and impact of reducing emissions. J. Dairy Sci. 2014, 97, 3231-3261. [CrossRef]

41. Mills, J.A.N.; Kebreab, E.; Yates, C.M.; Crompton, L.A.; Cammell, S.B.; Dhanoa, M.S.; Agnew, R.E.; France, J. Alternative approaches to predicting methane emissions from dairy cows. J. Anim. Sci. 2003, 81, 3141-3150. [CrossRef]

42. Patra, A.K.; Lalhriatpuii, M. Development of statistical models for prediction of enteric methane emission from goats using nutrient composition and intake variables. Agric. Ecosyst. Environ. 2016, 215, 89-99. [CrossRef]

(C) 2019 by the authors. Licensee MDPI, Basel, Switzerland. This article is an open access article distributed under the terms and conditions of the Creative Commons Attribution (CC BY) license (http://creativecommons.org/licenses/by/4.0/). 


\title{
The Effects of System Changes in Grazed Dairy Farmlet Trials on Greenhouse Gas Emissions
}

\author{
Tony van der Weerden ${ }^{1, *}$, Pierre Beukes ${ }^{2}$, Cecile de Klein ${ }^{1}$, Kathryn Hutchinson ${ }^{3}$, \\ Lydia Farrell ${ }^{2, \dagger}$, Tinke Stormink ${ }^{1, \ddagger}$, Alvaro Romera ${ }^{2}$, Dawn Dalley ${ }^{4}$, Ross Monaghan ${ }^{1}$, \\ David Chapman ${ }^{4}$, Kevin Macdonald ${ }^{2}$ and Robyn Dynes ${ }^{5}$ \\ 1 AgResearch, Invermay Agricultural Centre, Mosgiel 9053, New Zealand; \\ cecile.deklein@agresearch.co.nz (C.d.K.); tinke.stormink@outlook.com (T.S.); \\ ross.monaghan@agresearch.co.nz (R.M.) \\ 2 DairyNZ Ltd., Private Bag 3221, Hamilton 3240, New Zealand; pierre.beukes@dairynz.co.nz (P.B.); \\ lydia.farrell64@gmail.com (L.F.); alvaro.romera@dairynz.co.nz (A.R.); kevin.macdonald@xtra.co.nz (K.M.) \\ 3 AgResearch, Grasslands Research Centre, Palmerston North 4410, New Zealand; \\ kathryn.hutchinson@agresearch.co.nz \\ 4 DairyNZ Ltd., Canterbury Agricultural \& Science Centre, Lincoln 7608, New Zealand; \\ dawn.dalley@dairynz.co.nz (D.D.); david.chapman@dairynz.co.nz (D.C.) \\ 5 AgResearch, Lincoln Research Centre, Lincoln 7674, New Zealand; robyn.dynes@agresearch.co.nz \\ * Correspondence: tony.vanderweerden@agresearch.co.nz; Tel.: +64-3-4899012; Fax: +64-3-4893739 \\ + Present Address: School of Agriculture and Environment, College of Sciences, Massey University, \\ Palmerston North 4442, New Zealand. \\ $\ddagger$ Present Address: DuPont Industrial Biosciences, 2300 AE Leiden, The Netherlands.
}

Received: 15 October 2018; Accepted: 4 December 2018; Published: 7 December 2018

Simple Summary: Dairy farm system practices aimed at reducing nitrate leaching can also reduce emissions of the greenhouse gases methane and nitrous oxide. A study comparing 'current' and 'improved' grazed dairy system practices showed that 'improved' systems generally produced lower greenhouse gas emissions while milk production was maintained. The amount of feed eaten per hectare was the key driver of total greenhouse gas emissions per area, with 'improved' systems generally exhibiting lower total enteric methane and less $\mathrm{N}$ flowing through the herd.

Abstract: An important challenge facing the New Zealand (NZ) dairy industry is development of production systems that can maintain or increase production and profitability, while reducing impacts on receiving environments including water and air. Using research 'farmlets' in Waikato, Canterbury, and Otago (32-200 animals per herd), we assessed if system changes aimed at reducing nitrate leaching can also reduce total greenhouse gas (GHG) emissions (methane and nitrous oxide) and emissions intensity (kg GHG per unit of product) by comparing current and potential 'improved' dairy systems. Annual average GHG emissions for each system were estimated for three or four years using calculations based on the New Zealand Agricultural Inventory Methodology, but included key farmlet-specific emission factors determined from regional experiments. Total annual GHG footprints ranged between $10,800 \mathrm{~kg}$ and $20,600 \mathrm{~kg} \mathrm{CO}_{2} \mathrm{e} / \mathrm{ha}$, with emissions strongly related to the amount of feed eaten. Methane $\left(\mathrm{CH}_{4}\right)$ represented $75 \%$ to $84 \%$ of the total GHG footprint across all modelled systems, with enteric $\mathrm{CH}_{4}$ from lactating cows grazing pasture being the major source. Excreta deposition onto paddocks was the largest source of nitrous oxide $\left(\mathrm{N}_{2} \mathrm{O}\right)$ emissions, representing $7-12 \%$ of the total GHG footprint for all systems. When total emissions were represented on an intensity basis, 'improved' systems are predicted to generally result in lower emissions intensity. The 'improved' systems had lower GHG footprints than the 'current' system, except for one of the 'improved' systems in Canterbury, which had a higher stocking rate. The lower feed supplies and associated lower stocking rates of the 'improved' systems were the key drivers of lower total GHG emissions in all three regions. 'Improved' systems designed to reduced N leaching generally also reduced GHG emissions. 
Keywords: environmental modelling; pasture systems; nitrous oxide; methane emissions; nitrate leaching

\section{Introduction}

Agriculture is responsible for $47.9 \%$ of total greenhouse gas (GHG) emissions in New Zealand (NZ) but contributions to national emissions of methane $\left(\mathrm{CH}_{4}\right)$ and nitrous oxide $\left(\mathrm{N}_{2} \mathrm{O}\right)$ are $86 \%$ and 95\%, respectively [1]. Dairy farms primarily emit two GHG: (1) $\mathrm{CH}_{4}$ from enteric fermentation in the cow rumen, and (2) $\mathrm{N}_{2} \mathrm{O}$ arising mainly from denitrification of urinary nitrogen (N) in the soil and nitrogen fertiliser application. Methane emissions from dairy cattle have increased $130 \%$ from 1990 to 2015 [1]. In 2015, enteric $\mathrm{CH}_{4}$ was the major contributor (73\%) while $\mathrm{N}_{2} \mathrm{O}$ from agricultural soils represented $21 \%$ of total GHG emissions from the agricultural sector [1]. The main drivers for this change are a doubling of the national dairy cow population since 1990 [2] and an increase in the application of synthetic $\mathrm{N}$ fertiliser ( $>600 \%$ ) over this same period [1]. In New Zealand, dairy cows graze ryegrass-dominant pastures, of which perennial ryegrass (Lolium perenne) is the major species, with supplements (e.g., maize silage, barley grain) typically less than $100 \mathrm{~g} / \mathrm{kg}$ of feed intake. Cows typically calve at the end of winter (i.e., July-September) and are milked for 8-10 months [3]. Similar pasture-based grazing systems for dairy cows are used in Australia [4,5] and Ireland [6].

An important challenge facing the NZ dairy industry, and globally, is to develop farm systems that can maintain or increase production (to meet increasing population demand) and profitability, while reducing impacts on receiving environments including water and air [7-9]. Various hypotheses have been advanced on changing dairy farm systems to reduce their environmental impact. Lowering stocking rate can result in more feed per cow, resulting in better-fed cows with more production per cow [3]. Fewer cows with better feed conversion efficiency could mean less feed is required for maintenance and more is converted into product. If cow genetic merit can be improved at the same time then these lower-stocked, well-managed systems can produce the same amount of product per hectare as higher-stocked systems [10]. The lower-stocked system will require less feed per area and, therefore, reduce the amount of $\mathrm{N}$ consumed and excreted by the herd. Nitrogen leaching will be reduced since the amount of urinary $\mathrm{N}$ deposited onto pasture is a major source of nitrate leaching [11]. Also, with lower feed intake from the smaller, more efficient herd it can be expected that the amount of enteric $\mathrm{CH}_{4}$ emitted will be reduced [3].

A reduction in $\mathrm{N}$ fertiliser use will usually reduce $\mathrm{N}$ leaching $[12,13]$ and $\mathrm{N}_{2} \mathrm{O}$ losses from soils [14]. Less fertiliser will reduce the total amount of pasture grown, and also assist in a small reduction in the total $\mathrm{N}$ concentration of the herbage $[4,15]$ and, therefore, reduce the amount of $\mathrm{N}$ flowing through the stock, and excreted as urinary and dung $\mathrm{N}$. Reducing $\mathrm{N}$ fertiliser can be achieved through optimising its use, by targeting $\mathrm{N}$ application to pastures that have the greatest yield potential and to paddocks displaying signs of deficiency (yellowing and poor performance), rather than whole-farm $\mathrm{N}$ applications [16]. There is also the possibility of some compensation from less fertiliser through improved clover vigour and soil health resulting in greater natural $\mathrm{N}$ fixation $[17,18]$.

Other strategies for reducing environmental impacts of dairy farm systems include improved reproductive performance of the herd, which results in less involuntary culling and lower replacement rates (reviewed in [19]). Replacements produce $\mathrm{CH}_{4}$ and urinary $\mathrm{N}$ without contributing to milk production [20]. Greater use of high energy/low $\mathrm{N}$ feed (grain or forage) will reduce total urinary $\mathrm{N}$ excreted through lowering $\mathrm{N}$ intake [21] and improve the energy intake when pasture growth or pasture quality is low. This strategy also dilutes the effect of excess crude protein supplied by the pasture [22]. Off-paddock facilities can be used to reduce $\mathrm{N}$ returns to pasture during periods of low $\mathrm{N}$ utilisation and in turn decrease the risk of $\mathrm{N}$ leaching in winter and spring [23]. In addition, off-paddock facilities protect wet pasture from treading damage [24,25]. 
Farmlet systems trials (Pastoral 21-Phase 2 (P21), [26,27]) were run over a five-season period from 2011 to 2016 with the aim of developing industry-accessible, adoptable, system-level solutions for profitably increasing production while reducing $\mathrm{N}$ leaching [7]. Four dairy regions were used to provide contrasting challenges to dairy production due to different soil types, climates and local management practices. 'Improved' dairy systems for each region were initially developed to improve water quality outcomes via strategic changes to the current system. Some of these changes were recognised to also deliver reduced emissions of GHG whilst maintaining or increasing milk production and profitability [3]. The key changes included:

1. Using fewer, higher producing, cows

2. Smaller $\mathrm{N}$ fertiliser inputs

3. Lower herd replacement rate

4. Greater use of high energy/low $\mathrm{N}$ feed

5. Using off-paddock facilities to reduce the time cows spend on pasture (or on forage crops).

These five components were used to design the P21 farmlet systems trials with all or some of them applied to the 'improved' system in each location. Here, we examine whether 'improved' dairy systems designed to reduced $\mathrm{N}$ leaching also reduce GHG emissions. The effects of these system changes, or 'stacked mitigation options', are evaluated for total GHG emissions and emissions intensity (kg GHG per kg milksolids) by comparing 'current' and 'improved' dairy systems in these locations. This analysis tests the hypothesis that system changes aimed at reducing nitrate leaching will also reduce total greenhouse gas emissions and emissions intensity (kg GHG per kg milksolids). As part of this study, we determined which of the five key system changes delivered the greatest benefit.

\section{Methodology}

\subsection{Farmlets}

Relatively small-scale farms (farmlets ranging from 13 to 39 ha) were used to evaluate the system changes implemented in each of the three regions studied: the Waikato, Canterbury, and Otago (Table 1). These systems' studies ran from 2011 to 2015 in the Waikato, from 2011 to 2014 in Canterbury and from 2012 to 2015 in Otago.

In all systems, replacement stock were removed from the milking platform at birth and reared on support blocks, returning to the milking platform (pasture areas used for feeding milking cows) as rising 2-year old cows ( 22 months) before calving. In the modelling analysis, the support was included in the inventory calculations to ensure analysis of a complete system. $\mathrm{N}$ fertiliser applications on these blocks were assumed as $100 \mathrm{~kg} / \mathrm{ha} /$ year, based on expert opinion.

Details of the methodology used for estimating GHG emissions from the farmlets in all three regions can be found in the Supplementary File S1.

Table 1. 'Improved' system changes applied to farmlet system trials in Waikato, Canterbury, and Otago, New Zealand.

\begin{tabular}{cccccc}
\hline Region & $\begin{array}{c}\text { Fewer, Higher } \\
\text { Producing, } \\
\text { Cows }\end{array}$ & $\begin{array}{c}\text { Reduced N } \\
\text { Fertiliser } \\
\text { Inputs }\end{array}$ & $\begin{array}{c}\text { Reduced Herd } \\
\text { Replacement } \\
\text { Rate }\end{array}$ & $\begin{array}{c}\text { Greater Use of } \\
\text { High Energy/Low } \\
\text { N Feed }\end{array}$ & $\begin{array}{c}\text { Off-Paddock } \\
\text { Facilities }\end{array}$ \\
\hline Waikato & $\checkmark$ & $\checkmark$ & $\checkmark$ & $\checkmark$ & $\checkmark$ \\
Canterbury & $\checkmark$ & $\checkmark$ & $\checkmark$ & $\checkmark$ & $\checkmark$ \\
Otago & & $\checkmark$ & $\checkmark$ & & $\checkmark$ \\
\hline
\end{tabular}

\subsection{Waikato}

Two farmlets (13 ha each) were established at Scott Farm, Hamilton, New Zealand $\left(37^{\circ} 46^{\prime} \mathrm{S}\right.$, $175^{\circ} 22^{\prime} \mathrm{E}$ ) in June 2011 [7]. One system represented a current Waikato farm system ('current'), while 
the other employed technologies that might be required in improved farm systems ('improved') to reduce nitrate leaching. The 'improved' system was based on the concept of producing the same amount of milk per ha, but with the highest level of efficiency allowed by available technologies.

The stocking and replacement rates were lower for the 'improved' system (Table 2) and dairy cows with higher genetic merit were used (breeding worth of $\$ 170$ vs. $\$ 90$, respectively; Table 2). Reducing the stocking rate (SR) increased the annual feed allowance per cow which, combined with the higher genetic merit of cows in the 'improved' system, led to increased kg MS/cow. All this translated into a reduced need for $\mathrm{N}$ input, as less feed was required (i.e., producing the same with less).

An off-paddock facility was used in the 'improved' system where cows were removed from pasture onto a loafing pad for between 8 and $16 \mathrm{~h}$ daily from March until June (autumn until early winter). The loafing pad, also called a stand-off pad, was a plastic-lined area with wood chip bedding where cows could lie and where some of the dung and urine could be collected into the effluent system. The goal was to reduce $\mathrm{N}$ returns to pasture during a period of low $\mathrm{N}$ utilisation, thereby reducing $\mathrm{N}$ leaching risk during periods of drainage in winter/spring. All solid excreta deposited to the standoff pad was collected and stored until the following spring. A further goal was to protect wet pastures from treading damage.

The 'improved' farmlet cows were offered up to $3 \mathrm{~kg} \mathrm{DM} / \mathrm{cow} /$ day of low-crude protein grain to improve their energy intake when pasture growth or pasture quality was low. This strategy also had the aim of diluting excess crude protein supplied by the pasture. The 'current' system used bought in pasture and maize silage when DM requirements could not be met from its pasture growth.

Liquid effluent from the milking shed, collecting yard, and loafing pad was spread on the farmlets. Dung solids deposited in the milking shed and collecting yard were mechanically separated from the liquid phase for both systems. Emissions from these solids, and from solids captured by the loafing pad in the 'improved' system, were included in the GHG footprint calculations although these solids were exported from the farmlets to be spread in another location.

\subsection{Canterbury}

The Canterbury systems trial $\left(43^{\circ} 38^{\prime} \mathrm{S}, 172^{\circ} 28^{\prime} \mathrm{E}\right)$ examined the effect of two 'improved' farm systems with contrasting stocking rates of 3.5 and 5 cows/ha for 'improved(LOW)' and 'improved(HIGH)', respectively (Table 2; [16]). The farmlet size was 8.25 ha milking platform (MP) plus 2 ha wintering crop (WC) and 6.75 ha MP plus 1 ha WC, respectively.

The 'improved(LOW)' system used dairy cows with higher genetic merit than the 'improved(HIGH)' system (breeding worth of 140 vs. 133, respectively).

A combination of 'standard' ryegrass/white clover pasture and 'diverse' pasture (containing chicory, plantain, ryegrass, and clover) was incorporated into the 'improved(LOW)' system, in contrast to the 'improved(HIGH)' system that solely relied on 'standard' ryegrass/white clover pasture. In the 'improved(LOW)' system, non-lactating cows were wintered on forage kale and oats silage, while the 'improved(HIGH)' system cows were wintered on fodder beet and pasture silage. Cow replacement rates were the same for the two systems.

There was insufficient resourcing to include a 'current' system in Canterbury. However, a suitable farm nearby (Lincoln University Dairy Farm, 'LUDF') represented current Canterbury practices from 2011 to 2013, with a stocking rate of 4 cows/ha and non-lactating cows wintered on fodder beet [28]. Therefore, the LUDF was adopted as a representative 'current' system (Table 2), ensuring the methodology used for estimating the GHG footprint is consistent with the P21 farmlets. 


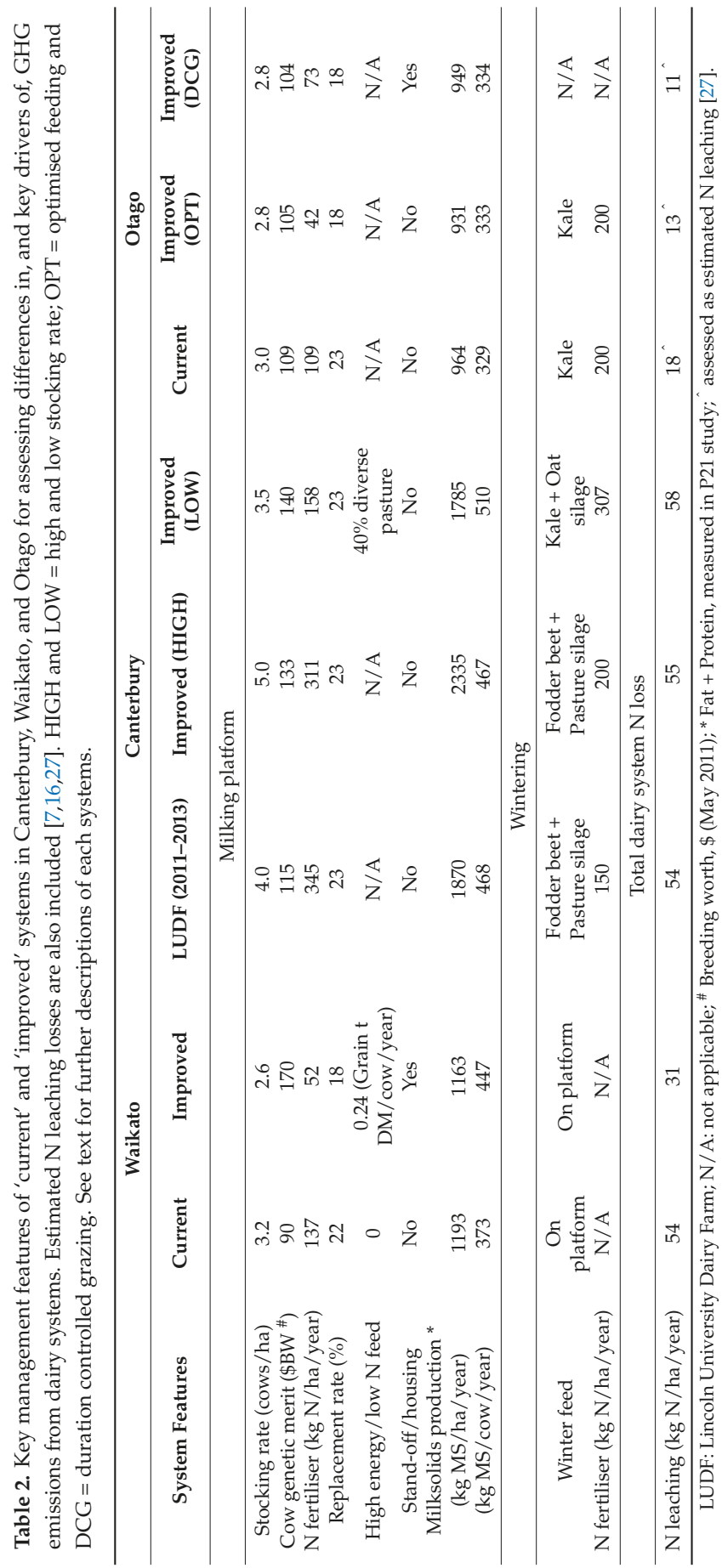




\subsection{Otago}

In Otago $\left(46^{\circ} 17^{\prime} \mathrm{S}, 169^{\circ} 43^{\prime} \mathrm{E}\right)$, three farmlet systems were used, consisting of 110 cows each (Table 2). Firstly, a 'current' system (37 ha milking platform) adopted management practices typical of the region. Secondly, a 'improved optimised' ('improved(OPT)') system (39 ha) focused on improved cow feeding without the need for additional spending on costly farm infrastructure, and thirdly, a 'improved duration-controlled grazing' ('improved(DCG)') system (39 ha) that utilised an off-paddock facility (loose-housed deep litter animal shelter) for housing cows periodically during winter, spring, and autumn [27].

There were several key differences between the 'current' and the two 'improved' systems. Both the 'improved(OPT)' and 'improved(DCG)' systems included a lower replacement rate (18\%) compared with $23 \%$ for the 'current' system, while N fertiliser applications were lower (42-73 kg N/ha/year) on the 'improved' system milking platforms compared with $109 \mathrm{~kg} \mathrm{~N} / \mathrm{ha}$ /year on the 'current' milking platform. In the 'improved(OPT)' system, pasture was supplemented with whole crop cereal silage during lactation. Short rotation (Italian) ryegrass pastures were also incorporated to better align pasture growth rates with cow feed demand.

In addition, optimised grazing management of winter brassica crops along with allocation of more feed per cow during winter months were used to improve body condition score (BCS) relative to the 'current' herd. A key management goal of this farmlet was to ensure that cows calved later, and in better condition, onto higher pasture covers to decrease the reliance on $\mathrm{N}$ fertiliser and supplements and better match pasture growth with cow demand.

In the 'improved(DCG)' system cows were removed from pasture overnight $(12 \mathrm{~h})$ in spring and autumn during the milking season, when critical soil moisture thresholds and grazing times were reached, to protect pastures from damage and, for autumn grazing, reduce urinary nitrogen return to soils prior to winter. Shorter grazing times in spring led to relatively large amounts of pasture requiring conservation as silage on this farmlet; combined with the relatively large amounts of effluent returned to pasture (more details below), $\mathrm{N}$ fertiliser inputs were lower compared with the control farmlet and ranged between 63 and $83 \mathrm{~kg} \mathrm{~N} / \mathrm{ha} /$ year.

During winter, cows were housed full time in a loose-housed deep litter animal shelter with the aim of improving BCS relative to the 'current' herd through improved utilisation of feed energy. The shelter $\left(767 \mathrm{~m}^{2}\right)$ initially contained $300 \mathrm{~m}^{3}$ of woodchip bedding material, with another $150 \mathrm{~m}^{3}$ added midway through the winter period. Adjacent to the shelter was a feeding apron. Non-lactating cows were housed in the animal shelter fulltime during the winter months (June until mid-August; see Table S2) until calving commenced.

Details of the manure management from the shelter use can be found in the Supplemental File. Briefly, liquid from excreta deposited in the animal shelter was collected in an effluent pond, whereas solid manure was removed from the shelter and stored prior to spreading onto the milking platform paddocks. Manure deposited onto the adjacent feeding apron was scraped and stored behind a weeping wall, with the liquid fraction contained in an effluent pond. Data collected by [29] were used for estimating the greenhouse gas emissions from the manure management.

\subsection{Greenhouse Gas Emissions}

Annual GHG emissions for each system were estimated for three (Canterbury and Otago) or four (Waikato) years, using calculations based on the New Zealand Agricultural Inventory methodology (NZAI; [1]). In brief, this methodology uses estimates of dry matter intake (DMI), N inputs, and $\mathrm{N}$ leaching losses, in combination with $\mathrm{CH}_{4}$ and $\mathrm{N}_{2} \mathrm{O}$ emission factors (EF). In this study a combination of NZAI emission factor values and $\mathrm{CH}_{4}$ and $\mathrm{N}_{2} \mathrm{O}$ emissions factors were used that were measured for key components of the milking platform or the wintering period for each system [30-32]. We used these targeted measurements to provide us with emission factor results for key components in the farmlets that we otherwise would not able to assess as the NZAI emission factors are not sufficiently disaggregated. For example, NZAI uses the same methane emission factor for all feeds and therefore 
cannot distinguish between different feed types. As some of the key changes in our 'improved' systems were related to different feed types, we used our targeted measurements to get more specific $\mathrm{CH}_{4}$ (and $\mathrm{N}_{2} \mathrm{O}$ ) emission factors for these feed types. Similarly, as NZAI uses only one manure management system (anaerobic lagoons), we conducted targeted measurements of key components of the manure management system for the South Otago farmlet that used an off-paddock facility to ensure we could capture any difference in emissions as a result of the off-paddock facility.

The GHG footprint boundary was limited to $\mathrm{CH}_{4}$ and $\mathrm{N}_{2} \mathrm{O}$ emissions, and excluded carbon dioxide $\left(\mathrm{CO}_{2}\right)$ emissions from fertiliser manufacturing and use, fuel use, electricity use, and infrastructure construction. This ensured the footprint aligned with the boundaries of the NZAI. The footprint included both on-farm and off-farm sources of $\mathrm{CH}_{4}$ and $\mathrm{N}_{2} \mathrm{O}$ emissions. On-farm sources included enteric $\mathrm{CH}_{4}$ from the milking platform and wintering paddocks, $\mathrm{N}_{2} \mathrm{O}$ from soils receiving $\mathrm{N}$ inputs and $\mathrm{CH}_{4}$ and $\mathrm{N}_{2} \mathrm{O}$ emissions derived from manure management. Off-farm sources included $\mathrm{N}$ fertiliser use for producing pasture for replacement stock, N-excreta deposited by replacement stock, enteric $\mathrm{CH}_{4}$ from replacement stock and $\mathrm{N}$ fertiliser used for growing crops and supplements.

In addition to farm-scale GHG footprints, key sources of emissions were separated to determine the impact of off-paddock facilities on GHG emissions by combining the sources of emissions that are influenced by the presence or absence of such a facility. These sources included (i) direct and indirect $\mathrm{N}_{2} \mathrm{O}$ emissions associated with excreta deposition onto paddocks, because removing cows from paddocks onto off-paddock facilities would directly influence the amount of excreta deposited onto paddocks, (ii) and $\mathrm{N}_{2} \mathrm{O}$ and $\mathrm{CH}_{4}$ emissions associated with manure collected, stored, and subsequently applied to land (i.e., manure management). Both off-paddock facilities included in this study were assessed, the loafing pad in Waikato and animal shelter in Otago.

All $\mathrm{CH}_{4}$ and $\mathrm{N}_{2} \mathrm{O}$ emissions were converted to $\mathrm{CO}_{2}$-equivalent emissions using the 100-year time horizon global warming potentials of $25 \mathrm{~kg} \mathrm{CO}_{2}$-equivalent per $\mathrm{kg} \mathrm{CH}_{4}$ and $298 \mathrm{~kg} \mathrm{CO}_{2}$-equivalent per $\mathrm{kg} \mathrm{N}_{2} \mathrm{O}$ [33]. Greenhouse gas footprints for each system were calculated on an area basis ( $\mathrm{kg} \mathrm{CO}$-equivalent per milking platform hectare; $\mathrm{kg} \mathrm{CO}_{2} \mathrm{e} / \mathrm{ha}$; Table 3) and intensity basis ( $\mathrm{kg} \mathrm{CO}$-equivalent per $\mathrm{kg}$ milksolids produced; $\mathrm{kg} \mathrm{CO}_{2} \mathrm{e} / \mathrm{kg} \mathrm{MS}$; Table 4). 


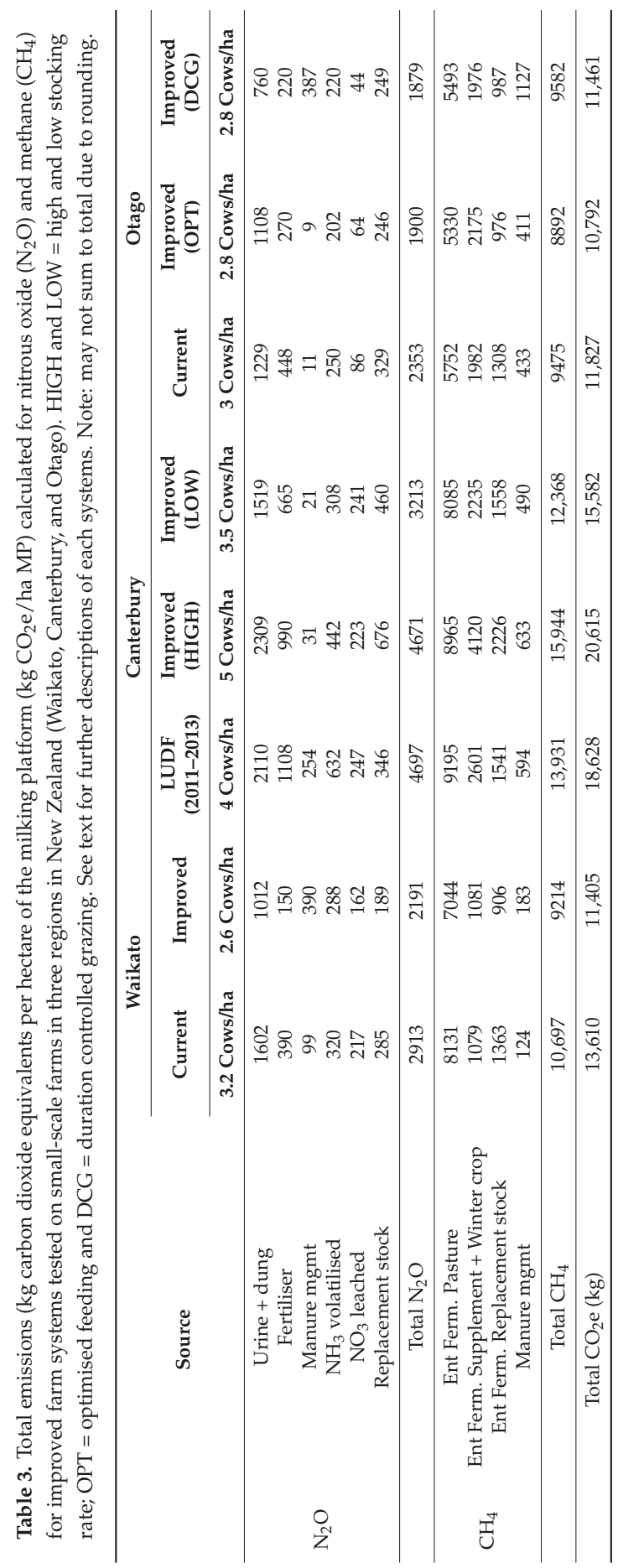




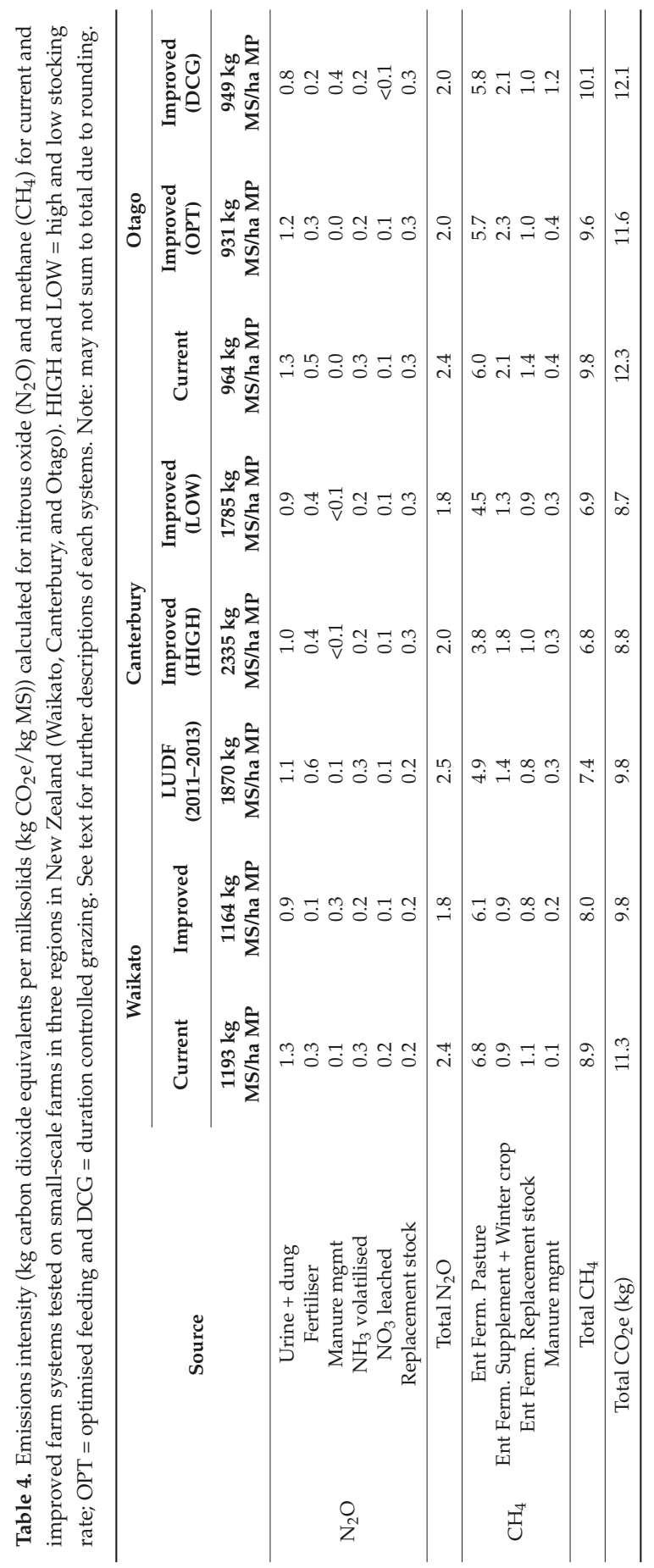




\section{Results and Discussion}

\section{1. $\mathrm{CH}_{4}$ Emissions}

\subsection{1. $\mathrm{CH}_{4}$ Emissions per Area $\left(\mathrm{kg} \mathrm{CO}_{2} \mathrm{e} / \mathrm{ha}\right)$}

Methane represented between $75 \%$ and $84 \%$ of the total GHG footprint across all farmlet systems, with emissions ranging from $8892 \mathrm{~kg} \mathrm{CO} 2 \mathrm{e} / \mathrm{ha}$ ('improved(OPT)', Otago) to 15,944 $\mathrm{kg} \mathrm{CO} 2 \mathrm{e} / \mathrm{ha}$ ('improved(HIGH)', Canterbury) (Table 3). This broad range reflects contrasting feed supplies (sum of pasture production and supplements brought onto the farm) available to support stocking rate (SR) across systems ranging from 2.6 cows / ha in the Waikato 'improved' system to a substantially greater SR of 5.0 cows / ha in the 'improved(HIGH)' system in Canterbury (Table 2).

The majority of the emissions were from enteric fermentation by cows grazing pasture during lactation. Greater use of pasture as a feed source in Waikato compared against Canterbury and Otago explains the greater contribution of pasture-derived $\mathrm{CH}_{4}$ via enteric fermentation, representing $60-62 \%$ of the total GHG emissions (Table 3). Enteric $\mathrm{CH}_{4}$ from supplements was responsible for $8-10 \%$ of the total footprint in Waikato. In contrast, pasture-derived $\mathrm{CH}_{4}$ emissions for Canterbury and Otago represented $44 \%$ to $52 \%$ of the total GHG emissions per hectare while $\mathrm{CH}_{4}$ from supplements and winter forage crops collectively contributed $14-20 \%$ of the total GHG footprint (Table 3).

In the Waikato, the 'improved' system produced $14 \%$ lower $\mathrm{CH}_{4}$ emissions per hectare compared with the 'current' system, while in Canterbury the 'improved(LOW)' system produced 22\% lower $\mathrm{CH}_{4}$ emissions per hectare compared with the 'improved(HIGH)' system. These reductions were primarily driven by stocking rate, although the lower replacement rate in the 'improved' system in Waikato and lower $\mathrm{CH}_{4}$ from supplement and crop intake in the 'improved(LOW)' system in Canterbury also contributed to this reduction. In Otago, total $\mathrm{CH}_{4}$ emissions from the 'improved(OPT)' system were $6 \%$ lower than $\mathrm{CH}_{4}$ emissions from the 'current' system, primarily due to lower emissions via enteric fermentation during lactation. In contrast, the 'improved(DCG)' system emitted a similar amount of $\mathrm{CH}_{4}$ as the 'current' system, with reduced enteric fermentation on the milking platform and the lower emissions from replacement stock (via lower replacement rate) being balanced by a tripling of estimated $\mathrm{CH}_{4}$ emissions from manure storage and handling (Table 3).

\subsection{2. $\mathrm{CH}_{4}$ Emissions Intensity ( $\mathrm{kg} \mathrm{CO} 2 \mathrm{e} / \mathrm{kg}$ MilkSolids)}

Milk production per unit area was relatively unaffected by farm system in the Waikato and Otago, whereas in Canterbury there was a substantial difference in $\mathrm{kg}$ MS/ha, with $1785 \mathrm{~kg}$ and $2335 \mathrm{~kg}$ and MS/ha being measured for the 'improved(LOW)' and 'improved(HIGH)' systems, respectively (Table 2).

When emissions were expressed on an intensity basis, the data showed $\mathrm{CH}_{4}$ emissions from the Waikato 'improved' system were $10 \%$ lower than from the 'current' system $\left(8.0 \mathrm{~kg} \mathrm{vs} .8 .9 \mathrm{~kg} \mathrm{CO} \mathrm{CO}_{2} \mathrm{e} / \mathrm{kg}\right.$ MS, respectively; Table 4). This was due to the reduced feed requirements per unit of area, and thus enteric $\mathrm{CH}_{4}$ emission, enabled by the planned increase in production efficiency (less, more efficient, cows). In Canterbury, milk production in the 'improved(LOW)' system was $24 \%$ lower, similar to the reduction in $\mathrm{CH}_{4}$ emissions. As a result, $\mathrm{CH}_{4}$ emission intensities were similar for the two systems (6.9 vs. $6.8 \mathrm{~kg} \mathrm{CO} 2 \mathrm{e} / \mathrm{kg}$ MS for the 'improved(LOW)' and 'improved(HIGH)' systems, respectively; Table 4). In Otago, $\mathrm{CH}_{4}$ emissions intensity was similar for all three systems, with the 'current', 'improved(DCG)' and 'improved(OPT)' systems producing $9.8 \mathrm{~kg}, 10.1 \mathrm{~kg}$, and $9.6 \mathrm{~kg} \mathrm{CO} \mathrm{CO}_{2} / \mathrm{kg} \mathrm{MS}$, respectively (Table 4$)$. 


\section{2. $\mathrm{N}_{2} \mathrm{O}$ Emissions}

\subsection{1. $\mathrm{N}_{2} \mathrm{O}$ Emissions per Area ( $\left.\mathrm{kg} \mathrm{CO}_{2} \mathrm{e} / \mathrm{ha}\right)$}

Nitrous oxide represented between 16 and $25 \%$ of the total GHG footprint across all farmlet systems, with emissions ranging from $1879 \mathrm{~kg} \mathrm{CO}_{2} \mathrm{e} / \mathrm{ha}$ ('improved(DCG)', Otago) to $4671 \mathrm{~kg} \mathrm{CO}_{2} \mathrm{e} / \mathrm{ha}$ ('improved(HIGH)', Canterbury), reflecting the SR, which ranged from 2.8 cows/ha (OPT and DCG, Otago) to 5.0 ('improved(HIGH)', Canterbury) (Table 3).

Excreta deposition onto paddocks was the largest source of $\mathrm{N}_{2} \mathrm{O}$ emissions, representing $9-12 \%$ of the total GHG footprint for all systems apart from 'improved(DCG)' in Otago, where this source represented only $7 \%$ of the total footprint. This latter system included removal of cows from paddocks when soils were wet, resulting in less excreta deposited onto soil. Nitrogen fertiliser use and emissions associated with replacement stock were the next most important sources of $\mathrm{N}_{2} \mathrm{O}$ emissions, where fertiliser represented between $1 \%$ and $4 \%$ of the total GHG footprint, while replacement stock represented $2 \%$ and $4 \%$ of the total GHG footprint.

\subsection{2. $\mathrm{N}_{2} \mathrm{O}$ Emissions Intensity ( $\mathrm{kg} \mathrm{CO}_{2} \mathrm{e} / \mathrm{kg}$ MilkSolids)}

In the Waikato, $\mathrm{N}_{2} \mathrm{O}$ emission intensity represented $1.8 \mathrm{~kg} \mathrm{CO}_{2} \mathrm{e} / \mathrm{kg}$ MS for the 'improved' system, which was $25 \%$ lower than the $2.4 \mathrm{~kg} \mathrm{CO}_{2} \mathrm{e} / \mathrm{kg}$ MS calculated for the 'current' system. The main driver of the reduction was less $\mathrm{N}$ entering the farm system in the form of $\mathrm{N}$ fertiliser and supplements. The reduction in pasture growth resulted in less pasture eaten for the farm system, thus reducing the excreta return (Table 4). Higher annual pasture allowance per cow, higher BW cows and longer lactations meant more milk was produced per cow in the 'improved' system. When combined, these factors resulted in lower emissions intensity i.e., $\mathrm{kg} \mathrm{CO}_{2} \mathrm{e} / \mathrm{kg}$ milksolids in the 'improved' system than for the 'current' system (Table 4).

In Otago, a 19\% reduction in $\mathrm{N}_{2} \mathrm{O}$ emission intensity calculated for the 'improved(DCG)' system (from 2.4 to $2.0 \mathrm{~kg} \mathrm{CO} \mathrm{CO}_{2} \mathrm{e} / \mathrm{kg} \mathrm{MS}$ ) was primarily driven by lower $\mathrm{N}$ fertiliser use, which reduced GHG intensity by $0.3 \mathrm{~kg} \mathrm{CO}_{2} \mathrm{e} / \mathrm{kg}$ MS. A further factor was the reduction in excreta deposition onto paddocks, achieved by removing cows for $12 \mathrm{~h}$ per day when soils were wet (autumn and spring) and full time in winter when cows were not lactating (Table S2). This management strategy accounted for a reduction of $0.5 \mathrm{~kg} \mathrm{CO}_{2} \mathrm{e} / \mathrm{kg}$ MS, which was slightly more than the increase in $\mathrm{N}_{2} \mathrm{O}$ emissions associated with additional manure management $\left(+0.4 \mathrm{~kg} \mathrm{CO}_{2} \mathrm{e} / \mathrm{kg} \mathrm{MS}\right)$. In Canterbury, emission intensity for the two 'improved' systems were similar, at $1.8-2.0 \mathrm{~kg} \mathrm{CO}_{2} \mathrm{e} / \mathrm{kg}$ MS.

\subsection{Total GHG Footprint}

\subsubsection{GHG Emissions per Area ( $\left.\mathrm{kg} \mathrm{CO}_{2} \mathrm{e} / \mathrm{ha}\right)$}

Total GHG footprints range between 10,792 $\mathrm{kg}$ and $13,610 \mathrm{~kg} \mathrm{CO} 2 \mathrm{e} / \mathrm{ha}$ for the Waikato and Otago, with 'improved' systems producing a lower GHG footprint. This was particularly evident in the Waikato, where the reduction was $16 \%$, while the reductions in footprint in the Otago farmlets were smaller, at $3 \%$ and $9 \%$ for the 'improved(DCG)' and 'improved(OPT)' systems, respectively. The emissions from the Canterbury systems were greater compared with other the regions, at 15,582 and 20,615 $\mathrm{kg} \mathrm{CO}_{2} \mathrm{e} / \mathrm{h}$ a for the 'improved(LOW)' and improved(HIGH)' systems, respectively (Table 3). Total GHG emissions from the Canterbury 'current' system, which was based on data collated from the nearby Lincoln University Dairy Farm (SR of 4 cows/ha), were $18,628 \mathrm{~kg} \mathrm{CO}_{2} \mathrm{e} / \mathrm{ha}$. The emissions from the 'improved' systems were either 11\% higher (improved(HIGH)) or 16\% lower (improved(LOW)) than from this 'current' system. Combining regions, total GHG emissions/ha were strongly related to the amount of feed eaten/ha (Figure 1). 


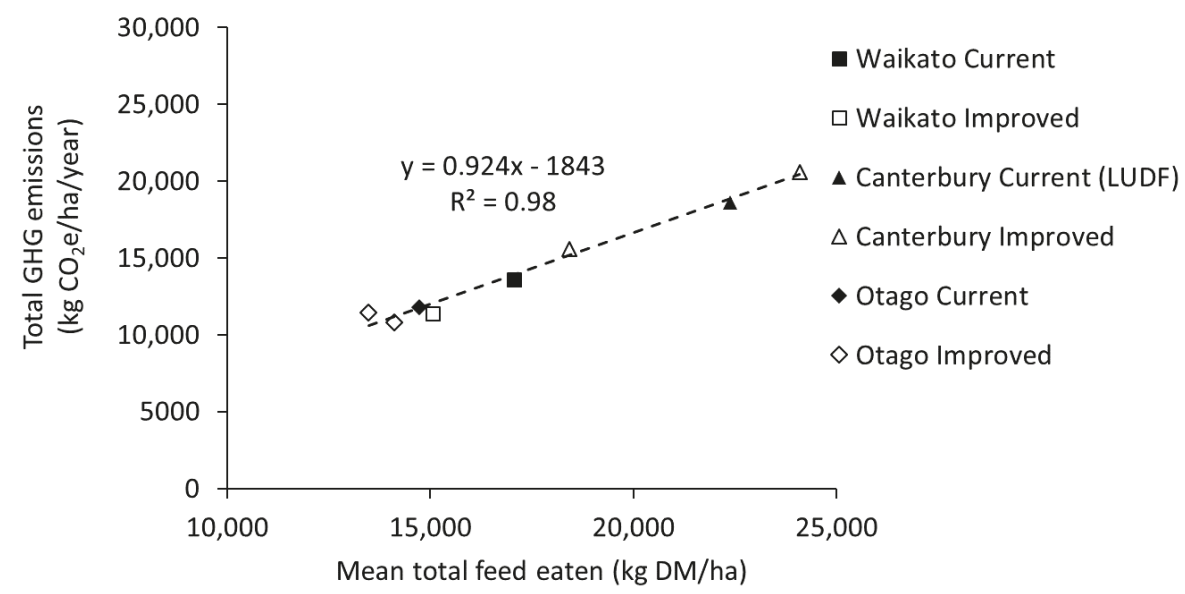

Figure 1. Relationship between mean total feed eaten (kg DM/ha) and total GHG emissions for 'current' and 'improved' systems trialled in three regions of New Zealand. Also included is the Canterbury 'current' system based on an updated analysis of the Lincoln University Dairy Farm (LUDF) system (P. Beukes, pers. comm.).

The Canterbury systems had the largest contrast in feed eaten (18,400 vs. $24,100 \mathrm{~kg} \mathrm{DM} / \mathrm{ha})$, resulting in the largest difference in GHG emissions per hectare (15,582 vs. 20,615 $\mathrm{kg} \mathrm{CO}_{2} \mathrm{e} / \mathrm{ha}$; Table 3). Emissions from the LUDF 'current' system [28], were similar to the 'improved(HIGH)' system, at 18,628 $\mathrm{kg} \mathrm{CO}_{2} \mathrm{e} / \mathrm{ha}$. However, this 'current' system produced $1870 \mathrm{~kg} \mathrm{MS} / \mathrm{ha}$, which was substantially less than the milk production of the 'improved(HIGH)' system (2335 kg MS/ha; Table 2). Inclusion of off-paddock facilities in the Waikato and Otago 'improved' systems resulted in a decrease in excreta deposited onto paddocks and an increase in the amount of manure that required active management (see Table S4). To assess the impact of off-paddock facilities on GHG emissions, direct and indirect $\mathrm{N}_{2} \mathrm{O}$ emissions associated with excreta deposition onto paddocks and $\mathrm{N}_{2} \mathrm{O}$ and $\mathrm{CH}_{4}$ emissions associated with manure management were collated. Attempting to present these emissions on a per area basis can be difficult to interpret, given these facilities are farm structures; therefore, emissions have been calculated and presented as $\mathrm{kg} \mathrm{CO}_{2} \mathrm{e} / \mathrm{cow} /$ year. Our analysis showed that using an off-paddock facility results in a decrease in emissions per cow from excreta deposited onto paddocks, but this was more than offset by an increase in emissions per cow from manure management, resulting in a net increase in GHG emissions (Figure 2). The degree of the increase in emissions was dependent on the extent of the facility's use. For instance, the loafing pad in Waikato increased manure/excreta-related GHG emissions by $10 \%$ while the off-paddock facility in Otago led to a $35 \%$ increase in associated emissions per cow (Figure 2).

In order to assess the potential impact of adopting 'site-specific' rather than 'NZ-default' EF values on the calculated GHG emissions, we compared our results to those calculated when adopting the EF values from the NZ inventory methodology (results not shown). Adopting the NZ-default EF values had very limited impact on the relative difference in emissions between 'current' and 'improved' systems. For Waikato, the reduction in emissions remained at 16\%. For Canterbury, the increase in GHG emissions from 'current to 'improved(HIGH)' changed from 7\% (site-specific EFs) to 8\% (NZ-default EFs). The decrease in GHG emissions from 'current' to 'improved(LOW)' changed from $18 \%$ to $19 \%$. In Otago, using the NZ-default EF values did not impact on the relative difference between the 'current' and 'improved(OPT)', but it did slightly affect the result for 'improved(DCG)'. When using the site-specific EF values that were based on experimental results, a $3 \%$ reduction in total GHG emissions was calculated. However, adopting the inventory approach resulted in a $1 \%$ 
reduction in GHG emissions between these two systems. This is most likely due to the fact that the NZ inventory methodology only includes the manure management system 'anaerobic lagoons', as this system is applicable to the vast majority of NZ dairy systems. However, given that the manure management system of the 'improved(DCG)' system is very different to the 'anaerobic lagoon' system, we believe the calculations based on the site-specific EF values are more accurate and realistic. Our study, therefore, represents the GHG footprint of dairy systems adopting 'current' and 'improved' management practices, estimated using the NZ inventory approach combined with site specific EF values where appropriate.

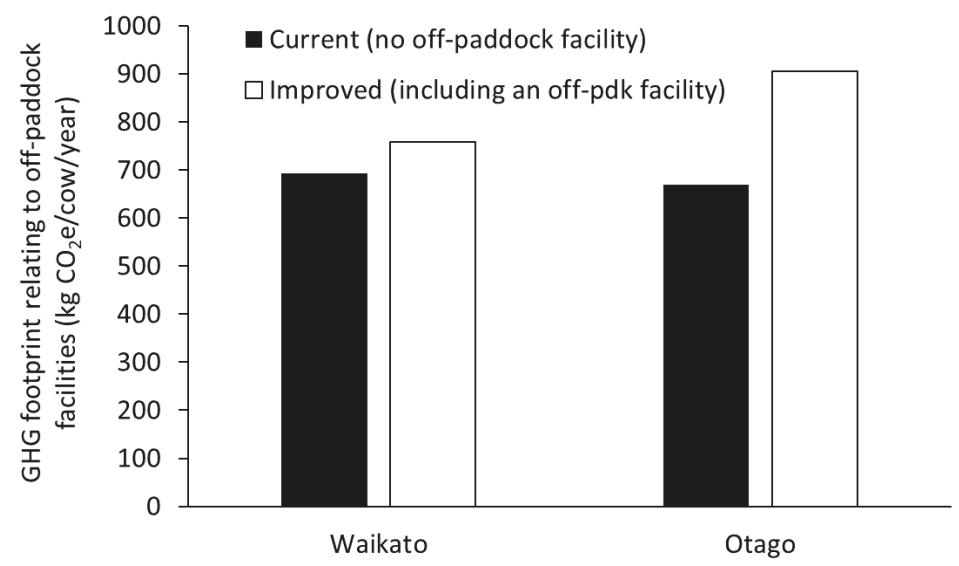

Figure 2. Effect of off-paddock facilities on net greenhouse gas emissions $\left(\mathrm{kg} \mathrm{CO}_{2} \mathrm{e} / \mathrm{cow} /\right.$ year$)$ associated with $\mathrm{N}_{2} \mathrm{O}$ from excreta deposition onto paddocks, and $\mathrm{N}_{2} \mathrm{O}$ and $\mathrm{CH}_{4}$ emissions from manure management.

\subsubsection{GHG Emissions Intensity ( $\mathrm{kg} \mathrm{CO}_{2} \mathrm{e} / \mathrm{kg}$ MilkSolids)}

When total emissions were represented on an intensity basis, emissions ranged from $8.7 \mathrm{~kg}$ to $12.3 \mathrm{~kg} \mathrm{CO} 2 \mathrm{e} / \mathrm{kg}$ MS. The 'improved' systems in all three regions produced lower GHG emission intensities, with reductions of 13\%,11-12\%, and 6\% being calculated for 'improved' systems in Waikato, Canterbury, and Otago (OPT), when compared with the corresponding 'current' systems (Table 4). In most cases, the lower GHG intensities were largely a result of management practices such as reduced $\mathrm{N}$ fertiliser use and lower replacement rates lowering GHG emissions from the 'improved' system, because the difference in MS production between 'improved' and 'current' systems was small (Figure 3). For the 'improved(HIGH)' system in Canterbury, lower GHG intensities were largely a result of higher MS production, rather than reduced inputs. The 'improved(DGC)' system in Otago, based around standing cows off wet paddocks, and wintering cows in an animal shelter, produced a small reduction $(2 \%)$ in the GHG emissions intensity due to increased emissions from manure management, as shown above. Across all regions, total GHG emissions/ha were strongly related to amount of milk produced/ha (Figure 3). Analysis of the data, determined by comparing a single regression model with a combined model that included system type as a treatment, showed there was no significant difference in the 'current' vs. 'improved' systems $(p>0.05)$. The lack of significance was possibly due to the relatively small dataset, as the results showed lower GHG emissions for the same MS production from the 'improved' systems compared to the 'current' systems.

We compared our GHG emission intensity results with Gerber et al. [34], which presents $\mathrm{N}_{2} \mathrm{O}$ and $\mathrm{CH}_{4}$ emissions intensities from dairy cattle systems in 155 countries. For the comparison, we converted our results from $\mathrm{kg}$ MS to $\mathrm{kg}$ of fat and protein corrected milk (FPCM; [34]). The NZ dairy cattle systems modelled in our study produced between 4200 and $6700 \mathrm{~kg}$ FPCM per year, with $\mathrm{CH}_{4}$ emissions of 
between 0.6 and $0.8 \mathrm{~kg} \mathrm{CO}$ e per $\mathrm{kg}$ FPCM and $\mathrm{N}_{2} \mathrm{O}$ emissions of between 0.1 and $0.2 \mathrm{~kg} \mathrm{CO}$ e per $\mathrm{kg}$ FPCM. Our results therefore compared well with those presented by Gerber et al. [34] for moderate to high intensity production systems.

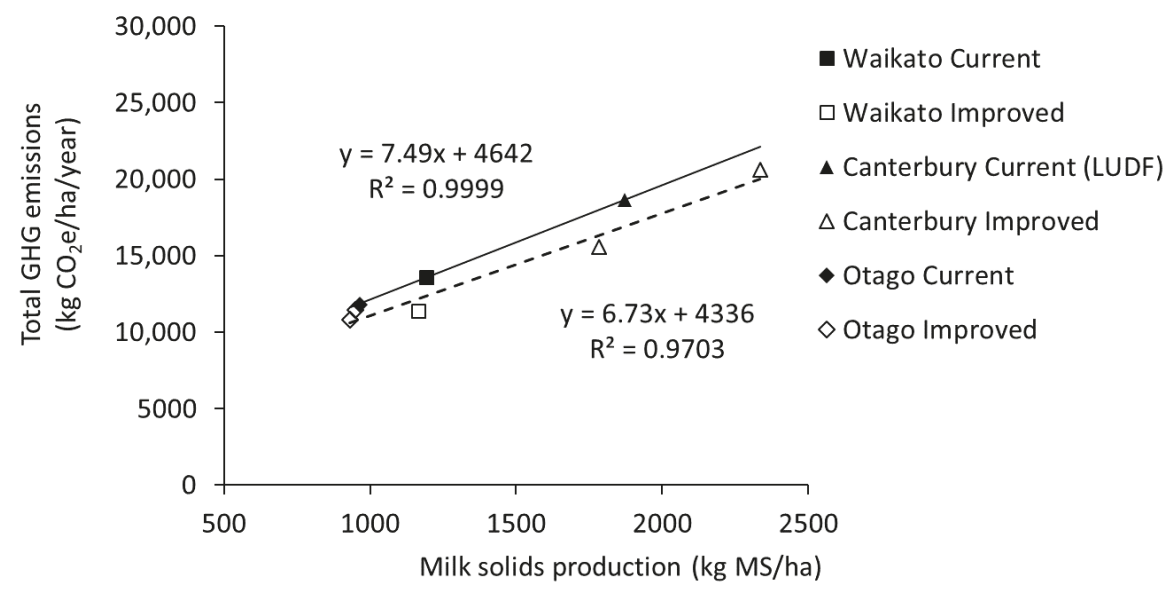

Figure 3. Relationship between milk production (kg MS/ha) and total GHG emissions for 'current' and 'improved' systems trialled in three regions of New Zealand. Also included is the Canterbury 'current' system based on an updated analysis of the Lincoln University Dairy Farm (LUDF) system (P. Beukes pers. comm.). There was no significant difference in the regression models.

\subsection{General Discussion}

Lower total GHG emissions, albeit not significant, were demonstrated in the 'improved' systems. Farm system trials are conducted at relatively large scales, making it challenging to replicate system treatments. Consequently, we have not been able to demonstrate 'significantly' lower GHG emissions from the 'improved' systems. However, our results do suggest that system changes aimed at reducing nitrate leaching can also reduce total greenhouse gas emissions and emissions intensity. The amount of feed eaten per ha was the key driver of total GHG emissions per area (Figure 1). Pasture-based dairy farming systems in the temperate environment of New Zealand have evolved to match seasonal pasture supply to the feed demand. The profitability and productivity of these systems is driven by stocking rate (cows/ha) which enables very high pasture utilisation and reasonable production per cow $[35,36]$. Both targeted nitrogen fertiliser application and supplement use contribute to feed supply (per hectare) and enable flexibility in stocking rate and profitability for many farming businesses. The amount of feed eaten per ha has an overriding effect on GHG emissions per ha because enteric $\mathrm{CH}_{4}$ from lactating cows is the major contributor to GHG emissions, as is the case with other pasture-based dairy systems $[8,37]$. Lower stocking rates are necessary when lower $\mathrm{N}$ inputs result in lower feed supply per ha (a function of $\mathrm{N}$ inputs including direct $\mathrm{N}$ fertiliser use for on-farm pasture production and off-farm supplement production). It has been shown that lower $\mathrm{N}$ inputs reduce farm-gate $\mathrm{N}$ surplus and thus the potential risk of $\mathrm{N}$ losses to the environment e.g., [7,38]. Others have also observed this relationship through measurements [39,40] and modelling [41]. Limiting the amount of $\mathrm{N}$ brought into a farm system as $\mathrm{N}$ fertiliser and supplements will reduce $\mathrm{N}$ intake and excretion by the herd, depositing less urinary $\mathrm{N}$ onto paddocks, and ultimately reducing $\mathrm{N}_{2} \mathrm{O}$ emissions. When combined with having cows with greater genetic merit (in the Waikato study), an increased feed conversion efficiency meant less feed was required for the herd for maintenance and more feed converted into product, resulting in lower feed requirements but similar milk production per hectare. Previous modelling $[3,42,43]$ showed that the combination of reduced stocking rates and high genetic merit 
cows consistently reduced total GHG emissions and emissions intensity, but with inconsistent impacts on milk production. The Waikato 'improved' system presents an example of a future vision, with minimal sacrifice of production per hectare $(2 \%)$ whilst demonstrating reductions in GHG emissions (by $16 \%$ and $13 \%$ when expressed on an area or emissions intensity basis, respectively) and $\mathrm{N}$ leaching (by 40-50\%; [7]). As for the Waikato, the Canterbury and Otago 'improved' systems also required less fertiliser $\mathrm{N}$ input, which lowered $\mathrm{N}_{2} \mathrm{O}$ emissions. The 'improved (OPT)' system in Otago also produced a lower GHG emission intensity (6\% reduction), however there was also a small decrease in MS production (3\% reduction). Estimated $\mathrm{N}$ leaching for this system was reduced by 23\% [27], providing another example of how GHG emission and N loss reductions could be achieved, albeit not as substantially as found for the Waikato study.

Others have also demonstrated reduced on-farm GHG emissions with less $\mathrm{N}$ fertiliser use (e.g., [44]). A combination of reduced $\mathrm{N}$ fertiliser use and lower stocking rates has been shown to have the largest impact on GHG emissions [45,46]. Using a Life Cycle Assessment method, Basset-Mens et al. [47] assessed the eco-efficiency of three contrasting New Zealand dairy systems. These researchers concluded that GHG emissions per area and per unit product (i.e., intensity-based) was lowest with the least intensive system, where no $\mathrm{N}$ fertiliser was used and cow stocking rate was 2.3 per ha compared with more intensive systems supporting 3.0 and 5.2 cows per ha. Potential eutrophication of waterways was projected to follow a similar pattern, with the least intensive system having the smallest potential for impact on waterways [47].

Manure management impacted heavily on the GHG footprint associated with the 'improved(DCG)' system, resulting in a footprint similar to that of the Otago 'current' system (Table 4). This negated any benefits achieved from removing cows off wet paddocks.

Previous work by Garnsworthy [48] predicted that improving fertility levels and breeding management in dairy cows, and therefore reducing the number of heifer replacements required, could reduce methane emissions at a herd level by $10 \%$ to $11 \%$. In a modelling study by Beukes et al. [3], they estimated the contribution of the reduced replacement rate strategy to GHG reductions to be in the order of $5 \%$. In the two regions of this study where replacement rates decreased from 'current' to 'improved' (Waikato from $22 \%$ to $18 \%$, and Otago from $23 \%$ to $18 \%$ ), we estimated a reduction of $3 \%$ to $4 \%$ in total GHG emissions from the 'current' system. The farmlet trials in the Waikato and Otago demonstrated the merit of lower herd replacement rates from the current New Zealand average of $22-23 \%$ [2] to c. $18 \%$ as an option for making modest reductions in total GHG emissions.

One of the Canterbury systems included a contrast of feed types, with the 'current' and 'improved(HIGH)' systems relying on standard ryegrass/white clover pasture swards on the milking platform while non-lactating cows were wintered on fodder beet and pasture silage. In contrast, $40 \%$ of the milking platform in the 'improved(LOW)' system consisted of diverse pasture containing chicory, plantain, ryegrass, and clover, with non-lactating cows wintered on forage kale and oat silage. Although the diverse pasture was modelled to produce lower $\mathrm{N}_{2} \mathrm{O} \mathrm{EF}_{3}$ values for deposited urine [30], the emission intensities associated with total $\mathrm{N}_{2} \mathrm{O}$ loss from dung and urine did not differ between the two systems (Table 4). This was partly due to the 'improved(LOW)' system including kale in the winter period, which had a higher $\mathrm{EF}_{3}$ value than the fodder beet crop grazed in the 'current' and 'improved(HIGH)' systems.

Given the potential benefits of fodder beet over kale, for both $\mathrm{CH}_{4}$ and $\mathrm{N}_{2} \mathrm{O}$ emissions, and the similar amounts of silage consumed (see Supplement A), substituting kale for fodder beet in the 'improved' system, may result in even lower total GHG emissions for the 'improved' system. A similar suggestion was presented by Chapman et al. [16] for $\mathrm{N}$ leaching. These authors concluded that if the Canterbury 'improved(LOW)' system incorporated a fodder beet winter crop (rather than kale), $\mathrm{N}$ leaching could be reduced by $25-28 \%$.

The Otago farmlet systems included the use of palm kernel expeller (PKE) in year 3 (Table S1; Supplement A). When averaged over the three years of the study, the use of PKE represented $1.9 \%$, $0.5 \%$, and $1.7 \%$ of the dry matter intake for the CON, OPT, and DCG systems, respectively. There 
have been recent concerns linking consequences of indigenous deforestation with palm oil production, which has placed pressure on restricting the use of PKE on NZ dairy farms [49]. Deforestation results in additional GHG emissions through land use change, among other impacts. While our study has focused solely on biological emissions (i.e., $\mathrm{N}_{2} \mathrm{O}$ and $\mathrm{CH}_{4}$ only) from dairy production, we have estimated the increase in total GHG emissions for the Otago systems when the carbon (C) footprint associated with the use of PKE is included. A recent study suggests a C footprint of 0.506 $\mathrm{kg} \mathrm{CO}$-equivalents per $\mathrm{kg}$ PKE DM used on NZ dairy farms [50]-this value includes emissions due to land use change. Based on this value, the additional $C$ footprint from the use of PKE in the CON, OPT, and DCG systems in Otago averaged over three years was estimated to be 49, 12, and $43 \mathrm{~kg} \mathrm{CO} 2 \mathrm{e} /$ ha/year, respectively. Compared to the biological emission-based footprint (Table 3), the inclusion of the LCA-based C footprint associated with PKE use represents an additional $0.4 \%$, $0.1 \%$, and $0.4 \%$, respectively. This additional footprint does not change the emission intensity values shown in Table 4, as the increase was less than $<0.1 \mathrm{~kg} \mathrm{CO}_{2} \mathrm{e} / \mathrm{kg}$ MS.

The New Zealand dairy industry aims to identify dairy systems that can maintain or increase production while reducing impacts on receiving environments including water and air [9]. As such, the 'improved' systems designed in this study included a package of measures that incorporated the best available knowledge to reduce impacts on water whilst maintaining or increasing productivity $[7,16,27]$. Improved systems will be more attractive to farmers if they deliver additional benefits such as reduced impact on water quality, or if a reduction in milk production is not associated with a reduction in profitability. Across the three regions, the implementation of stacked mitigation options aimed at reducing $\mathrm{N}$ leaching may have changed the relationship between MS and GHG emissions per hectare. While the analysis across regions showed no significant difference in the regression models describing milk production and GHG emissions for 'current' and 'improved' systems, probably due to the relatively small dataset, it does suggest a reduction in emissions intensity may be possible.

Our modelling suggests, for the systems examined here, total GHG emissions could be reduced by between $4 \%$ and $16 \%$. Given the New Zealand dairy industry plan to contribute to meeting this nation's 2030 emissions reduction target of 30\% below 2005 levels [51], our modelled reductions are relatively modest. These reductions are based on currently available management options and research into additional agricultural mitigation options is continuing to be an important focus for New Zealand [48]. This includes research into developing low-methane animals, methane vaccines and inhibitors, low GHG feeds, and novel nitrification inhibitors [52-54]. Increasingly 'improved' dairy systems modelled here, and future strategies identified through the current research efforts, will be essential options for farmers to meet social and regulatory requirements in New Zealand. Profitability and cost effectiveness of the 'improved' systems modelled here are yet to be explored.

\section{Conclusions}

Our analysis indicates that system changes aimed at reducing nitrate leaching can also reduce total greenhouse gas emissions and emissions intensity. The reduced feed supplies and associated lower stocking rates of the 'improved' farmlet systems evaluated here were the key drivers of lower total GHG emissions in all three regions. The main effects of these improved farmlet attributes were smaller total enteric methane emissions and less $\mathrm{N}$ flowing through the herd, which lowered $\mathrm{N}$ excretion and, therefore, direct and indirect $\mathrm{N}_{2} \mathrm{O}$ losses. A system with fewer cows with greater genetic merit contributed to greater milk production per cow per lactation, less $\mathrm{N}$ leaching, and lower GHG emission intensities. Smaller but important contributions to lowering emissions were made by dietary changes, e.g., introducing low-protein grain supplements, cereal silages, fodder beet winter feed, herb-containing ryegrass pastures, and by lowering herd replacement rates. Off-paddock facilities contributed to protecting wet soils and reducing $\mathrm{N}$ leaching, but resulted in pollution swapping and increased total GHG emissions per cow. Our results suggest that total GHG emissions can be 
reduced through lower-stocked systems, where individual cow performance is optimised through better feeding of high genetic merit animals to compensate for the lower stocking rates.

Supplementary Materials: The following are available online at http:/ /www.mdpi.com/2076-2615/8/12/234/s1, Supplementary File S1.

Author Contributions: Conceptualization, C.d.K. and R.D.; Methodology, P.B., C.d.K, L.F., T.S. and T.v.d.W.; Validation, P.B., C.d.K., K.H. and T.v.d.W.; Investigation, D.C., D.D., K.M., A.R. and R.M.; Data Curation, P.B., D.D., L.F., T.S. and T.v.d.W.; Writing-Original Draft Preparation, P.B., C.d.K., R.D., K.H. and T.v.d.W.; Writing-Review \& Editing, P.B., D.C., D.D., C.d.K., R.D., K.M., A.R., R.M. and T.v.d.W.; Funding Acquisition, C.d.K. and R.D.

Funding: This research was funded by the New Zealand Agricultural Greenhouse Gas Research Centre (http:/ / www.nzagrc.org.nz) (project number 14-IFS8.2) and the Sustainable Land Management and Climate Change Fund (https:/ / www.mpi.govt.nz/funding-and-programs/farming/sustainable-land-management-andclimatechange-research-program/) (contract AGR131402) administered by the Ministry for Primary Industries (Wellington, New Zealand).

Acknowledgments: We thank Dave Clark, Chris Glassey, Chris Roach, Grant Edwards, David Stevens, and Andrew Wall for their involvement in the initial set up and on-going management decision making of these farm system studies. We also thank Alasdair Noble for assistance with statistical analysis. This work could not have been completed without permission to align with work conducted through the Pastoral 21 Programme (C10X1117), jointly funded by the Ministry of Business, Innovation and Employment (MBIE), DairyNZ Inc., Fonterra, Beef + Lamb New Zealand and the Dairy Companies Association of New Zealand.

Conflicts of Interest: The authors declare no conflicts of interest.

\section{References}

1. Ministry for the Environment. New Zealand's Greenhouse Gas Inventory 1990-2015; Publication Number: ME 1309; Ministry for the Environment: Wellington, New Zealand, 2017; p. 502, ISSN 1179-223X (electronic). Available online: http:/ / www.mfe.govt.nz/node/23304/ (accessed on 8 August 2017).

2. DairyNZ and LIC. New Zealand Dairy Statistics 2015-16. Available online: https:/ / www.dairynz.co.nz/ publications/dairy-industry/new-zealand-dairy-statistics-2015-16/ (accessed on 31 July 2017).

3. Beukes, P.C.; Gregorini, P.; Romera, A.J. Estimating greenhouse gas emissions from New Zealand dairy systems using a mechanistic farm model and inventory methodology. Anim. Feed Sci. Technol. 2011, 166-167, 708-720. [CrossRef]

4. Pembleton, K.G.; Rawnsley, R.P.; Turner, L.R.; Corkrey, R.; Donaghy, D.J. Quantifying the interactions between defoliation interval, defoliation intensity and nitrogen fertiliser application on the nutritive value of rainfed and irrigated perennial ryegrass. Crop Pasture Sci. 2017, 68, 1100-1111. [CrossRef]

5. Wales, W.J.; Kolver, E.S. Challenges of feeding dairy cows in Australia and New Zealand. Anim. Prod. Sci. 2017, 57, 1366-1383. [CrossRef]

6. Coffey, E.L.; Delaby, L.; Fleming, C.; Pierce, K.M.; Horan, B. Multi-year evaluation of stocking rate and animal genotype on milk production per hectare within intensive pasture-based production systems. J. Dairy Sci. 2018, 101, 2448-2462. [CrossRef] [PubMed]

7. Beukes, P.C.; Romera, A.J.; Gregorini, P.; Macdonald, K.A.; Glassey, C.B.; Shepherd, M.A. The performance of an efficient dairy system using a combination of nitrogen leaching mitigation strategies in a variable climate. Sci. Total Environ. 2017, 599-600, 1791-1801. [CrossRef]

8. O'Brien, D.; Geoghegan, A.; McNamara, K.; Shalloo, L. How can grass-based dairy farmers reduce the carbon footprint of milk? Anim. Prod. Sci. 2016, 56, 495-500. [CrossRef]

9. Clark, D.A.; Caradus, J.R.; Monaghan, R.M.; Sharp, P.; Thorrold, B.S. Issues and options for future dairy farming in New Zealand. New Zeal. J. Agric. Res. 2007, 50, 203-221. [CrossRef]

10. Beukes, P.C.; Romera, A.J.; Clark, D.A. Farming within limits-Can systems fundamentals be the key? N. Z. Soc. Anim. Prod. 2013, 74, 241-244.

11. McDowell, R.W.; Monaghan, R.M.; Dougherty, W.; Gourley, C.J.P.; Vibart, R.; Shepherd, M. Balancing water-quality threats from nutrients and production in Australian and New Zealand dairy farms under low profit margins. Anim. Prod. Sci. 2017, 57, 1419-1430. [CrossRef]

12. Ledgard, S.F.; Penno, J.W.; Sprosen, M.S. Nitrogen inputs and losses from clover/grass pastures grazed by dairy cows, as affected by nitrogen fertiliser application. J. Agric. Sci. Camb. 1999, 132, 215-225. [CrossRef] 
13. Wachendorf, M.; Büchter, M.; Trott, H.; Taube, F. Performance and environmental effects of forage production on sandy soils. II. Impact of defoliation system and nitrogen input on nitrate leaching losses. Grass Forage Sci. 2004, 59, 56-68. [CrossRef]

14. Davidson, E.A. The contribution of manure and fertilizer nitrogen to atmospheric nitrous oxide since 1860. Nat. Geosci. 2009, 2, 659-662. [CrossRef]

15. Shepherd, M.; Lucci, G. A review of the effect of autumn nitrogen fertiliser on pasture nitrogen concentration and an assessment of the potential effects on nitrate leaching risk. Proc. N. Z. Grassl. Assoc. 2013, 75, 197-202.

16. Chapman, D.; Edwards, G.; Dalley, D.; Cameron, K.; Di, H.; Bryant, R.; Romera, A.; Clement, A.; Malcolm, B.; Curtis, J. Nitrogen leaching, production and profit of irrigated dairy systems using either low or high inputs of fertiliser and feed: The Pastoral 21 experience in Canterbury. In Science and Policy: Nutrient Management Challenges for the Next Generation; Currie, L.D., Hedley, M.J., Eds.; Occasional Report No. 30; Fertilizer and Lime Research Centre, Massey University: Palmerston North, New Zealand, 2017.

17. Ledgard, S.F.; Sprosen, M.S.; Penno, J.W.; Rajendram, G.S. Nitrogen fixation by white clover in pastures grazed by dairy cows: Temporal variation and effects of nitrogen fertilization. Plant Soil 2001, 229, 177-187. [CrossRef]

18. Egan, M.; Galvin, N.; Hennessy, D. Incorporating white clover (Trifolium repens L.) into perennial ryegrass (Lolium perenne L.) swards receiving varying levels of nitrogen fertilizer: Effects on milk and herbage production. J. Dairy Sci. 2018, 101, 3412-3427. [CrossRef] [PubMed]

19. Knapp, J.R.; Laur, G.L.; Vadas, P.A.; Weiss, W.P.; Tricarico, J.M. Invited review: Enteric methane in dairy cattle production: Quantifying the opportunities and impact of reducing emissions. J. Dairy Sci. 2014, 97, 3231-3261. [CrossRef]

20. Waghorn, G.C. Application of greenhouse gas mitigation strategies on New Zealand farms. In Proceedings of the International Conference, Livestock and Global Climate Change 2008, Hammamet, Tunisia, 17-20 May 2008.

21. Kebreab, E.; France, J.; Beever, D.E.; Castillo, A.R. Nitrogen pollution by dairy cows and its mitigation by dietary manipulation. Nutr. Cycl. Agroecosyst. 2001, 60, 275-285. [CrossRef]

22. Luo, J.; Ledgard, S.F.; de Klein, C.A.M.; Lindsey, S.B.; Kear, M. Effects of dairy farming intensification on nitrous oxide emissions. Plant Soil 2008, 309, 227-237. [CrossRef]

23. de Klein, C.A.M.; Ledgard, S.F. An analysis of environmental and economic implications of nil and restricted grazing systems designed to reduce nitrate leaching from New Zealand dairy farms. I. Nitrogen losses. N. Z. J. Agric. Res. 2001, 44, 201-215. [CrossRef]

24. Laurenson, S.; Houlbrooke, D.J.; Beukes, P.C. Assessing the production and economic benefits from preventing cows grazing on wet soils in New Zealand. J. Sci. Food Agric. 2016, 96, 4584-4593. [CrossRef]

25. van der Weerden, T.J.; Laurenson, S.; Vogeler, I.; Beukes, P.C.; Thomas, S.M.; Rees, R.M.; Topp, C.F.E.; Lanigan, G.; de Klein, C.A.M. Mitigating nitrous oxide and manure-derived methane emissions by removing cows in response to wet soil conditions. Agric. Syst. 2017, 156, 126-138. [CrossRef]

26. Chapman, D.; Clark, D.; Beukes, P.; Edwards, G.; Dalley, D.; Pinxterhuis, I.; Romera, A.; Shepherd, M.; Cameron, K.; Di, H.; et al. Strategies for increasing dairy systems research approach in two regions of New Zealand. Proc. Australas. Dairy Sci. Symp. 2012, 5, 417-421.

27. Shepherd, M.; Hedley, M.; MacDonald, K.; Chapman, D.; Monaghan, R.; Dalley, D.; Cosgrove, G.; Houlbrooke, D.; Beukes, P. A summary of key messages arising from the Pastoral 21 Research Programme. In Science and Policy: Nutrient Management Challenges for the Next Generation; Currie, L.D., Hedley, M.J., Eds.; Occasional Report No. 30; Fertilizer and Lime Research Centre, Massey University: Palmerston North, New Zealand, 2017.

28. Beukes, P.C. (DairyNZ, Hamilton, New Zealand). Personal communication, 2017.

29. Chrystal, J.; Monaghan, R.; Hedley, M.; Horne, D. Volumes and nutrient concentrations of effluent products generated from a loose-housed wintering barn with woodchip bedding. In Integrated Nutrient and Water Management for Sustainable Farming; Currie, L.D., Hedley, M.J., Eds.; Occasional Report No. 29; Fertilizer and Lime Research Centre, Massey University: Palmerston North, New Zealand, 2016.

30. Di, H.J.; Cameron, K.C.; Podolyan, A.; Edwards, G.R.; de Klein, C.A.M.; Dynes, R.; Woods, R. The potential of using alternative pastures, forage crops and gibberellic acid to mitigate nitrous oxide emissions. J. Soils Sediments 2016, 16, 2252-2262. [CrossRef] 
31. Jonker, A.; Scobie, D.; Dynes, R.; Edwards, G.; de Klein, C.; Hague, H.; McAuliffe, R.; Taylor, A.; Knight, T.; Waghorn, G. Feeding fodder beet decreased methane emissions from dry and lactating dairy cows in pastoral systems. Anim. Prod. Sci. 2017, 74, 145-147.

32. van der Weerden, T.J.; Styles, T.M.; Rutherford, A.J.; de Klein, C.A.M.; Dynes, R. Nitrous oxide emissions from cattle urine deposited onto soil supporting a winter forage kale crop. N. Z. J. Agric. Res. 2017, 60, 119-130. [CrossRef]

33. Forster, P.; Ramaswamy, V.; Artaxo, P.; Berntsen, T.; Betts, R.; Fahey, D.W.; Haywood, J.; Lean, J.; Lowe, D.C.; Myhre, G.; et al. Changes in atmospheric constituents and in radiative forcing. In Climate Change 2007: The Physical Science Basis; Contribution of Working Group I to the Fourth Assessment Report of the Intergovernmental Panel on Climate Change; Cambridge University Press: Cambridge, UK; New York, NY, USA, 2007; p. 996.

34. Gerber, P.; Vellinga, T.; Opio, C.; Steinfeld, H. Productivity gains and greenhouse gas emissions intensity in dairy systems. Livest. Sci. 2011, 139, 100-108. [CrossRef]

35. Dillon, P.; Roche, J.R.; Shalloo, L.; Horan, B. Optimising financial returns from grazing in temperate pastures. Utilisation of Grazed Grass in Temperate Animal Systems. In Proceedings of the Satellite Workshop, 20th International Grassland Congress, Cork, Ireland, 3-6 July 2005; pp. 131-147.

36. Macdonald, K.A.; Penno, J.W.; Lancaster, J.A.S.; Roche, J.R. Effects of stocking rate on pasture production, milk production and reproduction of dairy cows in pasture-based systems. J. Dairy Sci. 2008, 91, 2151-2163. [CrossRef] [PubMed]

37. Aguirre-Villegas, H.A.; Passos-Fonseca, T.H.; Reinemann, D.J.; Larson, R. Grazing intensity affects the environmental impact of dairy systems. J. Dairy Sci. 2017, 100, 6804-6821. [CrossRef]

38. Oenema, J.; Burgers, S.; Verloop, K.; Hooijboer, A.; Boumans, L.; Berge, H.T. Multiscale effects of management, environmental conditions, and land use on nitrate leaching in dairy farms. J. Environ. Qual. 2010, 39, 2016-2028. [CrossRef]

39. Humphreys, J.; O'Connell, K.; Casey, I.A. Nitrogen flows and balances in four grassland-based systems of dairy production on a clay-loam soil in a moist temperate climate. Grass Forage Sci. 2008, 63, 467-480. [CrossRef]

40. Monaghan, R.M.; Paton, R.J.; Smith, L.C.; Drewry, J.J.; Littlejohn, R.P. The impacts of nitrogen fertiliser and increased stocking rate on pasture yield, soil physical condition and nutrient losses in drainage from cattle grazed pasture. N. Z. J. Agric. Res. 2005, 48, 227-240. [CrossRef]

41. Beukes, P.C.; Scarsbrook, M.R.; Gregorini, P.; Romera, A.J.; Clark, D.A.; Catto, W. The relationship between milk production and farm-gate nitrogen surplus for the Waikato region, New Zealand. J. Environ. Manag. 2012, 93, 44-51. [CrossRef] [PubMed]

42. Dynes, R.A.; Smeaton, D.; Rhodes, A.P.; Fraser, T.J.; Brown, M.A. Modelling farm management scenarios that illustrate opportunities farmers have to reduce greenhouse gas emissions while maintaining profitability. N. Z. Soc. Anim. Prod. 2011, 71, 167-171.

43. Vibart, R.; Vogeler, I.; Dennis, S.; Kaye-Blake, W.; Monaghan, R.; Burggraaf, V.; Beautrais, J.; Mackay, A. A regional assessment of the cost and effectiveness of mitigation measures for reducing nutrient losses to water and greenhouse gas emissions to air from pastoral farms. J. Environ. Manag. 2015, 156, $276-289$. [CrossRef] [PubMed]

44. de Klein, C.A.M.; Monaghan, R.M.; Ledgard, S.F.; Shepherd, M. A system's perspective on the effectiveness of measures to mitigate the environmental impacts of nitrogen losses from pastoral dairy farming. In Meeting the Challenges for Pasture-based Dairying: Proceedings of the 4th Australasian Dairy Science Symposium, 31 August-2 September 2010; Edwards, G.R., Bryant, R.H., Eds.; Lincoln University: Christchurch, New Zealand, 2010; pp. 14-28.

45. Adler, A.A.; Doole, G.J.; Romera, A.J.; Beukes, P.C. Cost-effective mitigation of greenhouse gas emissions from different dairy systems in the Waikato region of New Zealand. J. Environ. Manag. 2013, 131, $33-43$. [CrossRef] [PubMed]

46. Adler, A.A.; Doole, G.J.; Romera, A.J.; Beukes, P.C. Managing greenhouse gas emissions in two major dairy regions of New Zealand: A system-level evaluation. Agric. Syst. 2015, 135, 1-9. [CrossRef]

47. Basset-Mens, C.; Ledgard, S.; Boyes, M. Eco-efficiency of intensification scenarios for milk production in New Zealand. Ecol. Econ. 2009, 68, 1615-1625. [CrossRef] 
48. Garnsworthy, P.C. The environmental impact of fertility in dairy cows: A modelling approach to predict methane and ammonia emissions. Anim. Feed Sci. Technol. 2004, 112, 211-223. [CrossRef]

49. Vibart, R.; MacKay, A.; Wall, A.; Vogeler, I.; Beautrais, J.; Dalley, D. A farm-scale framework to assess potential farm- and regional-scale implications of removing palm-kernel expeller as a supplementary feed for dairy cows. Anim. Prod. Sci. 2017, 57, 1336-1342. [CrossRef]

50. Ledgard, S.; Falconer, S. Total Greenhouse Gas Emissions from Farm Systems with Increasing Use of Supplementary Feeds Across Different Regions of New Zealand. Report Prepared for the Ministry of Primary Industries; SLMACC-AGR30624; Milestone 12; 2015. Available online: https:/ / www.mpi.govt. $\mathrm{nz} /$ funding-and-programmes/farming/sustainable-land-management-and-climate-change-researchprogramme/sustainable-land-management-and-climate-change-slmacc-research-reports / (accessed on 14 November 2018).

51. United Nations Framework Convention on Climate Change. Intended Nationally Determined Contributions, New Zealand Submission to ADP 2015. Available online: http://www4.unfccc.int/submissions/ INDC/Published\%20Documents/New\%20Zealand/1/New\%20Zealand\%20INDC\%202015.pdf (accessed on 29 October 2018).

52. New Zealand Agricultural Greenhouse Research Centre. Highlights 2017. Available online: https://www. nzagrc.org.nz/knowledge, listing,457,nzagrc-highlights-2017.html (accessed on 2 November 2018).

53. Pastoral Greenhouse Gas Research Consortium. Research 2018. Available online: https://www.pggrc.co.nz/ research (accessed on 2 November 2018).

54. Ministry for Primary Industries. Global Partnerships in Livestock Emissions Research, an International Research Fund in Support of the Global Research Alliance on Agricultural Greenhouse Gases 2016. Available online: https:/ /www.mpi.govt.nz/funding-and-programmes/farming/global-partnerships-in-livestockemissions-research/ (accessed on 2 November 2018).

(C) 2018 by the authors. Licensee MDPI, Basel, Switzerland. This article is an open access article distributed under the terms and conditions of the Creative Commons Attribution (CC BY) license (http:/ / creativecommons.org/licenses/by/4.0/). 


\title{
Article \\ Greenhouse Gas Emissions in Dairy Goat Farming Systems: Abatement Potential and Cost
}

\author{
Alexandra Sintori, Irene Tzouramani and Angelos Liontakis * \\ Agricultural Economics Research Institute (AGRERI), Hellenic Agricultural Organization (DEMETER), \\ PC. 11528 Athens, Greece; al_sintori@agreri.gr (A.S.); tzouramani@agreri.gr (I.T.) \\ * Correspondence: aliontakis@agreri.gr
}

Received: 31 August 2019; Accepted: 5 November 2019; Published: 10 November 2019

Simple Summary: Agriculture and particularly livestock farming is associated with the production of certain gases that contribute to global warming, commonly referred to as greenhouse gases. These gases are the result of the use of machinery and other inputs such as fertilizers and pesticides or are associated with the digestion process of animals. In this work, we have analyzed data from dairy goat farms in Greece to estimate the amount of greenhouse gases per kilogram of milk produced and identify farming practices that can result in their reduction. We found that greenhouse gases per kilogram of milk are fewer in farms that are characterized by higher milk production per goat. Furthermore, certain practices like the use of homegrown feed instead of purchased feed and the use of compound feedstuffs or oil-rich feedstuffs like cottonseed cake can result in lower greenhouse gases in goat farms. Also, the analysis suggests that the reduction of greenhouse gases can lead to a reduction of farm income, especially in the case of intensive farms. This finding has to be taken into consideration by policy makers and possible measures to compensate for this income loss have to be explored.

\begin{abstract}
Dairy goat farming is an important agricultural activity in the Mediterranean region. In Greece the activity offers occupation and income to thousands of families mainly located in mountainous and semi-mountainous areas of the country where it utilizes low productivity pastures and shrub lands. Furthermore, goats are more resilient to climate changes compared to other species, and are often characterized as ideal for keeping in drought areas. However, there is still limited evidence on total greenhouse gases (GHG) emitted from goat farms and their mitigation potential. In this context, this study aims to estimate GHG emissions of goat farms in Greece and explore their abatement options using an economic optimization model. Three case studies are explored i.e., an extensive, a semi-intensive and an intensive goat farm that correspond to the main goat production systems identified in Greece. The analysis aims to assess total GHGs as well as the impact of abatement on the structures, gross margins and labor inputs of the farms under investigation. The issue of the marginal abatement cost is also addressed. The results indicate that the extensive farm causes higher emissions $/ \mathrm{kg}$ of milk produced $\left(4.08 \mathrm{~kg} \mathrm{CO}_{2}\right.$-eq) compared to the semi-intensive and intensive farms (2.04 kg and $1.82 \mathrm{~kg}$ of $\mathrm{CO}_{2}$-equivelants, respectively). The results also emphasize the higher marginal abatement cost of the intensive farm. In all farm types, abatement is achieved primarily through the reduction of the livestock capital and secondarily by other appropriate farming practices, like substitution of purchased feed with homegrown feed.
\end{abstract}

Keywords: dairy goat farming; linear programming; GHG emissions; abatement cost; mitigation options; carbon footprint 


\section{Introduction}

Goat farming is an important agricultural activity in Greece since it is mainly located in less favored areas of the country where it utilizes low-productivity pastureland and shrubland. It is estimated that goat farming yields income for 64,049 Greek farms that breed over 3.5 million goats [1]. The activity aims primarily at the production of milk and secondarily at the production of meat. According to Kitsopanidis [2], milk is on average responsible for over $70 \%$ of gross revenue of dairy goat farms, with the exception of very hardy, local breeds. It is estimated that $75 \%$ of the Greek goat milk is used for the production of cheeses, especially Feta. Furthermore, the activity contributes highly to regional development and helps maintain the population in depressed and marginal areas. Therefore, the preservation of the activity and the income it yields is important not only for farmers but also for policy makers.

The prevailing goat farming system in the country is the extensive one with or without transhumance, in which the nutrition of the livestock is based on grazing. The main characteristic of the extensive breeding farms is the low invested capital and the low-productivity livestock, consisting mainly of native races [3]. More modern and intensive farms that aim to increase their productivity through supplementary feeding, mainly from on-produced cereals and forage, are also present. Specifically, three commercial goat production systems are identified in Greece, namely the traditional extensive farming system, the semi-intensive farming system and the intensive farming system [2]. As mentioned above, in the extensive farming system feed requirements are met mainly through pasturing. In the semi-intensive farming system additional supplementary feed is provided, while in the intensive farming system no pasture is utilized. This heterogeneity among the alternative goat farming systems results in differences in their socioeconomic as well as their environmental sustainability.

One of the main environmental issues associated with livestock farming is the emission of greenhouse gases (GHGs). GHG emissions are particularly high in the case of ruminant livestock farming because of methane production through enteric fermentation [4,5]. The issue of GHG emissions in livestock farms has been addressed in a number of studies that focus mainly on cattle farms [6-9]. On the other hand, studies that focus on the emission of GHGs from sheep and goat farms refer mainly to meat and wool production farming systems that have different technical and economic characteristics from dairy farms (e.g., $[10,11])$. In the case of small ruminant dairy farming in Greece, limited studies on GHG emissions from sheep farms and their abatement potential are available (see [12]).

This study aims to address the issue of GHG emissions in dairy goat farms, using an economic optimization model, developed to capture and represent the structure and function of Greek goat farms. The use of such model in GHG studies has the advantage that it accounts for all possible sources of GHG emissions in goat farms and therefore reduced emissions from one source at the optimal solution does not result in increased emissions from other sources. Furthermore, since the model is an optimization model, abatement options are explored within the context of gross margin maximization. In other words, abatement practices and options that are proposed by the model are the least-cost options for the farms. Furthermore, this cost is precisely estimated and marginal abatement cost curves are derived. Thus, the analysis and the results it yields can be useful not only for agriculturalists but also for farmers, agricultural advisors and policy makers.

\section{Materials and Methods}

Optimization models, and specifically linear programming (LP) models are commonly used in agricultural studies (e.g., [13-16]). They yield the optimal amongst all feasible farm plans, taking into account technical and agronomic constraints of the farms. When the matter of GHG emissions in livestock and crop livestock farms is addressed, the complexity of the farm operation, the multiple sources of emissions, and the substitution possibilities between alternative activities require the use of a model that can capture all the interrelationships of these activities. That said, a number of studies use LP models to assess GHGs from various sources and identify cost-effective mitigation strategies (e.g., $[9,10,17-21])$. 
The general expression of a linear programming model is as follows [22]:

$$
\operatorname{Max} g(x)=z=c_{1} x_{1}+c_{2} x_{2}+\ldots+c_{n} x_{n}
$$

Subject to the constraints:

$$
\begin{gathered}
a_{11} x_{1}+a_{12} x_{2}+\ldots+a_{1 n} x_{n} \leq b_{1} \\
a_{21} x_{1}+a_{22} x_{2}+\ldots+a_{2 n} x_{n} \leq b_{2} \\
a_{m 1} x_{1}+a_{m 2} x_{2}+\ldots+a_{m n} x_{n} \leq b_{m} \\
x_{j} \geq 0
\end{gathered}
$$

where $x_{j}(j=1,2, \ldots, n)$ are the decision variables of the model, they are unknown and determined by the model according to what maximizes gross margin (e.g., number of productive goats, hectares of cereals or forages etc.), $c_{j}$ are known economic parameters (e.g., gross margin per unit of activity $x_{j}$ ), $a_{i j}$ $(i=1,2, \ldots, m)$ are known technical parameters (e.g., hours of labor or variable inputs per activity $\left.x_{j}\right)$ and $b_{i}$ are also known parameters that express the availability of inputs (e.g., maximum available labor, capital or land inputs).

The characteristics of the optimization model that was used in this analysis is described in more detail in the following paragraphs. The data used in the analysis is also presented in the same section.

\subsection{Model Specification}

The model used in this analysis has 241 decision variables and 236 technical and economic constraints and it is presented in Figure 1 which represents the LP matrix. The decision variables of the model (Activities $i$ in Figure 1) can be grouped in three main categories. The first one includes all the decision variables that refer to crops, pasture, grassland, shrubland and feeding i.e., to the distribution of produced and purchased feed. The second category refers to labor variables, and the final category to livestock and product variables. In addition to the non-negativity constraint of all decision variables, variables which refer to the livestock capital are restricted to receive only integer numbers and therefore the model is in fact a mixed-integer programming model. The constraints of the model (Constraints $j$ in Figure 1) refer mainly to the feeding of the livestock but also to the availability of labor, land and other inputs. In Figure 1, the constraints of the model and their technical parameters $\left(\alpha_{i j}\right)$ as well as their right hand side parameters $\left(b_{i}\right)$ are presented in all lines except for the first line that presents the activities $\left(x_{j}\right)$.

The model is built to accurately reflect the structure and function of Greek goat farms and allocates all their available inputs and resources to the alternative economic activities and practices according to what maximizes their total gross margin (objective function). Therefore, the farm plan it suggests is in economic terms the optimal. It should be noted that the model is built according to the dairy sheep model described in detail in Sintori [23]. 


\begin{tabular}{|c|c|c|c|c|c|c|c|c|c|c|c|c|c|c|c|c|c|c|c|c|}
\hline 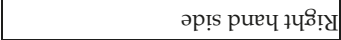 & $\Omega_{\Lambda}$ & 시 & Ni & ㅅ. & 시 & 시 & 시 & గil & VI & 只 & 全 & 只 & 公 & 시 & 只 & VI & V & $\mathrm{VI}$ & VI & \\
\hline (ךәуч) plos sdoxכ & & & & & & & $: 3$ & & & & & & & & & & 7 & & $: \nexists$ & $\overbrace{0}^{\infty}$ \\
\hline 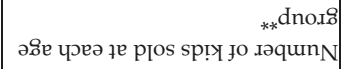 & & & & & : & & & : & & 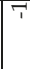 & & & & & & & & & $: \nexists$ & 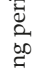 \\
\hline 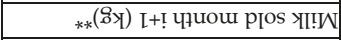 & & & & & 3 & & & 旅 & & & & & & & 7 & & & & & 莡 \\
\hline 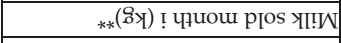 & & & & & $\overline{1}$ & & & 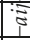 & & & & & 7 & & $\tau$ & & & & & \\
\hline 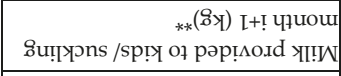 & & & & & : & & & & & & & & & 7 & & & & & & 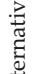 \\
\hline 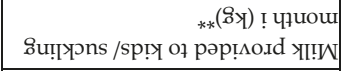 & & & & & : & & & & & & & & 7 & 7 & & & & & & 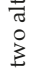 \\
\hline 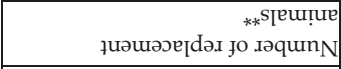 & & & & & : & & & : $:$ & & $T$ & 7 & & & & & & & & $: \bar{z}$ & 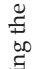 \\
\hline słео8 әреи јо дәqun $\mathrm{N}$ & & & & & $\overline{1}$ & & & : & & & & $\vec{T}$ & & & & & & & $: 3$ & 胥 \\
\hline **\$ \$ұео8 әрешәу јо дәquin $\mathrm{N}$ & & & & & $\stackrel{\bar{z}}{1}$ & & & : & & $: \Xi$ & $: \nexists$ & $: \bar{z}$ & $: \bar{z}$ & & & & & & $: z$ & 崖 \\
\hline 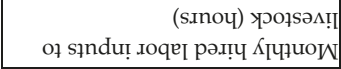 & & & & & & & & & & & & & & & & & & & : & 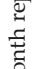 \\
\hline 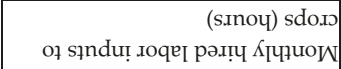 & & & & & & & 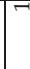 & & & & & & & & & & & & $: \Xi$ & 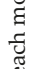 \\
\hline 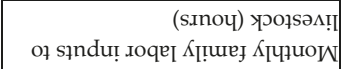 & & & & & & & & & & & & & & & & & & & & 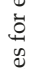 \\
\hline 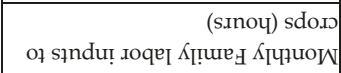 & & & & & & & 7 & & 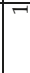 & & & & & & & & & & & 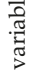 \\
\hline 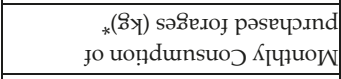 & & & & & : $:$ & 7 & & & & & & & & & & & & & $: z$ & $\stackrel{0}{3}$ \\
\hline 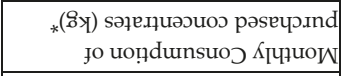 & & & & & : & $\bar{z}$ & & & & & & & & & & & & & $:$ & $\stackrel{\frac{\infty}{\widetilde{\tau}}}{\stackrel{g}{\Xi}}$ \\
\hline 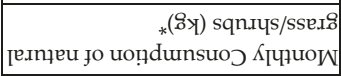 & & & & $\checkmark$ & & & & & & & & & & & & & & & & 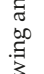 \\
\hline 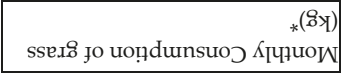 & & & 7 & & & & & & & & & & & & & & & & & $\begin{array}{l}D_{0} \\
\text { bे } \\
\text { పै }\end{array}$ \\
\hline 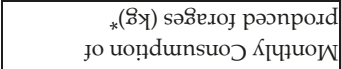 & & 7 & & & $: \bar{z}$ & & & & & & & & & & & & & & & $\stackrel{\Xi}{\Xi}$ \\
\hline 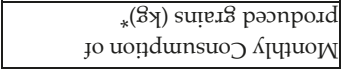 & & & & & & $\sqrt{3}$ & & & & & & & & & & & & & & 节 \\
\hline 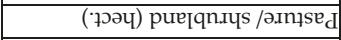 & & & & $:$ : & & & & & & & & & & & & 7 & & $\tau$ & & "ే \\
\hline 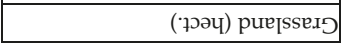 & & & : & & & & is & & & & & & & & & & $=$ & & $: \approx$ & $\bar{z}$ \\
\hline 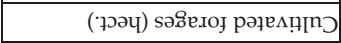 & & $: \Xi$ & & & & & : & & & & & & & & & 7 & 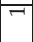 & & $:$ & $\frac{\pi}{0}$ \\
\hline 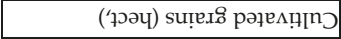 & $: \bar{z}$ & & & & & & : & & & & & & & & & 7 & - & & $: \bar{z}$ & 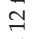 \\
\hline 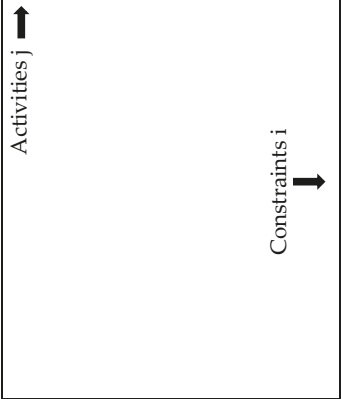 & 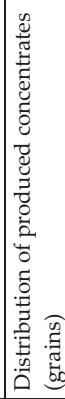 & 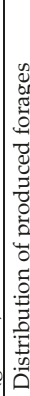 & . & 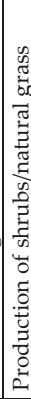 & 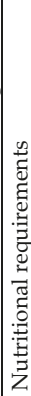 & 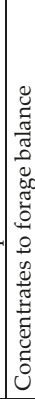 & 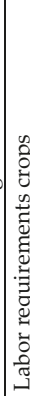 & 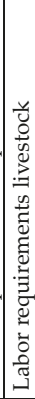 & 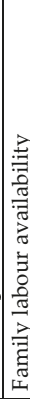 & $\begin{array}{l}00 \\
\frac{0}{0} \\
\frac{0}{2} \\
\end{array}$ & 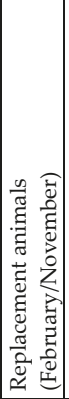 & 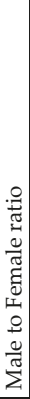 & 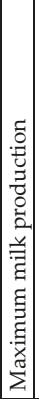 & 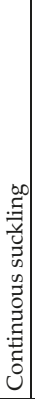 & 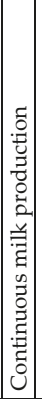 & 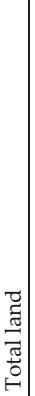 & 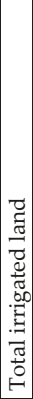 & 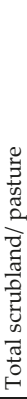 & 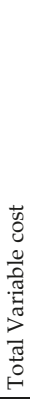 & 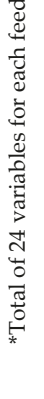 \\
\hline
\end{tabular}




\subsubsection{Crop, Pasture, Grassland and Feeding Variables}

Crop activities of the goat farms involve forage and grain production for livestock feeding but also crop production for sale. The main crops cultivated in Greek goat farms are maize for grain and alfalfa for hay. Other crops may also be cultivated like maize for silage or barley for grain. For each crop, pasture and grassland used, one variable is included in the model that expresses the land in hectares allocated to the activity. The economic parameter of the specific variable is negative and expresses the cultivation cost per hectare excluding labor which is represented by a different set of variables. Feeding variables are defined according to month, type of feed and livestock category. In other words, the consumption of each feed (e.g., produced maize, purchased maize, produced alfalfa hay, purchased mixtures) is presented monthly and for two separate categories of livestock i.e., growing and adult animals. This structure allows the model to simulate farm decision making regarding the distribution of homegrown feed and purchase of additional feeds throughout the year. Furthermore, the use of such detailed data on feeding practices of the farms allows the model to be accurate and realistic regarding the predicted type and amount of feed required by the livestock, but also the methane emitted from enteric fermentation. Finally, it should be emphasized that the economic parameters of the variables that refer to purchased feed are negative and represent the price per kilo for each feed, while the economic parameter of each variable that refers to the consumption of homegrown feed is zero, since the cost of production is in fact the economic parameter of the related crop variable and, therefore, it has already been accounted for.

\subsubsection{Labor Variables}

In order for goat farms to operate one main required input is labor. In Greece, goat farms are in their majority traditional and family owned with very low mechanization degree, since extensive and semi-intensive farms rarely even use milking machines. The amount of labor inputs required in these farm types are also increased because of grazing. Labor variables incorporated in the model represent the amount of labor inputs required each month of the year in hours. The model allocates the available family labor between all crop and livestock activities of the farm. Variables representing the additional hired labor required each month in the above activities are also incorporated in the model. The economic parameters of these variables are negative and represent the wage per hour in livestock and crop activities.

\subsubsection{Livestock and Product Variables}

Livestock variables incorporated in the model refer to the number of female and male goats, replacement animals and kids that constitute the livestock of the farm. Two variables are used to represent the female goats that are kept in the livestock representing two different kidding periods. One variable refers to the goats that give birth in late November and the other to the goats that give birth in late February. These two kidding periods were chosen to reflect the practices of Greek goat farms, that aim to satisfy the increased demand for goat meat during Christmas and Easter. The economic parameters of these variables are negative and represent the annual variable cost of keeping and breeding one animal for one year, except for labor and feeding cost, since both labor and feeding are represented by the variables already described in previous paragraphs. As far as kids are concerned, they are represented in the model by a set of variables according to their age group in months. Specifically, 12 variables are used in the model to reflect the young kids between the ages of one and six months born during the alternative two kidding periods. The economic parameters of these variables are positive and express the gross margin per animal sold at each specific age. As mentioned above, all livestock variables are allowed to receive only integer numbers.

The final set of variables incorporated in the model represents milk production per month and per kidding period. Milk variables include variables that refer to suckling as well as variables that 
refer to milk production for sale. The economic parameter of the milk for sale variables is positive and expresses milk price.

\subsubsection{Feeding Constraints}

The main component of the model reflects the balance of the monthly feed requirements of the livestock. Minimum intake of dry matter, net energy of lactation, nitrogen and fiber matter is ensured through monthly constraints. The feed requirements of the livestock are estimated according to Zervas et al. [24] (see Table 1). For the female productive goats these feed requirements include requirements for preservation, activity and pregnancy. Extra requirements for lactation are estimated per kilogram of produced milk. For male productive goats, the requirements refer to their preservation, activity and reproduction. For the replacement animals, the feed requirements are estimated every month taking into account the live-weight increase. The weight increase is also taken into account in the case of the kids, for which feed requirements are estimated for the period that they remain in the farm.

Table 1. Livestock feed requirements.

\begin{tabular}{|c|c|c|c|}
\hline Animal Characteristics & Dry Matter (kg/day) & $\begin{array}{c}\text { Digestible Nitrogen } \\
\text { (g/day) }\end{array}$ & $\begin{array}{c}\text { Net Energy for } \\
\text { Lactation (MJ/day) }\end{array}$ \\
\hline \multicolumn{4}{|c|}{ Productive goats } \\
\hline \multicolumn{4}{|c|}{ Preservation } \\
\hline \multicolumn{4}{|l|}{ Live weight (kilos) } \\
\hline 50 & 1.6 & 40 & 5.2 \\
\hline 60 & 1.8 & 46 & 5.8 \\
\hline 70 & 2.0 & 52 & 6.6 \\
\hline \multicolumn{4}{|c|}{ Pregnancy } \\
\hline Live weight (kilos) & & & \\
\hline 50 & 1.4 & 105 & 8.4 \\
\hline 60 & 1.5 & 120 & 9.0 \\
\hline 70 & 1.6 & 140 & 9.8 \\
\hline \multicolumn{4}{|c|}{ Lactation (per kilo of milk) } \\
\hline Fat content & & & \\
\hline $3.0 \%$ & - & 50 & 2.8 \\
\hline $3.5 \%$ & - & 55 & 3.0 \\
\hline $4.0 \%$ & - & 60 & 3.2 \\
\hline $4.5 \%$ & - & 65 & 3.4 \\
\hline \multicolumn{4}{|c|}{ Male goats } \\
\hline \multicolumn{4}{|c|}{ Live weight (kilos) } \\
\hline 80 & 2.1 & 63 & 8.1 \\
\hline 100 & 2.2 & 75 & 9.6 \\
\hline \multicolumn{4}{|c|}{ Growing animals } \\
\hline \multicolumn{4}{|l|}{ Age (in months) } \\
\hline $0-1$ & & 80 & 3.2 \\
\hline $1-2$ & $0.3-0.6$ & 80 & 3.6 \\
\hline $2-3$ & $0.6-0.8$ & 77 & 4.2 \\
\hline $3-4$ & $0.8-1.0$ & 74 & 4.6 \\
\hline $4-5$ & $1.0-1.1$ & 68 & 4.9 \\
\hline $5-6$ & $1.1-1.2$ & 62 & 5.1 \\
\hline $6-7$ & $1.2-1.3$ & 60 & 5.2 \\
\hline
\end{tabular}

On-produced feed crops, external feed inputs, available grassland and pastureland/shrubland are used for the balance of the feed requirements of the flock. The composition and the nutritional value per kilogram of feedstuff is taken from Kalaisakis [25], Jarrige [26], Zervas et al. [24] and Feedipedia [27] 
(Table 2). The nutritional value and the production of grassland and pasture are estimated taking into account Papachristou [28], Zervas et al. [24], F.R.I. [29], Platis and Papanastasis [30], Platis et al. [31]. Additional monthly constraints are incorporated in the model to ensure minimum and realistic intake of concentrate feeds, according to the feeding practices of the farms.

Table 2. Nutritional value of feed.

\begin{tabular}{ccccc}
\hline Type of Feed & $\begin{array}{c}\text { Dry Matter } \\
\mathbf{( g / / g g})\end{array}$ & $\begin{array}{c}\text { Digestible } \\
\text { Nitrogen }(\mathbf{g} / \mathbf{k g})\end{array}$ & $\begin{array}{c}\text { Net energy for } \\
\text { Lactation } \mathbf{( M j} / \mathbf{k g})\end{array}$ & $\begin{array}{c}\text { Fiber Matter } \\
(\mathbf{g} / \mathbf{k g})\end{array}$ \\
\hline Maize for grain & 0.880 & 0.073 & 8.40 & 0.022 \\
Barley for grain & 0.860 & 0.077 & 7.60 & 0.044 \\
Cotton seed & 0.922 & 0.195 & 7.99 & 0.211 \\
Alfalfa hay & 0.850 & 0.105 & 4.10 & 0.280 \\
Maize silage & 0.300 & 0.018 & 2.15 & 0.053 \\
Herbaceous material & 0.202 & 0.019 & 1.13 & 0.038 \\
(pastures) & 0.472 & 0.021 & 1.64 & 0.280 \\
Shrubs & 0.275 & 0.015 & 1.45 & 0.090 \\
\hline
\end{tabular}

\subsubsection{Additional Constraints}

Another component of the model ensures that monthly labor requirements of all production activities are balanced, mainly with family labor inputs. Additional hired labor can be used, if necessary, in both livestock and crop activities.

Land constraints are also incorporated in the model to ensure that the total area utilized by the various crop activities, grassland and pastureland/shrubland is smaller than the available land of the farm. Moreover, one land constraint refers to total available irrigated land of each farm and another to total available pastureland/shrubland. A final set of constraints reflects the demography of the livestock and the maximum milk and meat production capabilities per goat.

\subsubsection{Greenhouse Gas (GHG) Emissions}

In order to accurately derive mitigation options for the goat farms, it is important to identify all potential sources of GHGs related to the activity, and include them in the model. The main GHGs, in livestock farms are methane $\left(\mathrm{CH}_{4}\right)$ from enteric fermentation and methane and nitrous oxide $\left(\mathrm{N}_{2} \mathrm{O}\right)$ from manure. In addition, in a crop-livestock farm, nitrous oxide emissions $\left(\mathrm{N}_{2} \mathrm{O}\right)$ from nitrogen fertilizers should also be accounted for (see for example [10,32]). Carbon dioxide emissions $\left(\mathrm{CO}_{2}\right)$ from the use of machinery are an additional source of GHGs. A graphical representation of the model used in the analysis and the emission sources it includes is presented in Figure 2. The emissions sources that the model takes into account are also summarized in Table 3. 


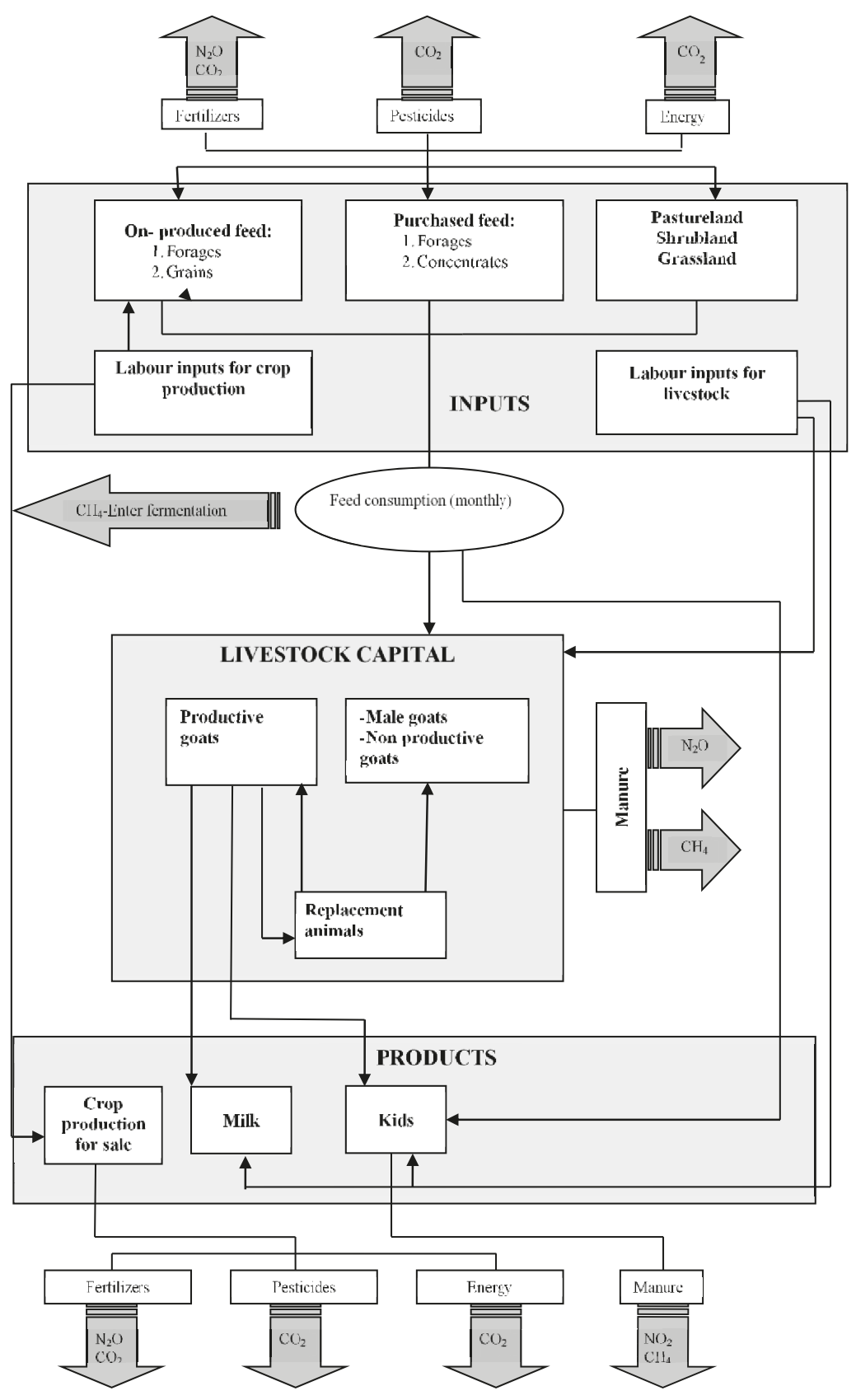

Figure 2. Graphical representation of the mathematical programming model and the emission sources considered in the analysis. 
Table 3. Emission sources considered in the analysis.

\begin{tabular}{|c|c|c|}
\hline Emission Sources & $\begin{array}{c}\text { Included in the } \\
\text { Analysis }\end{array}$ & $\begin{array}{c}\text { Not Included in the } \\
\text { Analysis }\end{array}$ \\
\hline \multicolumn{3}{|c|}{ Livestock emissions } \\
\hline Enteric $\mathrm{CH}_{4}$ & $x$ & \\
\hline $\mathrm{CH}_{4}$ from manure deposited onto pasture & $x$ & \\
\hline $\mathrm{CH}_{4}$ from manure management & $X$ & \\
\hline Direct $\mathrm{N}_{2} \mathrm{O}$ emissions from manure deposited onto pasture & $x$ & \\
\hline Indirect $\mathrm{N}_{2} \mathrm{O}$ emissions from manure deposited onto pasture & $x$ & \\
\hline $\begin{array}{c}\mathrm{N}_{2} \mathrm{O} \text { emissions from leaching and run-off from manure } \\
\text { deposited onto pasture }\end{array}$ & & $X$ \\
\hline Direct $\mathrm{N}_{2} \mathrm{O}$ emissions from manure management & $x$ & \\
\hline Indirect $\mathrm{N}_{2} \mathrm{O}$ emissions from manure management & $x$ & \\
\hline $\begin{array}{c}\mathrm{N}_{2} \mathrm{O} \text { emissions from leaching and run-off from manure } \\
\text { management }\end{array}$ & & $x$ \\
\hline \multicolumn{3}{|l|}{ Crops } \\
\hline Direct $\mathrm{N}_{2} \mathrm{O}$ emissions from use of fertilizers & $x$ & \\
\hline Indirect $\mathrm{N}_{2} \mathrm{O}$ emissions from use of fertilizers & $x$ & \\
\hline $\mathrm{N}_{2} \mathrm{O}$ emissions from leaching and run-off & & $x$ \\
\hline $\begin{array}{c}\mathrm{CO}_{2} \text { pre-chain emissions associated with the use } \\
\text { manufacture and transport of inputs (fertilizers } \\
\text { and pesticides) }\end{array}$ & $x$ & \\
\hline $\mathrm{CO}_{2}$ from energy use within the farm & $x$ & \\
\hline \multicolumn{3}{|l|}{$\begin{array}{l}\text { Purchased feed } \\
\end{array}$} \\
\hline Direct $\mathrm{N}_{2} \mathrm{O}$ emissions from use of fertilizers & $x$ & \\
\hline Indirect $\mathrm{N}_{2} \mathrm{O}$ emissions from use of fertilizers & $x$ & \\
\hline $\mathrm{N}_{2} \mathrm{O}$ emissions from leaching and run-off & & $X$ \\
\hline $\begin{array}{c}\mathrm{CO}_{2} \text { pre-chain emissions associated with the use } \\
\text { manufacture and transport of inputs (fertilizers } \\
\text { and pesticides) }\end{array}$ & $x$ & \\
\hline $\begin{array}{c}\mathrm{CO}_{2} \text { from energy use required for the cultivation and } \\
\text { transport of purchased feed }\end{array}$ & $x$ & \\
\hline
\end{tabular}

It should be noted that $\mathrm{CH}_{4}$ and $\mathrm{N}_{2} \mathrm{O}$ have been converted to $\mathrm{CO}_{2}$-equivalents $\left(\mathrm{CO}_{2}\right.$-eq) using the conversion factors proposed by the Intergovernmental Panel on Climate Change (IPCC) [4] i.e., $1 \mathrm{~kg}$ of $\mathrm{N}_{2} \mathrm{O}=298 \mathrm{~kg}$ of $\mathrm{CO}_{2}$-eq and $1 \mathrm{~kg}$ of $\mathrm{CH}_{4}=25 \mathrm{~kg}$ of $\mathrm{CO}_{2}$-eq. The method used to estimate emissions from various sources in the goat farms is described in more detail in the following paragraphs. Emissions from all sources estimated as $\mathrm{CO}_{2}$-equivalents are added together to estimate total GHG emissions of the goat farms.

Methane production from enteric fermentation is the most important source of GHGs in small ruminant livestock farms and it is associated with the feeding practices of each farm. Farmers choose to feed their livestock with on-produced feed and purchased feed taking into account their cost and their nutritional value. Linear programming models select the optimal combination of feedstuff and suggest the ration that helps maximize gross margin (least cost ration). For this reason, the ration used in this analysis is not fixed and methane emissions are predicted from intake, taking into account the requirements of the livestock estimated as previously described and the composition of feedstuff, that can be found in Table 2 (see also [33,34]). Specifically, for each of the variables that refer to feed consumption the methane emissions per kilogram have been estimated and included in the model as the technical parameter of this variable in a new constraint regarding GHG emissions. To estimate the percent of gross energy intake lost as methane from enteric fermentation $\left(E C H_{4} / E B\right)$ the following equation was used [33]:

$$
E C H_{4} / E B=9.84-0.0461 A D L-0.0509 E E+0.00366 S t+0.00648 C P
$$


where: $A D L=\mathrm{g}$ of lignin $/ \mathrm{kg}$ of $\mathrm{DM}, E E=\mathrm{g}$ of ether extract $/ \mathrm{kg}$ of DM, $S t=\mathrm{g}$ of starch $/ \mathrm{kg}$ of DM and $C P=\mathrm{g}$ of protein $/ \mathrm{kg}$ of DM.

Methane emissions from manure are estimated using the Tier 2 methodology proposed by the IPCC [4], which takes into account the management system of manure and the energy consumption of livestock (Equation (3)).

$$
E F=(V S \cdot 365) \cdot\left[B_{0} \cdot 0.67 \mathrm{~kg} / \mathrm{m}^{3} \cdot \sum_{S, k} \frac{M C F_{S, k}}{100} \cdot M S_{(S, k)}\right]
$$

where: $E F=$ annual methane emissions from manure $\left(\mathrm{kg} \mathrm{CH}_{4} /\right.$ head/year $), V S=$ daily volatile solid excreted ( $\mathrm{kg}$ of dry matter/head/day), $B_{0}=$ maximum methane producing capacity for manure produced $\left(0.18 \mathrm{~m}^{3} \mathrm{CH}_{4} / \mathrm{kg}\right.$ VS for Greece), $M C F_{(S, k)}=$ methane conversion factors for each manure management system and climate region ( $1.5 \%$ for Greece), $M S_{(S, k)}=$ fraction of manure handled using manure management system $\mathrm{S}$ to climate region $\mathrm{k}$ (estimated for each farm according to their farming practices) and 365 are the days within the year.

VS is estimated from the gross energy intake (GE) expressed in MJ/head/day, the digestibility of the feed (DE/100) e.g., $65 \%$,the ash content of manure (ASH/100) (8\% for goats according to the IPCC) and the conversion factor for dietary GE per kg of dry matter (18.45 MJ/kg), using Equation (4):

$$
V S=G E / 18.45 \cdot(1-D E / 100) \cdot(1-A S H / 100)
$$

The methodology to estimate the energy requirements per livestock category, which is necessary for the implementation of the Tier 2 methodology has already been presented.

Direct $\mathrm{N}_{2} \mathrm{O}$ emissions from manure management and pastureland are estimated according to the Tier 1 methodology [4], using the live weight of each livestock category (Equation (5)):

$$
N_{2} O_{D(m m)}=\frac{44}{28} \cdot \sum_{S} N e x \cdot M S_{(S)} \cdot E F_{(S)}
$$

where: $\mathrm{N}_{2} \mathrm{O}_{D(m m)}=$ direct $\mathrm{N}_{2} \mathrm{O}$ emissions from manure management $\mathrm{kg} / \mathrm{year} / \mathrm{head}, \mathrm{N}_{e x}=$ annual $\mathrm{N}$ excretion ( $\mathrm{kg}$ of $\mathrm{N} /$ head/year), $E F_{(s)}=$ emission factor for direct $\mathrm{N}_{2} \mathrm{O}$ emissions from manure management system $S\left(\mathrm{~kg} \mathrm{~N}_{2} \mathrm{O}-\mathrm{N} / \mathrm{kg} \mathrm{N}\right)$. $E F_{(s)}$ equals $0.02 \mathrm{~kg} \mathrm{~N} \mathrm{~N}_{2} \mathrm{O}-\mathrm{N} / \mathrm{kg} \mathrm{N}$ when manure is managed in solid storage and $0.01 \mathrm{~kg} \mathrm{~N}_{2} \mathrm{O}-\mathrm{N} / \mathrm{kg} \mathrm{N}$ when manure is deposited on pasture [4]. It should be noted that according to the IPCC guidelines $\mathrm{N}_{2} \mathrm{O}$ emissions generated by manure deposited on pastures is reported under Emissions from managed soils. In this analysis, however, these emissions have been considered, so that comparison between grazing and housed animals can be made.

$N_{e x}$ is estimated taking into account the typical animal mass (TAM) in $\mathrm{kg} / \mathrm{head}$ and the $\mathrm{N}$ excretion rate using the equation ( $N_{\text {rate }}$ for goats $=1.28 \mathrm{~kg}$ of N/1000 kg of animal mass $/$ day):

$$
\text { Nex }=N_{\text {rate }} \cdot \frac{T A M}{1000} \cdot 365
$$

where 365 are the number of days within the year.

According to the IPCC (2006), for the estimation of indirect $\mathrm{N}_{2} \mathrm{O}$ emissions, first the fraction of $\mathrm{N}$ that volatilizes as $\mathrm{NH}_{3}$ and $\mathrm{NO}_{\mathrm{x}}$ is estimated according to Equation (7) and then the amount of manure nitrogen that is lost due to volatilization of $\mathrm{NH}_{3}$ and $\mathrm{NOx}$ is estimated using Equation (8):

$$
\begin{gathered}
N_{\text {volatilization-MMS }}=\sum_{S} N e x \cdot M S_{(S)} \cdot \operatorname{Frac}_{\text {GasMS,(s) }} \\
N_{2} \mathrm{O}_{G(m m)}=\left(N_{\text {volatilization-MMS }} \cdot E F_{4}\right) \cdot \frac{44}{28}
\end{gathered}
$$


where: MMS stands for manure management system, Frac $_{G a s M S(s)}=$ is the Fraction $\mathrm{N}$ that volatilizes as $\mathrm{NH}_{3}$ and $\mathrm{NO}_{\mathrm{x}}(0.12)$ and $E F_{4}=$ emissions factor for $\mathrm{N}_{2} \mathrm{O}$ from $\mathrm{N}$ that volatilizes $(0.010 \mathrm{~N} 2 \mathrm{O}-\mathrm{N} / \mathrm{kg}$ $\mathrm{NH}_{3}-\mathrm{N}+\mathrm{NO}_{x}-\mathrm{N}$ volatilized).

In our analysis, we have also included direct and indirect $\mathrm{N}_{2} \mathrm{O}$ emissions from the use of nitrogen fertilizers. First, the total amount of nitrogen applied in fields has been calculated using the amount and the type of fertilizer (see also $[17,34]$ ). Then direct and indirect emissions from the applied $\mathrm{N}$ have been estimated according to the Tier 1 methodology and the emission factors proposed by the IPCC [4].

Carbon dioxide linked to energy use is another GHG of crop-livestock farms. The main sources of energy in these farms are fuel (mainly diesel) and electricity (see also [7]). To estimate the emissions from energy use, fuel or electricity requirements for every farm operation and type of machinery are accessed and multiplied by appropriate emission factors [10]. Specifically, as far as electricity is concerned and due to the fact that in Greece lignite is used for the production of electricity, the emission factor considered in the analysis is quite high $\left(0.855 \mathrm{~kg}\right.$ of $\mathrm{CO}_{2}$-eq per $\left.\mathrm{KWh}\right)$. The emission factors per liter of petrol and diesel used in the analysis are 2.23 and $2.66 \mathrm{~kg}$ of $\mathrm{CO}_{2}$-eq, respectively.

Other inputs, like fertilizers and pesticides have also caused GHG emissions when they were manufactured. These emissions have been taken into account as well, using farm-level data to estimate the amount of inputs used and related literature to estimate the emissions caused by the manufacture of these inputs. Carbon dioxide emissions from the manufacture of fertilizers are assumed $0.3 \mathrm{~kg}$ of $\mathrm{CO}_{2} \mathrm{eq} / \mathrm{kg}$ of $\mathrm{N}, 0.9 \mathrm{~kg}$ of $\mathrm{CO}_{2} \mathrm{eq} / \mathrm{kg}$ of $\mathrm{P}$ and $0.6 \mathrm{~kg}$ of $\mathrm{CO}_{2} \mathrm{eq} / \mathrm{kg}$ of $\mathrm{K}$. The energy requirements for the manufacture of herbicides, insecticides and fungicides are $287 \mathrm{MJ} / \mathrm{kg}, 263 \mathrm{MJ} / \mathrm{kg}$ and $195 \mathrm{MJ} / \mathrm{kg}$, respectively [35-39]. Emissions are then calculated by multiplying the total energy requirements with 0.069 , which is the amount of $\mathrm{CO}_{2}$ produced per MJ of energy consumed.

Other pre-chain emissions have also been estimated and included in the analysis, following the work of Olesen et al. [7]. As mentioned above, farmers choose whether to feed their livestock with on-produced or purchased feed. Therefore, $\mathrm{N}_{2} \mathrm{O}$ emissions from nitrogen fertilizers and $\mathrm{CO}_{2}$ emissions from energy requirements have also been estimated per kilogram of purchased feed, according to the methodology that has already been presented in the previous paragraph. However, to estimate the amount of inputs (e.g., fertilizers) required for the production of the purchased feed data from 150 farms producing these feeds and operating in Continental Greece have been used. The data is part of a larger data set obtained during the implementation of the program "Search for Innovative Occupations of Tobacco Producers in the Rural Sector (Measure 9, Reg (EU) 2182/02)" and involve detailed information regarding the practices used to produce feedstuff commonly purchased by goat farms.

The original optimization model presented in Figure 1 was used to obtain the optimal farm plan of the goat farms. GHG emissions from various sources and total GHG emissions were then estimated at this optimal solution and used as the basis of our estimations ( $0 \%$ abatement level). The second step of our methodology is to derive the optimal farm plan across increasing levels of abatement, and assess impact on farm structure and gross margin. Following a number of studies (e.g., $[17,23,40])$, this was achieved by inserting an additional constraint in the model. Specifically, if $a$ is the level of abatement $(a<1)$ and $e_{0}{ }^{*}$ the total emissions at the optimal farm plan, then a new constraint is inserted in the model which restricts total farm emissions below $(1-a) e_{0}{ }^{*}$. The shadow price of this constraint is used to estimate GHG marginal abatement cost for each production system. Additionally, marginal abatement cost curves are derived for each farm type. In order to obtain the marginal abatement cost curves the right-hand side parameter of the emissions constraint was reduced marginally i.e., 1 tone, and the impact on gross margin was estimated. This procedure was performed a number of times to derive the cost curve. It should be emphasized that this kind of sensitivity analysis is usually performed automatically in LP models, but in this analysis some variables are restricted to receive only integer numbers. Therefore, sensitivity analysis could not be performed automatically and marginal costs were obtained manually. 


\subsection{Materials}

To estimate the parameters of the model ( $c j$, aij and bi) data from actual goat farms were used. Studies that implement the LP methodology commonly utilize data from representative or typical farms of the region under study (see for example [14]). LP models are not statistical models and, therefore, data from a large number of farms is not usually required. On the other hand, to increase the predictive ability of such models detailed data was used and the model was validated through the comparison of the predicted values (optimal solution) and the actual values of the representative farms. In this analysis, data from three goat farms were used. The goat farms were selected to represent the common production systems identified in Greece. Table 4, summarizes the main characteristics of these production systems as described in the literature. All of the above characteristics were taken under consideration during the selection of the goat farms, the characteristics of which are also presented in Table 4. All farms are located in Continental Greece, specifically the intensive and the extensive farms, were located in the region of Thessaly (Prefectures of Karditsa and Magnesia, respectively) and the semi-intensive farm in the region of Epirus (Prefecture of Preveza).

Table 4. Main Characteristics of the production systems identified in Greece and of the representative farms used in the analysis.

\begin{tabular}{|c|c|c|c|c|c|c|}
\hline \multirow{2}{*}{ Characteristics } & \multicolumn{3}{|c|}{ Farming Systems [2] } & \multicolumn{3}{|c|}{ Representative Farms } \\
\hline & Extensive & Semi-Intensive & Intensive & Extensive & Semi-Intensive & Intensive \\
\hline Farm size & No significant & $\begin{array}{l}\text { iversification (ext } \\
\text { larger) }\end{array}$ & tensive usually & $\begin{array}{c}350 \\
\text { productive } \\
\text { goats }\end{array}$ & 300 & 300 \\
\hline Breeds & $\begin{array}{c}\text { Hardy local } \\
\text { breeds, }\end{array}$ & $\begin{array}{l}\text { Improved } \\
\text { local breeds }\end{array}$ & $\begin{array}{l}\text { Highly } \\
\text { productive } \\
\text { breeds foreign } \\
\text { breeds or local } \\
\text { improved } \\
\text { breeds }\end{array}$ & Local breeds & $\begin{array}{l}\text { Improved } \\
\text { local breeds }\end{array}$ & $\begin{array}{c}\text { Highly } \\
\text { productive } \\
\text { local } \\
\text { improved } \\
\text { breeds }\end{array}$ \\
\hline $\begin{array}{l}\text { Use of pastures- } \\
\text { shrublands }\end{array}$ & $\begin{array}{l}\text { About } 80 \% \text { of } \\
\text { feeding } \\
\text { requirements, } \\
\text { supplementary } \\
\text { feeding during } \\
\text { winter }\end{array}$ & $\begin{array}{l}50 \% \text { of the } \\
\text { feeding } \\
\text { requirements }\end{array}$ & $\begin{array}{l}0 \% \text { of the } \\
\text { feeding } \\
\text { requirements }\end{array}$ & $\begin{array}{l}75 \% \text { of the } \\
\text { feeding } \\
\text { requirements }\end{array}$ & $\begin{array}{l}30 \% \text { of the } \\
\text { feeding } \\
\text { requirements }\end{array}$ & $\begin{array}{l}0 \% \text { of the } \\
\text { feeding } \\
\text { requirements }\end{array}$ \\
\hline $\begin{array}{c}\text { Use of } \\
\text { concentrates }\end{array}$ & $\begin{array}{l}\text { About } 15 \% \text { of } \\
\text { nutritional } \\
\text { requirements }\end{array}$ & $\begin{array}{l}\text { Higher than } \\
\text { extensive, } \\
\text { lower than } \\
\text { intensive }\end{array}$ & $\begin{array}{l}\text { Mainly used to } \\
\text { satisfy livestock } \\
\text { feeding } \\
\text { requirements }\end{array}$ & $\begin{array}{l}20 \% \text { of the } \\
\text { feeding } \\
\text { requirements }\end{array}$ & $\begin{array}{l}60 \% \text { of the } \\
\text { feeding } \\
\text { requirements }\end{array}$ & $\begin{array}{l}62 \% \text { of the } \\
\text { feeding } \\
\text { requirements }\end{array}$ \\
\hline $\begin{array}{c}\text { Annual milk } \\
\text { yield (kg/goat) }\end{array}$ & $\begin{array}{l}\text { Estimated for } \\
\text { Makedonitiki } \\
\text { breed by } \\
\text { Kitsopanides [2] } \\
\text { at } 134\end{array}$ & $\begin{array}{l}\text { Estimated } \\
\text { for Skopelou } \\
\text { breed by } \\
\text { Kitsopanides } \\
\text { [2] at } 292\end{array}$ & $\begin{array}{l}\text { Estimated for } \\
\text { Saanen and } \\
\text { Alpine breeds by } \\
\text { Kitsopanides [2] } \\
\text { at } 580-625\end{array}$ & 115 & 300 & 520 \\
\hline $\begin{array}{c}\text { Level of } \\
\text { mechanization } \\
\text { (level of usage of } \\
\text { equipments (e.g., } \\
\text { for preparation } \\
\text { of feed, milking } \\
\text { machines etc.) }\end{array}$ & Low & $\begin{array}{l}\text { Moderate } \\
\text { (usually no } \\
\text { milking } \\
\text { machine) }\end{array}$ & Very high & $\begin{array}{l}\text { Low (no } \\
\text { milking } \\
\text { machine) }\end{array}$ & $\begin{array}{l}\text { Moderate } \\
\text { (no milking } \\
\text { machine) }\end{array}$ & Very high \\
\hline $\begin{array}{c}\text { Invested } \\
\text { capital/goat }\end{array}$ & $\begin{array}{l}\text { Low-low } \\
\text { productivity } \\
\text { livestock }\end{array}$ & Moderate & Very high & Low & Moderate & Very high \\
\hline
\end{tabular}


Table 4. Cont.

\begin{tabular}{|c|c|c|c|c|c|c|}
\hline \multirow{2}{*}{ Characteristics } & \multicolumn{3}{|c|}{ Farming Systems [2] } & \multicolumn{3}{|c|}{ Representative Farms } \\
\hline & Extensive & Semi-Intensive & Intensive & Extensive & Semi-Intensive & Intensive \\
\hline $\begin{array}{l}\text { Prolificacy index } \\
\text { (number of kids } \\
\text { per goat per } \\
\text { birth) }\end{array}$ & $\begin{array}{l}\text { Estimated for } \\
\text { Makedonitiki } \\
\text { breed by } \\
\text { Kitsopanides [2] } \\
\text { at } 1.14\end{array}$ & $\begin{array}{l}\text { Estimated } \\
\text { for Skopelou } \\
\text { breed by } \\
\text { Kitsopanides } \\
\text { [2] at } 1.37\end{array}$ & $\begin{array}{l}\text { Estimated for } \\
\text { Saanen and } \\
\text { Alpine breeds by } \\
\text { Kitsopanides [2] } \\
\text { at 1.72-1.74 }\end{array}$ & 1.2 & 1.5 & 1.80 \\
\hline $\begin{array}{l}\text { Percent of milk } \\
\text { income to total } \\
\text { farm income }\end{array}$ & $\begin{array}{l}\text { Estimated for } \\
\text { Makedonitiki } \\
\text { breed by } \\
\text { Kitsopanides [2] } \\
\text { at } 57 \%\end{array}$ & $\begin{array}{l}\text { Estimated } \\
\text { for Skopelou } \\
\text { breed by } \\
\text { Kitsopanides } \\
\text { [2] at } 74 \%\end{array}$ & $\begin{array}{l}\text { Estimated for } \\
\text { Saanen and } \\
\text { Alpine breeds by } \\
\text { Kitsopanides [2] } \\
\text { at } 80 \%\end{array}$ & $60 \%$ & $75 \%$ & $86 \%$ \\
\hline
\end{tabular}

As can be seen in Table 4, the livestock of the extensive farm consists of hardy local breeds that are characterized by low productivity. More specifically, the farm breeds 350 reproductive female goats with an annual production of milk of $115 \mathrm{~kg} / \mathrm{goat}$. The average live-weight of the goat is $50 \mathrm{~kg}$ and the prolificacy index is 1.2 .

The farm produces barley and uses only 2 hectares of grassland. Feeding of the livestock is based mainly in pasturing, since the farm uses 100 hectares of summer pasture and 50 hectares of winter pasture (mainly shrub cover). Additional feed is purchased, mainly maize, cotton seed and alfalfa. Additional parameters used in the model regarding the extensive farm can be found in Table 5 .

Table 5. Main parameters used in the linear programming (LP) model.

\begin{tabular}{|c|c|c|c|}
\hline Model Parameter & Extensive Farm & Semi-Intensive Farm & Intensive Farm \\
\hline \multicolumn{4}{|c|}{ Variable costs of cultivated crops ( $€$ /hectare) } \\
\hline Maize for grain & - & 2142 & 1651 \\
\hline Maize for forage & - & - & 734 \\
\hline Alfalfa for hay & - & - & 1148 \\
\hline Barley for grain & 591 & - & 1071 \\
\hline \multicolumn{4}{|c|}{ Crop yield (tones/hectare) } \\
\hline Maize for grain & - & 15 & 11 \\
\hline Maize for forage & - & - & 54 \\
\hline Alfalfa for hay & - & - & 15 \\
\hline Barley for grain & 3 & - & 3 \\
\hline \multicolumn{4}{|c|}{ Price of purchased feedstuff $(€ / \mathrm{kg})$} \\
\hline Maize for grain & 0.20 & 0.20 & - \\
\hline Barley for grain & - & 0.30 & - \\
\hline Alfalfa hay & 0.22 & 0.22 & 0.16 \\
\hline Mixture & - & 0.40 & 0.40 \\
\hline Cotton seed & 0.25 & - & - \\
\hline $\begin{array}{l}\text { Variable cost for livestock } \\
\text { (except for feeding and } \\
\text { labor) (€/adult goat) }\end{array}$ & 18.96 & 26,49 & 39.2 \\
\hline Replacement rate & $22 \%$ & $7 \%$ & $16 \%$ \\
\hline $\begin{array}{l}\text { Average price of meat } \\
\text { sold }(€ / \mathrm{kg})\end{array}$ & 4.25 & 2.9 & 3.43 \\
\hline $\begin{array}{l}\text { Average price of milk } \\
\text { sold }(€ / \text { kilo })\end{array}$ & 0.63 & 0.60 & 0.73 \\
\hline
\end{tabular}

The livestock of the semi-intensive farm consists of 300 female productive goats, with an annual milk production of $300 \mathrm{~kg} /$ goat and a prolificacy index of 1.5. The farm maintains maize cultivation for grain production and utilizes 50 hectares of pastureland (mainly shrub cover). Additional purchased 
feed is used, namely maize, barley, alfalfa and ready to buy feed mixes for goats. Table 5, summarizes the main technicoeconomic characteristics of the semi-intensive farm.

Finally, the intensive farm has a livestock of 300 female productive goats with an annual production of milk of about $520 \mathrm{~kg} /$ goat, an average live-weight of $70 \mathrm{~kg}$ and a prolificacy index of 1.8 . For the feeding of the highly productive livestock, maize for grain and forage production, alfalfa and barley are cultivated. Additionally, special feed mixtures and alfalfa is purchased (see also Table 5).

The detailed technical and economic data required from the three farms were obtained in the summer of 2015 and refer to the year 2014.

\section{Results}

Carbon emissions at the optimal farm plan for the extensive, the semi-intensive and the intensive farms were first estimated and are presented in Tables 6-8, respectively. The constraint on total emissions was then inserted and the emissions at the new optimal farm plans were again obtained for various levels of abatement ( $\alpha=10 \%, 15 \%$ and $20 \%$ ), through parametric optimization. Emissions per source at various levels of abatement are also presented in Tables 6-8. The values of certain variables of the model, that summarize the optimal farm plan at these abatement levels for the extensive, the semi-intensive and the intensive farm, are presented in Tables 9-11, respectively. This way, the best abatement strategy for each farm can be identified. Finally, the marginal abatement cost for each of the farms was estimated and the marginal abatement cost curve is built and presented in Figures 3-5.

\subsection{GHG Emissions}

As can be seen in Tables 6-8, the results of the analysis emphasize the significance of $\mathrm{CH}_{4}$ in goat farms. Methane represents $75 \%, 65 \%$ and $52 \%$ of total emissions of the extensive, the semi-intensive and the intensive farms, respectively. Methane emissions refer mainly to $\mathrm{CH}_{4}$ from enteric fermentation, as the $\mathrm{CH}_{4}$ produced from manure management is negligible. Methane is particularly high in the extensive-farming system, where the feeding of livestock is based on grazing. On the other hand in the case of the intensive farm, methane from enteric fermentation is considered low, because of the high amount of compound feed used in the ration. Nitrous oxide emissions from manure management are also a significant source of GHGs in dairy goat farms, since it accounts for $20 \%, 25 \%$ and $34 \%$ of total emissions of the extensive, the semi-intensive and the intensive farming systems.

Table 6. Annual greenhouse gas (GHG) emissions of the extensive farm (in $\mathrm{kg}$ of $\mathrm{CO}_{2}$-eq).

\begin{tabular}{|c|c|c|c|c|c|c|c|c|}
\hline \multirow[b]{2}{*}{ Abatement $(\alpha)$} & \multicolumn{2}{|c|}{$0 \%$} & \multicolumn{2}{|c|}{$10 \%$} & \multicolumn{2}{|c|}{$15 \%$} & \multicolumn{2}{|c|}{$20 \%$} \\
\hline & Total & $\begin{array}{l}\text { Per kg of } \\
\text { Milk* }\end{array}$ & Total & $\begin{array}{l}\text { Per kg of } \\
\text { Milk }\end{array}$ & Total & $\begin{array}{l}\text { Per kg of } \\
\text { Milk }\end{array}$ & Total & $\begin{array}{l}\text { Per kg of } \\
\text { Milk }\end{array}$ \\
\hline Total GHGs & 305,576 & 4.08 & 275,025 & 3.95 & 259,740 & 3.92 & 244,461 & 3.91 \\
\hline $\begin{array}{l}\mathrm{CH}_{4} \text { enteric } \\
\text { fermentation }\end{array}$ & 226,471 & 3.03 & 203,644 & 2.92 & 192,858 & 2.91 & 181,971 & 2.91 \\
\hline $\mathrm{CH}_{4}$ manure & 3207 & 0.04 & 2997 & 0.04 & 2848 & 0.04 & 2690 & 0.04 \\
\hline $\mathrm{N}_{2} \mathrm{O}$ manure & 59,771 & 0.80 & 55,901 & 0.80 & 53,103 & 0.80 & 50,158 & 0.80 \\
\hline $\mathrm{N}_{2} \mathrm{O}$ fertilizer & 899 & 0.01 & 450 & 0.01 & 450 & 0.01 & 450 & 0.01 \\
\hline $\begin{array}{l}\mathrm{N}_{2} \mathrm{O} \text { fertilizer- } \\
\text { purchased feed }\end{array}$ & 3250 & 0.04 & 2914 & 0.04 & 2452 & 0.04 & 2050 & 0.03 \\
\hline $\begin{array}{l}\mathrm{CO}_{2} \text { energy- } \\
\text { purchased feed }\end{array}$ & 8435 & 0.11 & 7187 & 0.11 & 6371 & 0.10 & 5420 & 0.09 \\
\hline $\mathrm{CO}_{2}$ energy-farm & 3543 & 0.04 & 1536 & 0.02 & 1536 & 0.02 & 1536 & 0.02 \\
\hline
\end{tabular}


Table 7. Annual GHG emissions of the semi-intensive farm (in $\mathrm{kg}$ of $\mathrm{CO}_{2}$-eq).

\begin{tabular}{|c|c|c|c|c|c|c|c|c|}
\hline \multirow[b]{2}{*}{ Abatement $(\alpha)$} & \multicolumn{2}{|c|}{$0 \%$} & \multicolumn{2}{|c|}{$10 \%$} & \multicolumn{2}{|c|}{$15 \%$} & \multicolumn{2}{|c|}{$20 \%$} \\
\hline & Total & $\begin{array}{l}\text { Per kg of } \\
\text { Milk }\end{array}$ & Total & $\begin{array}{l}\text { Per kg of } \\
\text { Milk }\end{array}$ & Total & $\begin{array}{l}\text { Per kg of } \\
\text { Milk }\end{array}$ & Total & $\begin{array}{c}\text { Per kg o } \\
\text { Milk }\end{array}$ \\
\hline Total GHGs & 284,120 & 2.04 & 255,708 & 2.00 & 238,268 & 1.98 & 227,296 & 1.96 \\
\hline$\underset{\text { fermentation }}{\mathrm{CH}_{4} \text { enteric }}$ & 182,281 & 1.31 & 163,790 & 1.28 & 154,348 & 1.27 & 146,580 & 1.27 \\
\hline $\mathrm{CH}_{4}$ manure & 2767 & 0.02 & 2547 & 0.02 & 2379 & 0.02 & 2302 & 0.02 \\
\hline $\mathrm{N}_{2} \mathrm{O}$ manure & 71,219 & 0.51 & 65,691 & 0.51 & 61,153 & 0.51 & 59,284 & 0.51 \\
\hline $\mathrm{N}_{2} \mathrm{O}$ fertilizer & 1349 & 0.01 & 1349 & 0.01 & 1349 & 0.01 & 1349 & 0.01 \\
\hline $\begin{array}{l}\mathrm{N}_{2} \mathrm{O} \text { fertilizer- } \\
\text { purchased feed }\end{array}$ & 6178 & 0.04 & 4700 & 0.04 & 3961 & 0.03 & 3400 & 0.03 \\
\hline $\begin{array}{l}\mathrm{CO}_{2} \text { energy- } \\
\text { purchased feed }\end{array}$ & 14,662 & 0.11 & 11,967 & 0.09 & 9413 & 0.08 & 8716 & 0.08 \\
\hline $\mathrm{CO}_{2}$ energy-farm & 5665 & 0.04 & 5665 & 0.04 & 5665 & 0.05 & 5665 & 0.05 \\
\hline
\end{tabular}

Table 8. Annual GHG emissions of the intensive farm (in $\mathrm{kg}$ of $\mathrm{CO}_{2}$-eq).

\begin{tabular}{|c|c|c|c|c|c|c|c|c|}
\hline \multirow[b]{2}{*}{ Abatement $(\alpha)$} & \multicolumn{2}{|c|}{$0 \%$} & \multicolumn{2}{|c|}{$10 \%$} & \multicolumn{2}{|c|}{$15 \%$} & \multicolumn{2}{|c|}{$20 \%$} \\
\hline & Total & $\begin{array}{l}\text { Per kg of } \\
\text { Milk }\end{array}$ & Total & $\begin{array}{l}\text { Per kg of } \\
\text { Milk }\end{array}$ & Total & $\begin{array}{l}\text { Per kg of } \\
\text { Milk }\end{array}$ & Total & $\begin{array}{l}\text { Per kg of } \\
\text { Milk }\end{array}$ \\
\hline Total GHGs & 332,797 & 1.82 & 299,518 & 1.81 & 282,878 & 1.80 & 266,238 & 1.79 \\
\hline $\begin{array}{l}\mathrm{CH}_{4} \text { enteric } \\
\text { fermentation }\end{array}$ & 169,926 & 0.93 & 152,886 & 0.92 & 144,684 & 0.92 & 136,352 & 0.92 \\
\hline $\mathrm{CH}_{4}$ manure & 3151 & 0.02 & 2846 & 0.02 & 2700 & 0.02 & 2,549 & 0.02 \\
\hline $\mathrm{N}_{2} \mathrm{O}$ manure & 111,501 & 0.61 & 100,615 & 0.61 & 95,638 & 0.61 & 90,150 & 0.61 \\
\hline $\mathrm{N}_{2} \mathrm{O}$ fertilizer & 3609 & 0.02 & 3100 & 0.02 & 2637 & 0.02 & 2372 & 0.02 \\
\hline $\begin{array}{l}\mathrm{N}_{2} \mathrm{O} \text { fertilizer- } \\
\text { purchased feed }\end{array}$ & 7183 & 0.04 & 6206 & 0.04 & 5587 & 0.04 & 5075 & 0.03 \\
\hline $\begin{array}{l}\mathrm{CO}_{2} \text { energy- } \\
\text { purchased feed }\end{array}$ & 23,363 & 0.13 & 20,036 & 0.12 & 17,882 & 0.11 & 16,124 & 0.11 \\
\hline $\begin{array}{l}\mathrm{CO}_{2} \text { energy- } \\
\text { farm }\end{array}$ & 14,065 & 0.08 & 13,829 & 0.08 & 13,750 & 0.09 & 13,616 & 0.09 \\
\hline
\end{tabular}

Emissions per $\mathrm{kg}$ of goat milk are estimated at 4.08, 2.04 and $1.82 \mathrm{~kg}$ of CO2-eq for the extensive, the semi-intensive and the intensive dairy goat production system respectively. The carbon footprint of goat milk is particularly high in the case of the extensive-farming system. On the other hand in the semi-intensive and the intensive farming system emissions per $\mathrm{kg}$ of milk are low and comparable to the emissions estimated for cow's milk (see also $[6,41,42]$ ). The reasons for this variation of carbon footprint among the alternative farming systems are the high productivity of more intensive farms and the significant amount of compounds in the ration used in the semi-intensive and the intensive farms, compared to the low productivity of the extensive farms and the grazing/forage-based nutrition.

As can be seen in Tables 6-8, when emissions are restricted to various levels, the emissions per $\mathrm{kg}$ of produced milk were also reduced, in all farm types. In other words, lower levels of total farm emissions correspond not only to lower milk production levels but also to lower carbon footprint of milk. Specifically, emissions from enteric fermentation per $\mathrm{kg}$ of milk are reduced across various levels of abatement, as the result of adopting appropriate feeding practices. Carbon dioxide emissions from purchased feed are also reduced, which indicates that either farms purchase fewer feedstuffs or purchase feedstuffs that cause fewer emissions when they are produced. These results depict the optimal abatement plan for goat farms, as will be discussed in more detail in the next paragraph.

\subsection{Abatement Cost and Strategies}

Tables 9-11 summarize the optimal farm plan of the extensive, semi-intensive and intensive farm. The tables emphasize the fact that in all cases abatement has a negative impact on farm gross margin, particularly in the case of the intensive farm. Specifically, in the intensive farm $10 \%$ and $20 \%$ reduction in emissions result in $9 \%$ and $18 \%$ loss in farm gross margin, respectively. The reduction in farm gross 
margin in the case of the semi-intensive and the extensive farm, when emissions are reduced by $10 \%$ and $20 \%$, is about $2 \%$ and $5 \%$, respectively.

Table 9. Optimal farm plan of the extensive farm.

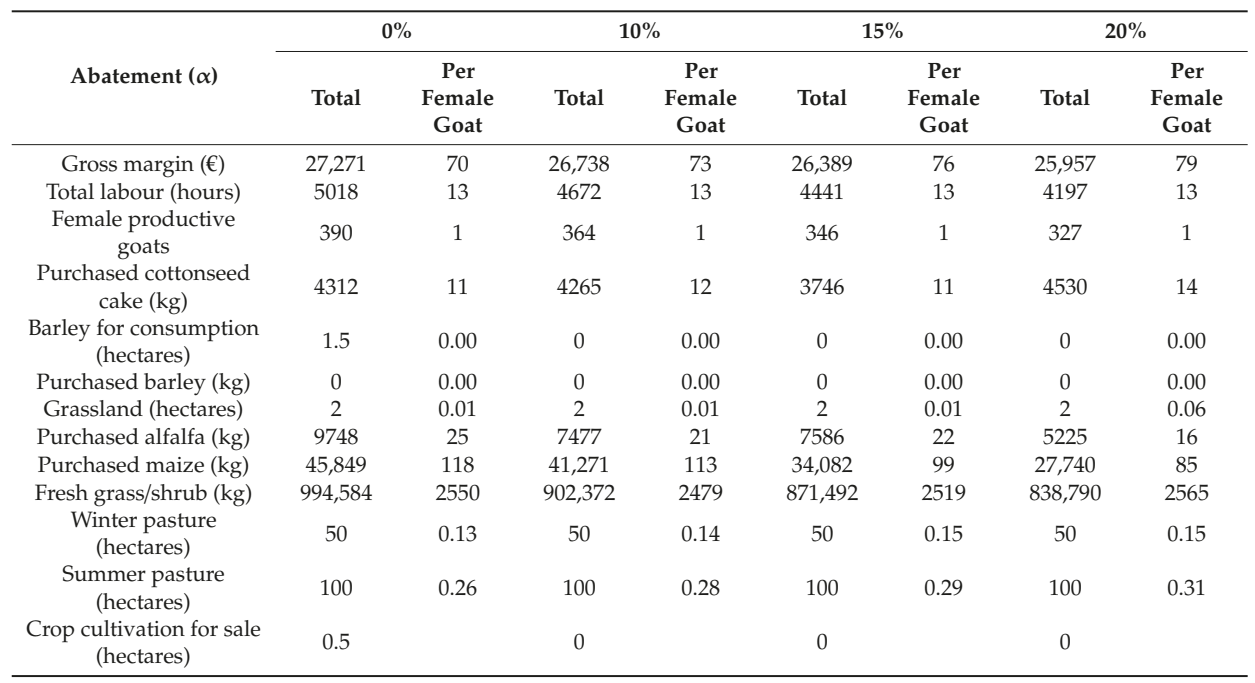

Table 10. Optimal farm plan of the semi-intensive farm.

\begin{tabular}{|c|c|c|c|c|c|c|c|c|}
\hline \multirow[b]{2}{*}{ Abatement $(\alpha)$} & \multicolumn{2}{|c|}{$0 \%$} & \multicolumn{2}{|c|}{$10 \%$} & \multicolumn{2}{|c|}{$15 \%$} & \multicolumn{2}{|c|}{$20 \%$} \\
\hline & Total & $\begin{array}{c}\text { Per } \\
\text { Female } \\
\text { Goat }\end{array}$ & Total & $\begin{array}{c}\text { Per } \\
\text { Female } \\
\text { Goat }\end{array}$ & Total & $\begin{array}{c}\text { Per } \\
\text { Female } \\
\text { Goat }\end{array}$ & Total & $\begin{array}{c}\text { Per } \\
\text { female } \\
\text { Goat }\end{array}$ \\
\hline Gross margin $(€)$ & 47,275 & 136 & 46,440 & 146 & 46,000 & 151 & 45,296 & 157 \\
\hline Total labour (hours) & 7140 & 21 & 6559 & 21 & 6270 & 21 & 5,946 & 21 \\
\hline $\begin{array}{c}\text { Female productive } \\
\text { goats }\end{array}$ & 348 & 1 & 319 & 1 & 305 & 1 & 289 & 1 \\
\hline $\begin{array}{l}\text { Maize for consumption } \\
\text { (hectares) }\end{array}$ & 2 & 0.006 & 2 & 0.006 & 2 & 0.007 & 2 & 0.007 \\
\hline Pasture (hectares) & 50 & 0.144 & 50 & 0.157 & 50 & 0.164 & 50 & 0.173 \\
\hline Purchased alfalfa (kg) & 17,781 & 51 & 12,930 & 41 & 10,935 & 36 & 8,699 & 30 \\
\hline Purchased maize $(\mathrm{kg})$ & 59,692 & 172 & 32,812 & 103 & 26,419 & 87 & 20,570 & 71 \\
\hline Purchased barley (kg) & 0 & 0 & 11,334 & 36 & 10,010 & 33 & 8779 & 30 \\
\hline
\end{tabular}

The impact of abatement in the case of the intensive farm can be explained by the high productivity and specialization of the farm in milk production. Over $85 \%$ of the gross production value of the farm comes from milk production, while milk yield/goat and price of milk/ $/ \mathrm{g}$ are very high $(520 \mathrm{~kg} / \mathrm{goat}$ and $0.73 € / \mathrm{kg}$ of milk, respectively). The high productivity of the intensive farm is also emphasized by the high gross margin per goat in Table 11.

Furthermore, the analysis indicates that, in all farm types, the mitigation of GHGs is primarily achieved by the reduction of the herd size, especially when high levels of abatement are imposed. Specifically, in the extensive farm $10 \%$ and $20 \%$ abatement leads to $7 \%$ and $16 \%$ reduction in livestock size, respectively. In the case of the semi-intensive farm the reduction in livestock size is $8 \%$ and $17 \%$, while in the intensive farm the reduction is even higher, $9 \%$ and $19 \%$, respectively. These findings 
are in accordance with previous studies regarding mitigation of GHGs in livestock farms (see for example $[17,23])$.

Table 11. Optimal farm plan of the intensive farm.

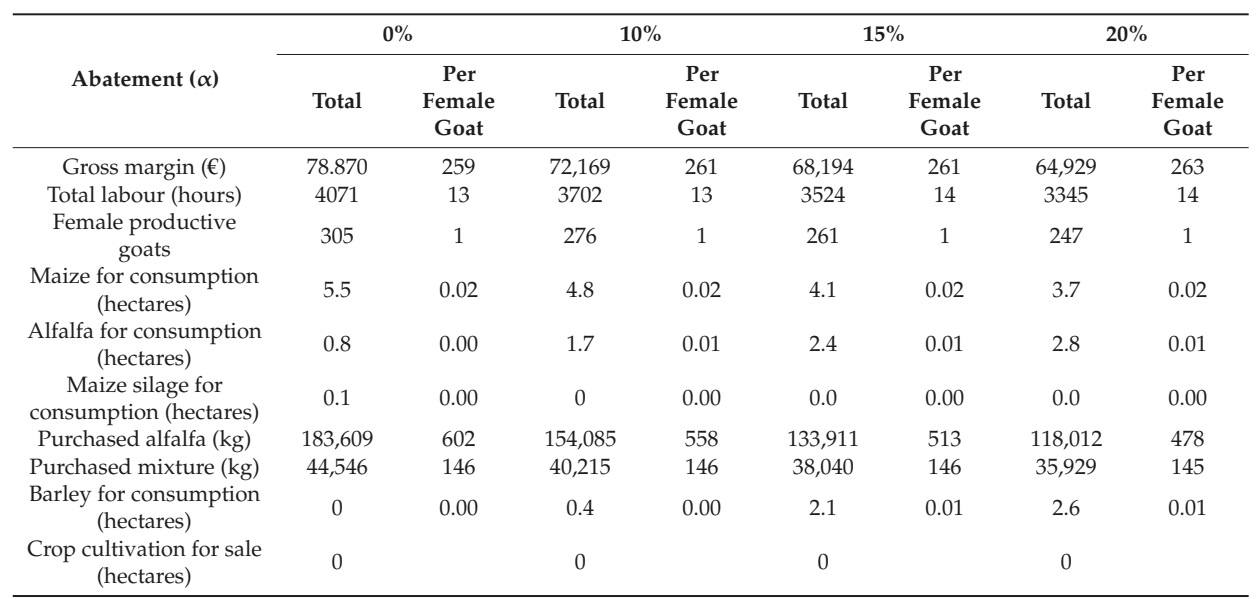

However, adjustments in farming practices may also achieve some level of abatement. Specifically, as previously commented, the results indicate that the reduction of purchased feed and their substitution with on-produced feed is a strategy that can lead to lower emissions in all goat production systems. However, as can be observed in the case of the extensive farm, the use of purchased cottonseed cake is suggested as good practice to reduce emissions, since the amount consumed per goat either remains stable or increases across the various levels of abatement. The explanation for this finding lies in the fact that the inclusion of oil-rich feedstuffs in the ration of ruminants can lead to lower $\mathrm{CH}_{4}$ emissions from enteric fermentation [43].

Furthermore, in the case of the semi-intensive and the extensive farms, the use of pastureland/shrubland and grassland is also included in the optimal farm plans, when abatement is imposed. In these low productivity farms, the use of pasture and grassland and the switch to on-produced feed reduce the feeding cost and compensate at a great extent the loss in total gross margin caused by abatement.

These results are also confirmed by the marginal abatement cost curve of the extensive, the semi-intensive and the intensive farm type which are presented in Figures 3-5, respectively. As can be seen in the figures the marginal abatement costs of the extensive and the semi-intensive farms are very low compared to the intensive farm. Specifically, the marginal abatement cost of the extensive farm is $11 € / \mathrm{t}$ at the $95 \%$ level of the original emissions, $35 € / \mathrm{t}$ at $80 \%$ and $76 € / \mathrm{t}$ at $60 \%$. In the case of the semi-intensive farm the marginal abatement cost is about $50 € / t$, until $30 \%$ of the original emissions are abated and reaches $220 € / \mathrm{t}$ at $40 \%$ abatement level. On the other hand, in the case of the intensive farm the marginal abatement cost reaches $250 € / \mathrm{t}$ at only $10 \%$ abatement, indicating that intensive farms, already achieve the production of low carbon footprint milk and further abatement comes at a higher cost.

Two scenarios are investigated in this analysis, regarding the potential to restore the gross margin of the goat farms that is reduced as the result of GHG abatement. First, the impact of milk price increase is investigated using parametric optimization. The results indicate that a small price increase of about $5 \%-6 \%$ allows the extensive and the semi-intensive farms to maintain their original gross margin and still abate $20 \%$ of their emissions. This price increase may for example come as the result of the labeling of milk as a low-carbon product. In the case of the intensive farm the price increase should be $14 \%$ in order for the farm to achieve its original gross margin level. 


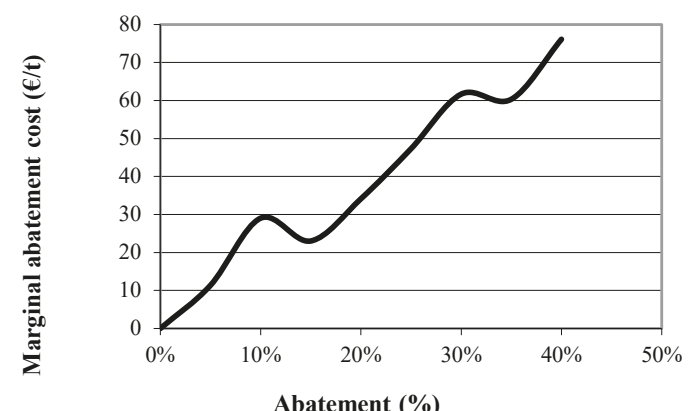

Figure 3. Marginal abatement cost curve of the extensive farm.

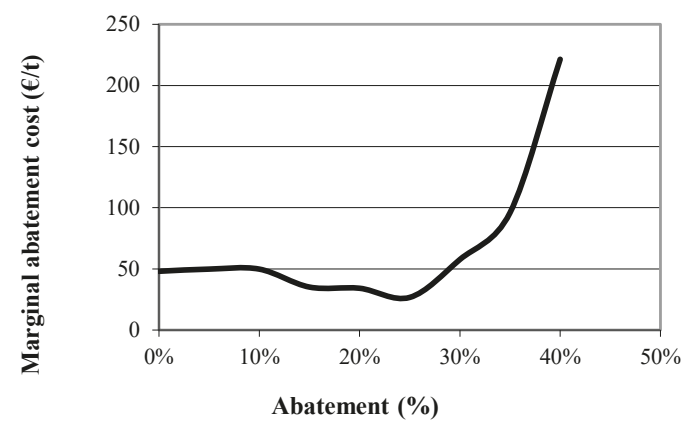

Figure 4. Marginal abatement cost curve of the semi-intensive farm.

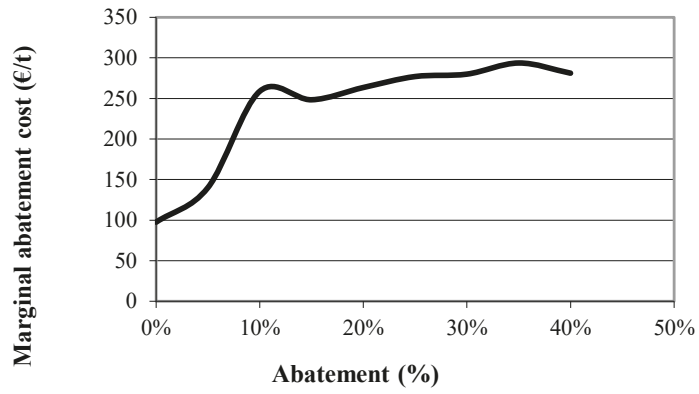

Figure 5. Marginal abatement cost curve of the intensive farm.

Alternatively, as far as policy measures are concerned, the loss in farm gross margin can be restored if farms are offered compensation/subsidy per productive goat. This compensation should be less than $6 € /$ goat in the cases of the extensive and the semi-intensive farming system but should reach $56 € /$ goat in the case of the intensive system, at $20 \%$ abatement level. It should be noted, however, that the majority of goat farms in Greece are extensive and semi-intensive farming systems, while only a few farms are characterized as intensive. Therefore, the cost of this policy measure may not be prohibitive, though this should be further investigated.

Finally, it should be mentioned that abatement has a significant impact on labor in all three production systems (see Tables 9-11). Specifically, $10 \%$ and $20 \%$ abatement results in $7 \%-9 \%$ and $16 \%-19 \%$ reduction in required labor inputs of the farms, respectively. This is an important finding, given the fact that the activity is mainly located in less favored areas of the country, where alternative occupations are scarce. 


\section{Discussion of Results and Conclusions}

In this study a mixed-integer programming model was used to estimate GHG emissions in dairy goat farms in Greece and explore their abatement opportunities and cost. The analysis is undertaken in three goat farms that represent the extensive, semi-intensive and intensive production systems and takes into account all potential emission sources within the farm as well as pre-chain emissions.

The results of the analysis indicate that in all production systems, the main source of GHG emissions is enteric fermentation. Emissions per $\mathrm{kg}$ of milk are particularly high in the extensive farm, mainly because of its low productivity. The analysis also emphasizes that the intensive-farming system can produce milk with very low carbon footprint, while the carbon footprint of milk produced in semi-intensive farms is also relatively low.

Moreover, the analysis also suggests that imposing high levels of abatement unavoidably leads to the reduction of livestock size and, therefore, milk production. However, lower levels of abatement can be achieved by adjusting farming and especially feeding practices. These mitigation practices include the use of oil-rich feedstuffs, like cottonseed cake, in the ration of livestock and the substitution of purchased feed with on produced feed. These findings are important for farmers who are encouraged to adopt not only economically but also environmentally sound farming practices. The substitution of purchased feed with homegrown feed reduces emissions that are associated with their transportation to the farm, while at the same time reduces the feeding cost of farmers. However, such an adjustment in the feed would entail serious adjustments to the production system of farms, including new investments in land and machinery, as well as a different labor usage. Thus, further investigation is required concerning these implications.

As far as the marginal abatement cost is concerned, it is increasing across various levels of abatement and is significantly higher in the case of the intensive farm. The results reveal that the high productivity of the intensive farm causes a significant loss of gross margin when abatement is imposed. The abatement cost of the extensive farm is smaller, because of its smaller milk yield and, therefore, its smaller gross margin per goat. Abatement also results in a significant reduction of labor required in all farm types, which should also be taken into account when designing environmental policy measures.

Moreover, the results of the analysis indicate that the loss in gross margin caused by abatement may be restored by a small milk price increase in the case of extensive and semi-intensive farms. Further investigation is required to establish whether this price increase is possible from the promotion of milk labeled as a low-carbon footprint product. From the policy makers' point of view, a small compensation offered to farmers per productive goat can also restore the original gross margin of extensive and semi-intensive farms, when abatement is imposed. Finally, it should be emphasized that even though the carbon footprint of milk is higher in extensive farms, other environmental benefits may emerge from these production systems that are beyond the scope of this study but have to be considered when estimating their overall sustainability.

Author Contributions: Conceptualization, A.S.; methodology, A.S., A.L.; software, A.S.; validation, A.S., A.L.; formal analysis, A.S., A.L., I.T.; investigation, A.S., A.L., I.T.; data curation, A.S.; writing—original draft preparation, A.S., A.L.; writing-review and editing, A.S., A.L., I.T.; visualization, A.S., A.L., I.T.; supervision, I.T.; project administration, A.S.; funding acquisition, A.S.

Funding: This study is a part of post-doctoral research, funded under the Project 'Research \& Technology Development Innovation Projects'-AgroETAK, MIS 453350, in the framework of the Operational Program 'Human Resources Development'. This study is also co-funded by the European Social Fund through the National Strategic Reference Framework (Research Funding Program 2007-2013) coordinated by the Hellenic Agricultural Organization-DEMETER (Agricultural Economics and Policy Research Institute/Scientific supervisor: Dr Tzouramani).

Conflicts of Interest: The authors declare no conflict of interest. The funders had no role in the design of the study; in the collection, analyses, or interpretation of data; in the writing of the manuscript, or in the decision to publish the results. 


\section{References}

1. Hellenic Statistical Authority. Farm Structure Survey; Press Release: Athens, Greece, 2016. Available online: http://www.statistics.gr/documents/20181/76d51b89-18ed-426b-8227-01790d9c2a3d (accessed on 1 November 2019).

2. Kitsopanides. Economics of Animal Production; ZITI Publishing: Thessaloniki, Greece, 2006.

3. Hellenic Ministry of Rural Development and Food (HMRDF). Sheep and Goat Sector Development. Available online: http://www2.minagric.gr/images/stories/docs/ypoyrgeio/dimosieyseis-Arthra/meleti_gia_ Nea_KAP/filadia_zoikis/aigoproboatotrofias.pdf (accessed on 1 November 2019).

4. IPCC. Guidelines for National Greenhouse Gas Inventories; Institute for Global Environmental Strategies (IGES) for the IPCC: Kanagawa, Japan, 2006.

5. Pitesky, M.E.; Stackhouse, K.R.; Mitloehner, F.M. Chapter 1-Clearing the Air: Livestock's Contribution to Climate Change. In Advances in Agronomy; Sparks, D.L., Ed.; Academic Press: Burlington, MA, USA, 2009; Volume 103, pp. 1-40. ISBN 0065-2113.

6. Weiske, A.; Vabitsch, A.; Olesen, J.E.; Schelde, K.; Michel, J.; Friedrich, R.; Kaltschmitt, M. Mitigation of greenhouse gas emissions in European conventional and organic dairy farming. Agric. Ecosyst. Environ. 2006, 112, 221-232. [CrossRef]

7. Olesen, J.E.; Schelde, K.; Weiske, A.; Weisbjerg, M.R.; Asman, W.A.H.; Djurhuus, J. Modelling greenhouse gas emissions from European conventional and organic dairy farms. Agric. Ecosyst. Environ. 2006, 112, 207-220. [CrossRef]

8. Veysset, P.; Lherm, M.; Bébin, D. Energy consumption, greenhouse gas emissions and economic performance assessments in French Charolais suckler cattle farms: Model-based analysis and forecasts. Agric. Syst. 2010, 103, 41-50. [CrossRef]

9. de Oliveira Silva, R.; Barioni, L.G.; Hall, J.A.J.; Moretti, A.C.; Fonseca Veloso, R.; Alexander, P.; Crespolini, M.; Moran, D. Sustainable intensification of Brazilian livestock production through optimized pasture restoration. Agric. Syst. 2017, 153, 201-211. [CrossRef]

10. Petersen, E.H.; Schilizzi, S.; Bennett, D. The Impacts of Greenhouse Gas Abatement Policies on the Predominantly Grazing Systems of South-Western Australia; International and Development Economics Working Paper 02-9; Asia Pacific School of Economics and Government, Australian National University: Canberra, Australia, 2002.

11. Benoit, M.; Laignel, G. Sheep-for-meat farming systems in French semi-upland area. Adapting to new context: Increased concentrates and energy prices, and new agricultural policy. In Proceedings of the 8th European IFSA Symposium: Empowerment of the Rural Actors: A Renewal of Farming Systems Perspectives, Paris, France, 6-10 July 2008; pp. 6-10.

12. Sintori, A.; Tsiboukas, K.; Zervas, G. Evaluating Socio-economic and Environmental Sustainability of the Sheep Farming Activity in Greece: A Whole-Farm Mathematical Programming Approach. In Methods and Procedures for Building Sustainable Farming Systems; Costa, M., Alexandra, A., da Silva, E.L.S., Eds.; Springer: Dordrecht, The Netherlands, 2013; pp. 219-235.

13. Alford, A.; Griffith, G.; Cacho, O. A Northern Tablelands Whole-Farm Linear Program for Economic Evaluation of New Technologies at the Farm-Level; No. 1160-2016-93030; Economic Research Report No. 13; NSW Agriculture: Armidale, Australia, 2004.

14. Veysset, P.; Bebin, D.; Lherm, M. Adaptation to Agenda 2000 (CAP reform) and optimisation of the farming system of French suckler cattle farms in the Charolais area: A model-based study. Agric. Syst. 2005, 83, 179-202. [CrossRef]

15. Sofi, N.A.; Ahmed, A.; Ahmad, M.; Bhat, B.A. Decision making in agriculture: A linear programming approach. Int. J. Mod. Math. Sci. 2015, 13, 160-169.

16. Crosson, P.; O'Kiely, P.; O'Mara, F.P.; Wallace, M. The development of a mathematical model to investigate Irish beef production systems. Agric. Syst. 2006, 89, 349-370. [CrossRef]

17. De Cara, S.; Jayet, P.A. Emissions of greenhouse gases from agriculture: The heterogeneity of abatement costs in France. Eur. Rev. Agric. Econ. 2000, 27, 281-303. [CrossRef]

18. Breen, J.P.; Donellan, T. Estimating the Marginal Costs of Greenhouse Gas Emissions Abatement using Irish Farm-Level Data. In Proceedings of the 83rd Annual Conference of Agricultural Economics Society, Dublin, Ireland, 30 March-1 April 2009; Agricultural Economics Society: Dublin, Ireland, 2009. 
19. Moraes, L.E.; Wilen, J.E.; Robinson, P.H.; Fadel, J.G. A linear programming model to optimize diets in environmental policy scenarios. J. Dairy Sci. 2012, 95, 1267-1282. [CrossRef] [PubMed]

20. de Oliveira Silva, R.; Barioni, L.G.; Hall, J.A.J.; Folegatti Matsuura, M.; Zanett Albertini, T.; Fernandes, F.A.; Moran, D. Increasing beef production could lower greenhouse gas emissions in Brazil if decoupled from deforestation. Nat. Clim. Chang. 2016, 6, 493-497. [CrossRef]

21. Smith, E.G.; Upadhyay, M. Others Greenhouse gas mitigation on diversified farms. In Proceedings of the Western Agricultural Economics Association-Western Economics Association International Joint Annual Meeting, San Francisco, CA, USA, 6-8 July 2005.

22. Kaiser, H.M.; Messer, K.D. Mathematical Programming for Agricultural, Environmental and Resource Economics; John Wiley and Sons: New York, NY, USA, 2014; ISBN 9780874216561.

23. Sintori, A. Analysis of the Decision Making Process with Multiple Goals: The Case of Dairy Sheep Farming in Continental Greece. Ph.D. Thesis, Agricutlural University of Athens, Athens, Greece, 2012; p. 365.

24. Zervas, G.; Kalaisaikis, P.; Feggeros, K. Farm Animal Nutrition; Stamoulis Publishing: Athens, Greece, 2000.

25. Kalaisakis, P.; Giourdas, M. Applied Animal Nutrition; Giourdas M. Publishing: Athens, Greece, 1965.

26. Jarrige, R. [Alimentation des Ruminants]: Principes de la Nutrition et de L'alimentation des Ruminants: Besoins Alimentaires des Animaux: Valeur Nutritive des Aliments; INRA Pub.: Versailles, France, 1980; ISBN 2853402886.

27. Feedipedia. An Online Encyclopedia of Animal Feeds. Available online: https://www.feedipedia.org/ (accessed on 1 February 2019).

28. Papachristou, T.G. Utilization of available forage in shrublands from goats: Selection and nutritional value of forage. In Proceedings of the 1st Greek National Conference of the Hellenic Range and Pasture Society, Athens, Greece, 16 June 1996; The Hellenic Range and Pasture Society: Drama, Greece, 1997.

29. FRI (Forest Reearch Institute). Final Report of the Program "Agrometeorological Models for the Prediction of the Production and Quality of Pastures"; NAGREF: Thessaloniki, Greece, 2000.

30. Platis, P.D.; Papanastasis, V. Relationship between Shrub Cover and Available Forage in Mediterranean Shrublands. Agrofor. Syst. 2003, 57, 59-67. [CrossRef]

31. Platis, P.D.; Papanastasis, V.P.; Papachristou, T.G.; Tsiontsis, A.G. Varation of quantity and quality of forage in grasslands of the lowland ecological zone in the Prefecture of Thessaly. In Proceedings of the 4th Greek National Conference of the Hellenic Range and Pasture Society, Volos, Greece, 10-12 November 2004; The Hellenic Range and Pasture Society: Athens, Greece, 2006.

32. Schils, R.L.M.; de Haan, M.H.A.; Hemmer, J.G.A.; van den Pol-van Dasselaar, A.; de Boer, J.A.; Evers, A.G.; Holshof, G.; van Middelkoop, J.C.; Zom, R.L.G. DairyWise, A Whole-Farm Dairy Model. J. Dairy Sci. 2007, 90, 5334-5346. [CrossRef] [PubMed]

33. Giger-Reverdin, S.; Sauvant, D. Methane Production in Sheep in Relation to Concentrate Feed Composition from Bibliographic Data. In Sheep and Goat Nutrition: Intake, Digestion, Quality of Products and Rangelands; Ledin, I., Morand-Fehr, P., Eds.; CIHEAM-IAMZ: Zaragoza, Spain, 2000; pp. 43-46.

34. Petersen, E.; Schilizzi, S.; Bennett, D. The impacts of greenhouse gas abatement policies on the predominantly grazing systems of south-western Australia. Agric. Syst. 2003, 78, 369-386. [CrossRef]

35. Wells, D. Total Energy Indicators of Agricultural Sustainability: Dairy Farming Case Study; Technical Paper; Ministry of Agriculture and Forestry: Wellington, New Zealand, 2001; ISBN 0-478-07968-0.

36. Wood, S.; Cowie, A. A Review of Greenhouse Gas Emission Factors for Fertiliser Production. IEA bioenergy task 38. Available online: www.sciencetheearth.com/uploads/2/4/6/5/24658156/2004_wood_a_review_of_ greenhouse_gas_emission_factors.pdf (accessed on 1 February 2019).

37. Defra. Guidelines for Company Reporting on Greenhouse Gas Emissions Annexes Updated July 2005; Defra: London, UK, 2005.

38. Helsel, Z.R. Energy in pesticide production and use. Encycl. Pest Manag. 2006, 1, 1-4.

39. Kaltsas, A.M.; Mamolos, A.P.; Tsatsarelis, C.A.; Nanos, G.D.; Kalburtji, K.L. Energy budget in organic and conventional olive groves. Agric. Ecosyst. Environ. 2007, 122, 243-251. [CrossRef]

40. Smith, E.G.; Upadhyay, B.M. Greenhouse Gas. Mitigation on Diversified Farms. In Proceedings of the Annual Meeting of the Canadian Agricultural Economics Society, San Francisco, CA, USA, July 2005.

41. Lesschen, J.P.; van den Berg, M.; Westhoek, H.J.; Witzke, H.P.; Oenema, O. Greenhouse gas emission profiles of European livestock sectors. Anim. Feed Sci. Technol. 2011, 166-167, 16-28. [CrossRef] 
42. FAO. Livestock's Long Shadow: Environmental Issues and Options; FAO: Rome, Italy, 2006.

43. Ludemann, C.; Howden, S.; Eckard, R. What is the best use of oil from cotton (Gossypium spp.) and canola (Brassica spp.) for reducing net greenhouse gas emissions-biodiesel, or as a feed for cattle? Anim. Prod. Sci. 2016, 56, 3442-3450. [CrossRef]

(C) 2019 by the authors. Licensee MDPI, Basel, Switzerland. This article is an open access article distributed under the terms and conditions of the Creative Commons Attribution (CC BY) license (http://creativecommons.org/licenses/by/4.0/). 
MDPI

St. Alban-Anlage 66

4052 Basel

Switzerland

Tel. +41616837734

Fax +41 613028918

www.mdpi.com

Animals Editorial Office

E-mail: animals@mdpi.com www.mdpi.com/journal/animals

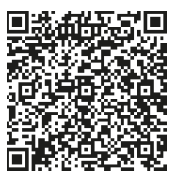




MDPI

St. Alban-Anlage 66

4052 Basel

Switzerland

Tel: +41 616837734

Fax: +41 613028918

www.mdpi.com 